\title{
ORGANIZATION AND MANAGEMENT FOR EFFICIENT IRRIGATION WATER-USE:
}

\author{
An Empirical Study in the Sudan
}

Doctoral Dissertation

submitted for the degree of Doctor Agricultural Sciences of the Faculty of Agricultural Sciences

Georg-August-University Göttingen (Germany)

\author{
by \\ Yasir Khalil \\ born in Alexandria (Egypt)
}

Göttingen, March 1998 
D7

$1^{\text {st }}$ examiner: Prof. Dr. Dr. Winfried Manig

$2^{\text {rd }}$ examiner: Prof. Dr. Dr. Dr. Frithjof Kuhnen

Day of the Promotion: May, $14^{\text {th }} 1998$ 


\section{ABSTRACT \\ Yasir Khalil: Organization and Management for Efficient Irrigation Water-Use - An Empirical Study in the Sudan}

Sudan, the largest country in Africa, symbolizes the problems challenging the continent. The most threatening one is food security for an increasing population. Considering the drought conditions that built up in the area - culminating in the mid 1980s - irrigation became a cornerstone to boost food supplies. This sub-sector has historically played a substantial role in the production of food and cash crops in Sudan. However, there is now growing evidence that the opportunities for the further lateral expansion of irrigation schemes will be faced by the limitations of the availability of foreign currency and the availability of water resources. The former is dependent on the performance of the Sudanese economy and the later is, in addition, interdependent with the plans of other countries. Though the first limitation has reached a critical level, it is recognized that water rather than other resources will be the main determinant of irrigation development. Thereby, if Sudanese agriculture is to develop, there is a need to improve the utilization of available water through improving its management and the organizational contexts in which this is practiced.

Within this area of interest, the major task of the study has been to map the factors that hinder this goal. The study is divided into two parts. The first deals with the theoretical framework of key concepts and relevant issues. It discusses, however, the different aspects that have an influence on the performance of irrigation systems and emphasizes, in particular, those of technology and the environment. In addition, the meaning and conditions of institutional change are also discussed in detail. The second part of the study, the analytical section, comprises the methodology and the results of field work which has been conducted under two irrigation bureaucracies - the New Halfa Scheme in the eastern part of Sudan, and the Gendettu Scheme in the north.

The results of the study stressed the need for a comprehensive development approach which considers all natural resources. Furthermore, within the special reference to the environment of the schemes, it has been found that the political conditions are of particular importance. This result highlights the question as to what extent participation is applicable in bureaucratic irrigation schemes in countries that have similar conditions. The study also comes to the conclusion that irrigation water efficiency has a socio-economic dimension and therefore has to be linked with productivity and profitability. In this connection, modernizing the relevant technologies and sustaining the integration with support institutions are of relevant importance. Consequently, a central conclusion of this study is that the efficiency of water utilization also requires, at the same time, the efficient utilization of other resources and inputs supplied by support institutions. In addition, the absence of tenants' participation and the dominance of the schemes administrations goals, as representatives of the state, have resulted in a contradictory efficiency; the efficiency of water users vis-à-vis the efficiency of the state.

Concerning communication, a yawning gap has been registered between the different actors of the schemes. This focus has tended to direct attention to the role of farmers' organizations in the articulation between water users and scheme management. The conclusion that could be drawn from this analysis is that farmers' organizations need to play this role independently. Finally the study stresses that, to achieve the goals for charging for irrigation water, these need to be accompanied by institutional changes. 


\begin{abstract}
Yasir Khalil: Organisation und Management zur verbesserten Wassernutzung in der Landwirtschaft des Sudan - eine empirische Studie

Der Sudan, das größte Land Afrikas, kann stellvertretend gesehen werden für die Probleme, die den afrikanischen Kontinent bewegen. An erster Stelle ist die Ernährungssicherung für eine steigende Bevölkerungszahl anzusehen. Bei Betrachtung der Dürre-Probleme dieser Region, die ihren Höhepunkt Mitte der 80er Jahre hatten, wird das Thema Bewässerung zunehmend zu einem Pfeiler, wenn es um die Verbesserung der Nahrungsmittelversorgung geht. Dieser Sub-Sektor spielt, historisch gesehen, eine wichtige Rolle für die Produktion von Nahrungsmitteln und landwirtschaftlichen Exportprodukten im Sudan. Jedoch gibt es zunehmende Anzeichen dafür, daß die Ausdehnung der Bewässerungssysteme generell in Konfrontation mit einer beschränkten Verfügbarkeit von Fremdwährung und Wasserressourcen stehen wird. Die erste Beschränkung ist abhängig von der Leistungsfähigkeit der sudanesischen Wirtschaft und die zweite von den Plänen anderer Länder. Da der erste Faktor seinen kritischen Punkt erreicht hat, ist es klar, dass Wasser, und nicht andere Ressourcen, die entscheidende Rolle bei der Entwicklung der Bewässerungssysteme spielen wird. Somit ist es notwendig, wenn die sudanesische Landwirtschaft entwickelt werden soll, das Management der Wassernutzung und die damit verbundenen organisatorischen Rahmenbedingungen zu vervollkommnen.
\end{abstract}

Folglich war es die Hauptaufgabe der Studie, die Faktoren, die dem Ziel einer wirtschaftlichen Wassernutzung hinderlich sind, herauszuarbeiten. Die Studie teilt sich in zwei Abschnitte. Der erste Teil setzt sich mit den theoretischen Rahmenbedingungen relevanter Konzepte und Ansätze auseinander. Es werden die verschiedenen Aspekte, die Einfluß auf die Leistungsfähigkeit von Bewässerungssystemen haben, hervorgehoben. Dabei werden besonders Technologie und Umwelt betont. Zusätzlich werden die Bedeutungen und Bedingungen des Institutionellen Wandels diskutiert. Der zweite Teil der Studie widmet sich der Empirie, d.h. den Methoden und Ergebnissen der Feldforschung. Diese wurde in zwei Bewässerungs-Schemes durchgeführt: New Halfa Scheme in Ostsudan und Gendettu Scheme im Norden des Landes.

Die Ergebnisse dieser Studie zeigen auf, daß ein umfassender Entwicklungsansatz alle natürlichen Ressourcen einbeziehen muß. Weiterhin dürfen auch die politischen Verhältnisse im Umfeld der Schemes nicht vernachlässigt werden. Das Ergebnis weist besonders auf die Frage hin, in welchem Ausmaß Partizipation anwendbar ist in den bürokratisch organisierten Bewässerungs-Systemen in Ländern mit ähnlichen Bedingungen. Es konnte festgestellt werden, daß auch die sozioökonomische Dimension beachtet werden muß, wenn die Effizienz der Bewässerung betrachtet wird, d.h. Produktivität und Rentabilität müssen in die Kalkulationen miteinbezogen werden. In diesem Zusammenhang ist es von von äußerster Wichtigkeit, der Modernisierung entsprechender Technologien und der Einbeziehung unterstützender Institutionen große Bedeutung zukommen zu lassen.

Die zentrale Schlußfolgerung dieser Studie ist also, daß die Effizienz der Wassernutzung auch die gleichzeitige effiziente Nutzung anderer Ressourcen und Inputs, die von zuliefernden Institutionen zur Verfügung gestellt werden, erfordert. Zusätzlich ist anzumerken, daß das Nichtvorhandensein von Pächter-Partizipation und die Vorherrschaft der Interessen der Scheme-Verwaltung, als Repräsentanten des Staates, der Effizienz entgegenwirken, das heißt, daß sich die Effizienz der Wassernutzer und die des Staates diametral gegenüberstehen.

Besonders hervorgehoben werden muß die mangelnde Kommunikation zwischen den verschiedenen Beteiligten der Schemes. Dieser Punkt führt die Aufmerksamkeit direkt zur Rolle der Bauernorganisationen als Verbindung zwischen den Wassernutzern und dem Scheme Management. Die Schlussfolgerung, die aus dieser Analyse gezogen werden kann, ist, daß die Bauernorganisationen ihre Aufgaben unabhängig wahrnehmen müssen. Schließlich betont die Studie, daß zur Erreichung der Ziele, die mit der Erhebung von Bewässerungsgebühren verbunden sind, gleichzeitig instutionelle Veränderungen erforderlich sind. 


\section{ACKNOWLEDGEMENTS}

I m greatly indebted to Professor Dr. Dr. W. Manig for his presice supervision of this study. I am also indebted to him, as student of irrigation management and organization, because of his rich advises and contribution in the literature of this discipline which enabled me to understand the interdependencies of the study. I am also deeply grateful to Professor Dr. Dr. Dr. F. Kuhnen who gave me the chance to be one of his Ph.D. students, and for his willingness to examine this work.

I would like to extend my appreciation to Professor Dr. J. Müller and Professor Dr. H. Meliczek for their academic and human support, specially at a time when continuing this work was almost impossible. I appreciate also the constructive advises given to me in the course of the field study by Professor M. Abd-El-Kadir of Khartoum University. Thanks are also due to innumerable officials of NHAC and NAPC - as well as the farmers and traders of New Halfa and Shendi area.

I acknowledge sincerely the friendly assistance of A. Bartelsmeier, R. Ensermu and C.F. Ananda - the symbol of helpfulness and loyalty. Thanks are due also to the staff of Institute of Rural Development. Particular thanks are of course due to the DAAD who made this study possible in the first place.

Finally, I'm not sure if 'thank' is the right word that could be used for my family, in particular my mother and my sisters. I think the right word is congratulation. This work is the fruit of their long journey of giving and self-denying.

Last but not least, I would like to thank my friends who have contributed in one way or another to the success of this work.

Most of all, I am deeply grateful to God who gave me the craft and the light to end this work.

Yasir Khalil

Göttingen, March 1998 
to my family, all thanks and appreciation. 


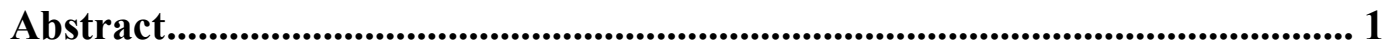

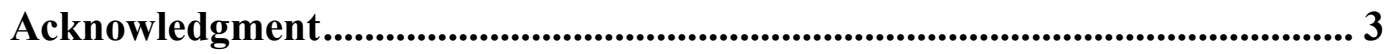

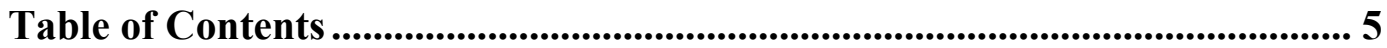

List of Tables ........................................................................................................................ 8

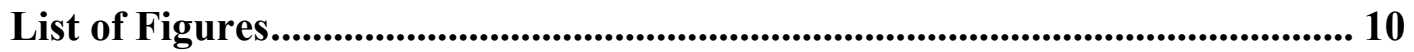

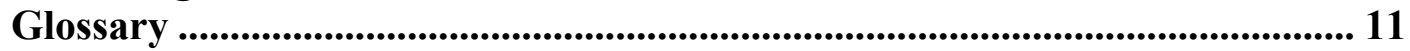

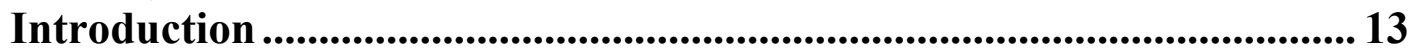

Part I : Theoretical Framework

Harvest of Experiences: The Need of Learning from the Past ........... 17

1. Irrigation Organization and Management: Definitions of the Key Concepts.................................................................................................. 20

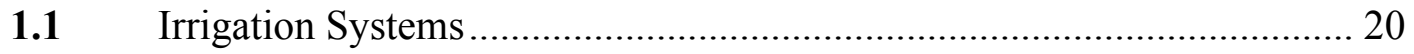

1.1.1 Nature and Characteristics of Irrigation Systems ................................ 20

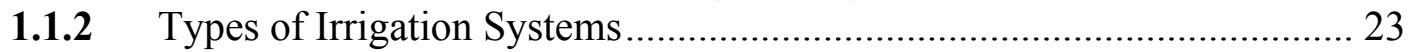

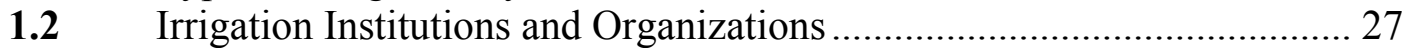

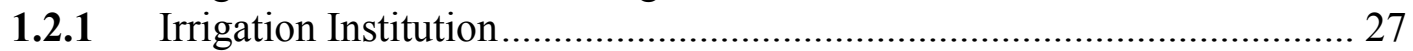

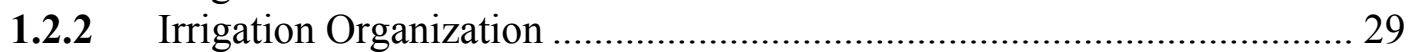

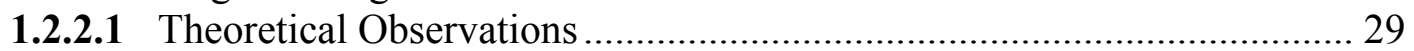

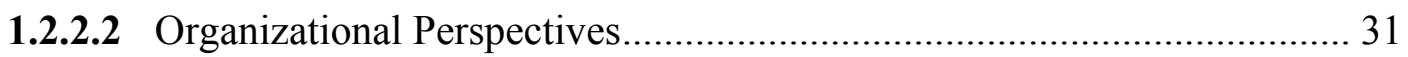

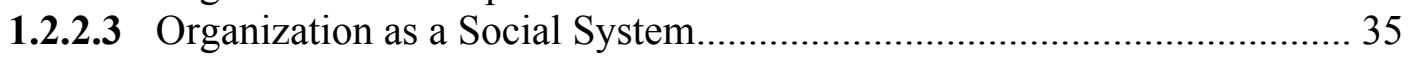

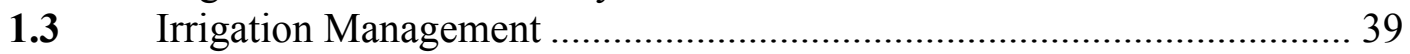

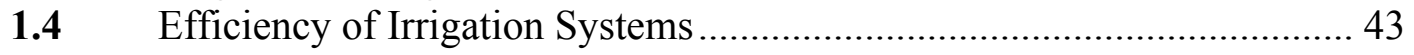

2. The Relevant Dimensions and Factors that Influence Irrigation Organization and Management ...........................................................45

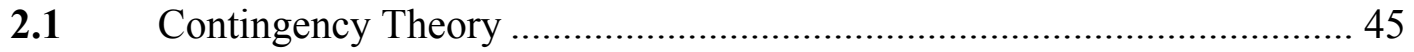

2.2 Objectives of Irrigation Management ................................................... 46

2.3 The Context of Irrigation Management ..................................................... 49

2.3.1 The Organization's Applied Technology ............................................... 51

2.3.1.1 The Appropriate Technology: Continual Debate ..................................... 51

2.3.1.2 Technology and Irrigation System......................................................... 53

2.3.2 Historical Factors 55

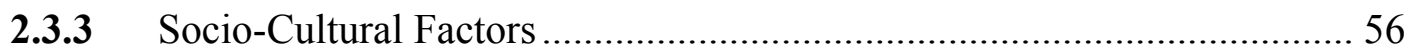

2.3.4 The Political Context ........................................................................... 57

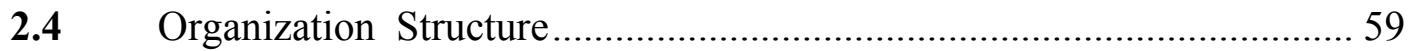

2.5 Farmers Involvement in Irrigation Management ..................................... 64

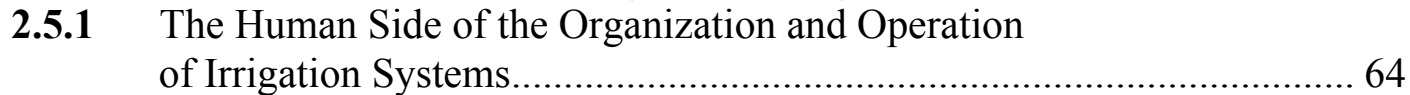

2.5.2 Participation of Water Users in Irrigation Management.......................... 67

3. Organizational Approaches and Strategies for Improving the Performance of Irrigation Systems ................................................. 74

3.1 Institutional Changes as a New Development Strategy.......................... 74

3.1.1 The Process of Institutional Change: Why do institutions Change? ........ 74 
3.1.2 Theory of institutional Innovation ......................................................... 76

3.1.3 Transaction Costs Theory …………………………………………..... 81

3.1.3.1 Initiation and Definition ........................................................................ 83

3.1.3.2 Transaction Costs and Efficiency …………………………………....... 87

3.1.3.3 Transaction Costs and the agricultural Contract...................................... 90

3.1.4 Institution Building (Institutionalisation................................................... 91

3.1.5 Organizational Change and Organizational Development (OD) .............. 94

3.2 Price Policy as a Means for inducing Optimum Water-Use Efficiency ... 97

3.2.1 Water and the Market......................................................................... 97

3.2.2 Water Pricing systems and Institutional Change ..................................... 101

3.2.2.1 Bases for setting water Rates .............................................................. 101

3.2.2.2 Methods of Setting water Rates ........................................................... 102

3.2.2.3 Institutional factors and Strategies related to Collection of Water Rates. 104

\section{Part II : Irrigation Scheme Management Organizations in the Sudan: Empirical Part}

\section{Agriculture and the National Economy ........................................................ 106}

4.1 Structure of the Agriculture Sector............................................................ 106

4.2 Irrigation Schemes in the Context of the Sudanese Agriculture Development........................................................................ 111

4.3 Limitations of the Irrigated Agricultural Development ………………..... 113

4.3.1 Performance of the National Economy …………………………………... 113

4.3.2 Demand-Supply Water Gap.................................................................. 114

5. Implementation of the Field Study ............................................................. 117

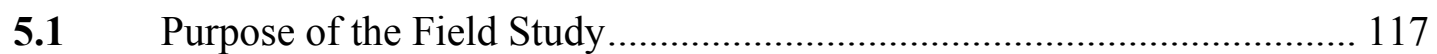

5.2 Study Area .................................................................................. 120

5.2.1 Why New Halfa and Gendettu? ......................................................... 121

5.2.2 Profile of the Common Characterestics ..................................................... 123

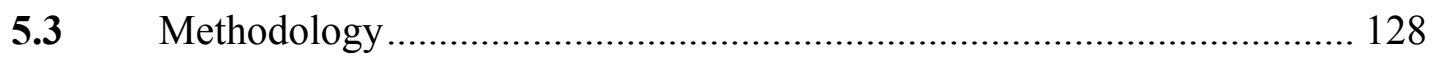

5.3.1 Factors that have Governed Investigation Methods ……………………. 128

5.3.2 Sampling Technique ........................................................................... 130

5.3.3 Some Findings of the Field Investigation Methods ................................... 134

5.4 Background to Schemes under Study ..................................................... 136

5.4.1 Agro-ecological Context....................................................................... 136

5.4.1.1 Rainfall and Other Climatic Factors .................................................. 136

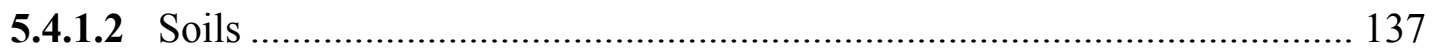

5.4.1.3 Cropping Pattern .................................................................................... 137

5.4.2 Production Relations: from Sharecroping Arrangement to

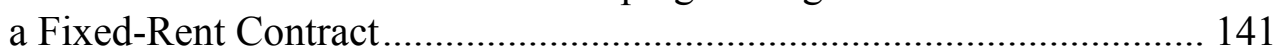

5.4.3 Some Features of Organizational Structure ............................................... 147

5.4.4 Technical Context ............................................................................. 160

5.4.4.1 Khashm El Girba Dam........................................................................ 160

5.4.4.2 The Layout of the New Halfa Irrigation Canal System.............................. 160

5.4.4.3 Gendettu's Pumpstations ....................................................................... 163

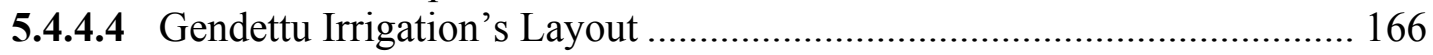




\section{Implications of The Results: Organizational and Managerial Obstacls to Water Use Efficiency .................................................... 169}

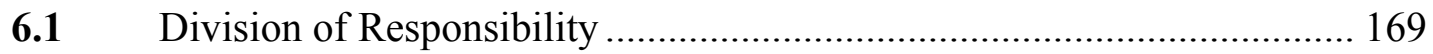

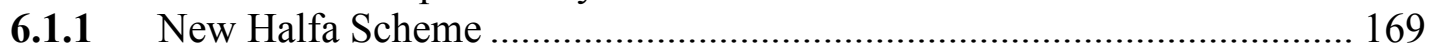

6.1.1.1 Scheme Administration (NHAC) and Ministry of Irrigation (MOI) ........ 169

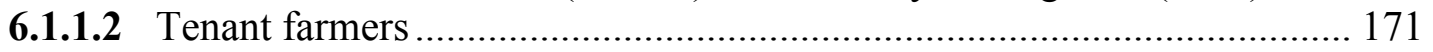

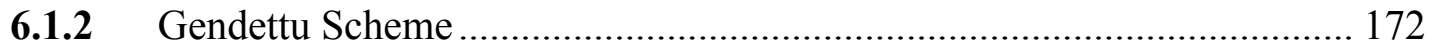

6.2 The Role of Scheme's Administration in the Problems of Water Management ......................................................... 173

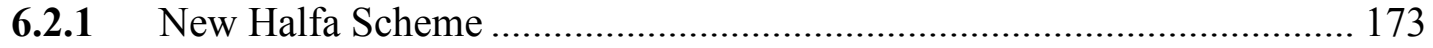

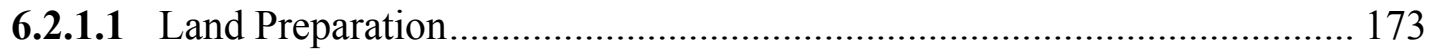

6.2.1.2 Land Grading/Levelling.................................................................... 179

6.2.1.3 Reasons of water Shortag ............................................................... 180

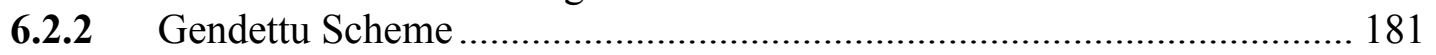

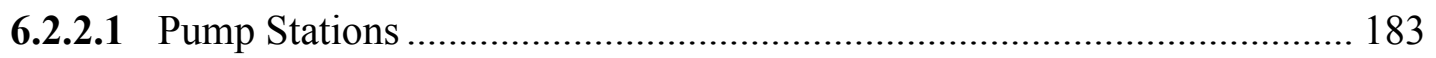

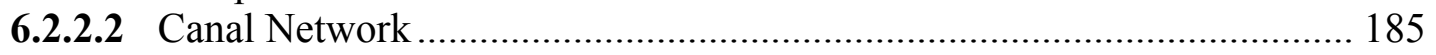

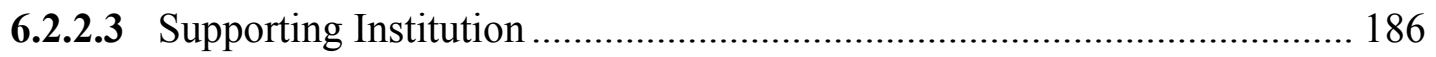

6.3 Farmer's Management: Water-User's Behavior.................................... 187

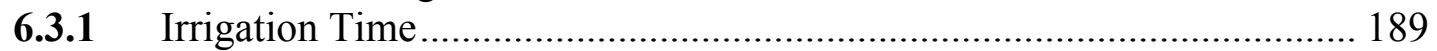

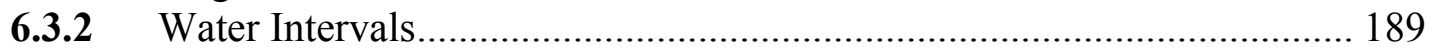

6.3.3 Crops Preferability: Wheat and Dura vis-a-vis Cotton............................ 193

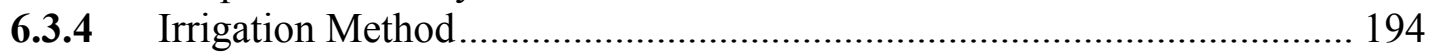

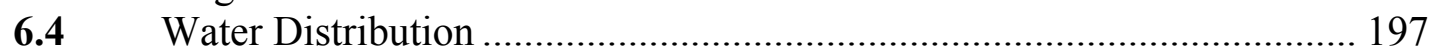

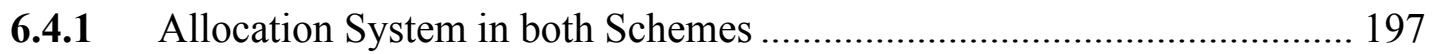

6.4.2 Who Controls the Water? ........................................................................ 201

6.4.3 Water Distribution between the Tenants ................................................ 204

6.4.4 Who takes over the Task of Irrigation? ................................................. 208

6.4.5 Availability of Water and Productivity.................................................. 213

6.5 Communication Systems .................................................................... 217

6.5.1 The Relationship between Tenants and Project's Management .............. 217

6.5.1.1 Production Relationship and the ,Government's Crop “ .......................... 218

6.5.1.2 Farmers' View on the Formal Channels of Articulation ......................... 219

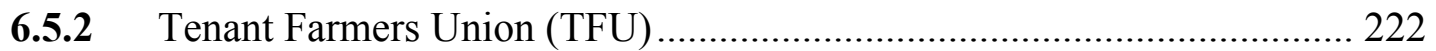

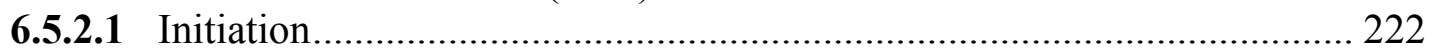

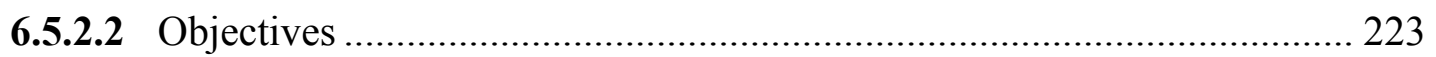

6.5.2.3 The Organizational Set Up of the Unions........................................... 223

6.5.2.4 Performance and Role in Scheme management .................................... 225

6.5.3 The Relationship between the Organizations ......................................... 229

6.6 The Price Policy.................................................................................. 236

7. Summary and Conclusion ............................................................................243

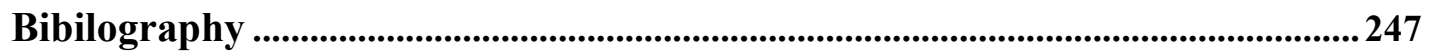




\section{LIST OF TABLES}

Table 1.1: Intellectual Shifts in Organization Analysis ........................................ 38

Table 4.1: Distribution of the Land-Use in Sudan............................................ 107

Table 4.2: $\quad$ Irrigated Area - current and Potential (1992) .................................... 110

Table 5.1: $\quad$ Basic Schemes Attitudes .................................................................. 126

Table 5.2: Some Quantative Answers from the interview with three Members of one Family in Village 13 Villages ....................... 136

Table 5.3: Joint Accounts' Components in New Halfa Scheme .......................... 144

Table 6.1: Offcials Reports on problems in New Halfa Scheme........................ 173

Table 6.2: $\quad$ Factors Hindering Tenants from Increasing

the Productivity \% (New Halfa) ........................................................ 174

Table 6.3: Percentage of Reasons that hamper the Performance

in the Farm and the Scheme ............................................................. 175

Table 6.4: Do you hire a tractor or other Machines? ......................................... 176

Table 6.5: Distribution of Planting Time in New Halfa according to

Crops and Tenant Groups .............................................................. 178

Table 6.6: Causes of Water Shortage Ranked by the Tenants

of New Halfa Scheme.

Table 6.7: Officials Reports on Reasons for the Under Performance

of Gendettu Scheme

Table 6.8: Tenants in Gendettu report on the most important

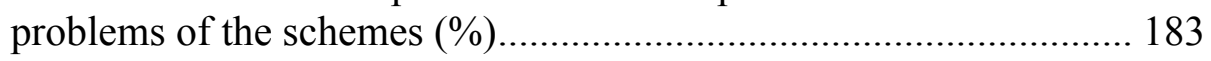

Table 6.9: Tenants in Gendettu Report on Causes of Water Shortage ............... 185

Table 6.10: Reasons for the Dissatisfaction Concerning Tenant's Behavior ....... 187

Table 6.11: The Total Number of Applications for each Crop............................ 191

Table 6.12: Percentage of Duaration of Irrigation in New Halfa ........................ 192

Table 6.13: Percentage of Water Intervals Practiced by the Tenats

in New Halfa by Crop................................................................. 193

Table 6.14: Distribution of the Angayas in Hawasha per Crop \% ....................... 195

Table.6.15: Reasons of Water Ditribution Problems (Officials) .......................... 199

Table 6.16: Tenant report on the Presence of the Khafir......................................... 204

Table 6.17: Reasons of the water Distribution Problems (Tenants) ..................... 205

Table 6.18: Suggestions from the Tenants for the resolutions of

Water Problemes......................................................................... 207

Table 6.19: Distribution of Irrigation Task among Tenants and hired Labors ..... 208

Table 6.20: Contribution of the family Labor to Total Labor Demand in Irrigation Operations (New Halfa Scheme)................................. 209

Table 6.21: Distribution of Family Members Contributing their Labor to Farm Operations ...................................................... 210

Table 6.22: Number of Weeding per Crops in the Two Areas of the Scheme ..... 210

Table 6.23: Family Labor Contribution in Farm Operations (Percentage)........... 211

Table 6.24: Labor Requirement in Man-Day for each Crop (Gendettu) .............. 212 
Table 6.25: Average Yield per Feddan Among the Sample

According to the Location of the Field (New Halfa).

Table 6.26: Disparities in Yield within Water Course in New Halfa .................... 216

Table 6.27: Average Yield for the two Major Crops in Some Sections of Gendettu Scheme Comparing with Private Scheme in the Area (Tonnes/Fedan) ................................................................ 216

Table 6.28: The Attitude Toward TFU in both Schemes .................................... 226

Table 6.29: Reasons of Tenants Dissatisfactin with TFU .................................. 227

Table 6.30: Officials report on Reasons of the Ineffective Role of the TFU ....... 228

Table 6.31: Prices of Some Inputs in the Last two Seasons ................................. 235

Table 6.32: Water and Land Changes in Seasons 81/82-90/91 in New Halfa Scheme (Ls/Feddan)

Table 6.33: Water Charges in Seasons 91/92 and 92/93 in New Halfa Scheme (Ls/Feddan)

Table 6.34: Water Charges in Selected Seasons per Crop (Gendettu) ................. 238

Table 6.35: Cropping Patterns as Suggested by the Tenants in New Halfa Scheme

Table 6.36: What would you Grow and Why if You would become another Five Feddan

Table 6.37: Do You agree to Pay Water Fees with Guarantee its Convenyes to the Field

Table 6.38: Do You Think that Water Prices can be Effective Means for Improving Water-Use (Officials) 


\section{LIST OF FIGURES}

Figure 1.1: Components of Irrigation System ..................................................... 24

Figure 1.2: Irrigation System Structures by Number of Levels .......................... 26

Figure 1.3: Types of Irrigation Systems by Size and Organization .................... 27

Figure 2.1: The Relationship Between Context and Structure According

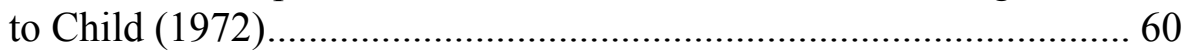

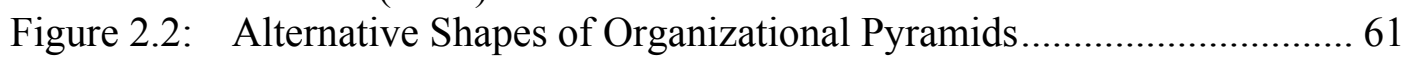

Figure 4.1: Central Sudan: Development of Mechanized Agriculture ................ 108

Figrue 4.2: Sudan Irrigation Schemes ............................................................. 109

Figure 5.1: Study Locations: New Halfa and Shendi....................................... 120

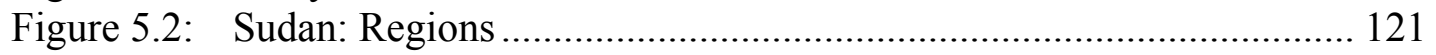

Figure 5.3: Sample of New Halfa Scheme According to Section, Block and

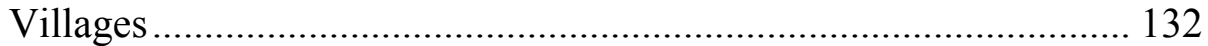

Figure 5.4: Distribution of the Sample in Gendettu Scheme ............................. 134

Figure 5.5: The Rotation System in New Halfa Scheme ................................... 139

Figure 5.6: Croppig Cycle in New Halfa Scheme.............................................. 140

Figure 5.7: Croppig Cycle in Gendettu Scheme ................................................ 141

Figure 5.8: Organization Charts - NHAC (1980)............................................... 148

Figure 5.9: Agricultural Administrative Structure in New Halfa Scheme........... 150

Figure 5.10: Personnel at and Below Section Level (New Halfa Scheme) ........... 151

Figure 5.11: Proposed Organization Chart (NHAC) ............................................ 156

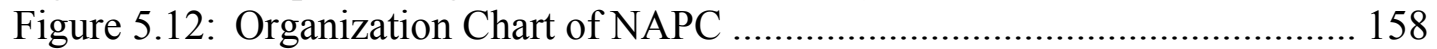

Figure 5.13: Organization Chart in Gendettu Scheme (1992/93) ....................... 159

Figure 5.14: Layout of Irrigation Field Distribution System ................................ 162

Figure 5.15: Gendettu Irrigation Layout .......................................................... 164

Figure 6.1: The Relationship Between TFU and NHAC .................................. 224 


\section{GLOSSARY}

\section{List of Abbreviations}

$\begin{array}{ll}\text { ABS } & \text { Agricultural Bank of Sudan } \\ \text { ARC } & \text { Agriculture Research Corporation } \\ \text { DPU } & \text { Development Planning Unit } \\ \text { EO } & \text { Extension Officer } \\ \text { FAEA } & \text { Federal Agricultural Extension Administration } \\ \text { FAO } & \text { Food and Agriculture Organization of the United Nations } \\ \text { FOP } & \text { Field Outlet Pipe conveying water from Minor to Abu Ashreen } \\ \text { GDP } & \text { Gross Domestic Product } \\ \text { GTZ } & \text { German technical cooperation } \\ \text { IBRD } & \text { (Deutsche Gesellschaft für Technische Zusammenarbeit) } \\ \text { IMF } & \text { International Bank for Reconstruction and Development } \\ \text { ITK } & \text { International Monetary Fund } \\ \text { LPMU } & \text { Indigenous Technical Knowledge } \\ \text { LWC } & \text { Livestock Production and Market Unit } \\ \text { MOI } & \text { Land and Water Charge } \\ \text { NAPC } & \text { Ministry of Irrigation } \\ \text { NCR } & \text { Northern Agricultural Production Corporation } \\ \text { NHAC } & \text { National Council for Research } \\ \text { NHIRP } & \text { New Halfa Agricultural Corporation } \\ \text { NIE } & \text { New Halfa Irrigation Rehabilitation Project } \\ \text { NIRP } & \text { New Institutional Economics } \\ \text { NRIRP } & \text { National Irrigation Rehabilitation Program } \\ \text { ODA } & \text { Northern Region Rehabilitation Project } \\ \text { PRA } & \text { Overseas Development Administration } \\ \text { RRA } & \text { Participatory Rural Appraisal } \\ \text { SPS } & \text { Rapid Rural Appraisal } \\ \text { TPO } & \text { Sudan Plantations Syndicate } \\ \text { USBR } & \text { Technical Planning Office } \\ & \text { United States Department of the Interior, Bureau of } \\ & \text { Reclamation. }\end{array}$

\section{Miscellenous}

Abu Ishreen (Abu XX) Abu Sitta (Abu VI)

Amlak

Angaya

Arab El Butana

Bersim

Dura

El Double

Feddan

Gadwal

Halfawyeen

Hawasha
Tertiary canal feeding a number

Quartenary canal feeding a hawasha

Freehold land

Area comanded by a gadwal

The Arabs (Nomads) of the Butana region

Iucerne (Medicago sativa)

Sorghum (sorghum vulgare)

Twin Abu Ishreen

An area of land approximately equal to 1.038 acres $=0.42$ ha.

Field ditch or furrow taking off from $\mathrm{Abu} \mathrm{Vi}$

the Nubians who come originally from Wadi Halfa in North Sudan a holding of land; in New Halfa a 5-feddan (in Gezira 10-feddan) worked by a tenant 
Hukkam

Kantar

Karkade

Khaffir

Khashm El Girba

Lubia

Masakin

Number

Rubat

Samad

Sheil

Wadi the rulers in Islamic kingdoms and colonial time

a yield of crop equal to $141.523 \mathrm{~kg}$; 1 kantar feddan $=337 \mathrm{~kg}$. ha.

Hibiscus sabdariffa

Water bailiff

The former name of the New Halfa Scheme hyacinth bean, grown mostly for fodder but sometimes for food 'poor people'; a class of subject commoners

Block, usually 90-feddan (37.8 ha.)

small irrigation basin

Senior farmer

Credit, a system of money lending repaid at harvest with a specific quantity of crop yield equivalent to the loan

seasonal watercourse 


\section{Introduction}

The problem of an irrigation water supply, which is directly related to the production and supply of food, is gradually becoming one of the crucial issues facing mankind. It is a fact that one clearly remarks in different studies, especially in those about the future of developing countries, that water as it used today will not be enough to face the present and new challenges of these countries. Herein lies a major development dilemma.

It becomes clear that the major problem in the area of water resources is not a Malthusian specter of impending scarcity, but one of instituting more rational and better management practices. In the case of water, as of any other resource, the problem must be viewed in the wider context of the rational use of natural resources for the achievement of a sustainable development process, as envisioned by the New International Economic Order proclaimed by the United Nations. A full understanding of such facts which make it possible to increase production through improving the utilization of available resources, without increasing the supply of it, in addition to other factors such as opening markets and adjusting price systems, were important factors through which many countries in Latin America and Asia overcame their economic problems in the 1980s and 1990s. It seems that, mainly because of the nature of their national political systems, Africans were not in a position to put these factors in practice. It is to be argued, therefore, that much of the difficulty that surrounds attempts to understand the reasons for the low performance of national resources in Africa derives from the inadequate treatment of, or the attempt to ignore completely, this dimension of natural resource utilization.

Many developing countries, especially those with arid and semi-arid conditions, are already seriously short of water. Because of growing competition for the limited water resources, a heightened environmental awareness, a continuously and rapidly increasing population, and scarce and costly capital, this problem will become more acute in the future. This leads to the question whether successful agriculture indeed requires such large quantities of water as are applied today. The answer, which has been empirically prooved in different places in these parts of the world, is that the present level of water used in irrigation is, to some extent, wasteful. All these facts have stimulated more interest in the careful use of water than in simply increasing its supply.

The foremost challenge related to water scarcity in developing countries is the need to increase generally efficient water-use in agriculture, urban areas, and industry. Improved efficiency in agricultural water-use is required both to maintain productivity growth and to allow the reallocation of saving water from irrigated agriculture, which generally accounts for 80 percent of water diverted for use in developing countries, to urban and industrial uses. Experience shows that using less water to grow grain increases the water available for other uses as surely as building a dam or diverting a river.

For example, at a pilot project in Egypt funded by USAID (US Agency for International Development), an improved management of irrigation systems is largely credited with boosting rice yields 35 percent. In Pakistan, by some estimates, better irrigation management could annually save over 50 cubic kilometers - four times the storage capacity of the nations" "Tarbela Dam" - at one-fourth the cost of developing new water supplies. Similarly, in Sudan, according to a study by the National Council for Research (1976), if the total irrigation system in the Sudan improved by ten percent, the country could save - from its present irrigation water requirement - an amount almost equal to its share from the 
Jonglei canal project (phase I). Another study conducted by the Hydraulic Research Station (1989) argues that saving ten percent of the water consumption in the Gezira scheme by improving water management would release the amount of water equal to the storage capacity of the "Sennar Dam."

Africa is the major continent suffering from the problems of water shortage. Two-thirds of African nations have at least one third less annual runoff than the global average. Drought conditions that persistently plague the continent's dry region have, in recent years, threatened many nations, and Sudan in particular, with famine. The FAO (Food and Agriculture Organization of the United Nations) estimates that up to 80 percent of the land in Africa is threatened by degradation, as rural people put their own short-term survival ahead of long-term natural resource sustainability, and that two million hectares of forest are lost every year. In view of these observations, forty-three African countries declared the 1990s as The Decade of Water Management in Cairo in 1990.

Water management is one of the major challenges in charting a course for environmentally sustainable development. Population growth exacerbates water constraints. Yet, even if more active population policies were adopted, the average rate of population growth among African countries is expected to decline only slightly over the next 25 years, from 2.8 percent today. This will render advances in poverty reduction extremely difficult, and underlines the fact that the fundamental issue in Africa's food-population equation in the foreseeable future is that of raising agricultural resource productivity. Likewise, the Middle East has a history of such contradiction between population and water. There are many reasons, therefore, to believe that the solution of dangerous problems in this area, like religious fanaticism hindering the peace process, is embedded in improving the performance of water-use. The achievement of such a task will introduce an atmosphere and resources to redress the causes that "fuel" these problems, namely ignorance and poverty.

The Nile Basin, with its nine riparian states, embodies all the challenges that transnational management of fresh water could possibly present. Most of the course of the Nile traverses semi-arid or totally arid regions, all of its riparian states are agriculturally-based societies with rapidly growing populations, all are poor and to varying degrees aiming to sustain food security. All of them need, therefore, and to different extents, a higher share of water. But, in the light of the facts that several of the riparian states have been and remain politically hostile to one another (the triangular contradiction between Egypt, Sudan, and Ethiopia) and that cooperation between them concerning the development of the river is only partial, and regarding the economics difficulties that face all of these countries, it seems that increasing the supply of water, particularly in the short and medium term, is very difficult.

It can be concluded that improving the technical and agro-economic aspects are not enough for the success of irrigation projects to face future challenges. In addition, if not firstmost, the institutional arrangements for managing irrigation water play in this context a major role and should be made the focus of dialogues and discussions concerning irrigated agriculture. This is the aim of this study through two empirical cases from the Sudan. The main purpose of this research is to discuss comprehensively the institutional factors that hinder improving the irrigation water-use in Sudanese agriculture.

The study is divided into two parts. Part I takes on the task of surveying the major schools of thought and approaches to the characterization of irrigation institutions and organizations in literature. Chapter 1 begins this task by providing the definitions of key concepts used in 
the study. The focus is on analyzing the different dimensions of irrigation systems and the complex interactions within these contexts. This chapter also outlines the different determinants and criteria of the efficiency of irrigation systems.

Chapter 2 critically scrutinizes the more rigorous dimensions and factors that affect the management of irrigation organizations. The emphasis has therefore been directed at issues such as the objectives of irrigation organizations, the contextual factors that describe the organizational environment, the relationship between this environment and the organization structure - the topic which introduces the idea of institutional change - and finally the position of farmers in irrigation schemes. Among the different contexts that influence the performance of irrigation organization, special reference is given to the technological facts that have to be taken into consideration, the historical factors, the socio-cultural dimensions, and the magnitude of the political context in developing countries in general and Sudan in particular. It emphasizes, in addition, the human dimension of irrigation systems and the importance of water-users' participation.

Chapter 3 delineates in broad terms some approaches and strategies for improving the performance of irrigation systems. The first section of this chapter elucidates the process of institutional change and then traces the development of two theories that are bound with this process - namely the theory of institutional innovation and transaction cost theory, in addition to the concepts that constitute New Institutional Economics (NIE), so called in institutional literature. The chapter delves into the question of what makes these institutions/organizations more efficient, and discusses in the following sections some key factors to reach these goals, i.e. institutional building and organizational development in irrigation systems as well as the economic incentives represented in water pricing policy.

After having examined the various theoretical considerations of the study, these aspects are refuted empirically. The purpose of Part II is to delineate and examine in broad terms some aspects that hamper the efficient utilization of irrigation water at the very lowest level water management within individual farms sharing watercourses in two bureaucratic schemes in the Sudan. The management of irrigation organization at project level has received scant attention in literature. However, whereas the task is complex, it was clear that only a comprehensive analysis of all the factors that may contribute to poor performance at the lower levels of the system can indicate the correct mixture of remedies required, in the correct sequence. In other words, organization and management at project level has been fully reviewed as well as constraints at water-users' level.

Part II begins with an introductory chapter (Chapter 4) which briefly draws attention to the present situation and the future challenges of the Sudanese agricultural sector in general and the irrigated sub-sector in particular. Chapter 5 looks more closely at the study areas and the characteristics of the two schemes. It elucidates, in addition, the methodology of the field work and the factors that have governed the way of gathering data.

Chapter 6 presents the results of the study. It begins by determining the responsibilities of the main configurations of the schemes (who is responsible for what?). The second section defines in detail the role of each one in the problems of water management. Though water distribution is clearly of central importance in any irrigation project, it was long a relatively neglected subject. The study analyses the allocation system in both schemes (6.4) and tries to find answers to the questions: Who really controls water distribution between the tenants? What role has the Tenant Farmers' Union (TFU) in this connection? And who takes over the 
task of irrigation? This section also examines the relationship that might exist between the availability of water and productivity. The features of a communication system in the absence of participation and whether irrigation systems can operate efficiently under despotism are discussed in Section 6.5. In addition, the role of TFU (6.5.2) as well as the need for farmers to be provided with effective and integrated irrigation assistance and an extension service is strongly emphasized in this section (6.5.3). Finally, this chapter closely examines the economic incentives through water pricing as a means of improving water management (6.6) in particular. It also rejects a claim made by some officials that tenants are absolutely against charging and/or increasing water fees.

In essence, from the theory and concepts presented in Part I and the results of the empirical section, the study arrives at several conclusions relating to the organization and management of irrigation water-use in Sudan. 


\section{Part I: Theoretical Framework}

\section{Harvest of Experiences: The Need of learning from the Past}

For many decades of development, the agricultural sector has been „the great white hope“ for most of developing countries to compensate the negative effects of rapid population increases and to put an end to what is known as vicious circle. To realize this goal, many capital-intensive irrigation projects and vast financial investments have been made. Moreover, because of the scarcity of fertile land and developmental water supplies still available for irrigation development, the costs of new projects have escalated significantly, whence, irrigation decision makers have been turning increasing attention to improving and maintaining existing irrigation systems, and the term (tendency toward) newly constructed has been mostly replaced by rehabilitated systems. In other words, it is now widely recognized that the key to increase agricultural production in the future is the improvement of existing irrigation systems. Unfortunately, the outcomes of vast majority of these irrigation systems, either new or rehabilitated, often fall short of expectations and differed, however, distressingly from those that had been planned.

Manifold reasons for this flat have been and still the target for many researchers and studies. Each one stresses specific reason as a determinative. This way of thinking coincides with the same approach that has, sometimes, predominated within the scope of economic development literature during this period i.e., the 'one best determinative factor', where one factor can be enough to explain the phenomenon of underdevelopment!

Viewing the irrigation system itself has been, for a long, a debatable question: is the irrigation system a technical process or scientific issue, therefore, belongs to natural science?, or socio-technical process having several dimensions and, therefore, has to be considered and analyzed according to its comprehensive nature? There is almost universal agreement in this field that the tasks of irrigation management were seen, at one time, as essentially 'technical' as being within the domain of certain specialists, particularly engineers (UPHOFF 1991:17). Accordingly, we have used the concept of physical or engineering irrigation efficiency as a substitute for knowledge of the effect of the human element in water management (LEVINE 1980:56). This is exactly what is referred to as a weakness or defect within the bound of concept and at the level of conversion in practice that causes, therefore, the failure of irrigation schemes (HUPPERT/WALKER 1988:11). It is almost taken for granted that if the irrigation sector is developed the way it was done in the past (by improving efficiency of use of the land and water base), all other problems facing the farmers and the agency will be solved. In contrast, the result that has been seen everywhere showed that re-orientation of this perspective must be done.

The other theoretical perception of irrigation systems that is now widely accepted is to understand it as a "socio-technical enterprise with organizational and cultural factors ranking alongside physical and material ones" (UPHOFF 1991:17). ${ }^{11}$ The design and operation of many irrigation systems in the developing countries are often inefficient because the importance of the management component and of social constraints has been, or is, underestimated (LEVINE 1980:51). Poor performance and the bottlenecks in the

\footnotetext{
${ }^{1}$ For a more detailed discussion of this definition see UPHOFF 1986 Chapter1.
} 
optimal resource utilization in irrigation systems are then not only a consequence of technical deficiencies in the design of these systems but, basically, stem from weaknesses in the organizational and level of management of the schemes (SAGARDOY 1986:1, MANIG 1989:19). A conducive institutional arrangement, therefore, is highly required to have their full utilization (HAGE and FINSTERBUSCH 1987).

According to this approach, therefore, it is the management input that ultimately determines the efficiency with which the other input factors...land, labor, and capital.., are converted into desirable outputs such as increased physical products, higher financial returns to private participation, and improved well-being for society as a whole (FAIRCHILD and NOBE 1986:381). This management can only be effective within an appropriate organization. Since that time, a great deal of interest in the institutional and organizational dimensions of irrigation management has overgrown and policy makers began to formulate strategies for the organization of irrigation groups at various levels in the irrigation system. A major purpose of these organizations is to structure effective linkages between the water users and the system authorities.

At project level also, the center of focus has changed several times, changed. It has for long been centered in planning and design on the physical main network of canals between the headworks and the tertiary outlets (WALKER/CLEVERINAGE 1989: M.XI.3) and, therefore, the control of water at this level. As a result, thinking many that technical irrigation efficiencies and performances tend to be much lower at the watercourse and farm levels (the tertiary canals) than in the main water delivery system, the area below the turnout has been and still is, largely a "no man's land" (REDDY 1986:98).

At the same time, it becomes clear though, that there was little use in introducing improvement programs at tertiary levels as long as a predictable, adequate and reliable flow through the outlet was not guaranteed (WALKER and CLEVERINAGE 1989: M.XI.3). This, therefore, brings to a conclusion that only a comprehensive analysis of all the numerous reasons and factors that may be contributing to poor performance at the lower levels of a system can indicate the correct mixture of remedies required in the correct sequence. In other words, organization and management at the whole project level need to be fully reviewed, as well as constraints at the farmer's level. In this connection, feedback between all levels is necessarily required and subjects like the ecological perspectives, participation, the role of farmers in irrigation management, and the need to respect their interests and traditional knowledge, have to be fairly discussed.

Equity and allocation of water that consider one of the very important tasks of irrigation management, if not the most, have been also for long a raised issue. In almost every case, the problem of discrepancy along the canal concerning water distribution was considered as a participant factor that characterized, in the first place, the large irrigation schemes in developing countries. The reasons may have a physical base, but often reflect problems in system management. This phenomenon is complex and interlinked with the patterns of wealth and power in irrigation communities.

Interests and goals conflict of influential groups in irrigation communities have also a considerable effect on determining the degree of technology. Choosing appropriate technology in irrigation systems, as in other economic activities, and trying to find a possible compromise between the advantages and disadvantages of each alternative, is another challenge in developing countries. Irrigation development requires and depends on 
adequate provision and successful joining of water management technology as well as appropriate institutions and organizations for the governance of that technology (COWARD 1980:27).

As a result of manifold and manifest problems experienced by farmers in many irrigation systems, and the problems experienced by the systems themselves in addition to other considerations, a philosophy has developed to the effect that irrigation modernization can take place only with radical departures from traditional practice. This results in improving the efficiency viewed from the perspective of engineering efficiency: efficiency in use of water, efficiency in mechanics of operation and maintenance, and efficiency in irrigation system costs (LEVINE 1980:61).

Introduction of modern technologies allows for a higher productivity and increasing surplus that can be skimmed off, although these forms do not correspond to the social and cultural systems in most of developing countries (MANIG 1989:38). There are ample need nowadays, for these countries, to thought-out and shape up the present concepts of technology practiced in irrigation schemes as a condition for lasting efficiency. For example, modern technology is urgently required to solve problems concerning land preparation, like land leveling, and the seasonal excessive workload of farmers during periods of increased water requirement. Moreover, some call for resuming applicationoriented, interdisciplinary technological research, to determine whether modern technique such as automated irrigation and leaser leveling can guarantee sustainable irrigated agriculture in developing countries (HÜBENER/WOLF 1991:18). The performance capacity of such technology has to be assessed in terms of productivity per unit area, water and labor. As more furtherance for such idea, one design of sprinkler systems- the center pivot system- which was largely responsible for the rapid expansion of irrigation on the U.S. high plains in the last decades (POSTEL 1984:39) is recommended as a serious alternative for the future agriculture in developing countries, because of the several advantages regarding increasing labor productivity and its considerable effects on the agricultural structure in the long run (MANIG 1993) ${ }^{2}$.

More debatable among the discussions concerning the causes of the ubiquitous disappointment of irrigation schemes, is the issue of water pricing - pricing adjustments versus quantitative control debate. As we have seen, much faith is placed on structural adjustment programs concerning water pricing, to rescue water use in the irrigated projects from its predicament. Many commentators concur in their view that the profligate waste and inefficiency in use of irrigation waters are a result from the extraordinary extent to which water is not treated as a 'commodity'. Therefore, many view increasing the high price of water as an effective means for inducing optimum irrigation water use efficiency. Whereas others, on the other hand, feel that high prices may actually create a disincentive for optimum water use in the long run and recommended, oppositely, other methods like rationing or limiting the allowable use and shutting off the supply accordingly (KELLER 1986:346).

We conclude the above by saying that the accumulated experiences show quite that all these factors together must be considered, on an equal footing, in order to accomplish the

\footnotetext{
2 The author stressed that because of the characteristics of the farming systems in the developing countries, such alternative is not generally recommended.
} 
goals of irrigation schemes and these can only be achieved through effective management and well-structured organizations.

\section{Irrigation Organization and Management: Definitions of the Key Concepts}

Before attempting to discuss and suggest how the performance of irrigation organizations and management should be improved, in order to optimize the use of water, we need definitions of a few terms that will be used frequently.

\subsection{Irrigation Systems ${ }^{3}$}

Well understanding of irrigation system; its meaning, characteristics, and forms, is the first step in assessing improving the performance of irrigation systems. Kind of involved system, its physical possibilities and constraints as well as the human relationships associated with it, sets certain limits on and provides certain opportunities for water management and its institutional framework that one should know before trying to make any improvements.

\subsubsection{Nature And Characteristics of Irrigation Systems}

COWARD (1980a) certify the coordinated nature of water management as a take-off point for his definitions of irrigation system. Management of water environment often depends on the coordinated action of two or more potential water users (for impounding the water, conveying it, disposing of the excess.....etc.). Irrigated agriculture therefore characteristically requires coordination of activities. A system of irrigated agriculture then can be defined as a landscape to which is added physical structures that impound, divert, channel, or otherwise move water from a source to some desired location. These structures are operated cooperatively for the purpose of producing food or fiber (COWARD 1980a:15-16). ${ }^{4}$ Irrigation units, according to these analyses, may be viewed in a variety of perspectives: as hydrologic entities, as engineering networks, as farming systems or as organizational entities. In actuality, an irrigation unit is simultaneously all of these perspectives, and irrigation development is the task of creating these complex units. It is, consequently, a task that is concerned with the development not only of landscapes and physical structures but also of patterns of interaction and organization. Briefly, it must confront the issues of governance and enlist human and other resources and procedures to arrange appropriate institutions and organizations in addition to appropriate irrigation

\footnotetext{
${ }^{3}$ According to the Technical Advisory Committee (TAC) of the International Agricultural Research Center, system is "any set of elements or components that are interrelated and interact among themselves. Specification of a system implies a boundary delimiting the system from its environment. Two systems may be a subsystem of another" (SCHMEHL 1986: 68). A farming system is under managerial control and the boundary represents the limits of that control (UPTON 1987:5). A functional system is characterized by its synergy i.e., all elements in the system (such as people, things, and concepts) working together to produce a greater output than the sum of the outputs of these elements operating independently (SINGH 1988:358).

4 The basic elements of this definition has been found in VANDERMEER (1968), "changing water control in a Taiwanese Rice-Field irrigation system," Annals of the Association of American Geographers (58) pp. 720-747.
} 
technologies ${ }^{5}$. Similar to this line of thinking, MÜLLER (1979:59) links up three factors in his definition of irrigation system. An irrigation system can be defined through the application of water by the people with the object of high agricultural production.

Laying stress on the ecological perspectives of the agriculture process (the system Approach), an irrigation delivery system is defined, according to NOBE/SAMPATH (1986:5) as "a created entity with complex interdependent social, economic, legal, biochemical and physical factors, processes, and procedures designed to transport water from a source to the root zones of plants and remove excess water through horizontal or vertical drainage. At the farm level, the water input is combined with other farm inputs and managed to produce crops of economic value." Thus, a system approach to irrigation management encompasses the total set of process and interactions involved in irrigated agriculture- not just the water input.

This grasp of the vital principle of interaction of systems components, which has been developed since the beginning of seventies, was necessary to overcome the greatest technical and institutional handicap to agricultural development in the newly developing countries.

With a similar approach, EARLY (1983) defined an irrigation system as "the entire set of increasing social, economic, biological, and physical factors. objectives, and entities, from the source of water through the conveyances to the farm and the land that is irrigated, including the drainage network that removes water excess from the boundary of the irrigation service area. The fundamental objective of an irrigation system is to increase agricultural output through improved management of water" (SCHMEHL 1986:86). ${ }^{6}$ Thereby, a certain interest in harmony between irrigation system and its whole environmental and experienced background is not only necessary but also considered as a condition which must be realized to achieve full utilization of the available potentials.

On the other hand, the social dimension of the agriculture process ${ }^{7}$ have a vital influence on Walter and Cleveringa's definition of irrigation system. It is, accordingly, a system in which persons use water in an organized way and at a specific location so that irrigationspecific products and services produced will contribute to fulfil the goal of the water users and other interested groups (WALTER and CLEVERINGA 1989:Vol. 1 p. II.1.2). The characteristics of irrigation systems then are as follows (HUPPERT and WALTER 1988:35):

- socio-technical: stress the coordinated cooperation of and the adapted interaction between the social and technical attributes of the system;

- open: that means, there are mutual relationships between the irrigation system and its environment; the ecological, technological, economical, administrative, legal and socio-cultural environment;

\footnotetext{
${ }^{5}$ For a good discussion of the role of irrigation development in the agricultural development see COWARD 1980a.

${ }^{6}$ One of the subsets of the irrigation system is the farm irrigation system, which, in turn, is a subset of the farming system.

7 The establishment of International Irrigation Management Institute (IIMI) in Srilanka 1984, has been indicated that the social dimensions of irrigation system should take more attention in the future (KNOTH 1989: 4).
} 
- goal oriented: oriented towards goals which are determined through the internal and external interest groups. These goals are situational specific.

Parts of an irrigation system has also, in many cases, the character of non-profit organization. Goals like profits get back against ones like expanding the production significantly beyond the level of subsistence. The achieved performances are often qualitative and, thus, hard to be measured and controlled. It is also of interest to be noted that because irrigation systems are human enterprises, adaptability, learning and improvement should be part of irrigation systems' capacity.

It is almost taken for granted recently, that irrigation systems are not pure technical structures, but, in the first place, complex socio-technical structures. The technical and social dimensions of an irrigation system must be comprehended as a complex and interacted factors not as a substitute or alternative for each other, or as a "either ... or" question. Therefore, any swing from one to the other extreme is not useful. A recent discussion of the magnitude of understanding this vital feature of irrigation systems was presented by UPHOFF (1991:198-204). He noted that, "studies of irrigation management have satisfied most observers that social and technical factors are so embedded in each other that it makes no sense even to try to think of irrigation as 'mostly' one or the other, or to decide that it is some percentage social (x percent) and another percentage $(100-x)$ technical. This kind of zero-sum thinking obscures the extent to which each set of factors influences the other. The most tenable conclusion is that irrigation is best understood as a compound socio-technical process" (UPHOFF 1991:198).

Concentration on one set of independent variables and ignore the others leads, certainly, to sub-optimal outcomes. Optimization usually involves some combination of factors from two or more sets to achieve the greatest production possibilities within accepted constraints. For example, when an irrigation system encounters a drainage problem with a growing extent of waterlogging, some combination of drainage structures and changes in operating rules is likely to improve the situation at less cost (or with most benefit) than if only physical or only managerial methods are employed. It is not a matter of solving problems first on one side and then on the other. Rather, there should be concurrent, or at least iterative, examination of possible adjustments in both the socio-organizational and physical-technical realms.

Taking these considerations of the nature of irrigation system into account, in designing stage, make it possible to operate and manage it efficiently both from the technical and social point of view. They help in solving the problems which may be faced by improving the management in ways that permit water users to participate and share better the burdens of management with an agency. This approach was applied by OAD $(1987)^{8}$ who found that:

- in convential technical designs, if the farm system is directly connected to the main system, without intermediate storage, this means that water users cannot take much responsibility for water distribution. Objective of the main system managers to have maximum stability of flow, by keeping discharge

\footnotetext{
${ }^{8}$ For a more detailed discussion of the results of applying this approach see: OAD (1982) Irrigation Water Management and Relative Water Supply in Irrigation systems in Indonesia. Ph.D dissertation, Department of Agricultural Engineering, Cornell University.
} 
levels within narrow parameters to minimize effects like erosion and sedimentation, will conflict with those of the water users which want operational flexibility. On the other hand, in contemporary system design and operation, large single water sources can be broken down and buffered by intermediate storage facilities -- stabilizing tanks or small reservoirs within the system. These facilities can be operated by users fairly easily because the volumes of flow from each source are fairly small, well within farmers' management capabilities. Such appropriate design of the system in which farmers' participation in managing water is permissible will encourage them to develop their organizations. Therefore, dispersed storage facilities are integrated into the organizational capacities of water users, so that farmers can easily vary their irrigation in frequency, duration and discharge.

- adoption of such approach is not only necessary to solve the problems concerning water capture and delivery between the main system level and the tertiary or downstream level, and remove the conflict between the tasks of systems' management and the users management, but also effective in resolving the problems concerning water distribution at tertiary level between the farmers. In a system where the water issued does not respond to downstream conditions and depend only on what is done upstream, water users will not be able to regulate it and will have no incentive for efficient use of water unless the volume being issued is less than users would ideally want for the command area. Having gate or orifice control at the field channel level to get an adjusted flow is possible when the socio-technical considerations, as applied under the OAD' conditions, are practiced. ${ }^{9}$ In a system that places value both on water use efficiency and on equal distribution, with social controls activated among farmers through their own organizations, one can move closer to optimum water use, combining structures that give physical control over water with social organizations that give some control over users.

In the final analysis, adopting a socio-technical perspective does not give any preordained answers about how to improve irrigation management. Rather, it is a way of thinking which if adopted throughout irrigation bureaucracies can reorient subsequent behavior. It should result in better management decisions and strategies. In the same vein, focussing on irrigation management leads one to view irrigation not only as a socio-technical enterprise but also as an organizational-managerial one. It requires drawing on disciplines like organization theory and cognitive science. For irrigation management, technical (physical structures) and social (organizations, understood as a human activities) factors, can be dramatized according to this approach, as the hardware and software needed for computerized data processing. Some tradeoff is of course possible between them at least in the design stages (UPHOFF 1991:200).

\subsubsection{Types of Irrigation Systems}

Irrigation system analogously vary from large to small, and have different physical structures resulting from various combination and layouts of parts. COWARD (1980a:27)

\footnotetext{
${ }^{9}$ The conditions he presumes are more like those of Southeast Asia, where the water shortage is relative not absolute as in South Asia.
} 
classified irrigation systems according to the 'take-over' of the management into three types. They may be community systems, operated and maintained by the water users themselves and /or their representatives; they may be bureaucratically managed systems, fully administered by an agency of the government; or they may be jointly managed systems, in which some functions are performed by the irrigation agency while others or the responsibility of one are more water-user communities. Similarly, addition to the size and property as a classifying factor, gravity flow irrigation systems ${ }^{10}$ could be classified, according to REDDY (1986:96-9 ) into:

- Individually Owned Irrigation Systems: in these systems, farmers manipulate and control the water on the farm. There is usually no interference from other farmers, and the farmer-owner can irrigate at his convenience. The supply of water is usually from a well.

- Community-Managed Irrigation Systems: in such systems, performance on the farm depends upon the farmers' ability to control the water on his farm and to share water with the other farmers in the command area. The water distribution system and the cooperation between the other farmers in that command area decides the project performance.

- Large-scale Irrigation Systems: A large-scale gravity flow system ${ }^{11}$ consists of three components, as shown in Figure 1.1: main system, unit command area (similar to community-managed system), and farm system (individual ownership), each with distinct properties.

Figure 1.1 Components of Irigation System

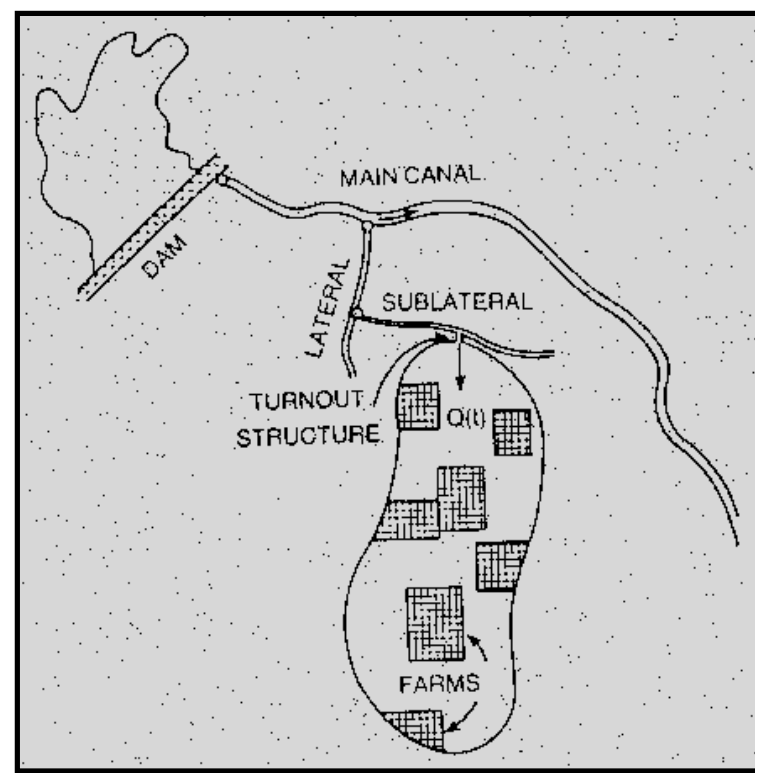

Source: REDDY 1986:96

10 Gravity flow is the most widely used irrigation method in the world.

11 like Gezira Scheme in the Sudan, the major projects in northwest Mexico, and the extensive systems of the Indian Subcontinent. 
Main System extends from the dam to the various outlets which supply water to a group of farmers. The irrigation bureaucracy operates the system.

Unit Command Area refers to the piece of land commanded by an outlet. Usually, a group of farmers is supposed to share the water available at the outlet among themselves and apply the water to their fields. They have not any control of the flow rate, duration, or timing of water received at the outlet.

Farm System refers to the individual farm in the command of an outlet. The farmer operates and manages the farm system. The flow rate and its timing and duration at an individual farm are influenced by the operation of the main system and the system below the outlet.

The performance of large-scale Irrigation Systems depends upon the integrated effort of the irrigation bureaucracy and the farmers in the command area, and the rules and tools provided for operation of the irrigation system. The overall performance of any irrigation system depends upon the performance of individual components (fields, unit command area, and the main system). The relative magnitude of performance of the three components varies from irrigation project to irrigation project, and for increased agricultural production good water control and management of all three components of the irrigation system is necessary.

It is supposed to be easy to associate irrigation development with large-scale activities ${ }^{12}$. The size of those projects requires the involvement of large-scale public agencies that are able to recruit the technical personnel required to plan and manage complex undertakings and to obtain the enormous financial resources required for construction (COWARD 1980a :24). Some have maintained a very elaborate administrative network that extends from the water source to the individual farmers' field. The extreme case has been the Gezira Scheme in the Sudan, where the farmers may have a kind of "invisible" involvement in actual system operations.

Often, the organizational patterns of large-scale irrigation systems may be characterized as joint. In such systems some management functions are the responsibility of the agency and others are lodged with farmer groups within the command area. The irrigation system under such organization has integrative character which links virtually many farming communities into a unified national water grid that irrigates large scales of farmland.

UPHOFF (1991:32-37) also found that variables like size and organization are more suitable for classifying irrigation systems than their structures and technologies. This is

12 It is of important also to be noted that the small-scale irrigation systems can play a basic role in leading successful agricultural development. COWARD (1980b) discusses a number of examples of "silent success" traditional, usually small-scale systems. These systems offer important insights regarding the solution of organizational problems, particularly at the level of the unit. Two interesting examples are found in the cases of Philippines and Indonesia. The so-called BISA Program (Bario irrigation Service Association) is largely oriented toward the installation of pump systems to service small command areas (usually several hundred hectares) in the Philippine. The government assistance provide significant improvements to critical elements of the physical infrastructure. Approximately the same, Indonesia's Sederhana Program is aimed at developing command areas of 2000 hectares or less with the use of physical structures that are simple to design and construct. 
partly because the physical structure of irrigation system is relatively similar across variations in size and technology. He noted that "the main difference found in the layout of systems is in the number of level of operation and organization they have." This is defined by the hierarchy of points at which water can be divided and controlled as shown in Figure 1.2. Number of levels correlates with size, but it does not translate directly into size, or vice versa. Gravity flow and groundwater systems, when one controls for size, are similarly configured as in Figure 1.2. All have a water source with main and subsidiary channels that carry, divide and spread the supply.

Figure 1.2 Irrigation System Structures By Number of Levels

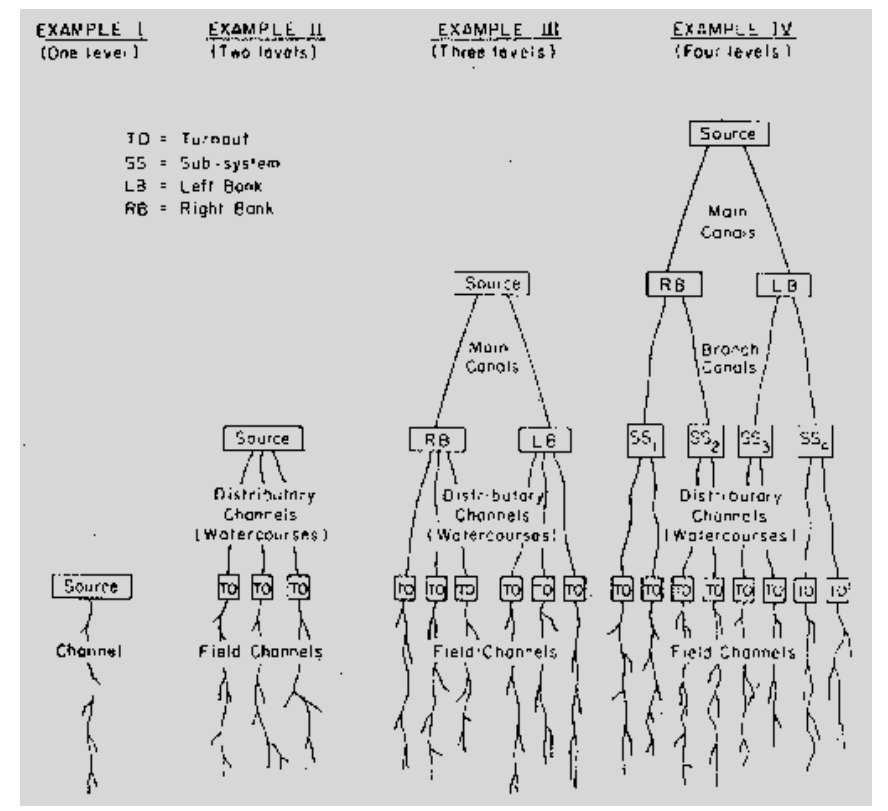

Source: UPHOFF 1991:32

Alternative modes of organization do diverge across large and small sizes of irrigation systems, at least to some extent, and provide a basis for classifying it. The principal options for operating an irrigation system according to differences in organization are: management by agency personnel, or management by water users. Differences in structure, that means, the number of levels sketched in figure 1.2, interact with the variable of organization and classified three scales of irrigation systems ${ }^{13}$ as follows:

( a ) small-scale systems have one or two levels of operation and one or a few point of water control. These systems usually serve less than 100 acres or only several hundreds of acres.

( b ) medium-scale systems: have three or four levels of operation at which water flow can be reduced and/or divided by control structures. Range from about 1000 acres upward

13 The reason for making these distinctions is that management tasks differ considerably in such scale terms. 
to several tens of thousands of acres; the maximum is in the range 50,000 to 100,000 acres $^{14}$.

( c ) large-scale systems: have five or more levels, with command areas from 50,000 to 100,000 acres or more, ranging up to a million or more in some countries.

UPHOFF et al. (1991) has subdivided these three size categories again by mode of organization into five types of irrigation systems as shown in Figure 1.3. Types (B, $\mathbf{C}$ and D) encompass the large majority of irrigation systems and the largest share of irrigated acreage. Type (A) for gravity flow systems is infrequent and the costs of its management are too great. Agencies sometimes undertake tasks for pump systems where the technology is unfamiliar to farmers and problems of maintenance and fuel supply must be overcome. The one type not found is large-scale, user-managed system with more than four levels of operation and organization, a hypothetical type $(\mathbf{F})$.

\section{Figure 1.3: Types of Irrigation Systems, by Size and Organization}

\author{
Smal-Scale \\ (1-2 Levels) \\ Medium-Scale \\ (3-4 Levels)
}

A

D

Agency-Managed

User-Managed

Source: UPHOFF et al. (1991) p.36.
B

$\mathbf{E}$
Large-Scale

$(5+$ Levels $)$

\section{C}

$\mathbf{F}$

It now remains to say that, apart from the size, the management of any irrigation systems entails the provision of an operational framework which makes it possible for farmers to combine the water input with other required inputs in order to achieve their goals.

\subsection{Irrigation Institutions and Organizations}

\subsubsection{Irrigation Institution}

For the purpose of the elaboration of the strategy of rural development, it is necessary to discuss the terms institutions and organizations. The term institution is used in the social science literature to refer to many concepts. It can refers to a specific organization or to a certain established human relationships, such as the family. Organizations are then one type

14 Medium-sized projects may by defined, according to SAGARDOY (1986:15), as those which are too small to allow consideration of unified or multipurpose project agencies (owing to their relatively high administrative costs) but which nevertheless require a substantial input of professional staff to operate and maintain them. A specialized water management organization, in general, is likely to be most feasible on medium-sized projects. Small projects, in turn, are definable as those in which official staff are either not required or not available to operate and maintain the main water delivery system, except perhaps for the headworks. They are typically in the 50-200 ha size range, with between 40 and 100 members and depend on simple technology (e.g. simple diversion weirs of boulders or brushwood). 
of institution (families and markets are other examples) (HAGE/FINSTERBUSCH 1987:2). It can be also used to denote the rules that individuals use to order specific relationships with one another. TANG/OSTROM (1993) asserts this last sense, viewing an institution as "the rules actually used (rules-in-use or working rules) by a set of individuals to organize repetitive activities that produce outcomes affecting those individuals and potentially affecting others" (p. 4). An irrigation institution is therefore "the set of working rules for supplying and using irrigation water in a particular location." These working rules as defined by OSTROM (1986) are used to determine who is eligible to make decisions in some arena, what actions are allowed or constrained, what procedures must be followed, what information must or must not be provided, and what costs and payoffs will be assigned to individuals as a result of their actions. They are, as pointed out by COMMONS (1957), ,those actually used, mentioned, and enforced when individuals make choices in operational or collective-choice settings“" (TANG/OSTROM 1993:4). Institutions therefore, according to the above, shape human behavior and the pattern of human interactions and their results.

Institutions are the social rules, conventions, and other elements of the structural framework of social interaction (BARDHAN 1989:1). The close relationship and interaction between institutions and the social processes were further stressed and implied as a focus to make it easy to understand to what extent they influence each others. COWARD (1980a:17-9) defines institution as "a concept associated with ideal behavior and expectations and can be used as a generic concept for the variety of rules that help to pattern social behavior: norms, folkways, mores, customs, convention, fashion, etiquette, law" He argues that an understanding of the basic relationship between institutions and social structure requires recognition of the frequent inconsistency between 'what people believe should occur (the institutional element) and what actually occurs (the structural element)' A major reason for this inconsistency is that „changes in the social or nonsocial environment either make it difficult or impossible to act in certain established ways or make it easy or possible to act in certain new ways". Change in either the institutional or the social structural component creates demand for change in the other.

In such analysis, where institutions are defined as „clusters of roles, norms and societal concepts “, organizations are then seen as ,the instrumental concretizations of institutional patterns" (KÖTTER 1988:18). In this respect, MANIG (1989:6-7) take the view that institutions are "the regulating mechanisms of social processes." These regulating mechanisms, that are also assumed or implemented by organizations, are directly influenced by society's values, norms and historical experiences. Institutions as defined by MANIG are: „those stable regulatory and organizational principles and rules which govern interaction processes between the people themselves and, in this context, the environment and which are recognized and sanctioned by the societies in which they are found" They are, therefore, part of the culture. Organizations and associations in this view are part of the institutional framework of a society, as executive organs, put into practice and enforce institutional regulative principles; they should not, however, be regarded as institutions themselves, argued MANIG.

Within the scope of this discussion, some found the distinction between the terms institutions and organizations, is a distinction without a difference (RUTTAN 1978; RUTTAN and HAYAMI 1984). Where an institution is defined as the set of behavioral rules that govern a particular pattern of action and relationships, and an organization is generally seen as a decision-making unit - a family, a bureau - that exercises control of 
resources (RUTTAN 1978:328-9). ${ }^{15}$ The authors find the broad view which includes both concepts most useful for the purpose of their studies (RUTTAN/HAYMI 1984:204). Institutions in this analysis are then the rules of a society or of organizations that facilitate coordination among people by helping them form expectations which each person can reasonably hold in dealing with others. They reflect the conventions that have evolved in different societies regarding the behavior of individuals and groups relative to their own behavior and the behavior of others ${ }^{16}$. In the area of economic relations, they provide assurance respecting the action of others, and give order and stability to expectations in this complex and uncertain world. They must be, then, stable for an extended time period. But, they must also change, like technology, if development is to occur.

Irrigation agencies are variously referred to either as Organization or as Institution as if the two terms were identical (UPHOFF ET AL. 1991). Though distinction ${ }^{17}$ between both terms are necessary, one gains the most insight by regarding them as overlapping. Considering the irrigation agency as an organization means ,structures of recognized and accepted roles." As opposed to this, conceiving of the irrigation agency as an institution means examining it with a view to pinpointing the ,complexes of norms and behaviors that persist over time by serving collectively valued purposes" (UPHOFF ET AL. 1991:205). Whence, an irrigation agency by definition is always at least an organization. To be an Institution depends on the extent to which it has established its value, solidly, pervasively, even transcendently, in many if not all people's minds ${ }^{18}$. HUNTINGTON (1965) views: „Institutions are stable, valued, recurring patterns of behavior. Organizations and procedures vary in their degree of institutionalization... Institutionalization is the process by which organizations and procedures acquire value and stability" (RUTTAN 1978:329) ${ }^{19}$.

\subsubsection{Irrigation Organization}

\subsubsection{Theoretical observations}

During the first part of the twentieth century there developed many specific concepts about organizations. But there is almost universal agreement within the field that, over the last

15 He argues, what one organization - a household or a firm, for example - accepts as an externally given behavioral rule is the product of tradition or decision by another organization, such as organized labor, a nation's court system, or a religion. Thereby, a useful analogy can be drawn between these concepts of the institution and the organization, on the one hand, and external and internal scale of economics, on the other analogy. This view based on that of VINER (1932) who insisted that the external economies of scale enjoyed by one firm or industry come about as a result of internal economies in some other firm or industry (RUTTAN 1978:329).

16 This is consistent with the view expressed by both COMMONS (1950) and KNIGHT (1952). This definition also encompasses the classification employed by DAVIS and NORTH (1971:204). The purpose of such inclusive definition, as the authors argue, is: „to be able to consider changes in the rules of conventions that govern behavior (a) within economic units such as families, firms and bureaucracies, (b) among economic units as in the cases of the rules that govern market relationships, and (C) between economic units and their environment, as in the case of relationship between a firm and a regulatory agency "(RUTTAN/HAYAMI 1984:.204).

17 The distinction between 'Organization' and 'Institution' has been discussed in more detail in: UPHOFF (1986), Local Institutional Development: An Analytical Sourcebook, with cases. West Hartford, CT: Kumarian Press.

18 In this view, then, one can refer to Gezira Scheme in Sudan as the sole irrigation institution and the other schemes as organizations.

19 See Chapter 3..... 
two decades or so, the sociology of organizations has experienced a series of profound changes as to the way in which its subject matter is defined and the manner in which it is researched (REED 1992). In this respect, both the way in which the phenomenon of organization is characterized and the theoretical and methodological equipment, though most appropriate to its analysis, have undergone a series of highly significant transformation over the period ${ }^{20}$.

There are a network of concepts that allow the researcher to identify the relationships between selected components when he try to understand the nature of organizations and the social processes through which they are produced and reproduced. Over time, this network of concepts becomes more complex. Consequently, analytical frameworks are never fixed and immutable, they necessarily change over time to accommodate new ideas and empirical findings (REED 1992:74).

Organization theory, as WHITLEY (1988:65) has argued, is more like a "fragmented adhocray"; that is, a field of study characterized by: „limited reputational control over intellectual goals and priorities, low degrees of coordination of research strategies and results around common theoretical purposes, and subject to the conflicting pressures of specificity and applicability on the one hand, and generality and academic respectability on the other". In comparison with the rationally structured and tightly controlled disciplinary regimes operative in natural sciences, intellectual plurality and organizational fluidity are inherent within the field of organizational studies (REED 1992:131) ${ }^{21}$. Anyhow, the theory of organization is described as immature and known with the paucity of clear definitions.

As broad generalization one can argue that, the definitions of an organization differ according to the difference in the criteria which consider the basis of this definition e.g., viewing the organization itself, the appropriate unit of analysis or the emphasized core issue within it, the elements or subsystems which constitute the organizations, and above all, the used analytical perspective.

Within the framework of their discussions about the idea of organization, SCOTT and MITCHELL (1972:7-8), argued what they refer to as the organizational Vehicle. The organization carries material resources, technologies, human skills, and values. It provides the vehicle whereby productive factors are assembled, transformed into utilities of value, and distributed in the form of consumable goods and services. Intimately associated with this vehicle is the management of an organization. Management here is essentially the human instrumentality that activates organizations and controls their course. Through managers, who well understand their roles, the organization can optimally achieve the objectives for which it is established. According to the determinate role of human factors, they view Organization as a human invention, created by man to help him achieve ends which he could not possibly accomplish individually. So, Organizations are not only vehicles but also, with the help of the human instrument, factories. Organization is, in fact, the spot where the production function actually takes place.

20 For a succinct review of the "crisis" thesis that applies to the branch of sociology concerned with organizations see HASSARD, 1993.

21 It was the target for most scholars of the institution theory to overcome this problem. One of the prominent in this field refers to that by saying: „I want to see us develop an economic theory similar to that found in the natural sciences" ( COASE 1993:96). 
Within the scope of resemblance to a carrier, REED (1992:73), points out that reviewing of the competing sociological interpretations which have been offered of complex organizations, organizations can be viewed as "the crucial 'carriers' and 'products' of modernity." The transition from traditionalism to modernity is characterized in terms of an organizational revolution which has swept away all vestiges of the moral foundation and primary social institutions that once integrated the individual into a wider community and provided the social bonds through which stable personal identities could be forged. He speaks of Darwinian Struggle for survival and maintain the transformational feature of the organization under the influence of social norms and fragmented institutions. Organization theory becomes both a celebration of and a warning against, the structural transformations and cultural movements that modernity has let loose through a process of institutional transformation driven by the search for universal rationality, efficiency and effectiveness".

\subsubsection{Organizational Perspectives}

Most debates in organizational analysis can be reduced to discussions of the appropriate unit of analysis. Every perspective has emphasized the unit which considered as the main interpreter of the organization as an idea and function. These units of analysis, or the focus of attention, can be the whole organization; the individual; and the groups acting within the organization. According to this approach, BACHARACH/LOWlER (1980:210-13) have distinguished three theoretical perspectives:

\section{The Rational Managerial Perspectives}

The unit of analysis is the organization as a whole. Organization according to this analysis is a rational system of interdependent units functionally held together by a common goal. Attention here is focused on organizational structure (size, vertical and horizontal differentiation, role specialization, span of control and so forth) and work processes (communication, interaction, centralization, and the like). Such a perspective assumes a uniform effect of structure and process across the organization, combining across to create one measure of each variable for the total organization. One of the limitations of this perspective is its failure to depict organizations as dynamic entities subject to conflict and change. Structure has been refined in such a manner that it, rather than action, has become the focal point of analysis. Even when attention is paid to processes, they are conceptualized as if they were organizational structures.

\section{The Individualistic Perspective}

The unit of analysis is the individuals acting within the organization and the role that they occupy. This perspective casting the organization as a composite of individual actors and individual actions. Here, understanding the role of individual is a precondition for understanding the organization. In contrast to the twin assumptions of homogeneity and objectivity that guide the rational managerial perspective, the individualistic perspective assumes the organizations are heterogeneous and subjective. Moreover, while this perspective is based on a phenomenological bias that implies a focus on the individual, theorists tend to use the individual model as a metaphor for the functioning of the organization. As limitations of this perspective, overemphasis on the chaotic nature of action organization, and failure to consider the political and structural context that impinge on an individuals cognition and actions, are mentioned. 
Organizational economics (agency theory and transaction costs theory) is to mention here because of the central role given to the action of individual actors, that is to 'rational economic man'. The individual is seen to act in his or her own self-interest, consistent with being a rational economic 'man', and this leads to postulates of opportunism and guile in managerial behavior. Thus, in contrast to more collectivity-level or structuralist models in organizational studies which speak of the organization as a collective entity pursuing the organizational goal, organizational economics desegregates the organization into individuals, each of whom pursues his or her individual self-interest (DONALDSON 1995:169-70). The lack of explanation of organizational action by reference to the individual action of motivated individuals has been a persistent criticism of collectivitylevel structuralist explanations such as those in structural contingency theory. The new individualism of organizational economics has the potential to make good some of these deficiencies.

\section{The Group Bias Perspectives}

BACHARACH and LOWLER (1980) believe, on the other side, that the main void in organizational theory is the lack of concern with politics. To fill this void, they have broken from the perspectives that dominate intraorganizational analysis ${ }^{22}$ which ignore the power politics involved in interest groups and coalition bargaining. As empirical middle ground between concentrations on aggregate and on individual data, an alternative perspective is an organizational model that based on the group as the unit of analysis. It envisions the work group as the primary focus for the study of organizations.

The basic unit of traditional political analysis is the sub-group - for example, class interests, class relations, and class conflict; the basic unit of apolitical perspective is the total system. The current comparative interorganizational research, with the exception of some cases, has only peripherally treated subgroups and has tended to ignore subgroup differences, thereby preventing any systematic examination of the political tensions inherent in organizations. This perspective maintain, on the other side, the coalitions and bargaining as a two interrelated phenomena which form the foundation of an understanding of organizational politics. It has attempted to integrate the social psychology of politics with the structural analysis of organizations. Thereby, Organizations are best conceptualized as political bargaining system.

In this respect, where the organizational model is based on the group as the unit of analysis, REED (1992:84-92), discusses two other analytical frameworks which view organizations as negotiated orders and power relationships. The first framework, as opposed to systems theory, treat organizations as the temporary product or outcome of interactional process between individuals and groups that is always open to revision and reformulation by them. The emphasis, according to this framework, is on the structure in process. Structures have to be configured, confirmed and reconfirmed by the fundamental negotiating processes that give them 'organizational life' and meaning in the first place. Organizational structures are seen to be firmly embedded within a'dense and intricate 'Web' of interaction which gives them 'life' and relevance for the negotiation of social order between individuals and groups with very different interests and interpretations of what

22 He refers to three perspectives where : organizational actors considered as the passive entities presented in organizational psychology; organizations are viewed as loosely coupled systems; organization are viewed as structurally coordinated monoliths. 
'ought to happen'. The recognition of conflicting interests and values as integral features of the process through which organizational order is negotiated leads to a consideration of power relationships.

This framework concentrates on the theoretical reconstruction of reciprocal processes of negotiation over time and the manner in which they lead to the fabrication of relationships and arrangements that simultaneously facilitate and constrain the creation of new 'organizational orders'. The clearest articulation of this framework is to be discovered in the development of a social action approach from the late 1960s or early 1970s onwards. Social action theorists called attention to the social, historical and cultural contexts in which 'organizational projects' were mobilized. Therefrom, negotiated order theorists - whether their focus is on 'high' or 'low' politics within the organization - view it as organized anarchism or loosely coupled networks precariously held together by negotiating process and the power relationships emerging out of them. This approach then is focused on microlevel negotiating processes and the middle range structures which they produce. In other words, compared with the structural perspective, this approach lay too much stress on structure in process and not enough to the structuring of process. This limitation was the starting point for the development of other perspective which views organization as structures of power and domination.

The power framework as argued by REED (1992:93-102), is an attempt to overcome this polarization in preferred analytical logics - between structural or environmental determinism and organizational choice - by focusing on the more permanent configurations of power and domination which simultaneously constrain and enable the technical and political activities of social actors - whether these are constituted as individuals or as corporate groups. Formal or complex organizations must be approached initially as the tools or mechanisms through which these dominant groups secure and maintain the conditions necessary for their social reproduction and survival over time. Accordingly, organizations are contested terrains in which various groups and coalitions struggle to impose their preferences on structural designs and administrative processes.

As such, organizations are strategic sites for the conduct of pervasive power struggles between opposing groups over the control structures and practices - and their supporting rationales - through which work is organized, and the distributional outcomes which these mechanisms produce. In this sense, organizations are locales or arenas in which endemic conflicts over the distribution of power and the allocation of resources flowing from it are carried on. Thus, enshrined within all work organizations there lies a dialectic of control; that is, a dynamic process of struggle between contending groups to secure and command the conditions through which collective action is made possible. In this respect, the dialectic of control is the dynamic process which underlies the changing balance of power experienced in all complex organizations and the crucial effect which it has on the capacity to shape and reshape the structure and practices through which domination is simultaneously protected and challenged at the level of routine everyday life or the level of strategic decision-making and corporate governance ${ }^{23}$.

23 In this connection, KARPIK (1978), raises three questions; how ought we to study the social orientations of the actors who make up the organization?, should the 'corporation' be considered as a unitary power system or as the place where a plurality of power systems interlock?, and how can we explain the formation of collective choices through the relationships of opposition or alliance which are formed between the individuals and groups making up the organization? He concluded that power relationships are not merely internal to the organization. 


\section{The Cultural / Symbolic Perspective}

The symbolic or cultural framework shifts the focus of attention away from 'organizations' to organizing; it suggests that the process of organizing is most appropriately conceptualized as the enactment of cultural development and transformation. Culture becomes the basic resources and process through which social action and interaction are continually constructed and reconstructed to form a shared 'organizational reality'. Here, the subjective- rather than the objective- aspects of organizational reality become the central focus for analysis in so far as they call attention to the socially constructed frames of value and meaning through which coordinated social life becomes possible

The fundamental process of cultural enactment and reaffirmation is dependent on and expressed through specific symbolic forms such as values, ideologies, rituals and ceremonies. As a social expression of human consciousness and creation, complex organizations have to be sustained through generative processes that yield and shape meaningful interaction. Organizational structures and the patterns of symbolic relationships and meanings sustained through the constitutive processes of human interaction and the cultural forms by which they are expressed such as language, symbols, myths and stories. Organizational membership usually offers the prospect of more than one cultural identity and the forms of social conduct that it supports. The dominant cultures supported and reinforced by management often contain contradictory messages as to what to believe and how to act. This dominant cultures are unavoidably in competition with 'unofficial' subcultures - such as those entailed in membership of departmental, professional, craft and political groups - which offer alternative sources of meaning and legitimation for action that depart from approved norms. Any large-scale organization will contain competing, not to say conflicting, sources of cultural creation, enactment and mobilization which make the task of achieving effective cultural control even more fraught with uncertainty and ambiguity.

Managers play a pivotal role in this analytical framework. A dramatic illustration of the deep involvement of managers in processes of cultural production and enactment can be seen in the contribution of PFEFFER (1981). He has argued that "technical rationality is the 'religion' of formal or complex organizations and managers are its 'high priests'. But, a conception of organizations as cultural artifacts and symbolic constructions soon reveal the ideological status and political function of this religion". ${ }^{24}$

As limitation of the cultural/symbolic approach, as mentioned by some commentators ${ }^{25}$, is its very focus on the micro-process through which organizational reality is defined and organizational order constructed. They have argued that the cultural/symbolic framework entails a logic of analysis which unavoidably directs attention away from the extraorganizational structures of economic and political power and domination in which ideological production and identity work must be situated. By focusing on the status of organizational participants and managers in particular as creators of symbolic orders supporting and legitimating shred meanings, cultural theorists seem to neglect the

24 In contrast, both agency theory and transaction cost theory see corporate managers as inherently untrustworthily (DONALDSON 1995:166).

25 See, for example, THOMPSON, P. and McHUGH, D. (1990), Work Organization: A Critical Introduction (Macmillan, London). 
encompassing societal structures in which these processes are located (REED 1992:10312). This has encouraged the development of an alternative approach that attempts to overcome the theoretical separation or duality between 'structure' and 'process' that seems to pervade organizational analysis. This analytical framework treats organizations as 'Social practices' which require simultaneously reference to structure both as a constraint on actions and as a resource facilitating action that transforms established arrangements.

\subsubsection{Organizations as a Social Systems}

The systems approach is one of the cornerstone in the theory of organizations. It is the most widely perspective which considered the basis and point d'appui for the latter perspectives. Systems theory became established as the intellectual orthodoxy in the 1950s and shaped the overall agenda to which alternative perspective responded in a critical and creative fashion. The main assumption of this framework is: organizations are social units directed to the achievement of collective goals or the fulfillment of institutional needs for the wider society or environment of which they are a constituent part. The starting point for the systems framework is a conception of organization as a goal-oriented, purposeful system constituted through a set of common underlying abstract variables or dimensions relating to structural properties which are geared to the functional needs of a more inclusive social system. This framework then present an institutional analysis of structural forms.

Starting from this basis, MANIG (1989:5-6) defines the organizations as institutional term has specific characteristics with reference to the social process between members, the division of labor, and their structures. Organizations, as he pointed out, denote institutional entities in which persons or groups collaborate in view of achieving their goals. The structure is oriented towards duration and stability and is set up systematically. Organizations therefore are characterized as goal-oriented social entities having a formal structure and through which the members orientate their activities towards achieving the objectives. The formal structure should be understood as a system of rules which determine the relations between the members of the organizations. To point out the relationship between organization and management he concludes the definition of the former as the framework within which the latter (as a function) is realized and both of them are always components of a society's institutional systems .

In this context, the strict definition used by HAGE/FINSTERBUSCH (1987:11) summarize the elements or subsystems which constitute and shape an organization in seven elements. Organization is "a social collective which has existed for at least five years, including at least ten paid employees who work largely full time throughout the year, use essentially the same core technology, and are arranged in a variety of prescribed positions designed to achieve some specific collective output(s)". The distinguishing elements then are: size, duration, extent of reliance on salary, division of labor with occupational skills, technologyproduct group and specific outputs or goals ${ }^{26}$.

26 KAST and ROSENZWEIG (1974) have refereed to five primary subsystems: goals and values, technology, structure, psychosocial and managerial. 
The systems approach facilities understanding the important forces affecting organizations as well as the development of a comprehensive body of knowledge concerning their internal atmosphere and external environment. This body of knowledge provides the foundations for management practice. Organizations therefore are a subsystems of their environmental suprasystems. They are, accordingly, open systems in interaction with their environment and are continually changing (KAST/ ROSENZWEIG 1974).

Thereby, the systems framework analysis centers around the forms of structural design and the environmental conditions. Individual and group recalcitrance is a recurring problem that all organizations must face and respond to. One of the roles of management here is to achieve balance or equilibrium between the various segments or subsystems within the overall structure. Management must be used as equilibrium mechanism to ensure readjustment for the disturbed balance between the individual and the organization and between the latter and the environment under which it exist.

PARSONS (1956) constructs a theory of organization on the basis of the principle laid down in the social system (1951). PARSONS views organizations as system both in the own right and as constituent parts of larger systems. He suggests that "while organizations are sub-units of larger environments, they themselves possess several layers of, for example, individuals, groups and departments. " The basic problem for organizations is then ,to integrate, both vertically and horizontally, the functions which operate at different levels" (HASSARD 1993:23-4).

Later on, as innovation, to make the systems analysis more dynamic - that is, better equipped to explain the causes and consequences of organizational change, an 'opensystem' view of the organization has been developed. The most influential expression of this approach in recent years has been contingency theory. Both THOMPSON (1967) and LOWRENCE and LORSCH (1967) developed their analysis of the interdependence between organizations and their environments within an open-systems approach that regards the organization as an 'indeterminate' structure interdependent with its environment and facing the economic, informational, technological and social uncertainties which the latter presents. They maintain the initial logic of the systems framework in viewing the organization as a reactive or adaptive social unit which is largely determined by the character of the environment in which it functions. They continue, to a considerable extent, in an analytical tradition that sees the organization as being largely, if not totally a 'prisoner' or a 'victim' of its environment, rather than as a creator and manipulator of its task and institutional setting (REED 1992:75-84).

The most related perspective here, which is always referred to in discussing irrigation systems, is the socio-technical systems perspective. Treating organizations as open sociotechnical systems is still a dominant perspective in organizational theory. It is to be found, for example, in the 'quality of working life' movement which is preoccupied with the humanization of work through socio-technical design. CHERNS/DAVIS (1975) propose that far from imposing economic costs humanizing work through socio-technical design yields social, personal, and economic gains. This proposition is also reinforced by MILLER (1975) who points out, "the historical account reveals that attempts to maximize efficiency of the technical system, if social and psychological needs are not also satisfied, lead to suboptimal performance" and that "the converse is also true" (BLUNT/JONES 1992). 
Studying organizations from a socio-technical systems point of view began in earnest in the early 1950s in England. The approach differs from earlier ones, such as scientific management and human relations ${ }^{27}$, in that it is not biased towards either the technical or the social aspects of work and organization, but gives emphasis to both, and their interaction with the environment. In other words, the organization is perceived as an open system, susceptible to external influences, and interdependent with its environment.

Regarding an organization as an open systems, as KATZ (1966) and BARKO/PASMORE $(1986)^{28}$ have in detail exposed, means that it is seen as possessing similar attributes to a biological organism. More concretely, organizations take as their inputs, people, information and materials; productive work is carried out within the system to transform these inputs, and a finished product or services eventually emerge (BLUNT/JONES 1992:87). Socio-technical organizations has been therefore described, according to TRIST (1981), as "ones in which the core interface consists of the relations between a human system and a non-human system" (UPHOFF ET AL. 1991:218).

At the applied level, there are little detailed analysis of socio-technical systems theory, particularly in the developing countries. KIGGUNDU (1986), based on his study in Kenya (1985), found that applications of socio-technical systems theory in developing countries had been "spotty and limited in scope." He asserts that, in contrast to the principles of socio-technical systems theory which espouse open systems and democratic values and practices in the workplace, organizations in most developing countries are bureaucratic, mechanistic and autocratic. He lists the factors which, he claims, cause problems in attempting to apply socio-technical systems thinking in developing countries, including ${ }^{29}$ :

"Organization in developing countries exhibit disfunctional modes of conflict management, closer social and emotional interactions, intergroup rivalry, little capacity for openness, trust, and the rational expression of feelings, and well established hierarchical and social status barriers.“

On the other hand, KETCHUM's experience (1984) may appear to be divergent from this point of view. He is decidedly sanguine about the usefulness of socio-technical systems in developing countries, based on his experience in the $\mathbf{S u d a n}^{30}$. In answer to the question: are the socio-technical principles yielding superior economic and social outcomes in developed

27 Scientific management is the first major pillar in the development of classical organization concepts. Its initial input was given under the driving force of Frederick W. Taylor (1856 - 1915) in the latter part of the nineteenth and early part of the twentieth centuries. The primary emphasis of scientific management, which has been referred to before 1910 as "task management", was on planning, standardizing and improving human effort at the operative level in order to maximize output with minimum input. Scientific management was a micro approach. Latter, there developed a body of knowledge during the first half of the twentieth century whose primary emphasis was on macro level. March and Simon have referred to this body of knowledge as "administrative management theory." Other writers call it the traditional or classical theory of management (KAST/ROSENZWEIG $1974:$ 54-7).

28 KATZ/KAHN (1966), The Social Psychology of organizations, London: Wiley, pp.14-29, and, Barko, W., \& pasmore, W. (eds) (1986), Socio-technical systems: Innovations in Designing High Performing systems, Special issue of journal of Applied Behavioral Science, 22 (3), 195-360.

29 Some major general criticisms of socio-technical systems theory have been made by KELLY 1978, 1982. KELLY (1978), A Reappraisal of socio-technical systems theory, Human Relations, 31, 1069-99, and KELLY (1982), Scientific Management, Job Redesign and Work Performance, London: Academic Press.

30 KETCHUM (1984), Sociotechnical Design in a Third Word Country: The Railway Maintenance Depot at Sennar in the Sudan, Human Relations, 37 (2), 135-54. 
countries feasible in developing countries? his response was "a tentative, but hearty, yes" (BLUNT/JONES 1992:101).

It is finally to be concluded that each of the analytical frameworks reviewed before focus on different core issues as providing a basis for their conceptual development in empirical research on complex organizations. These core assumptions and concepts have been broadened out to incorporate a wider range of empirical phenomena. This extensional process of the conceptual cores has made these cores more vulnerable to attack and erosion by the other perspectives.

REED (1992:122-24) summarizes some overarching intellectual movements in organizational analysis accruing over the last twenty years or so as presented in Table 1.1. The standard of comparison is the 'agenda' of organizational analysis which has been established by the systems framework - the left-hand side of the Table. The intellectual hold of this agenda has been, over the last twenty years, superseded by the formulation of an interrelated set of issues and approaches which characterize the sociological analysis of organizations in very different terms to that prevailing in the mid or late 1960s. The central issue for the alternative agenda is the struggle to control the organizational mechanisms through which order is realized and contested. Here, the political and cultural process is seen as a primary point of reference. Also, the environment is no longer seen as an independent entity but is viewed as: ,a resource to be enacted and manipulated by those who are in a position to control the cognitive practices through which it is configured as an interpreted reality to be acted on by dominant coalitions within this organization."

\section{Table 1.1 Intellectual Shifts in Organizational Analysis}

\begin{tabular}{|ll|}
\hline \multicolumn{1}{|c|}{ From } & \multicolumn{1}{c|}{ To } \\
\hline Organization theory from above & Organization theory from below \\
\hline Regulative order & Struggle to control \\
\hline Organizational constraint & Organizational construction $\quad$ Formal \\
\hline Administrative structures & Political/cultural processes \\
\hline Situational contingencies & Strategic choice \\
\hline Environmental determinism & Environmental enactment \\
\hline
\end{tabular}

Source: REED 1992:123.

When we try to draw conclusions from this analysis of the theoretical frameworks of organizations, i.e., both the structure/environmental perspectives as well as the power and control of dominant groups perspectives, we are forced to maintain that each one represent a specific empirical case within its structural setting and its interaction with specific economic forces, political cultures and communities. The position adopted here, therefore, will be that both point of view have something to offer. We argue the importance of the environment in which organizations inforced their tasks, specially, the political context as well as the role of people associated with.

According to the definition of irrigation system which has been recognized from many researchers as discussed in this chapter, and the characteristics of organizations as discussed above, it is very important for an irrigation organization to be considered as a sociotechnical open system, and to understand the complex interactions with its contexts, as well as the human factors and all their backgrounds. The basic character of organizations 
in the field of irrigation systems which should be maintained is that: "organizations are not implemented in a social vacuum but should take into consideration the institutional, social, economic, and political structure in a society as well as the conception of values, norms, predominant behavioral attitudes, historical experience with specific methods and, therefore, the whole cultural system" (MANIG 1989:4).

\subsection{Irrigation Management}

,public and some large-scale irrigation schemes are known to have failed in many countries due to poor management" (FAO, 1994:36).

The word theory refers to „a body of fundamental principles underlying a science.“ Thereby, before making an attempt to discuss the definitions of irrigation management, it is of a great importance to note that the aim of this part of the study is not to find or establish a "master definition" for irrigation organization and irrigation management to be used in every case. But, first of all, it aims to underline the fundamental considerations and conditions of this two concepts which one have to keep in mind especially when the concerning theme is irrigation system in an 'underdeveloped' country. Two reasons, in this respect, can be argued:

First is the fact that the theoretical writings on irrigation organizations and management are still not enough, as well as little empirical work has relatively been done in this field specially in Africa. COWARD (1980) and HUPPERT/WALTER (1989:8) have maintained this conclusion. The former has argued that "the scholars of organizations will not find a well-articulated theory of irrigation organization to be further tested and refined, nor will the administrator find a handbook on the organizations of water users" In the same vein, the latters ${ }^{31}$ have noted that "we must piece ideas and arguments together because there is for irrigation management no established management theory to fall back on" (UPHOFF ET AL. 1991:33).

Second, the outcomes of the previous experiences, in general, emphasize other fact which view the difficulty of generalization when we deal with different cases. Every case study is dependent on its own and specific situation which is difficult to transfer, and this is what is referred to as the Situational or Contingency Approach. Thereby, different situations make different demands on management, and thus must be countered with different management-concepts. The irrigation management and organizations are the most indigenous aspects of irrigation. Therefore ,no single model or methods can be applied universally, even in the same state or region,, (LOWDERMILK 1986:438). Indeed, some commentators have argued that from the management point of view, it would be ideal if specific management actions could be recommended for each situation. In real terms, however, this is not possible (WALKER and CLEVERIHG 1989:II.2,1).

One of the first attempts, which have been made to develop workable appraisal approaches and have been conducted on system performance at the field level, is the interdisciplinary approach to diagnostic analysis (DA) developed by the Colorado State University OnFarm Water Management team during the 1970s, working with an integrated surface and groundwater irrigation water supply in the Punjab area of Pakistan (CLYMA and COREY

31 HUPPERT/WALKER (1989: 14), Situation conformity and service orientation in irrigation Management: Basic concepts, Eschborn: Deutsche Geselschaft für Technische Zusammenarbeit. 
1977). According to this approach irrigation management (IM) ,, is not water resources, dams, canals, command areas, soils, engineering, agronomy, economics, watercourses, social science, farmers, or plants. Instead, it is how these resources are manipulated and orchestrated by these disciplines to bring water to the root zones of crops with other inputs at the proper time, the proper rate, and the proper place and cost to produce food and fiber" (NOBE and SAMPATH 1986:6). Irrigation management is then not only control oriented but also the orchestration of scarce physical and biological resources, using the skills of several disciplines to bring water to the root zones of plants for increased food and fiber production for all classes of farmers ${ }^{32}$.

A more recent definition (SECLER and NOBE 1983) states that irrigation management is "a process that has at its core an efficiency objective of improving a production system's performance by adjusting inputs to produce a more desired level or mix of outputs .... an interdisciplinary system process with built-in learning mechanisms to improve system performance by adjusting physical, technological, and institutional inputs to achieve the desired levels of output" (NOBE AND SAMPATH 1986:6).

In the context of viewing the management process as a means of orchestrating, manipulating and adjusting inputs into outputs, management also refers to the organization (as a functional term) that: (1) transforms general policy goals into specific objectives defined as desired project inputs and (2) designs, prioritizes, and schedules program elements to produce output objectives (FAIRCHILD/NOBE 1986). Success in management, as has been emphasized by FAIRCHILD/NOBE, should be judged by output from the systems rather than by inputs to the system. They refer to the concept as "management by results" (MBR). In the MBR approach, the farmer is the "transformer" of inputs to outputs ${ }^{33}$.

Considering the input-output mechanism of the irrigation system, management itself is yet widely recognized as the more important input that ultimately determines the efficiency of the other factor inputs as well as the whole system. The gathered experiences through many case studies evaluations, whether in public or private agencies, show clearly that the quality of the management is the deciding factor of prosperity or failure for the systems which have more or less identical levels of input endowments. The physical resources of land, labor and capital are not productive unless they are organized and coordinated. To this extent, management may be viewed as a productive resource. Without inputs of management, a farm would not exist (UPTON 1987:90). The salient characteristic of the management input is, therefore, the long gestation periods associated with the acquisition of skills useful in allocating agricultural resources, or in performing complicated tasks (BINSWANGER/ROSENZWEIG 1986:519).

32 Further, by using a system approach to irrigation management which encompasses the total set of process interactions involved in irrigated agriculture - not just the water input, defines (1981) the irrigation management as "the process by which water is manipulated (controlled) and used in the production of food and fiber .... (it) is not water resources, dames, or reservoirs to capture water; nor codes, laws, or institutions to allocate water; nor farmers' organizations; nor soils or cropping systems. It is however, the way these skills and physical, biological, chemical, and social resources are utilized to provide water for improved food and fiber production" ( REDDY 1986 : 106 ).

33 MBR as a system-wide monitoring and evaluation approach, has been developed by SEKLER/NOBE (1983) to projects in India and Pakistan. 
In addition, and based on the socio-technical approach, management is defined as "the process of designing and controlling goal-oriented socio-technical systems in conformity with a given situational context." Designing means those activities aimed at creating a socio-technical system and sustaining its long-term viability. Controlling denotes the ability to influence the system in such a way that assumes a desired state (WALKER/CLEVERINGA 1989:II.1, 2-3). Management here determine the problems that appear in the designing and controlling the system and try to find suggestions to solve these problems.

In view of the identification of management's functions, in the irrigation literature, it has been noticed that the concentration was on water management. The definition of the latter, therefore, has connected with the duties of specific input i.e., the water. According to this tradition, FUKUDA (1976:104), represent the thinking in the 1970s, and defines water management as:

„Management as described here means comprehensive control of such functions at takingin, conveyance, regulation, measurement, distribution, application at the proper time and in the proper amount, and drainage of surplus water, aiming at a common target of increasing production and improving techniques of farming“.

SCHAAK (1984), with a more wide consideration, has concluded the definition of water management as follows:

"water management as it pertains to irrigation encompasses all aspects of providing the right amount of water at the proper time and place. This entails effective management and coordination from the supply sources through the distribution system and to the farm field" (HUPPERT 1989:54).

On the other hand, a second group of authors has viewed the pertinent functions of water distribution as the central for management of irrigation systems and stressed especially, however, the personnel related aspects. To this group belongs, for instance, LEVINE, COWARD and MARTIN ${ }^{34}$. In this respect, emphasize COWARD (1980a:19) the following irrigation management activities: "water allocation, system maintenance, and conflict management BOTTRAL (1981) led on DRUCKER and defined the goal formation, design and planning the budget, operation's planning, administration and control as the most important management functions of irrigation. He added, however, on these "specialized activities" the following responsibilities (HUPPERT 1989:55):

- water distribution;

- system maintenance;

- agricultural extension;

- watercourse improvement and advisory services; and

- management support activities: finance, personnel and monitoring.

A more comprehensive understanding of irrigation management that takes into consideration the multiple functions of management has been adopted by LOWDERMILK (19852.15). He argues that not only water distribution, but also "people, credits, inputs, price policy, other services for farmers .... must be managed in the true sense of good management". Lowdermilk has found out, then, that management includes "planning, setting objectives, measuring, coordinating, integrating, monitoring and evaluating"

34 LIVINE et al. (1979), COWARD (1980), MARTIN et al. (1986). 
HUPPERT/WALKER (1989) have outlined attributes of basic concept for management of irrigation system as follows:

- management is a process practiced within organizational framework; it is the process of realizing and implementing measures within the organizational framework (MANIG 1989:5);

- system management must be understood as a process, which permits interactive learning from previous steps;

- irrigation system management has four functions; planning, organizing, leading, and controlling . Each of which demands a continuous decision-making process;

- basically, management functions are performed by local water authorities, water users, and representatives of donor organizations. In many cases divided or split management responsibility between water users and authority is found;

- water user participation has hitherto been unsatisfactory; and

- sustainability and environmental compatibility must be duly taken into account by the irrigation system and be ensured by corresponding measures.

An important other attribute has been mentioned by UPHOFF ET AL. (1991:53) in the context of his contribution to the discussion about the role of management in improving the use of scarce resources, he states that: "we should always keep in mind that management is something to be optimized, not maximized. The costs of maximum management are unlikely to produce enough incremental benefits to justify an all-out effort by government staff and I or water users, and such efforts anyway are not likely to be sustainable simply in human terms. So tradeoffs must always be considered".

In big similarity with the definition articulated by HUPPERT and WALKER is that of the International Irrigation Management Institute (IIMI) which viewed irrigation management as "the process in which institutions or individuals set objectives for irrigation systems; establish appropriate conditions and identify, mobilize, and use resources, so as to attain these objectives; while ensuring that these activities are performed without causing adverse effects" (KNOTH 1989:24). It is, in brief, as WEBSTER defines "the judicious use of means to accomplish an end."

Irrigation management, according to the functions and characteristics discussed above, sustain the irrigation organization, irrespective of the size (water users organizations or household-farm), and enable it to accomplish the formal goals using different resources, namely crop production. Irrigation management is then a conditional factor which enable the organization or the farm to realize its ultimate goal. At the level of the household-farm (the base of the analysis in the empirical part), production management and water management are carried out simultaneously on the farm to achieve the production goals that are, finally, the purpose of an irrigation system and, also the decisive criterion for assessing its efficiency (MANIG 1994:249). 


\subsection{Efficiency of Irrigation System}

The quest for efficiency is so widespread in western society, since a few decades, that it has become almost synonymous with rationality itself (SCOTT/MITCHELL 1972:5). Efficiency as defined by the latter requires "continual effort to minimize system inputs and to maximize system outputs". This concept is a goal of all organizations and applicable to any system level under consideration (ranging from the smallest unit of an organization to the largest and most complex structure) and prevailed in all fields ${ }^{35}$. The quest is always for better and better methods to improve system input-output ratios by continuous refinement of managerial, engineering, and scientific techniques.

Another major reason for concentrating on improving project management is to increase the irrigation efficiency levels of available water supplies. Two facts should be referred to at the beginning of this discussion. First is that the definition of "efficiency" is disputed. The second is that irrigation water can not be $100 \%$ effectively used. Despite these facts, until recently, in the field of irrigation, "efficiency" was the most used indicator of system performance. Later on, there has been increasing consensus that broader concepts focusing on the use of water are more accurate performance indicators. Accordingly, LENTON (1986:50) viewed that the two principal measures of irrigation system performance are productivity (measured by water delivery, yields or potential yields) and equity (measured by productivity variations within an irrigation system).

In this respect, ISRAEL joins the efficiency of water use with productivity of irrigated agriculture and profitability of irrigated farming as three objectives that are important criteria for successful irrigation management. He argued that the efficiency of irrigated systems could be measured in terms of water duty ${ }^{36}$ per acre or the extent of command area irrigated. Efficieny and economic returen of irrigation schemesare closely related. Many examples of this realtionship are disussed in the works of CLARK (1970) and CARRUTHERS/CLARK (1981). The hydraulic efficiency is then an important factor but not sufficient for successful irrigation management (necessary but not adequate). ISRAEL refers to that by saying "hydraulic efficiency without agricultural productivity serves no purpose. Likewise, productivity which is not profitable is unwise because if achieved without regard to its cost, it may represent a subtraction from total social welfare" (UPHOFF ET AL. 1991:211). In the same vein, NOBE/SAMPATH (1986:4) considers improving the irrigation management as a condition for achieving these objectives. They argue that without improved management, improved irrigation efficiencies, and increased agricultural output higher returns to farmers will not occur.

Consequently, terms relating to Efficiency of Water Use reflect, as concluded by SHMUELI (1973:413), two different approaches for expressing efficiency of water use in irrigation: 1) An engineering-planning approach with emphasis on the water factor and concerned primarily with evaluation of technical performance of the irrigation system; and 2) an agronomic-economic approach, emphasized in this study of course, centered on yield as related to water input.

35 The measurement of efficiency in agriculture has been investigated in much detail since FARREL (1957).

36 The terms duty of water and water duty were used at the end of the 19th century and beginning of the 20th. They referred to the amounts of water applied in irrigation, according to the prevailing agricultural practices. In the 20th century, other terms came into use: water use, water requirements, or irrigation need, defined as the quantity of water delivered to a crop (field), exclusive of precipitation (SHMUELI 1973:413). 
It is very important also to note here that the efficiency of irrigation organizations is more connected with the goals that predominate in such organizations. Here raised the question of: which goals for which specific groups are achieved, and thus, which efficiency is considered ${ }^{37}$ Moreover, when Efficiency refers to how economically the organization converts its inputs into the desired outputs, Effectiveness refers, on the other hand, to the degree of goal attainment (FORD 1988:56). An efficient organization, therefore, may not necessary be effective. On the contrary, an organization may view the attainment of certain goals, no matter how long it takes, as more important than efficiency.

In irrigation systems where the main goal is the maximization of production i.e., expansion of cash or export cropping, the 'efficiency' is a more salient concern in managers' thoughts and actions than in other projects where the priority is oriented to 'equality' in the spread of water ${ }^{38}$. Furthermore, in projects where the economists dominate, the concern will not be only with water, but also with all the other inputs (labor, land, capital invested in irrigation facilities, managerial effort) that are used in the production of the crop.

LIVINE (1982) used a standard engineering criteria to focus on the relationship between water supply and demand, and its implications for system management. Levels or changes in Relative Water Supply (RWS) -- the ratio between supply and demand -- explain many actions by managers and water users and reflect inversely the amount of pressure that users can put on the staff controlling irrigation water. This function, as the studies have suggested, has been summarized as follows:

- once RWS falls below 1.5 (which means supply is less than 50 percent above the minimum in-field crop requirements), irrigation systems require more management effort than is acceptable and sustainable from users and managers;

- $\quad$ RWS of 2.0 (twice as much water as minimally necessary) represents the equivalent of ' 50 percent efficiency' by standard engineering criteria;

- raising the level of 'efficiency', operating with a lower RWS, demands much more management effort, and depending on how the costs of management are calculated, it may not be an economically profitable strategy. The economic benefits from more intensive water management may not be commensurate with the added costs involved;

- RWS and efficiency are the inverse of one another;

- the RWS concept implies that 100 percent 'efficiency' is undesirable as well as unattainable; and

37 Through the discussion of institutional optimality and efficiency, argued PAPANDREOU (1994:208-9), for the institutions selected by the community to be optimal a very strong assumption needs to be made: that the very process by which decisions are made by the group is optimal. That is, in order to have faith that the institutions selected by the community are efficient, one needs to believe that formal voting procedures and information gathering procedures followed by the community will ensure communitywelfare-maximizing choices. To reach this goal, assurances are needed that interest groups are not able unduly to influence decisions, or similarly, that the representatives making the decisions are not basing their votes on their own self-interests. On the contrary, NORTH's (1981:225) discussion of the abolition of slavery makes the implicit assumption that slavery may at one time have been an efficient institution. If so, it was efficient in achieving a specific welfare goal, one that favored the slave-owners and not the slaves .

38 It is worth noting that one of the main pillars of traditional neoclassical economics is the separability of equity and efficiency. But this breaks down under the theory of transaction costs because of the critical role of property rights that are recognized in this theory. 
- the concept is useful for thinking about irrigation management because it brings consideration of cost into evaluations in a way that standard notions of 'efficiency' do not.

Other dimension is represented by MANIG (1989:30) who see that: "the actual discussion about the insufficient performance in irrigation systems, especially in macro-hydraulic systems, and the resulting consequences for the organizations assumes that the water users' goals are not taken into sufficient consideration and therefore water, land, labor and capital are not utilized according to their potential". In a heterogeneous social structure, improving the farmers' efficiency in land and water utilization, he argued, is no end in itself for the influential urban-oriented elite.

It is finally to be concluded that beside the importance of increasing the efficiency of water use, it has to coincide with other steps that increase the productivity in order to achieve the efficiency of irrigation system. These steps should be, of course, in the field of improving the irrigation management and its organizational framework, which coordinate the inputoutput relationship and take into consideration all influential groups.

\section{The Relevant Dimensions and Factors that Influence Irrigation Organization and Management}

In this chapter the relevant factors that exercise an influence on irrigation management and its organizational context are treated. Before one can discuss these factors, it is important to view briefly the contingency approach which constitutes the basis of this discussion.

\subsection{Contingency Theory}

As discussed previously, the core conceptualization of an organization as 'a purposive social system geared to the fulfillment of a relatively stable set of environmentally induced needs for security, integration, continuity and survival', has formed the theoretical bedrock of the system framework in organizational analysis.

Contingency approach is one of many theoretical innovations that have been developed to make the system analysis more dynamic to explain the causes and consequences of organizational change. It is equally applied to organization and management and used also in the analysis of Third World cases. Contingency approach, then, concentrates on the immediate pressures that organizations face in their task environments and the internal structural accommodations which they have to make to meet these challenges. Factors such as volatile technological and political realignments within the environment- beside market change - have been identified as key contingencies which organizations have to respond to in the appropriate manner if they are to ensure their long-term survival. REED (1992:80) argued that change in these factors is likely to exert considerable pressure on the organization's production system to realign its goals and structures so that it maintains compatibility with its niche and to ensure continued satisfaction of the system's needs.

The writings of THOMPSON, BURNS/STALKER, and LOWRENCE/LORSCH, in the late 1960s provided a codification of the system/contingency framework, based on empirical work and theoretical innovations undertaken in the 1950s and early 1960s and 
considered the base for the researchers working within this perspective in the 1970s and $1980 \mathrm{~s}^{39}$. The core assumptions of these writings can be summarized in the following manner:

- the analysis is developed within an open-system approach;

- different environmental contingencies call for different organizational forms;

- technology and market are seen, by many authors, as the most influential contingencies. Accordingly, they view that when the two contingencies are crisscrossed they produce four major organizational forms that are effective in four different sets of contingencies. These forms are craft, mechanical, organic, and mechanical-organic organization. Of course, considering other contingencies would lead to other forms of organization;

- all complex organizations, as THOMPSON argued, need to achieve a suitable balance between their internal operational core and their external environmental circumstances, if they were to ensure their long-term survival and effectiveness;

- management had, here, a key role to play in designing, implementing and monitoring mechanisms;

- it is the task of the managers, in the opinion of LOWERENCE/LORSCH, to achieve the appropriate balance between functional differentiation (specialization) and structural integration (coordination) which will equip them to the changing they face; and

- a major thesis of contingency theory is that organizations can not be both efficient (low cost per unit of output) and innovative (number of new outputs or producers) at the same time. Often, however, organizations overemphasized one and encounter problems from the lack of the other, then they must be changed in the other direction (HAGE /FINSTERBUSCH 1987:4,5,59, and REED 1992:80-3).

\subsection{Objectives of Irrigation Management}

Organization, as viewed by organizational theorists, is not treated as an end. Organization is a human invention, created to enable people to achieve important goals or objectives. It is, as often defined, a group of people who come together to accomplish certain ends (a common purpose) (POTTER 1972:153; FORD et al. 1988:40). Objectives refer then to the purpose of an organization, i.e., to the effects or impacts it is expected to have. Therefore, they provide the criteria according to which management is undertaken and to be evaluated.

Irrigation systems vary not only physically and organizationally but also in terms of the goals they are to serve. So, for an irrigation system, understanding what and whose values are to be achieved; their directions and priorities, is the second step - after understanding the irrigation system itself - for assessing the performance of irrigation management. Yet, they determine, within the irrigation contexts the relative importance of different irrigation activities and outcomes.

39 For more informative review of contingency theory see BURREL/MORGAN, Sociological Paradigms and Organizational Analysis (HEINEMANN, London, 1979). 
Similar to the context of irrigation, vary the specific objectives which an irrigation organization must deal with according to the system, country, and over time. There are a number of influences on goals. The environment - individuals, groups, and institutions beyond the organization's strict boundaries - is always an influence to some extent on organizational goal setting and achievement. Furthermore, the organization's achievable goals may be restricted by its physical environment and technology. Because of technological limitations, certain goals simply cannot be achieved, no matter how badly the dominant group wants to achieve them. The goals then depends on the contextual factors which affect the organization and on the interactions among three different sets of actors: national policy makers, water users, and the agency. Each of these sets have various interests that have different priorities, and this results in complex multiple goal systems. At the same time, within each, there is likely to be some diversity and even conflict of objectives e.g., the engineers vis-a-vis the economists ${ }^{40}$.

Here arise underlying question: to what extent it is possible to find a „compromise“ between these multiple goals: the macro development goals, the government's, the project's, manager's, and water users' goals? and who should be the victim of this compromise?, asked MÜLLER (1979:60-70). He argues that goal-conflicts between the different target groups is the central social problem in large irrigation schemes. SEERS see this problem as "negative correlation between economic growth and development" For this reason, it is to be supposed that the purpose of organizations within a differentiated society is lastly to ,articulate and defend the interests of the specific groups within the society, (KÖTTER 1988:15). KÖTTER argues that ideally, in many developing countries where the rural poor are economically, socially and hence politically too weak, the state or the government is supposed to act as an 'honest broker' between the conflicting interests. He accounts for: ,there is, however, a permanent danger, particularly if the state is weak, that certain groups wield such an amount of power that they become able not only to suppress the interests of other groups, but also, openly or secretly, to creep into the organization itself and divert its activities in the direction of their own advantage,..

PARSONS (1956), in his theory, defines organization in functionalist ${ }^{41}$ terms, and suggests that "primacy of orientation to the attainment of a specific goal is the defining characteristic of an organization" (HASSARD 1993:23-4). His analysis highlights both the wide variation in sub-unit goal-orientations and the numerous ways in which sub-units adapt to changing environments. As organizations are situated at the cultural/institutional level, the corollary for PARSONS is that the systems analyst should determine the goals and values of formal organizations. The initial concern then is that, organization's goals

40 An interesting comparison with the differing attitudes of the engineers and the economists in the field of water resources development has been argued by BOULDING (1965:82-3). The distinction, he said, can be summed up by saying that, on the whole, the engineer is project-oriented whereas the economist is system-oriented. The economist is always concerned with ,might-have-been,", the engineer is always concerned with ,what will be,; the engineer is concerned with plans, the economist with unrealized alternatives. Hence, on the whole, the engineer is talking about ,what is, or ,what shortly will be,-- the economist is always talking about ,what is not, - giving the economist a certain disadvantage in the argument. One is tempted to say also, he argues, the engineer thinks mainly in physical terms whereas the economist is interested primarily in values. The more distinction between the mode of thinking of the economist and the engineer according to Boulding is: the engineer tends to regard his activity as a kind of „war against nature,, the economist, on the other hand, thinks of nature as a factor of production to be treated gently in a cooperative manner.

41 The functionalist vein of social science reefers to the approach in which all regular patterns of social behavior are perceived as having some function to perform in relation to the creation and maintenance of order in societies. 
must be legitimated by organizational values, which in turn must be consistent with social values. While the organization must federate its goals with those of the sub-systems which comprise the organization, its own goals must, in turn, federate with those of the wider system. It is indeed these processes which are at the heart of PARSONS' analysis in the social system.

As example for the variations in objectives, the macro-economic considerations shape the objectives that national decision-makers seek to achieve such as:

- the rate of return on public resources invested in the irrigation system;

- minimization of the recurrent costs of operation and maintenance;

- ensuring year-to-year stability of production; and

- political considerations related to external interests (e.g., earning foreign exchange through export, production to satisfy urban consumers) and domestic ones (e.g., providing large commercial agriculturists with water for their crops) (UPHOFF ET AL. 1991:58). In addition, they are also interested in aspects like elections and regime stability.

Water users, who are the beneficiaries of public irrigation systems, on the other hand, have different interests vis-a-vis the other two. Their objectives are shaped more by micro considerations: the maximization of household benefits (e.g., adequacy and reliability of water deliveries and the productivity per unit of land) and minimization of household costs (e.g., less time expended in weeding, or fewer water-borne diseases). Here come also into play many other considerations; political, health, status and others, besides the economic factors of the farm. Whether the organization take these goals into sufficient consideration or not depends mainly on the form/nature of this organization.

Irrigation agency managers and staff members constitute the third set of actors, which are established to further the objectives of the other two. They considered also, in addition to the water users, the internal goals (individual goals) definers of irrigation organization. The objectives of managers, therefore, come in the middle between the government and the public, whose goals do not always coincide. They are concerned with maximizing benefits and minimizing costs both for their agency (e.g., maximizing their returns: security, amount of income, stability, and power; and minimizing their own costs: budget, efforts, embarrassment,..etc.) and for themselves (e.g., higher, more secure incomes, or fewer postings to places where facilities are inadequate). Furthermore, productivity of resource utilization, equity of resource distribution, and stability of water supply without environmental depletion, can be mentioned as irrigation organization's goals (MANIG 1989:28).

WALKER (1981) classify other influential groups and refers to as external interest groups such as suppliers and buyers of the organization input and output, customers, investors, advisors, and so-called regulating groups in societies, such as politicians, administrators and local, regional and national elite. The concealed goals of these groups set expectations in, and exercise an influence at, all levels of the organizations i.e., during the planning, the design, the establishment, and the execution and determine therefore the irrigation organization's official goals (MANIG 1989:27). Of course, each group has its power means, to achieve their goals, which vary according to the importance of the organization for this group. 
Because these goals are manifold, complex, and interrelated, the conflict is therefore often expected $^{42}$. There are objectives, on the one side, which all interests groups agree upon, e.g., increasing production, productivity, and increasing the reliability and predictability of adequate and timely water flows as an aspect of improving water distribution. On the other side, objectives like equitable distribution may vary because of the relativity of the fairness' of understanding. For example, the upstream/downstream relationship is more related with the interests of influential political actors. In the light of this, KELLER (1986:350) viewed the dichotomy of the operational objectives of the public irrigation systems and the private beneficiaries as the root cause of many problems in managing them. He asserts that, for an individual farmer, water may not be his scare resource unless it is rationed, allocated, and/or distributed inequitably. Therefore, he is not usually concerned about water-use efficiency or fair and equitable distribution of water to other farmers, although these are the typical operational objectives for public irrigation system. Oppositely, reducing conflicts is more important objective for farmers and normally not stressed from the national policy makers and irrigation managers because it implies some deficiency in management. For the latters, is an objective like resource mobilization or sustaining system performance of first priority.

Where irrigation system management cannot achieve all of these goals, or cannot achieve them all fully because of physical, economic, political, social or other constraints, some ranking or weighing is needed. In other words, an ordering of aims has to be tailored with some knowledge of the context and of capabilities for system management. In addition, if equity of water distribution is discussed as an objective, for example, all actors groups should know any differentials, even if there is disagreement about what constitutes "fairness" in distribution (UPHOFF ET AL. 1991:62, 66).

\subsection{The Context of Irrigation Management}

As discussed previously, each management process is conducted in a specific environment and a successful manager or policy maker tailors this approach to fit the environment early in the managerial process. Also, the concepts that are viewed in the previous chapter, shows clearly that the proper performance of irrigation systems does not exclusively depend on the operational efficiency of the irrigation institution but it needs, in addition, adequate understanding of factors bound to the environment or context of the institution that impede and impinge on the achievement of objectives and therefore the irrigation performance.

After reading the organizational environment's literature, one is impressed by the variety of words used to describe the same concept. For example, WALKER/CLEVERINAGA (1989) refers to market conditions, water laws and indigenous knowledge of water users as environmental factors that influence the successful performance of irrigation system. UPHOFF ET AL. (1991) lists six major categories as contextual factors that describe the organizational environment: (a) agro-ecological, (b) technical, (c) economic, (d) historical, (e) socio-cultural and (f) political-legal. Yet, MANIG (1989) used the term Situation Variables to refer to these factors and adopt the KIESER/KUBICEK's (1976:8-9) classification of the various dimensions that influence the situation. These dimensions are:

\footnotetext{
${ }^{42}$ For more detailed reviews of the major categories of irrigation management objectives see UPHOFF 1986:15-18 and 199: 59-60.
} 
- dimensions of the organization's internal Situation including factors such as: achievement program, size of the organization, applied technologies (production and information technologies), legislation and ownership titles, age of the organization, type of foundation and development stage of the organization;

- dimensions of the organization's external Situation, basically included the global environment (natural, social and cultural conditions). These dimensions and factors are connected with each other and with the structure of the organization in a complex multicausal pattern.

When we try to draw conclusions from this analysis, the first one then will be that the context or the environment of the irrigation management is manifold and complex, even for small systems. In addition, it is the organization's source of inputs and sinks of outputs. However, and above all, the organizational context or environment is described, in most of the relevant literature, with the general and global concept of uncertainty. Uncertainties denote randomness, unpredictability or lack of information with which the organization has to deal. In global terms one could classify the environmental aspects as having either 'informational' or 'energetic' contingencies which define the amount of uncertainty to be dealt with. In view of these facts, irrigation as a mode of agriculture production can be viewed as a "socio-technical adaptation to particular habitat features and population characteristics". At a more micro level, the ecological perspective suggests that apparently irrational, unarticulated, or random activities in a particular irrigation system may be unraveled and made more intelligible if they are examined in relation to the habitat and sociopolitical context in which they occur (COWARD 1980a:21). Furthermore, THOMPSON (1967) and LAWRENCE/LORSCH (1967) have argued that "organizations are inherently uncertainty-absorbing instruments created for the pursuit of certain goals " (PENNINGS and TRIPATHI 1978:173).

Amongst the 'systems" approaches there are studies which emphasize the systemic relationships of environmental, technological and demographic conditions, and social responses to them. A notable example of such an approach is that of BOSERUP (1965) who presents the bold thesis that increasing population density explains the development of increasingly intensive systems of cultivation, involving also changes in technology and in social institutions. Another contribution is CHAMBERS and HARRISS (1977) who sought to explain variations between villages in a small region of South India in terms of the interrelations of environment (especially the availability of irrigation water) and population density, and found certain fairly distinct patterns of variation of wage rates, labor relationships and rural livelihoods that could be related to the basic dynamics of environment and population (HARRISS 1982:18).

The conclusion that can be drawn from the above is that an organization's environment consists of virtually everything outside the organization: the store of knowledge upon which it must draw its geographical location, and the economic, political, and social conditions in which it must operate. But, the organization's internal environment is also important, particularly in so far as the skills and commitment of its members are concerned (BLUNT 1992:138). So, in the light of these facts, the position may be that the organization is faced with a hostile environment as well as friction from within (HASSARD 1993:29). This leads also to inforce what the experience has pointed out, and that is ,an undifferentiated transfer of institutions and organizations from one system into another is likely to cause a lot of problems,, (KÖTTER $1988: 18$ ). 
It is not the intention here to delve into the social ecology of irrigation systems i.e., the interrelation between people, and their physical and political surroundings in depth. But, our emphasis in this section will be directed at factors which are system-specific (and play a significant role in the two case studies of this research) and, at the same time, broader factors that impinge on the management of all irrigation systems within a country or region. These factors are technological, historical, social, cultural, and political ones.

\subsubsection{The Organization's Applied Technology}

\subsubsection{The Appropriate Technology: Continual Debate}

The debate on the "quality" or the "degree" of technology in the developing countries is relatively old and complex. On the one hand, the economical theory recommended that each country has to use more the production factor which constitute a relative advantage to have an efficient allocation for their resources. This means, logically, that most of the developing countries have to use labor-intensive techniques in the irrigated agriculture because of their relative advantage in the labor factor.

On the other hand, if we agree that the more important technical criteria to assess the performance of irrigated projects are the regularity and symmetry of water distribution and the efficiency of water use, then raised the question, whether the practiced technology in these fields in the developing countries is capable of realizing this performance?

Some international organizations (the World Bank and the International Commission for Irrigation and Drainage (ICID) and researchers (POSTEL 1984, REPLOGLE 1986, HÜBENER and WOLF 1991 and MANIG 1993), on the other hand, suspected that the prevailed irrigation technique in the developing countries can make them able to use effectively the available potential. That is why, they argued, those countries couldn't face the challenge of development that require increasing the labor-productivity beside the productivity of soil and water to meet the increasing population and improving the standard of living as well. For a sustainable efficiency for irrigated agriculture in the developing countries, the up to now technical concepts should be well thought out and modernized. This means strengthening the orientations towards the wishes/requests, ideas, attitudes and the basic requirements of the water users. They believe also that improving the management concepts of the traditional irrigation systems alone is not enough and therefore they view that the modern technology should be strengthened as a strong alternative. Modernization of the technology then must not be seen as expensive solution but also as the'useful' solution.

Therefore, modernization of the irrigation technique can help to:

- achieving greater production and productivity ${ }^{43}$ (through increases in yield, cultivated area and cropping intensity) and, at the same time, fewer costs (through decreases in labor costs);

\footnotetext{
${ }^{43}$ Because of the economical and social conditions prevailing in the developing societies, the effects of technology use are not neutral. The benefits of utilizing modern technologies have reached all the groups more equally only in the countries whose development policy was based simultaneously on a broad income distribution and which, therefore, strive after better adjusted societal mode of distribution. In contrast, the use of modern technologies in the agricultural sector in developing countries has only shown clearly the unequal societal modes of distribution that still prevailed, since social differences were
} 
- solving the problems of labor shortage in the top seasons;

- more efficiency in water use and in the mechanics of operation and maintenance;

- fewer environmental problems; and

- make the organizational and managerial problems in the field easier.

In the final analysis, it is very important to say that using relative modern technology is not a substitute for improving irrigation management but, on the contrary, the latter is a condition or guarantee to get the advantages of the former. Furthermore, choosing the mode of this technology is connected with the goal structures that prevailed in organization. Every interest group is trying to choose, of course, the technologies that provide it advantages.

As stage during the development of these ideas, others have frequently viewed the "appropriate technology" as a solution for this dilemma. The opinion here was: addition to the high costs that is considered unbearable and the introduction of sophisticated irrigation technologies into traditional systems may serve to make them more dependent upon the outside bureaucracy. That is why- may be- the term "appropriate technology" has been sometimes understood in the developing countries as an equivalent to the simple or the "cheap" technology.

The decision in this field, in fact, has to pay attention to the interaction between the prospects of profitability of irrigation schemes and the technical surveys. Thus, there has to be a continual reciprocal action between technical surveys and economic consideration, so as to reach in each case the solution which will ensure maximum profitability from the point of view of the national economy (BERGMANN 1967:48).

Finally, it seems that according to the recognized fact water is now a very critical factor for many developing countries, and the other which say that the misuse of it was responsible for the law rates of productivity there, then sustaining the available amount of water and the efficiency of its use have to be considered as determinative factor for the choice of the irrigation technology. Indeed, it is very important to use the technology that suit the prevailing social and individual values systems in the society, but one is tempted to say also that sometimes it is necessary to change some of these values when the modern technology is the sole alternative. To put it in another way, we have to do some rethinking about, and revaluation of, the term "appropriate technology" 44 .

It is not recommended here, therefore, to use very modern irrigation methods as a substitute for one like gravity system when the latter is, technically and socially, more suitable for the intended project. But, we argued that steps on the way of modernization or improving this irrigation method should be done. Specially in the field of regulators systems, land

intensified and polarization has expanded. Therefore, institutional innovations as well as changes in the societal modes of distribution are always necessary in order that technological modernization contribute to the optimal achievement of objectives. Some of the structural effects that lead to an unequal distribution of the benefits resulting from the utilization of the modern technologies in agriculture and other effects are discussed in MANIG 1988: 44-8.

44, ,... no great improvements in the lot of mankind are possible, until a great change takes place in the fundamental constitution of their modes of thought... John Stuart Mill“" quotation from WATERSTON 1965:249. 
preparation and harvest ${ }^{45}$ machines, and outlet (field channel) control (e.g., installing a new type of control gate).

One of the important problems - may be the most important - in the traditional gravity-flow system, as HÜBENER and WOLF (1991) viewed, is the unleveled land. This problem need a lot of work and high costs, otherwise the water user will lose the control over water at the field and this, consequently, leads to dramatic results: some parts of the field become marshy and others die from the shortage of water ${ }^{46}$. On the other hand, increasing the cost of irrigation will result in decreasing the amounts allocated for the other agricultural processes. Using advanced technology will reduce the quantity of water, costs, and increase the productivity. The expected positive results will compensate then the high costs resulting from introducing such technical improvements. For instance, a recent study of ODA in the Nile Province of Sudan has found that: ,with spot irrigation, demand for water is only 14\% of that required by the open channel method, assuming no losses from source to point of use“ (WEDDERBURN/ERRINGTON, 1985:20) ${ }^{47}$.

The experience in U.S. has shown also that farmers using conventional gravity-flow systems can cut their water demand by 30 percent by capturing and recycling the water that would otherwise run off the field (POSTEL 1984:40). These reuse systems are required in some U.S jurisdictions where the farmers have also findings, however, that they often make good economic sense because pumping tailwater back to the main irrigation ditch generally requires less energy.

Lining irrigation canals is other step that can also help reduce water wastage, prevent waterlogging, and eliminate the erosion and weed growth that makes irrigation ditches deteriorate.

\subsubsection{Technology and Irrigation Management}

Considering the field crop, water may be placed in the root profile zone by a wide variety of surface or flood system; sprinkler system; and subsurface and surface drip irrigation system. Each method can present different difficulties for management. In other words, all methods can be managed to similar degrees of high efficiency, or mismanaged to similar degrees of low efficiency. Likewise, the water requirement of crops do not materially change for the various systems, but rather, the apparent differences really represent management losses, not crop-water use changes (REPLOGLE 1986:135) ${ }^{48}$.

Sprinkler systems, which come in many varieties, use more energy than gravity systems and require a large capital investment to install, but they have brought irrigation to rolling and steep lands otherwise suited only for dryland farming. One design of these systems is the center pivot system. REPLOGLE (1986:135-8) considers the built-in control and

45 The problem of 'after harvest' loss for many crops is known in most developing countries. It has been estimated that these losses are approximately 15-25 per cent of the crops. In New Halfa, the tenants reported that more than one fourth of the total wheat crop is lost because of the bad quality of the harvest machines.

46 See Chapter 6.1.2.1

47 The introduction of such technology, on the otherhand, can be faced with socio-economic aspects. See Chapter 5.3.6.4.

48 Although drip irrigation may be inherently more efficient by design, the wide average range of efficiency for each system - 40-80 percent for gravity flow, 75-85 percent for a center pivot sprinkler, and 60-92 percent for a drip system - shows that management is a key determinant (POSTEL 1984:40). 
management ease that are usually installed as part of the system, as one major attraction for the large center pivots and the drop systems that are independent of the system efficiencies. He counts these advantages and asserts that the flow meters installed with both systems provide the farm operator with much of his water management information. Pressure regulators provide steady flow for convenient water management and general ease of operation. Granted, maintenance problems peculiar to each system exist, but the water management decisions were frequently provided by equipment preprogramming by the farm operator himself, at his leisure. The feeling of control has positive selling points.

As conditions to get the expected organizational and managerial advantages concerning the introduction of such systems, we have to focus the attention on the following considerations (MANIG, 1993):

- the organizational structure must be reformed. In this respect, a unit to manage the "Station"; operation and maintenance; and water distribution may be necessary;

- furthermore, attached to this organization, should be established a conflict-solving corporation to coordinate between the different interests of water users. This condition is more urgent when the Station is managed through water user organization; and

- as a result of the considerable consequences on the agricultural structure in the long term, the encouragement of producing export or cash crops instead of food crops may be considered as probable disadvantage.

Surface systems, on the other hand, have often been constructed with minimum or nonexistent flow metering and rather haphazard flow control that place sever requirement on a farm operator. Therefore, these systems need to be attractive from the operational standpoint, economical, have simple but accurate open-channel flow measuring and control methods.

Drip or trickle irrigation is other advanced system. This system that is developed in Israel in the sixties, supply water and fertilizer directly onto or below the soil. An extensive network of perforated piping releases water close to the plant's roots, minimizing evaporation and seepage losses. These costly systems thus far have been used mainly for high-value orchard crops in water-short areas. They have been used on about 10 percent of Israel's irrigated land in the middle of eighties where experiments in the Negev Desert have shown per-hectare yield increases of 80 percent over sprinkler system. Introduced into the United States in the early seventies, these systems have been used latter on row crops too (POSTEL 1984:39-40).

Israel has pioneered the development of automated irrigation, in which the timing and amount of water applied is controlled by computers. The computer not only sets the water flow, it also detects leaks, adjusts water application for wind speed and soil moisture, and optimizes fertilizer use. The systems typically pay for themselves within three to five years through water and energy savings and higher yield (POSTEL 1984: 41).

Innovative water-saving technology is - according to the Israel's experience - one of two measures that are needed to accomplish the efficiency of water use ${ }^{49}$. The first one, which consider a key determinant, is the "careful management techniques" (LEES, 1986:612).

49 In Malaysia's Muda irrigation system, real time management of water releases from the dam, keyed to telemetric monitoring of weather and streamflow conditions, has significantly improved water use efficiency (ROSEGRANT 1995:2). 
Israel's overall gains in agricultural water use efficiency, through these measures, have been impressive: the average volume of water applied per hectare declined by nearly 20 percent between 1967 and 1981, allowing the nation's irrigated area to expand by 39 percent while irrigation water withdrawals rose by only 13 percent (POSTEL 1984:41). Farmers there are induced to adopt this technology in part by the attraction of saving money on water fees or profits to be gained with additional water saved, but to a large extent also by government incentives that reward the innovator with subsidies under writing the cost of new technology. It is valid also to say that the technology of pressurized extraction makes possible Israel's high degree of centralized monitoring of use, but also confers upon farmers considerable autonomy in on-farm control. The farmer can turn water on and off at will, but not a drop can be legally used without its being metered (LEES 1986:611).

\subsubsection{Historical Factors}

The history of an irrigation system -- the course of its development, who planned and finance it -- and the past experience of managers and water users, have significant influences on the course of performance of irrigation organizations. It is going to effects who is entitled or obliged to undertake the activities (decision-making, resource mobilization,...etc.) at different levels of the system. In addition, the past experience of the organizations' individuals influence their perceptions and expectations, their willingness to cooperate.

The evolution of irrigation (indigenous irrigation by water users or governmental agency) will shape the goals and orientations prevailing within the system. If irrigation was established: to minimize the effects of drought and famine (parts of India during British rule), to deal with land tenure and overpopulation problems (Sri Lanka), to support the expansion of cash or export cropping (Sudan during British rule), to achieve selfsufficiency or whatever the ground, the physical design (e.g., scale of project, water distribution structure) and the management pattern will be different in each case. Also the dominant role of the agency in irrigation management will vary according to who is entitled to take over the irrigation development (the government, colonial government, or foreign donor assistance). Yet, it is of interest to know whether the agency has been part of a Ministry of Agriculture where the agricultural considerations dominate in managing irrigation activities, or within some other ministry like ministry of irrigation where the agency is likely to regard irrigation as essentially a hydraulic exercise. Another historical influence derives from the role that irrigation has played in the development of the agriculture sector as a whole.

One of the studies which make use of certain basic ecological concepts and the role of historical aspects in development is that of Geertz's analysis of the economic history of Indonesia (1963). Geertz accounts for the differences between the patterns of development in Java on the one side, and in the Outer Islands on the other, in terms of their contrasted environmental and demographic contexts. He examined these contrasts historically and in relation to Dutch colonial policy. Such interests in the historical development of cultivation systems at a very broad level is matched by that of some historians who have also sought to explain long-term patterns of agrarian development. HARRISS (1982:19) summarize the argument of Geertz as follows:

"the physical conditions of Java have allowed production to be increased so as to keep pace with the rapidly growing population, though at constant levels of output per head. 
This has required the use of more and more labor-intensive cultivation practices and also some 'sharing of poverty' - as in the sharing out of access to land or of opportunities for wage work. He describes this whole pattern as one of 'involution' - in the sense that there has been increasing elaboration of existing social and economic structures - in contrast with the kind of transformation of older structures, and increasing inequality, which has occurred in parts of the Outer Islands " $"$.

\subsubsection{Socio-Cultural Factors}

Social and cultural factors affecting both water users' and irrigation bureaucracies' role in management. These factors are based on caste and religion, social customs and traditions, mores and taboos, local employment generated by the project, contribution of project benefits among the clientele of the project, contribution of the project to civic amenities, impact on environment, and impact on the quality of life in general. Many projects have failed because they did not meet the social objectives of their clientele.

REVANS (1967:174) stressed the importance of some of the cultural issues. As long ago as 1967 he was in Sudan, warning: "Many of the development problems of Africa can be understood and treated only by those who share the culture of the African, who understand his value system, his sense of fairness, his attitude to authority, and, what is often overlooked by the western observers what he wants out of life and what effort he is prepared to make to get it" . In the same context, the Food and Agriculture Organization of the United Nations (FAO) has rightly attributed the failure of planning in India to , its lack of cohesion with social factors and the impediments imposed by political, social, administrative and cultural forces,, (SINGH 1986:349).

Another examination of these variables, according to experiences in Asia and Africa, has been discussed in UPHOFF (1991:97-8, and 1986:51-2). He views residence patterns, social diversity within the cultivating community, social homogeneity in bureaucracies, interpersonal relations, and what he refers to as 'propensity for conflict' or conversely, aversion to conflict as most important socio-cultural variables.

Tasks of communication and coordination are more complex when residence patterns are dispersed rather than nucleated and do not correspond to the channel layout of the irrigation system i.e., when field neighbors are not village neighbors (as the case in the first case in this study - Gendettu). On the other side, in settlement schemes, system managers may have control over water users' living arrangements as well as over their water (the second case - New Halfa).

Heterogeneity in ethnic, cultural, and/or in economic terms, make the cooperation among water users may be more difficult and more management effort must go into conflict resolution. Differentiation can also occur in a homogeneous social situations. Experience suggests (in Gal Oya, Sri Lanka and New Halfa, Sudan) that conflict will be less if settlers are brought into an irrigation scheme from different areas located together homogeneously by place of origin. Whereas, in Mwea system in Kenya, managers thought that it would be better to mix up original clans when assigning houses and fields to new tenants.

The important cultural variable to be considered here is the ways that community used to deal with conflict. The experiences here says that some communities have effective roles

50 For a useful critique of Geertz's notion of 'involution', see AASS (1980) 
and procedures for resolving conflict, while others do not. SINGH (1986:167), in this context, asserts that the experience in Zambia has shown, if the community accepts only the authority of religious or tribal leaders, then these leaders should be consulted and asked not only to solve these problems but also to endorse the development of their villages." He has also noted, based on the experience in Israel (the settlers in a village in the northern part of the country) that any attempt by the development authorities to undermine the authority of local leadership ,is likely to result in undesirable situations,,.

The cardinal rules that can be drown from these and other experiences (e.g., Bas Bosen project in Haiti) are the importance of understanding the background of the population, especially in settlement areas where development authorities select the settlers. The planners here cannot afford to isolate themselves from the people they are to serve. Sensitivity to the abilities and sensibilities of the people is the key to success. The dignity of the population must always be upheld, and their communities of values must be respected and accommodated. The latest rule is that ,if there is a conflict between the abilities of the people and a development project, it is the project that must be changed, not the people, (SINGH 1986:169).

Just like the situation among water users, socio-cultural factors influence bureaucracies in the same way. Some bureaucracies are heterogeneous with regard to status and specialization of members, in addition, the social homogeneity has similar consequences as in communities for their smooth functioning.

Interpersonal relations prevailed (egalitarian, hierarchical, or deferential relations), viewed UPHOFF et al. (1991:98) as, "probably the most important cultural norm". Societies differ considerably in this regard and can change over time. Hierarchical norms give any staff more "power' over water users to regulate irrigation behavior. But, they also reduce the content and effectiveness of communication in both directions, contributing to gaps in knowledge and understanding on both sides of the management equation. They are especially important to consider within an irrigation bureaucracy; how superiors and subordinates relate to one another, and how much control and accountability there is within the organization. Some changes in these relations is sometimes necessary for achieving irrigation goals but it is also of importance to keep in mind that hierarchical norms and behaviors in bureaucracies are not very malleable. They "arise from and are reinforced by the larger cultural context" (p.98).

\subsubsection{The Political Context}

It is a known fact at the present that political realities, may be more than the other factors, are a crucial element of the contexts in which irrigation organizations function. Although this statement is relatively valid in the three main continental areas of the third world, consider Africa is considered as good field to examine the crucial influence of the broader external political environment on the functioning and management of development organizations. Here the intensity of government's engagement in irrigation sector plays a fundamental role. This engagement is therefore more close in countries where the following conditions dominate: the trade deficit is growing, the agriculture sector constitute a major part in the GDP, the water is a limited production factor in agriculture, and where the irrigated agriculture area is great. The more important indicator for the engagement intensity of the government according to HUPPERT (1989:86) is the "frequency of personnel transfer". The transfer of personnel in ministry of agriculture, irrigation 
administration and project management represent an environment of insecurity which have, considerably, negative effect on the efficiency of irrigation management.

In this respect, LEONORD (1988:908) according to his experience in Kenya notes that the state in Africa is still a fragile institution and that political systems depend heavily on patronage: "politics still dominates all other organizational and policy considerations". BROWN'S (1989) Liberian case study also confirms this result. He concludes: "there is little to suggest that the dominant influence was attitudinal, and much to suggest that attitudes and behavior were conditioned primarily by political influences" (BROWN 1993:99). These arguments ${ }^{51}$ are extension, in the same direction, to those argued by HOWELL (1974:99-100) in his wide-ranging survey of approaches to third world management. HOWELL questions the assumptions of conventional approaches and stress, for example, cultural and psyche-social influences and structural weakness. Such approaches, he argues, have some explanatory value but are collectively inadequate; indeed, he contends, 'they have all contributed to a harmful misdirection of interest in the study of the role of management in development planning'. His own thesis is that it is the political environment which is the critical influence on managerial performance, and that the way forward for managerial development is in the building upon existing organizational resources rather than the preoccupation with their shortcomings.

In his discussion on this important element of the irrigation management's environment concentrate UPHOFF ET AL. (1991:98-102) upon three visible aspects:

- the policies of government which set for the bureaucracy the objectives of irrigation management; the orientation of the political 'masters'; what sort of objectives preferred by government leaders (self-sufficiency, minimizing expenditures or create a more equitable society);

- the extent of interference by politicians in management i.e., whether there are complains about pressure for irregularities in water allocation or distribution (to benefit certain privileged groups), or about intervention in the operation of the agency, affecting staff transfers, promotion, etc.. Interference may be also practiced through unsanctioned payments extracted from water users for irrigation services, commonly referred to as 'corruption'; and

- the extent of water users' influence on the management decisions. This depend partly on the importance of farming sectors in the political-economic strategy and on the extent that water users are organized and able to make their collective voice heard. Whether they have electoral significance as a bloc or pressed to become 'clients' subordinate to rural or urban elite 'patrons'.

Within the scope of discussing the political environment, increase often the talking about corruption. A remarkable example here has been noted by WADE $(1982,1985)$. He argued that the irrigation engineers who are responsible for the canal systems in India, keep intentionally the predictable level of water down to get 'bribe' money (HUPPERT 1989: $86) .{ }^{52}$

51 These and other examples are discussed in greater detail in BLUNT/JONES 1992, and BLUNT et al 1993.

52 Bribe must not be in term of money. The experience in Gendettu showed also the political bribe (Chapter 6.1.3). 


\subsection{Organization Structure}

For a time, specifically since the notion of the contingency theory that have been developed by KATS/KAHN and THOMPSON, it is a rather common assumption that environment is related to the structure of complex organizations. The implication of this notion is that: for a given environment a particular structure is appropriate (PENNINGS and TRIPATHI 1978:171). In other words, there is no single ideal structure which is best for all organizations in all circumstances (SAGARDOY 1986:12). Although most of the research on this structure-environment relationship has been conducted in the industrialized nations of the west, it is valid to say that it is also relevant to the developing countries. This relationship is therefore regarded to as being culture-free. By the same token, there are certain relationships, such as the relationship between technology and organizational structure and that between organizational size and formalization which have yet to be directly and consistently refuted by empirical research (BLUNT/JONES 1992: 21).

The changes in the social or nonsocial environment ${ }^{53}$, as mentioned before, are the reason for the inconsistency which often occur between the institutional element and the structure element (COWARD 1980a:19). Change in either the institutional or the social structure component creates, however, demand for change in the other. Furthermore, since the structural elements show a great inertia in the face of changes, the strategically decisions concerning the organizational structure of an irrigation system have long-term effects. This means a stable function-specific organizational structure constitutes the framework for the situation-specific management of such systems (MANIG 1989: 4). The formal organization structure, however, describes the system of regulations and stipulations within the organizations which are important for the members' attitudes.

According to the two basic principles of work organization, i.e., the division of labor and the coordination, BLUNT/JONES (1992:111) defines the structure of an organization as "the way in which it chooses to divide its labor into separate work groups, and how it coordinate their activities". These two basic activities are also widely referred to in the literature as differentiation and integration and considers the more important aspects that are relevant to the form of organization structure (HUPPERT 1989:70). Furthermore, the way in which the various activities essential to the achievement of an organization's objectives can best be differentiated (in accordance with the specialist skills required for each activity) and then coordinated in order to produce the necessary unity of effort among the resulting specialist units, is referred to often as the horizontal dimension of the organizational structure. The vertical dimension, oppositely, is concerned with the way in which responsibilities are distributed among members working at different levels of the organization and its component units, from the project to the small group level.

In addition to the structural differentiation (the degree of specialization) and integration (the coordination within and between organizations), KIESER/KUBICEK had mentioned three other dimensions for the organizational structure namely ( MANIG 1989:7):

- the management system (configuration);

53 One of the ways to subdivide the environment from the social scientist's point of view has been to refer to three kinds of systems-the cultural system, the personality system, and the social system. This helps to separate and to keep in mind that there are different kinds of phenomena which we confront (POTTER 1972:157). 
- the competence distribution; and

- formalization

In search of the more variables that influence the organizational structure, CHILD $(1972,1984)$ criticize the studies that had given insufficient attention to the role of senior managers or decision-makers in the whole process of an organization's structural development e. g., Aston Studies (see p.47). Executives, he argues, interpret the same environmental or contextual factors differently, and to some degree organization's structure reflect these differences. Therefore, senior management acts, according to this line of thinking, as a mediating variable between contextual factors and organizational structure, as depicted in Figure 2.1. Senior management make strategic choices about what they consider to be appropriate structures for the contingencies they perceive (BLUNT/JONES 1992:127).

Figure 2.1: The Relationship Between

Context and Structure According To Child (1972)

\section{Environment \\ Contextual factors: Technology------Senior Management ---OrganizationalStructure Size}

Source: BLUNT/JONES 1992:127

A more comprehensive view is argued by COWARD (1980a:25-6) who take into consideration the two important organizational configurations in irrigation system i.e., that composed of the role of water users and the other which is relevant to the various waterauthority roles. The boundaries between the two configurations in community irrigation systems are thin and sometimes unclear because "they are guided by similar socio-cultural rules and because of the temporal circulation of individuals between the two configurations". In contrast, he argues, in irrigation systems where water authorities are more specialized and differentiated from the water users, develop an urgent need to an efficient articulation between the two configurations. In these systems, assert Coward that the major organizational feature influencing system management is the degree of integration of water users and water authorities.

It is valid to say that this line of thinking is in between other two lines. One is represented by SCOTT/MITCHELL (1972:222) and the other in UPHOFF et al. (1991). SCOTT and MITCHELL refer to a school which bind organizational effectiveness and control. This relationship is in detail discussed and illuminated by empirical research in PRICE (1968). Organizational effectiveness in this context is taken in the sense of BARNARD ${ }^{\mathbf{5}}$ who defines it as "the dispatch with which an organization achieves its goals". Although this definition has no distinct signal to the value of participation, it considers that the organizational control systems can implicitly lead to participation. But, this is not bound to happen. This means that participation here is not an inevitable consequence for the existence of control systems and their implementation. PRICE argues then that integral with control systems are, of course, the means or techniques by which an organization exercises influence over participation behavior, and he gives the sanctions a central role in this techniques.

\footnotetext{
${ }^{54}$ BARNARD, C. I. (1939), The Functions Of The Executive.
} 
UPHOFF et al. (1991), on the other hand, has discussed the factors that determine the differences in what can be called the height and gradient in organizational system. Both reflect and in turn affect the extent and ease of cooperation and communication within the structure. These factors are: the distance between persons and levels, the relationship between them, directions of the decisions and information flow, the degree of participation, and accountability.

According to the height and gradient UPHOFF et al. (1991:38-42) distinguished two forms of structures (p. 38-42) as in Figure 2.2. The first one is relatively tall and narrow, steeply sloped pyramid (A). This form refers to large systems which have more levels. The length here is more influenced through the distance between levels than the number of levels itself which is fixed by its system physical layout and size. The cooperation and communication between levels is, on the other hand, either promoted or impeded by social and psychological factors. The steeper gradient, in addition, means that:

- the flow of decisions and information is more downward than upward;

- the authority is concentrated at the higher levels;

- low or little participation at lower levels in decisions making;

- little accountability of persons at higher levels to those at lower levels; and

- the "angle of interaction", measured in terms of the ratio of downward flows of decisions and information to upward flows, is great.

Figure 2.2: Alternative Shapes of Organizational Pyramids

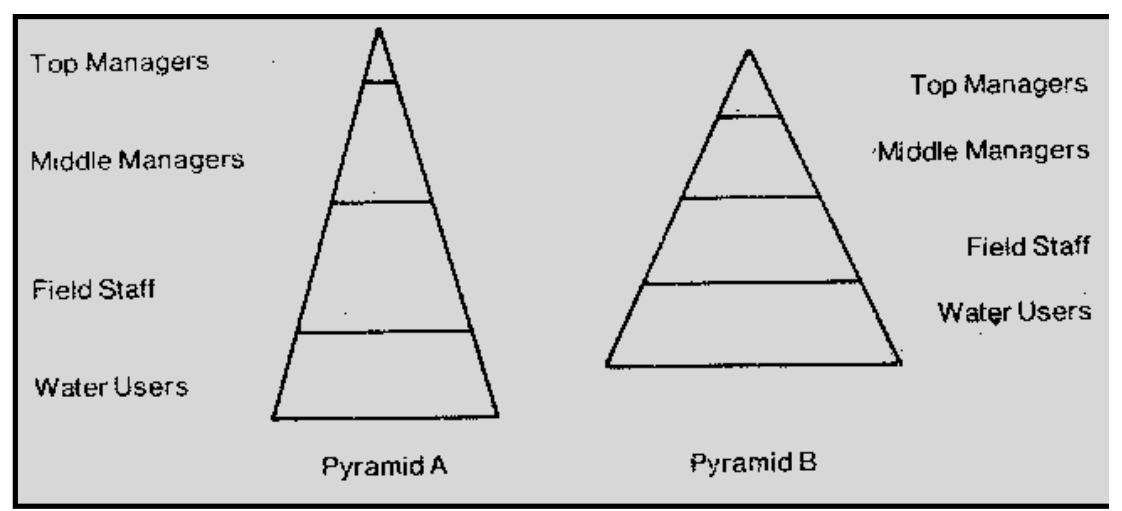

Source: UPHOFF et al. 1991:38

The second pyramid (B) is shorter and broader with flatter gradients. Mostly, this is the form of structure in small-scale systems and means that:

- the spatial distance between persons who have different responsibilities for operational and maintenance is short;

- the flow of decisions and information is fully two-directional ;

- delegation of authority to lower levels and more degree of participation by subordinates in decisions-making at the higher levels; 
- more accountability of persons at higher levels to those at lower levels, and

- the angle of interaction between levels is a little.

UPHOFF et al. (1991:44-50) based on the Aston Studies ${ }^{\mathbf{5 5}}$ analyses four variables that are "the most meaningful ones for comparing and assessing structural variation in irrigation bureaucracies". The first two variables are those of Aston Studies; concentration of authority and structuring of activities. The other two additional major variables are accountability and responsiveness. The former (accountability) denote the extent to which the performance of managers and staff is monitored and can be controlled, either by senior officials and / or by water users in an agency-managed system (or by farmer in usermanaged systems); the opposite end of this scale is personnel autonomy. Whereas, responsiveness means the extent to which the organization has information flows and decision-making mechanisms at all appropriate levels that permit informed changes in operation for modifying water and other resource use; the opposite of this is unresponsiveness, or rigidity.

Although responsiveness may seem to be the opposite of structuring which have in the most the precedence in all bureaucracies, a bureaucracy in fact "could be structured with standardized procedures to make it responsive". In Peru, for example, it has been found that responsiveness could be 'routinized' that establish certain kinds of organizational capacities. The structural feature associated with this variable would be "information flows and mechanisms for making changes in organizational structure and operation according to change either in the context or goals management" 56.

The variable responsiveness has been also characterized in the literature as a signal factor to whether the organization is well or poorly 'joined' and 'communicated'. Communication according to UPHOFF is concerned between levels instead of between system and subsystem of the organization. Finally, responsiveness is also said to reflect the "degree of openness" in an organization, that means its flexibility and response to the stimulants from their environment. Whether the organization operate as "open system" respond more readily to stimuli from its environment, which suit an irrigation agency as discussed in Chapter 1, or as a "mechanistic closed" one which is more self-contained, seeking to control all external changes ${ }^{57}$. This seems to be, for the most part, identical with the organic organization in contingency theory.

55 Aston's studies are some of the most widely respected studies within the field of organization theory, that have been done at the University of Aston in England. The Studies have been aimed at identifying the fundamental dimensions of Structure in bureaucratic organization that are essentially independent of each other. Towards this, the Studies have singled out two variables (from six) that represent two major dimensions of any management structure; namely: concentration of authority, and structuring of activities (specialization, standardization, and formalization). The researchers found these variables to be inversely correlated; the more concentration, the less structuring. UPHOFF et al. (1991:44) has nevertheless found, according to the cases considered in his study that the opposite appears to be true in irrigation bureaucracies: concentration and structuring usually go together.

56 The example illuminated here is from Taiwan. Taiwan irrigation systems exemplify this variable with well established procedures for changing the rules of water allocation and distribution in periods of water stress. Control over water can pass upward within Taiwanese systems in what can be called a default upward pattern of management. In these systems, responsiveness is linked to increasing concentration of authority to handle shortages whenever these arise.

57 The organizations are viewed also as self-sufficient entities. The emphasis in this approach is upon the internal operation of the organization and the adoption of rationalistic approaches taken from physical science models. The organization is considered as sufficiently independent that its problem can be analyzed in terms of internal structure, tasks and formal relationships. In organization theory, the closed 
The conclusion that UPHOFF has drawn from the above is:

1. concentration of authority and structuring of activities refer to the internal processes of bureaucratic functioning, and tend to coincide with higher gradients; whereas

2. accountability and responsiveness are more oriented to external context and correspond to lower gradients.

Empirically, through RONDINELLI's study (1986) of the USAID's projects undertaken in Africa in the decade up to 1986, it was found that high on the list of problems identified by these analyses were those associated with organizational structure and design. Furthermore, a corroborative result has been argued by KIGGUNDU (1989). On the basis of studies conducted by others in Africa and his own experience of organizations in Uganda, Kenya and Ghana, KIGGUNDU has drawn up a structural profile of a 'typical organization' in a developing country. He has divided the organization into three parts (top management, middle management, and operating levels) and analyzed the characteristics of each as follows (BLUNT/JONES 1992:131):

Top managers in a typical organization in a developing country are authoritarian and paternalistic, autocratic, overworked, and highly educated. Organizations typically do not have clearly stated and widely understood missions or objectives; they are heavily politicized, and have weak executive support systems. Senior managers also devote too much of their time to extra-organizational activities which have little to do with the organization's interests, such as political, tribal, religious, or personal family and business activities.

Middle managers, on the other hand, are seen in the above analysis as possessing inadequate management and administrative skills, insufficient specific knowledge and experience, low levels of motivation, and to be risk averse, unwilling to take independent action or initiative and like senior management, to be unwilling to delegate. As a whole, middle lines in developing country organizations are understaffed and are characterized by weak and/or inappropriate management and organization systems and controls.

At the operational levels, developing country organizations are judged by KIGGUNDU to be inefficient and costly, and overstaffed. Operators tend to be underutilized, underpaid, and not to be rewarded according to performance. This results in low morale, lack of commitment, high turnover and absenteeism. The conclusion of such profile is: inadequate coordination and communication between the different parts of the organization.

It is also worth noting that other commentators have recently arrived at very similar conclusions to those of KIGGUNDU. For example, JREISAT (1988:85-97) has described a number of structural and administrative deficiencies common to seven Arab Countries, including Sudan, which broadly corroborate KIGGUNDU's conclusions.

system perspective is frequently one where analysis is directed toward general laws of sociology or psychology and thus where the variables being researched are assumed to be unaffected by environmental forces. At the heart of this perspective is the positivist assumption that objective forces, detected by controlled scientific observation, can exert a direct influence on human activity. This is typically the case in experimental or laboratory approaches. This perspective emphasis therefore upon maximizing the internal efficiency. Further details in HASSARD 1993: 30-1. 


\subsection{Farmers Involvement in Irrigation Management}

Perhaps the most serious institutional and organizational issues in irrigation development are those related to the articulation between water users and the irrigation bureaucracy (COWARD 1980a:25). It is agreed upon now in irrigation management literature that one of the major reasons for poor performance of irrigation systems is the lack of feedback from the field to the center of decision-making. Top-down orders are easily given, but feedback flows are more restricted and liable to distortion (WALKER 1989:348). Unlike industrial systems, irrigation systems, argues KELLER (1986), are managed not only from the top toward the bottom, but also from the bottom up. This is because the very act of irrigation requires farmers to be entrepreneurs and take risks. Farmers are not in the ,payroll“ but must gamble their time, capital, and talents in the real present, in hopes of accruing future benefits. Because of this, a top-down management system is unworkable, since the bureaucracy and its employees do not take the risks. ${ }^{58}$

The communication and decision-making structure and information channels that are used and respected by the farming society are very important issues in irrigation organizations. In addition to the speculation on the nature of organizations and their role in society, discussed in Chapter 1.2.2.1, other fact can be drawn from the organizational theory; this is: „Theories about organizations typically treat communication in an implicit or a tangential manner" (EUSKE/ROBERTS 1989:42). Most definitions offered by organizational theorists are vague shorthand statements that lack precision and specificity in determining which variables should be the focus of message exchange ${ }^{59}$. In its broadest sense, communication is ,the social glue that ties members, subunits, and organizations together". Without communication, organizing could not occur.

\subsubsection{The Human Side of The Organization and Operation of Irrigation systems}

It is now more recognized that irrigation systems are human systems. As opposed to the technical or physical perspectives, conceiving of the irrigation system as a human system, is examining it with a view to pinpointing the role of human side in irrigation. CHAMBERS (1980:28) refers to this human side as ,the management of those who manage the water, the procedure for irrigation control, the processes of allocation of water groups or individuals, and the distribution of water within groups". Within this area of interest and, considering the irrigation as a 'happening', asserts KELLER (1986:334) that „, a traditional irrigation system does not irrigate..... it is merely a network of channels feeding prepared fields. Human enterprise does the irrigation". Furthermore, the control and allocation of the water to the field also requires continuous and direct human action. The human action is defined here as the 'men' in organizations and communities; the labor and management. Considering the human aspects is then not only essential to facilitate the management of irrigation, but also is a precondition for the efficiency of irrigation water utilization.

58 To elaborate on the above, he compares an irrigation system with free school. Merely putting the building in place and providing staff does not produce education. Education occur when students take the risks, the time, and the effort to attend the school and learn, in hopes that what they have learned will be of benefit to them in the future. Thus to get the students into a program, they must be attracted to it.

59 Some theorists conceive of communication as written versus oral channels or the transmission of messages (the mechanistic perspective). Others view organizational communication through the locus of message effects, filtered through cognitive processes of senders and receivers. Other theorists, although fewer in number, treat communication as the interpretation of information, the meaning of symbols, or the redundancy of message patterns. 
This point is reinforced by CRIDDLE (1975:139): „ohne Berücksichtigung der jeweiligen Bewässerungsmethoden besteht ein enger Zusammenhang zwischen der menschlichen Komponente und der Bewässerungseffizienz. Je grösser der Spielraum für menschliche Entscheidungen und Aktivitäten ist, desto grösser ist die Gelegenheit zum Missbrauch des Wassers". Therefore, disregard of this important component as many argue (CHAMBERS 1980; LOWDERMILK 1986; WEITZ 1986, and SINGH 1986), is considered as responsible for the failure of many projects in developing countries (e. g., India, Sri Lanka, and Israel).

In this context, NOBE and SAMPATH (1986:7), are confining their attention to the training of professionals and farmers which received little attention during the 1960s and $1970 \mathrm{~s}^{60}$. They have argued that the most economic resource for irrigation development today may not be financial capital for new schemes, but rather ,require the abilities of people to do the job- their knowledge, skills and professional commitment,.. In this regard, WIENER (1976:8), formerly the chairman of the famous Tahal National Water Program in Israel has also stated the importance of training farmers for operating successful irrigation systems:

„Engineering is not the fundamental problem underlying irrigation development in LDCs. Engineering principles are known and can be adapted, but the major problem, however, is to discover ways to utilize farmer clients more effectively in operations and maintenance and development programs which create rural transformation. Rural transformation essentially requires changes in farmers' behavior, motivations, and expectations, which is hardly possible until institutions exist to provide them with the improved production possibilities and incentives".

In the concrete, one is able to say that among the general interest of the human side in irrigation systems, the role of farmers as final water users- their knowledge, motivations and initiatives have been more highlighted. This has been strengthened by, as CHAMBERS (1992:7) argues, ,the growing recognition by development professionals of the painfully obvious fact that rural people were themselves knowledgeable on many subjects that touched their lives". He refers here to what is known as Indigenous Technical Knowledge (ITK). CHAMBERS (1992:20-1) describes the villagers' knowledge and capabilities by saying: ,villagers have a greater capacity to map, model, quantify and estimate, rank, score and diagram than outsiders have generally supposed them capable of. To enable these capabilities to be expressed, the principle is to assume that the people can do something until proved otherwise“.

Besides the fact that the traditional irrigation systems themselves do not irrigate but the farmer, it is also increasingly recognized that irrigation is not a task that governments or agencies can or should do alone. As COREY (1981) has stated from his experience in India: „Government should not do the farmers' business ... development experience worldwide indicates that field channel construction, operation and maintenance, on-farm improvements, and general management of the irrigation water conveyance system below the outlet can be accomplished but with direct farmer involvement." In general, as CHAMBERS (1983) suggested, government should unambiguously avoid doing that which

60 A recent survey of 63 world bank and USAID irrigation projects, they noted, found that only 1 per cent of the total project costs was developed to improving human capital. But, the situation in the 1980s is definitely improving. 
communities can do for themselves in their own interest, but should intervene when exceptional problems are beyond a community's power to overcome (LOWDERMILK 1986:434-5).

Irrigation agencies, as noted by WALKER/CLEVERINAGA (1989:M.IV.1/1), ,cannot field enough personnel to guard every gate, clean every canal, settle every conflict that arises throughout an irrigation system". This is not only against the scare available resources in the developing countries, but also, in the same time, it is simply against the wishes of farmers themselves which need to share an important part of these tasks. Therefore, it is the task of the agency, to be effective, to know how to make the project's clientele see themselves as partners in the effort and how to encourage the individual initiative dormant in the people. In other words, the project authority must be capable of discovering the active elements in the local population, to awaken their interests and mobilize their initiative. These elements may be found in the 'educated middle class, in the rural leaders, in the political parties, or in other groups'. Their successful activation requires first hand knowledge of the population, their customs and traditions and is often based more on perceptiveness and intuition than on direct rules and principles(SINGH 1986:353 ).

Within the scope of the evaluation of the irrigation project's performance until the mid 1980s it has been found that the most underrated and misunderstood dimension of irrigation development is that of the individual and collective irrigation behavior of farmers. The situation was briefly like that what LOWDERMILK (1986:428) has pointed out: „while much is known about the different physical aspects, the social and organizational aspects of irrigation continue to be the Achilles' heel in system development, improvement and operation". The lack of effective farmer involvement in irrigation projects, he alleges, is considered responsible for the high costs of systems, the perennial problems of operation and maintenance, low irrigation efficiencies, and resulting low crop production.

On the other hand, although participation can not be regarded as a panacea for problems of irrigation projects, experiences shows that where farmers are organized and have a sense of ownership in the system, they will not only maintain the system, but also assure that structures and facilities are not damaged (Philippines, Korea, Taiwan and Japan). This lead, of course, to higher crop production and levels of living for rural families.

Although much of the literature on farmer participation is dominated by current efforts in south and southeast Asia, in some countries, such as Chile and Argentina, there are longestablished practices whereby farmers participate actively and effectively in the organization and management of large-scale irrigation projects (LENTON 1986:58). Furthermore, evidence from many African countries such as Algeria, Tanzania, Kenya, Zambia, Senegal, Ivory coast, Nigeria (BLUNT and JONES 1992:167), Zimbabwe, Mali, The Gambia, and Cameroon (FAO 1994:37) suggests that the redistribution of power in organizations can lead to higher levels of effectiveness and improved quality of working life ${ }^{61}$.

For these and other reasons some (TANG 1993:20) argues that participation in management is not enough. In addition, farmers have an important role to play in the governance of these systems, ,unless farmers have the freedom to participate in both the governance and

61 For more details on the Africans' case, see for example the more recent studies of FAO in Malawi (1993), Zambia (1994), Zimbabwe (1994), and Tanzania (1994). 
management processes of their irrigation system, they will have little incentive to participate in collective efforts in operation and maintenance".

Finally, one is able to say that the literature on development has seldom known agreement among the development specialist, especially since the last decade, on specific theme like this concerning the importance of Participation. The extensive evaluation process for the development projects in developing countries that have been conducted in the 1980s by the development experts and donor organizations were, of course, behind this remark. To this extent some commentators (OAKLEY 1991) consider that we are currently, in terms of thinking and practice about development, in the age of participation.

\subsubsection{Participation of Water Users in Irrigation Management}

OAKLEY (1991) has followed the process of development that have been attempted to find solutions for the poverty in some of the developing countries for the past 30 years. The literature that has accompanied this search, he argued, reflects the periodic emergence of new strategies that have greatly influenced thinking and practice. He asserts that the disenchantment with the past major development strategies (for example Community Development, Integrated Rural Development, and Basic Needs) in the mid-1970s, led to the emergence of 'participation' as a major new force in development thinking. Participation here is considered hence as a ,critical element in tackling the problems of the poor in the third world." Therefore, because of the importance of the agency-managed irrigation schemes in solving such problems, and the vital role of participation in the success of these projects, one has to give more attention to this factor. The field study, as will be presented in Chapter 6, was concerned with analyzing the degree of formal participation and the concert content of it in the irrigation bureaucracies as well as the farmers' organizations.

Despite the widespread recognition of the participation's importance in attaining development, there is no agreement among development specialists concerning the nature of development participation. In this connection, WEITZ (1986:159), argues that: „since social factors have been so neglected in the study of development, there is little theory to guide policymakers in securing development participation among the masses." He asserts here what COHEN/UPHOFF have pointed out earlier: „Unfortunately, there is little systematic knowledge to draw on in the social sciences concerning development participation. Indeed, there is even little consensus on what constitutes political participation, despite much more work and writing on that subject".

In reviewing the available literature, it is valid to say that the term 'participation' in development literature, has been used to refer to many meanings. It embraces a broad set of attitudes, behaviour patterns, and activities. Because the task (defining participation) is not easy, many researchers and writers talk about participation without defining the concept and use it, more or less consciously, in different senses (SZELL 1992:603).

From a sociological standpoint, participation as defined by MÜLLER (1979:58) is the „taking part in interactions within social groups or societies.“ From a political standpoint it means ,taking a hand in the process of political consultation and decision-making”. Social and political participation, he argues, overflow in each other. They look, at all events, like two analytical views of the same action: ,soziale und politische Partizipation fliessen ineinander über, sind darum allenfalls als zwei analytische Betrachtungsweisen der 
gleichen Aktion anzusehen, ${ }^{62}$. He refers also to the two dimensions of participation that have been distinguished by the political scientists to simplify the analytical purposes, namely the quantitative and the qualitative dimensions. The first, which is stronger in the literature, grasp only the statistical aspect and the degree of formal participation, while the second grasp the dynamic aspect, that means, the concrete content of participation. The qualitative dimension, as MÜLLER argues, make the democratic trends clear and show also their institutional bounds. It is, on the other hand, not an easy task to evaluate the outcome of this dimension in particular and the participation in general.

The indicators of these two important dimensions have been counted and analyzed by OAKLEY (1991:248-9). As example for the quantitative indicators he ranked:

- Economic indicators: who is participating in the project's benefits; an analysis of those sections of the rural population who have directly benefited and a quantitative assessment of this benefit on their future ability to sustain the level of activities. Applying in irrigation systems these indicators could be through the analysis of the section of water users who benefited from the position of their farms on the watercourse or their position on the community (see Chapter 6, Section 6.4.5).

- Organizational indicators: number of participants, attendance of meetings ...etc. In the case studies discussed in Chapter 6 (6.5.2), for example, these indicators are the number of tenants' representatives in the Scheme Administration and the frequency of the joint meetings between the representatives of the tenants and the different levels of the field staff.

- Participation in project activities.

- Development momentum: number of project members aware of and in contact with development agencies' services. Number of project members who receive some kind of formal training from the project. Number of links established with similar project groups.

The other dimension, the qualitative, involves the quality of the participation or the human and behavioural aspects of the process of participation. It is refered to sometimes as the missing dimension. The qualitative indicators of a process of participation are directly related to the rural people involved in the project, and particularly to the change that occur in the nature, growth and behaviour of the project 'group' as a result of the project activities. OAKLEY (1991:250) has tempted to follow the particular factors, phenomena or features which would authentically represent the qualitative process of participation and suggested three broad areas of qualitative indicators ${ }^{63}$ :

- Organizational growth: internal structuring of project group; allocation of specific roles to group members; emerging leadership structures; formalization of group structure.

- Group behavior: changing nature of involvement of project group members; emerging sense of collective and solidarity; involvement in group discussions and decisions.

62 For a fuller discussion of the political context and its influence upon a process of participation see UNDP: Report on an International Seminar on Popular Participation, Ljubljana, Yugoslavia (New York, 1982).

63 For a more detailed discussion see OAKLEY (1985),, A manual for the monitoring and evaluation of the PPP. Rome, FAO.“ 
- Group self-reliance: increasing ability of project group to propose and to consider courses of action; changing relationship of group with project staff group facilitator; independent action undertaken by the group. The next and more difficult task after listing these indicator, as OAKLEY argued, is to determine how these indicators might be observed and recorded.

Within the framework of practice, one can distinguish between different kinds of participation. The criteria here are how participation might be considered, the extent to which it is practiced, and the group that undertakes the decision-making process. Whether participation is simply another management device designed to elicit greater productivity or whether it is a genuine attempt both to humanize work and to improve organizational effectiveness, PATEMAN (1970) refers to three kinds of participation; pseudo, full and partial participation ( BLUNT/JONES 1992:168):

Pseudo participation: describe situations in which workers are offered full explanations of decisions already made by management.

Full participation: existing only in circumstances where each member of an organization, or decision making body within it, has equal power to determine the outcome of deliberations associated with the decisions in question.

Partial participation: occurs where there is mutual exchange of information and influence between two parties before a decision is taken, but the right to decide finally resides in one group alone ( usually management ).

Through the different meanings of participation, HAGE/FINSTERBUSCH (1987:279) have used this which means participation in decision making. This type of participation, they argued, has been found to be very effective in helping organizations change. It is, however, not desirable in all forms of organizations. In other words, the value of participation depends upon certain contingencies and related to a given situation. In mechanical organizations, which depend on routines or assembly lines to coordinate specialized tasks and on centralized decision-making to direct the large organization, participation, decentralization, and democracy are disfunctional. On the other hand, the lack of participation in organic organizations would be fatal. HAGE/FINSTERBUSCH have pointed out situations that reveal places where participation, within and outside organization as well, is especially effective. Within organization:

- Whenever the tasks are complex, as in organic forms, power should be decentralized. Research is the most common example.

- Participation by terms in decision making is necessary to make them effective either as task group or as quality work circles. Over the long term this means some implicit sharing of power but not necessarily decentralization of the power structure.

Outside the organizations, there are also several situations where participation can have an important impact:

- For voluntary associations to be effective, it is necessary for them to rely upon widespread participation among their membership. While organizations can be both centralized and effective, voluntary associations can not (see the case of Tenant Farmers Union TFU Chapter 6.5.2). 
- For collaborative relationships between a national service organization and voluntary associations to be effective, it is necessary that there be genuine participation between them. In other words, the service organization must accept the recommendations of the voluntary associations and vice-versa.

- For effective linkages between independent agencies to achieve integrated development, it is necessary to have participation between them, that is, each organization accepts the recommendations of the others. Collaboration is essential to effective relationships and accepting recommendations is essential to collaboration. The absence of such linkages and collaboration has resulted in the failure of many irrigation systems (Chapter 6.5.3).

In view of discussing the arguments for participation in development, UPHOFF (1986) refers to substantive ones as an essential ingredient in development projects. He suggests a number of reasons, for example, why government might gain some net benefit from promoting participation (OAKLEY $1991: 15-18$ ):

- More accurate and representative information about the needs, priorities and capabilities of local people; more reliable feedback on the impact of government initiatives and programs;

- adoption of programs to meet local conditions so that scarce resources can be employed more efficiently;

- lower costs of access to the public for agricultural extension programs, nutrition education, immunization, etc. through local organizations and institutions;

- improved utilization and maintenance of government facilities and services;

- cooperation in new programs, which is more likely to occur when local organizations having the confidence of rural people share responsibility for the innovation.

In addition OAKLEY add the following arguments:

- Efficiency: Participation infers a greater chance that resources available to development will be used more efficiently;

- Effectiveness: Participation allows the rural people to have a voice in determining objectives, support project administration and make their local knowledge, skills and resources available which must result in more effective projects;

- Self-reliance: Participation helps to break the mentality of dependence which characterizes much development work and, as a result, promotes self-awareness and confidence and causes rural people to examine their problems and to think positively about solutions ${ }^{64}$;

- Sustainability: on a more general level, sustainability refers to continuity and see participation as fundamental to developing a self-sustaining momentum of development in a particular area.

64 MASLOW (1954) distinguishes five types of the needs: 1- physiological needs; 2- needs of security; 3needs of belong to someone; 4- needs of recognition and finally; 5- needs of self-realization. According to this concept, these five types of needs are hierarchically built upon each other in such away that people are interested in and motivated to satisfy their needs of higher order only when their needs of lower order have already been satisfied. Naturally this hierarchy is not rigid: the dividing-line where the turn towards the needs of higher order begins, is obviously not at the point where the needs of lower order were fully met. It is necessary to reckon also with the fact that the dividing lines between the types of needs are flexible and also a substitution process might take place (HETHY 1988:73). 
SZELL (1992:605), in this connection, add two important advantages:

- Participation offers the possibility of solving, through individual and/or collective bargaining, the contradictory interests of the different target groups in organization. This is considered the main social and organizational utility of participation;

- It helps to fight against what CROZIER has called „the bureaucratic phenomenon“ (1964) or ,the blocked society“ (1970) by democratization of decisions, humanization of interpersonal relations, and negotiating what some scholars would call today ,all-win“" solutions.

Moreover, some have suggested that the development approach must be turned around to see its impetus coming from below and not always directed from above. Another line of argument suggests that rural people are not ignorant, idle or apathetic, on the contrary, are resourceful and hard working. Finally, there is the argument that rural people should actively participate in development in order for them to contribute a countervailing force to those elite groups who inevitably dominate development resources and activities. People's participation is then a necessary counteracting force that should at least halt, if not reverse, the progression of the dependence, inequality, and centralization that seek the dominant forces to maintain in many third world countries(OAKLEY 1991:16). Since 1979 the UNRISD inquiry has laid particular emphasis upon this dimension of participation.

IFAD's experiences with irrigation suggests that participation is particularly critical in terms of sharing the costs of irrigation operation and maintenance. Others (PATIL, 1987), in addition, see the advantages in efficiency terms, particularly with regard to procedures and control of water distribution. Participation is for the most an important factor to facilitate the irrigation management and therefore to increase the irrigation performance. Farmer participation, as CHAMBERS (1985) has argued: 
„,may be defined as an approach (by irrigation agencies) to increase irrigation performance by providing effective incentives and conditions that enable farmers, both individually and collectively, to accept and fulfill irrigation management responsibilities where and when appropriate" (LENTON 1986 : 58).

UPHOFF (1986) suggests that when this commitment to participation in irrigation schemes is put into practice, it appears to have three main elements:

- first, participation in the structures that develop the scheme; this includes participation in the design, construction, operation and maintenance of the actual irrigation system;

- second, participation in the structures of water use within the system; the acquisition of the water; its allocation between participants; its distribution on an agreed basis and the tackling of any drainage problems; and

- third, participation in the organization of effort; vital for the day-to-day functioning of the scheme, such as decision making and local resources mobilization.

He also suggested that farmer's participation in irrigation management is directly linked to the quantity of water available. In extremes of both drought and excess water, farmers' participation is less necessary; however, when just enough water is available and its distribution becomes a careful balance between conflicting demands, then farmers' participation reaches its peak.

The most common participatory characteristic of irrigation schemes is the Water Users' Association (WUA), or other similar form of organization, which is the basic means whereby participants can become involved and carry out management functions. These Associations are also in view of their terms of reference, comparable with services cooperatives. They do management functions to support their members. These functions, very often, are not limited to operation and maintenance of the irrigation system, they include as well complementary ones like supplying the water-users with agricultural production means, arranging marketing and processing of agricultural products (KNOTH 1989:253). These kind of organizations, that have a cooperative framework, according to the experience of WEITZ (1986:163), offer the best means to help peasants become farmers:

"they make production more efficient; they expand the opportunities to acquire new technology and equipment that is too costly for the individual farmer to obtain himself; and they serve to transform a community of small-scale farmer into a significant economic bloc for dealing with suppliers and markets".

On the critical point of view, it remains to explain that participation is complex matter because of the complexity of involved interests, but also because it is the source of new contradictions between social actors. It is also a field full of paradoxes: ,the wishes of riskless participation (but participation is always risky), the dream of participation for oneself not for the other, the participation desired and feared, participation as a costly gift, (SZELL 1992: 609). Experience reveals that participation, which by many is conceived of as a means of fighting what has been called „the bureaucratic phenomenon“, very often becomes the source of new bureaucratic procedures or structures. Furthermore, in many cases, participation is more evident as an emotional commitment than a practical aspect of 
the project. It can be, as UPHOFF (1986), and KÖTTER (1988) have rightly argued: „more illusory than real“" or „more or less tokenism and lip-service.“"

When that happens people become frustrated and the idea of participation quickly loses its psycho-social support. This will be the case as long as the irrigation schemes are invariably staffed by professionals whose qualifications reflect the dominant physical activities and few maintenance of permanent cadre of social scientists. Participation as SZELL pointed out responds to people's needs but needs people's support. To be successful, it requires mature individuals with psychological, social, and strategic capacities ${ }^{65}$.

${ }^{65}$ In the context of the debate between academics and practitioners in the field see the succinct review of many case studies in the practice of participation in the three main continental areas of the third world which show how a number of projects, across the sectors, have tried to implement a process of participation and how this participation evolved methodologically (OAKLEY (ed.) in OAKLEY et al. 1991: 59-157): Ghana: The People's Participation Program (PPP) as a basic strategy of rural development which was launched by the FAO in 1980. Tanzania: four main elements; group formation and paraprofessionals; the use of outside agents; changes in old procedures and the establishment of new ones; and training. Lesotho: the involvement of peoples in soil conservation works. Philippines: Grass Roots Participation. Nepal: Forestry and Participation. Bangladesh: the Conscientisation Process to develop local organizations. Mexico: the importance of participation by beneficiaries; PIDER (Programa Integral Para el Desarrollo). Peru: Flora Tristan and Women's Participation. Bolivia: community involvement in health development. 


\section{Organizational Approaches and Strategies for Improving the Performance of Irrigation Systems}

\subsection{Institutional Changes as a New Development Strategy}

The importance of institutions in the economic analysis is not a novel idea. Many economists have recognized this, and institutional economists have been stressing the need to place institutions at the center of economic analysis for some time, and their analysis has generated a wealth of insights (PAPANDREOU 1994:3). In his discussions of the role of institutions, history, and theory on the development process, STIGLITZ (1989:26-7) argued that institutions have an impact on how developing economies perform; although, he argued, it should be attempt to pierce the institutional 'veil', to see beyond the forms to the real substance of economic transactions. And even after doing this the institutions have a life of their own. At the same time, he clearly pointed out, institutions should not simply be taken as given; they need to be explained. He further asserts the role of the history by saying that the fact that some institution serves an economic function does not mean that it is, in any sense, 'optimal', and that historical forces do not play an important role in understanding why we have certain institutions, and not others, or why those institutions take on the particular form that they do. We will see how the different schools have based on the historical factors to interpret the process of institutional change.

On the other hand, a rigorous analysis of the economic rational of the formation of the institution itself has been very rare ${ }^{66}$. In spite of some methodological resistance on the part of many institutionalists to endogenize institutions in economic term, it is, however, possible to point out that in the long- run historical-evolutionary process economic factors do play an important role in the shaping of institutions (BARDHAN 1989:3). This, of course, without denying that some exogenous irreducible rules and conventions must be presupposed in any economic analysis, or without ignoring the two-way feedback processes between economic and other historical-cultural factors.

\subsubsection{The Process of Institutional Change: Why do Institutions Change?}

JAMIESON (1987) argued that one view of development was of human evolution as problem-solving under pressure, as adaptive change. Change, he said, had accelerated and unpredictability had increased, making accurate and timely feedback more than ever vital for effective adaptive change. At the empirical level, changes in local and global conditions - ecological, social and political - appear to be accelerating. In matters more even than before to have timely feedback, prompt learning and rapid adaptive responses (CHAMBERS 1992b:64-5).

BERNSTEIN deals with the question of institutional problems in his discussion about institutional birth control. He refereed to whether the solution of problems lay in the development of new institutions, or whether there may not already be enough institutions of some kinds, and that perhaps we should turn our attention to emphasizing quality building within existing institutions (POTTER 1972:152). Resource enhancement, however, is on its own not enough as solution to institutional deficiencies. It is normally a short-term solution and should perfectly be supported by more basic institutional change or upgrading. Changes in or upgrading of policies, strategies, structures, administrative and management systems,

\footnotetext{
${ }^{66}$ See EGGERTSSON (1990), and PAPANDREOU (1994).
} 
are far more difficult to achieve, require strong institutional support and commitment, and consequently a more extended time frame. On the other hand, they have a more lasting and permanent impact on institutional efficiency and effectiveness (WALKER / CLEVERINAGA 1989:M.VI.4/1).

Institutional change ${ }^{67}$ in societies means principle changes in the figuration of the regulative and organizational principles and behavior and interaction patterns. The direction the change takes is usually towards an increasing differentiation in formerly general principles and patterns in specialized institutions that are interrelated, while at the same time there is an increasing necessity for integration in complex social systems. Differentiation means extending the chain of interdependencies that demand integration. Differentiation and integration are, thereby, complementary processes (MANIG 1992:79).

Institutional change in traditional social structures is caused by the multifarious influences of external modernization factors and the increase in internal tensions. Such factors result in breaking up of the traditional production and exchange systems and the political structure as well as changing the institutional regulating mechanisms governing the relations of the people among themselves and to the resource utilization ${ }^{68}$. Of the important factors that in the long run induce institutional change are the following (MANIG 1991:16):

- population growth,

- increased expectations among the population,

- changes in the demands,

- commercialization tendencies,

- technological change,

- government policy, and

- an increased in the endogenous social tensions as a result of the effects of the abovementioned factors.

Institutional change is a continual process through its feedback mechanism and resulting in increasing the complexity of the society. It is an adjustment process and, therefore, a part of development. The purpose of the institutional change as MANIG (1991:16-17) argued is: ,to internalize the greater productivity of the resource utilization while creating new equilibrium, which - on the other hand - are the basis for new change processes, etc. The trend in institutional change takes place in the direction of the division of certain functions from the old institutions and the creation of specialized institutions which necessitate integration in subordinate social systems. The complexity of the society increases“. "Thus, institutional changes have to be understood as adjustment to changed conditions and as permanent social transformation processes, as well as immanent components of development".

Institutional change entails social costs and requires time. The above mentioned factors, can lead to an increase in the social disparities such as polarization, stratification, and poverty, which then induce institutional change in the long run. Institutional change can be seen, therefore, as the result of the struggle between various groups that want a better share in the utilization of the resources and income distribution and those who try to hinder just that (MANIG 1992:10).

\footnotetext{
${ }^{67}$ We rely here heavily on MANIG: 1989:33-7; 1991:13-9; 1992:6-11.

${ }^{68}$ A transformation from 'inward-orientation' to 'outward-orientation' is an example of such change.
} 
In this respect, we begin by reviewing, briefly, the major schools of thought on the subject and then attempt to emphasize those factors that are determinant in the Sudan.

The Marxian theory is a well-known endogenous theory of institution. The central driving force behind institutions in this theory is the forces of production. Changing in these forces, particularly technological change, produce over time some tension between the existing structure of property rights and the productive potential of the economy, and it is through class struggle that this tension is resolved in history, with the emergence of new institutions. The nature of this tension, and the interaction between institutions and the utilization and development of the forces of production, have been studied with much greater rigor and micro-analytic in two strands of recent non-Walrasian economic literature (BARDHAN 1989:4) ${ }^{69}$. One strand is the neo-classical writers on property rights and transaction costs, refers to by Bardhan as (CDAWN) school (Coase-Demsetz-AlchianWilliamson-North). These writers developed a well articulated endogenous theory of institutions and traced changes in economic history to changes in the institutional ground rules. The other strand grew out of the theory of imperfect information (Akerlof-Stiglitz). It provides framework for analyzing institutions as substitutes for missing markets in an environment which, in some respect, similar to that in developing countries; pervasive risks, incomplete markets, information asymmetry, and moral hazard. That is why, argued Bardhan, it has to be seen in the recent literature in developing countries a number of attempts to model institutions, especially in agriculture, on these lines.

All three of these approaches to the endogenous theory of institutions- of the Marxist, CDAWN, and imperfect information schools - have, as BARDHAN pointed out, some broad similarities which may be not quite clear in all sides.

\subsubsection{Theory of Institutional Innovation}

RUTTAN/HAYAMI (1984) draw upon some of the ideas of the first two schools in building their theory of institutional innovation in which they treat institutional innovation as endogenous. Based on a concept of institution include that of organization, and consistent with the definition used by COMMONS (1950), the term institutional innovation, or institutional development, in this analysis as RUTTAN elsewhere illustrated ${ }^{70}$ refers to a change (1) in the behavior of a particular organization, (2) in the relationship between such an organization and its environment, or (3) in the rules that govern behavior and relationships in an organization's environment.

The authors who have effective participation in understanding the processes that enable a society to generate a continuous stream of institutional innovations in response to technical and economic opportunities or constraints, used here the same analytical tools that have been successfully used in the interpretation of the theory of induced technical change. The role of technical and institutional change in the economic growth and the relationship between them can not be seen through unidimentional perspective.

Though the dialectical relationship between changes in modes of production (technical change) and changes in production relationships, stressed in the Marxian historical perspective, Marx believed the former provided the more dynamic source of change in

\footnotetext{
${ }^{69}$ The Walrasian general equilibrium models are based on the assumption of zero transaction costs.

70 RUTTAN 1978, p.329
} 
social organization. Thereby, historians working within the Marxist tradition often tend to view technical change as dominating both institutional and cultural change. WITTFOGEL (1957), for example, views the irrigation technology used in wet rice cultivation in East Asia as determining political organization (RUTTAN/HAYAMI 1984:217) ${ }^{71}$. As well as technological determinism has been a dominant theme in the work of the American institutional school. It was the dialectical struggle and conflict between dynamic technology and static institutionalism which caused economic and political institution to undergo historical change and adjustment, according to Veblen's view. A similar tendency has been also registered in the literature of sociology and anthropology (RUTTAN 1978:330-1). In addition, institutional innovation has been viewed in the field of development economies (SCHULTZ 1964; HAYAMI and RUTTAN 1971) - where the primary emphasize is on the size of the income stream generated by technical change - as a lagged response to the rising economic value of man and the growth of productivity. Also the institutionalists, the old and the new, while they differ sharply on the welfare implications of technical change, both seem to share a view of technical change as the product of an autonomous inner logic of scientific discovery and technical innovation.

The other extreme line of though is represented in POLANYI, 1957; NORTH and THOMAS, 1970, 1973; CHANDLER, 1972. The Polanyi's analysis of the sources of the industrial revolution maintains that institutional rather than technical change is the dynamic source of economic development. NORTH and THOMAS in their pioneering attempt to explain economic growth in terms attribute the major sources of western economic growth to changes, brought about by the pressure of population against increasingly scarce resource endowments, in the institutions whose rules govern property rights. They attempt to demonstrate that technical innovation and productivity growth represent a lagged response both to institutional changes induced by long-run changes in relative factor and product prices and to changes in the size of the market. Growth according to NORTH and THOMAS can occur only if the economic organization is efficient. They repeatedly emphasize their commitment to the view that institutional change precedes, and is more fundamental than, technical change. Moreover, they emphasize that an expanding market economy constitutes to rising per capita income even in the absence of technical change. Working on a less cosmic scale, CHANDLER views that the economies of scale in American industry are far more a product of institutional innovation than a product of technical change (RUTTAN 1978:332-3).

Finally, arguments over the relative priority of technical or institutional change are generally unproductive. Technical and institutional change as DE JANVRY, et al. (1989) argues, are highly interdependent and therefore must be analyzed within a context of continuing interaction.

71 A serious 'misunderstanding', as the authors refereed to, can be observed in contemporary neo-Marxian critiques of the 'green revolution'. These criticisms have focused attention almost entirely on the impact of technical change on labor and land tenure relations. 
Both the theory and the experience of agricultural development in western and nonwestern economies have shown that the rate and direction of technical change are responsive to the rate of growth in demand and to relative resource endowments. In addition, the transfer of technology among regions and countries is responsive to essentially the same autonomous processes that induce the evolution of technical change from new knowledge. In this context, RUTTAN (1978:327) points out: „The demonstration that technical change can be treated as endogenous to the development process does not imply that the progress of either agricultural or industrial technology can be left to an 'invisible hand' that directs technology along an 'efficient' path determined by 'original' resource endowments or by the growth of demand. The production of the new knowledge that leads to technical change is the result of a process of institutional development. And technical change, in turn, represents a powerful source of demand for institutional change".

The theory of induced technical change gaves rise, therefore, to the need for a more careful consideration of the sources of institutional innovation and design. And this is what RUTTAN and HAYAMI (1984, 1985) have elaborated. In the theory of induced institutional innovation, shifts in the demand for institutional innovation are induced by changes in relative resource endowments and by technical change. In addition, advances in social science knowledge and culture endowment are considered as factors influences the supply of institutional change.

In the demand side, in addition to the similarity with the Marxian view, concerning the role of technical change, the authors share also with DAVIS and NORTH (1971) the view that basic institutions such as property rights and markets are more typically altered through the cumulation of 'secondary' or incremental institutional changes such as modifications in contractual relations or shifts in the boundaries between market and non-market activities (RUTTAN/HAYAMI 1984:205) ${ }^{72}$. This view is reinforced through experiences from the agricultural history of a number of countries that have showed that changes in factor endowments, technical change, and growth in product demand have induced change in property rights and contractual arrangements in order to promote more efficient resource allocation through the market. Institutional change in this context was directed toward the establishment of a new equilibrium in factor markets.

Institutional changes of this type are profitable for society only if the costs involved in the assignment and protection of rights are smaller than the gains from better resource allocation. If those costs are very high (the use of communal land), it may be necessary to design non-market institutions, in order to achieve more efficient resource allocation. In addition, RUTTAN and HAYAMI (1984:211) argued that group action to supply public goods may work effectively if the size of group involved is small. In the other case, where a large number of people are involved in the use of a public good, it is more difficult to regulate their resource use. In this case, action by a higher authority with coercive power, such as a government, may be required. As example for such public goods the authors discussed the 'socialization' of agricultural research. New information or knowledge resulting from research is typically endowed with the attributes of a public good characterized by non-rivalness or jointness in supply and utilization, and non-excludability or external economies. The public-good attributes of the agricultural research product

72 NORTH in his neoclassical property rights theory of history seem to have integrated a significant part of Marxist ideas (BARDHAN 1989). A major limitation of the Marxian model according to NORTH (1981) is the emphatic rejection of a causal link between demographic change and technical and institutional change (RUTTAN/HAYAMI 1984:220). 
together with the stochastic nature of the research production function make public support of agricultural research socially desirable. A socially optimal level of supply of such a good cannot be expected if its supply is left to private firms. In such a case, the result would be serious bias in the allocation of research resources ${ }^{73}$.

To note here is the role of the new income streams released by technical change. It represents a powerful motivation for private-sector research and development and for public-sector investment in the exploration of natural resources and the development of science and technology. In addition, the portioning of the new income streams that result from the efficiency gains associated with technical change or improvements in institutional performance represents a major incentive for further institutional change. Moreover, advances in technology can be expected to set in motion attempts by individuals to reallocate their personal resources and to organize and initiate collective action for the purpose of redefining property rights so as to achieve greater equity in the portioning of the new income streams (RUTTAN 1978:337). ${ }^{74}$ Likewise, advances in institutional efficiency that are associated with the rise of the corporate form of organization give rise to growth dividends that induce a demand for the corporate organization of labor, in the form of unions, and of farmers, in the form of cooperatives, so that each group may participate more effectively in the partitioning of the new income streams ${ }^{75}$.

Change in factor prices plays a role in the NORTH-THOMAS and SCHULTZ models of induced institutional change that is quite similar to the role it plays in the model of induced technical change. However RUTTAN (1978:338) argued that neither NORTH and THOMAS nor SCHULTZ attempt to provide a theory of the supply of institutional change. Furthermore, he pointed out: „we find little help in either the older institutional literature or the newer, neo-institutional literature". It looks like as if the analysis of the demand factors for these schools was the determinant and enough to explain the institutional change and/or as if the supply factors will - as a matter of course - follow the demand in the same direction. Anyway, there is an analogy between the supply of institutional change and the supply of technical change. The supply curve shifts to the right as a result of advances in knowledge in the social science and related professions such as business, planning, law, and social services. Moreover, such advances reduce the cost of institutional change just as advances in knowledge in the natural sciences and engineering reduce the cost of technical change. Institutional change also do not wait for research but may occur as a result of exercise of innovative effort by politicians, bureaucrats, entrepreneurs, and others as they conduct their daily activities. The timing or pace of institutional innovation may be influenced by external contact or internal stress.

73 Resources would flow primarily to those areas of mechanical technology that are adequately protected by patents and to those areas of biological technology where the results can be protected by trade secrets. Other areas, such as research on open pollinated seed varieties, biological control of insects and pathogens, and improvements in farming practices and management, would be neglected.

74 The author refers to SCHULTZ' discussion (1975) about the individual responses to disequilibrea and used the following quotation: ,the ability to deal with economic disequilibria is enhanced by education, and this ability is one of the major benefits to people privately in a modernizing economy“.

75 An early and vivid examination of the role of institutions, or of collective action, in the reallocation of the ownership of material and human resources and on the associated changes in the distribution of income in the process of economic growth, which dominate the COMMONS' work, is K. H. PARSONS: ,John R. Commons’ Point of View,“ Journal of Land and Public Utility Economics 17 (August 1942). 
The model of RUTTAN/HAYAMI (1984:213-4) envisage political entrepreneurs as protectors of institutions, as well as instigators of institutional change. They hypothesize that institutional innovation will be supplied if the expected return from the innovation that accrues to the political entrepreneurs exceeds the marginal cost of mobilizing the resources necessary to introduce the innovation. Thus the supply of institutional innovation depends critically on the power structure or balance among vested interest groups in a society. That means, if the institutional innovation is expected to result in a less to a dominant political bloc, the innovation may be forthcoming even if it is expected to produce a large net gain to society as a whole. And socially undesirable institutional innovation may occur if the returns to the entrepreneur or the interest group exceed the gains to society.

The other crucial issue to address is the Cultural endowments, including religion and ideology, which exert a vital influence on the supply of institutional innovation. They make some forms of institutional change less costly to establish and impose severe costs on others. The traditional patterns of cooperation in the Japanese village community, for example, have represented an important cultural resource on which to erect modern forms of cooperative marketing and joint farming activities. In other cultural resources, as in South Asian villages, the caste structure inhibits cooperation and encourages specialization. Likewise, religion as it has been understood and practiced by the elite, and therefore by the mass, in rural Sudan, inhibits institutional innovation in form of real participation and democracy $^{76}$.

NORTH (1981) has argued that modifications of social values - that is, changing ideologies - are a major factor in institutional change, and the so called New Institutional Economics (NIE) is incomplete without a theory of ideology (EGGERTSSON 1990:75) ${ }^{77}$. The aspiration of new ideology may reduce the cost to political entrepreneurs of mobilizing collective action for institutional change. Egypt during the 'Nasserist' era (specially during 1954-70) can be added to the examples from U.S.A, Japan, and China mentioned by RUTTAN and HAYAMI where ideology was an important factor affecting the supply of institutional change ${ }^{78}$.

RUTTAN and HAYAMI (1984:215) stressed again that institutional change was, throughout the history, generated through the process of trial and error much in the same manner that technical change was generated prior to the invention of the research. And from this fact they maintain that with the institutionalization of research in the social sciences and related professions the process of institutional innovation has begun to proceed much more efficiency; it is becoming increasingly possible to substitute social science knowledge and analytical skill for the more expensive process of learning by trail and error.

76 For example, the case of New Halfa's Farmers Union (see Chapter 6.5.2.4).

77 The successful theory of institutional change require then, as NORTH argues, not only a theory of the state and a theory of demographic change but also a theory of ideological behavior and a theory of technical change.

78 Arabic Nationalism in Naser's Egypt, reflected in slogans such as 'Freedom, Socialism, and Unity', provided ideological support for land ordinances culminating in the Agricultural Reclamation Laws, cultivation of the desert. This era has also witnessed the mobilization of communal resources to improve the industrial base through many projects including the vocational and technical education. This ideology was model for many countries in the Arabic Region and the Sudan (1970-84). 
Research which make us more able to understand the behavior of people in the developing countries is an important example of the contribution of advances in social science knowledge to the design of more efficient institutions. Similarly, the diffusion of education designed to raise the intellectual level of the general public and to facilitate better understanding of the private and social costs of institutional change may reduce the cost to political entrepreneurs of introducing socially desirable institutions and raise the cost of biasing institutional change in a manner that is costly to society.

From the above, RUTTAN/HAYAMI (1984) build a model of four elements that maps the general equilibrium relationships among resource endowments, cultural endowments, technologies and institutions. The model goes beyond the conventional general equilibrium model in which resource endowments, technologies, institutions, and culture are given. One advantage of this model is that it helps to identify areas of ignorance e.g., the capacity to model and test the relationship between cultural endowments and either technical or institutional change is relatively weak. A second advantage of the model is that it is useful in identifying the model components that enter into other attempts to account for secular economic and social change. The unidimensional perspective of the relationships bearing on technical and institutional change is then, according to this analysis, the result of failure to analyze historical change in a general equilibrium context.

\subsubsection{Transaction Cost Theory}

The theory of induced innovations postulates, in its pure neoclassical form, the existence of perfect markets for all products and factors as well as for risk. Prices thus convey all the relevant information to decision-makers and all agents face equal prices. Resources in this case are efficiently allocated irrespective of the personal distribution of assets. It is envisaged, according to HAYAMI and RUTTAN's elaboration of the public role in the resource allocation of the agriculture research, that the technology induced in such institutions for one particular product will be uniquely determined by relative factor prices, the size of the research budget, and the state of scientific knowledge. That means, consequently, no room for collective action to influence the allocation of a research budget towards alternative technological innovations. This view refers to an idealized vision of the world, which abstracts from the pervasiveness of transaction costs (DE JANVRY et al. 1989:361). Taking transaction costs into account, optimum technology becomes conditional on the distribution of assets and this means the possibility of more than one optimum alternative.

Research in this strand suggests that the cost of contracting and other transaction costs have profound implications for the allocation of resources and the structure of economic organization. It is primarily the addition to the neoclassical framework of positive costs of transacting that distinguishes Neo-institutional Economics (NIE) from traditional microeconomics and changes the agenda for research: The cost of transacting makes the assignment of ownership rights paramount, introduces the question of economic organization, and makes the structure of political institutions a key to the understanding of economic growth (EGGERTSSON 1990:14, ${ }^{79}$. Three areas are mentioned where the NIE attempts to generalize and apply the economic approach (EGGERTSSON 1990:29-30):

79 In many respects, the neo-classical and transaction cost approaches are complements rather than substitutes, addressing somewhat different issues and offering somewhat different ranges of admissible explanations (POLLAK 1985:583). 
First, new constraints have been explicitly added, the most important being the structure of property rights and transaction costs. The economic approach has been used to analyze traditional market exchange; exchange within organizations; and exchange in alternative economic systems. In terms of formal theories, the focus is here on the effects of change in constraints on equilibrium outcomes.

Second, attempts have also been made to explain or endogenize the organization of markets and the structure of contracts. Economic organizations, such as the firm, are modeled as a network of contracts. Competition among organizational forms leads to equilibrium contracts.

Finally, social and political institutions are also seen as outcome of exchange between individual agents. Competition for survival among institutions leads to equilibrium institutions. Neo-institutional economists have just begun to model social and political institutions and attempt to derive testable propositions.

In the historical growth process, there is, as BARDHAN alluded, a trade-off between economies of scale and specialization on the one hand and transaction costs on the other. In a small, closed, face-to-face peasant community, for example, transaction costs are low, but the production costs are high, because specialization and division of labor are severely limited by the extent of market defined by the personalized exchange process of small community. In a large-scale economy, as the network of interdependence widens, the impersonal exchange gives considerable scope for all kinds of opportunistic behavior (cheating, shirking, moral hazard), and the costs of transacting can be high. In western societies over time complex institutional structures have been devised (elaborately defined and effectively enforced property rights, formal contracts and guarantees, cooperate hierarchy, vertical integration, limited liability, bankruptcy laws, and so on) to constrain the participants, to reduce the uncertainty of social interaction - in general, to prevent the transactions from being too costly and thus to allow the productivity gains of larger-scale and improved technology to be realized ${ }^{80}$.

Another issue to address is the impact of technical change on transaction costs. This impact, as EGGERTSSON discuss, is ambiguous. On the one hand, technical change can help to lower transaction costs by introducing, for example, new and effective methods of

80 In point of fact, the variety in definitions of transaction costs as we will see, and the variety of the theoretical contexts through which these definitions apply, have influence on such conclusions. NIEHANS (1987), for example, who understand the transaction costs as the exchange costs of property rights on goods and production factors speaks about the absence of transaction costs in a planned economy and points out: "transaction costs arise from the transfer of ownership or, more generally, of property rights. They are a concomitant of decentralized ownership rights, private property and exchange. In a collectivist economy with completely centralized decision-making they would be absent; administrative costs would take their place“. On the other hand, CHEUNG (1987), who added to the transaction costs those of the internal coordination within organizations, argues that transaction costs in such economies are prohibitive high: ,we therefore conclude that the poor economic performance of a communist state is attribute to the high transaction costs of operating that organization" (citations from LÖCHEL 1995:24). 
measurement, but, on the other hand, technical change is associated with more complex commodities, and hence higher transaction costs. Technical change provides an opportunity to design new structures of economic organization that lower the costs of contracting, but the little systematic empirical evidence that exists suggests that the net effect of technical change has been to increase the cost of transacting in advanced industrial economies.

The dominance of the economic theory in the so called organizational economics (agency theory and transaction costs theory) is a subject of critique from some of the management and organization scholars who do not belong to economics discipline. Their concern is defending the boundaries of an autonomous theory of management and organization which is not subservient to any, more traditional discipline (here economics) and which is prepared to acknowledge positive rather than just negative functions for managers. Furthermore, it has been argued that the growing influence of agency and transaction cost theory presents a number of problems for organization studies:

- There is a problem in the lack of relationship of organizational economics to preexisting traditions of inquiry in management theory.

- There is a problem that organizational economics is a regressive simplification.

- Lastly, there is a problem of the evaluation and ideological coloration of organizational economics.

Proponents of organizational economics, on the other hand, argue that organizational economics has already made an important contribution to our understanding of the nature and purpose of organizations. They go on to forecast that, as a result of organizational economics, the prediction of HIRSHLEIFER (1986) will be realized in the field of organizations, namely that organization theory will become economics, as part of the development that BARNEY (1990) terms 'economic imperialism, 81 .

\subsubsection{Initiation and Definition}

The transaction costs theory derives from COASEs articles $(1937,1960)$ on the firm and on the social cost. COASE has summarized his contribution in these words: ,transaction costs were used in the one case to show that if they are not included in the analysis, the firm has no purpose, while in the other I showed, as I though, that if transaction costs were not introduced into the analysis, for the range of problems considered, the law had no purpose" (EGGERTSSON 1990:xiii).

As many assert, including Coase itself, WILLIAMSON $(1975,1979,1981)$, building on the older institutionalist tradition; on the work of COASE and on the „CARNEGIE tradition“

81 BARNEY and OUCHI (1986) use the term organizational economics to describe theoretical contributions to organization theory from economics. Organizational economics (OE) presents itself as being based upon a powerful, contiguous, established discipline, namely economics. Because of the superiority of the economics approach, the economist HIRSHLEIFER (1986) has predicted the takeover of the whole of social science: „As economics 'imperialistically' employs its tools of analysis over a wider range of social issues. it will become sociology and anthropology and political science. But correspondingly, as these other disciplines grow increasingly rigorous, they will not merely resemble, but will be economics. It is in this sense that 'economics' is taken here as broadly synonymous with 'social science" (DONALDSON 1995:164-5). 
(e.g., SIMON 1957), has been primarily responsible for developing of the transaction cost approach $^{82}$. Other important contributions are those of BARNEY, OUCHI, GOLDBERG, KLEIN, ALCHIAN, and DEMSETZ. In addition, transaction cost, as Williamson hold, combines the insights and arguments of both HAYEK (1945) and BARNARD (1938) that adaptation is the central problem of economic organization. Whereas HAYEK emphasized spontaneous coordination, effected through the price mechanism, BARNARD confined his attention to intentional coordination, effected through hierarchy. The apparent opposition of these two arguments notwithstanding, transaction cost economics avers that adaptations of both kinds are needed in a high performance economy and joins both in a common framework (WILLIAMSON 1993:102). The transaction costs approach was also inspired by the contributions of STIGLER and others to the economics of information ${ }^{83}$.

The transaction costs approach focus on the role of institutions in structuring complex, long-term relationships. It has been primarily concerned with firm and the organization of production. It is as ARROW defined a microanalytic enterprise. It requires that the details of governance structures and transactions be examined at a higher level of resolution than economists had hitherto though to be necessary. The difference between the firm-asproduction function and the firm-as-governance structure, is one illustration. Although the former is the familiar and for many purpose the appropriate construction, there are other purposes for which the firm-as-governance structure is more instructive. Transaction cost economics has been instrumental in bringing about this shift in emphasis (WILLIAMSON 1993:101-2 $)^{84}$. Applied to the family, the transaction cost approach treats the family as a governance structure rather than a preference ordering or a preference ordering augmented by a production technology (POLLAK 1985:584).

A clear-cut definition of transaction costs does not exist. Yet, there are many definitions. NORTH, for example use two of them. On the one hand, transaction costs are the information costs of the exchange of ownership rights to goods and production factors. On the other hand, transaction costs are the costs that are necessary to have the 'gains from trade'. Furthermore, he illustrate the relationships between transaction costs and the division of labor as follows (LÖCHEL 1995:23): „Transaction costs are the costs of specifying and enforcing the contracts that underlie exchange and therefore comprise all the costs of political and economic organization that permit economies to capture the gains from trade". In other definition, applied by WILLIAMSON, transaction costs are

82 Commenting on the role of Williamson, who acknowledges Coase as the originator of transaction cost theory, the latter argued: „My discussion with researches in this field has made it clear to me the Williamson's influence has been immense. In a real sense, transaction cost economics, through his writing and teaching, is his creation, (COASE 1993:98).

83 WILLIAMSON acknowledges also the contribution of STIGLER and pointed out: (1) SIMON (1957) had already covered many of the pertinent issues and, prior to STIGLER (1968), stressed the importance of information for the economic man. (2) the search for information is crucial to the theories of rational choice developed by both Stigler and Simon. (3) transaction cost economics is especially indebted to a strand of information economics, namely that originated by ARROW. (4) Arrow's microanalytic concerns with information (the 'fundamental paradox' of information; information asymmetry; appropriability; and the distinction between hidden action and hidden information), as well as related concerns about tacit information examined by POLANI (1962), are more central to transaction cost economics than are search costs (WILIAMSON 1993:110-112).

84 KREPS (1990) succinctly distinguishes between the neoclassical and transaction cost economics conception of the firm as follows: „The firm is like individual agents in textbook economics. Agents have utility functions, firms have a profit motive; agents have consumption sets, firms have production possibility sets. But in transaction cost economics, firms are more like markets - both (firm and market) are (governance structures) within which individuals can transact" (WILLIAMSON 1993:102). 
characterized as the costs of economic contracts. Unlike North and Williamson, ARROW choose more fundamental and very broad working definition. He sees transaction costs as the costs of running the economic system. Other very common definitions are those of COASE and DEMETZ. Coase speaks about the costs of price mechanism while Demsetz understand the transaction costs as the internalization costs of external effects (LÖCHEL 1995:23-4).

In general terms, transaction costs are the costs that arise when individuals exchange ownership rights to economic assets and enforce their exclusive rights. They are not the 'exchange of commodities' but, as defined by COMMONS, the alienation and the acquisition, between individuals, of the rights of property (LÖCHEL 1995:25). These costs are seen, in addition, in terms of both resources and time, of market and nonmarket transactions (RUTTAN 1978:344). The fundamental idea of transaction costs, according to the definition offered by MATTHEWS (1986), is that they consist of the costs of arranging a contract ex ante and monitoring and enforcing it ex post, as opposed to production costs, which are the costs of executing a contract. The distinction between transaction costs and production costs, according to $\mathrm{ARROW}$, is that the former can be varied by a change in the mode of resource allocation, while the latter depends only on the technology and tastes, and would be the same in all economic systems. In another definition (DAHLMAN 1979), transaction costs are opportunity costs, just like other costs in economic theory, and there are both fixed and variable transaction costs (EGGERTSSON 1990:14) ${ }^{85}$. On the other hand, some (PAPANDREOU 1994:254) use the term organizational costs interchangeably with transaction costs.

Transaction costs refer to a number of costs not typically considered in the neoclassical concept of production costs with atomistic agents, markets prices, and zero cost of marketclearing. They include those costs of information, negotiation, monitoring, supervising, coordination, and enforcement of contracts (DE JANVRY et al. 1989:362; BARDHAN 1989:5). Transaction costs economics asserts that they are significant determinates of the organization of production. And according to this School, transaction costs, and institutions that evolve to minimize these costs, are the key to the performance of economies.

The tardy introduction of transaction costs into economic theory is related to the fact that, until recently, most economic theories and models assumed full information, and transaction costs are in one way or another associated with the cost of acquiring information about exchange. Information costs constitute an important part of transaction costs but the two concepts are not identical. When information is costly, various activities related to the exchange of property rights between individuals give rise to transaction costs. Such activities, which are listed above, illustrated by (EGGERTSSON 1990:15) as follows:

1. The search for information about the distribution of price and quality of commodities and labor inputs, and the search for potential buyers and sellers and for relevant information about their behavior and circumstances.

85 For various definitions of transaction costs, see DAHLMAN (1979) and LÖCHEL (1995). 
2. The bargaining that is needed to find the true position of buyers and sellers when prices are endogenous.

3. The making of contracts.

4. The monitoring of contractual partners to see whether they abide by the terms of the contract.

5. The enforcement of a contract and the collection of damages when partners fail to observe their contractual obligations.

6. The protection of property rights against third-party encroachment - for example, protection against pirates or even against the government in the case of illegitimate trade.

M-form corporation and vertical integration are two concepts through which transaction costs approach solve the problems of market failure. Transaction cost theory holds that market failure occurs such that the normal economic pressure on economic actors to perform effectively breaks down and has to be replaced by hierarchical controls. In the large corporation with a multi-level hierarchy, middle managers enjoy a degree of independence from top management and begin to subordinate the corporate goals of the maximization of profit and shareholder wealth in favor of their personal selfaggrandizement. The solution is to increase control on middle managers by holding them directly accountable for the profitability of their division as assessed by an investigator control staff of head-office accountants and the like, that is, the M-form corporation.

Market failure can, again, occur in transactions where a supplier to a firm makes asset investments specific to that transaction, therefore transforming the exchange into bilateral monopoly away from market-determined prices. Haggling over price is liable to ensure and the avoidance of such transaction costs is attained by resource to administration of both transacting parties through a common hierarchy. This is achieved by the merger of the two firms through vertical integration; thus the duplicity and untrustworthiness of the managers in the two firms is resolved by placing a common boss over them (DONALDSON 1995:165-6). Note, in addition, that resource dependence theory sees vertical integration as a means to increase control over resources whereas transaction costs theory sees it as a way to minimize transaction costs.

A critiques of transaction cost theory was provided by PERROW (1986) and ROBINS (1987) (DONALDSON 1995:167-9). PERROW's critique includes challenging the idea that vertical integration cuts costs. He pointed out several costs that may rise as a result of two firms merging. Robins critiques, in this context, is a rather heterogeneous and complex set of remarks. He states that economic theory cannot be used to generate deductions about individual firm behavior in the manner of transaction cost theory. Robins argues against the use of transaction cost theory to construct causal, general propositions. He writes that this detracts from the primary thrust of institutionalism to offer an appreciation of the way in which specific historical structures shape economic behavior. Again, he challenges the presumption of transaction cost theory that the market is the natural medium of transaction that pre-dates efforts to organize transactions within hierarchy.

ROBINS nevertheless, sees a useful role for transaction cost theory as part of a more cautious approach of analyzing the specific forms of organization that arise in each environmental setting: 
- transaction cost theory provides the key mediation between the organization and its environment;

- transaction cost theory can be seen as the vehicle to integrate structural contingency theory with his larger explanatory effort; and

- transaction cost theory is central for the reintegration of organization theory and future research.

\subsubsection{Transaction costs and Efficiency}

According to welfare economics, institutions can be called 'efficient' to the extent that they are directly associated with Pareto-optimal resource allocations (the basic neoclassical model ${ }^{86}$. Therefrom, outcomes that deviate from the outcomes of this model will considered inefficient. The view of this model compare then between an ideal norm and an existing 'imperfect' institutional arrangement. Such traditional concept of optimality or efficiency found in welfare economics has come under strong criticism from institutional economists for using as its reference point a world of fully defined exclusive rights and zero transaction costs ${ }^{87}$. This criticism is closely associated with DEMSETZ who argues (1969) that the nirvana approach of the welfare economics differs considerably from a comparative institution approach in which the relevant choice is between alternative real institutional arrangements. Words like 'non-optimal,' 'inefficient,' and 'over-' or 'underutilization' are, according to DEMSETZ, misleading and ambiguous unless the outcome that they describe can be improved upon. He concludes that ,modern analysis has yet to describe inefficiency in a world where indivisibilities are present and knowledge is costly to produce“" (EGGERTSSON 1990:21-2).

DEMSETZ's view of efficiency is based on individual rationality. Institutions that evolve, according to his analysis, will be efficient throughout maximizing their net private benefits. Inefficiency is seen, therefore, as the locomotive of institutional change. Changes in knowledge, production functions, market values, aspirations, and new techniques, lead to a set of costs and benefits. Property rights adjust to internalize potential gains. Stability will be attained, thereby, when institutions are efficient. Yet, inefficiency, to the extent it exist, seems to be of a dynamic nature: a lag in adjustment to the new conditions. The duration of this lag depends on how rational agents are, the slowness of adjustment of social mores (PAPANDREOU 1994:201, 260-1) ${ }^{88}$.

86 This model is derived from general equilibrium models that show that an free market system tends to gravitate toward an equilibrium where all opportunities for mutually advantageous exchanges between individuals have been used. In equilibrium, no exchange can take place that makes someone better off without at the same time making at least one individual worse off: Given the initial distribution of wealth, the allocation of resources is shown to be (Pareto) optimal (EGGERTSSON 1990:19).

87 WILLIAMSON (1993) argued that COASE, in his 1960 article, was not the first who employed the fiction of zero transaction costs. The idea that castles bargaining leads to efficiency was employed von NEUMAN and MORGENSTERN (1944) and even earlier by EDGEWORTH (1881). However, transaction cost, he add, is a larger concept than bargaining costs and, as presented by Coase, invites comparative institutional analysis (p. 101)

88 The ideas constitute DEMSETZ's view of efficiency was subject of fuller critique and vivid explanation from PAPANDREOU: The fact that agents may form institutions by maximizing their net private benefits tells us nothing about the efficiency of the resulting institutions, argued Papandreou. In Demsetz's model, it is not efficiency that leads to change, but the maximization of net private benefits by individuals; these are not the same. It is not enough that individuals are wealth-maximizers to ensure efficiency, they must be exchanging within a well-specified framework which channels individuals self-seeking activity towards collective ends. Individual wealth-maximization is insufficient to explain optimal formation of institutions, just as it is insufficient to bring about optimality in a market with too few agents or too few markets. In 
EGGERTSSON (1990:102) add that the logical rationale of contractual arrangements, that failed in the neoclassical model, becomes apparent when transaction costs are added to the model. He further argues that, ceteris paribus, various contractual arrangements are designed to economize on transaction costs, and transaction costs reflect the scarcity of information. Under the assumptions of NIE, it is not clear how economic outcomes in a world of full information can be used as a yardstick of efficiency in real-world situation. The question of efficiency as summarized by EGGERTSSON is an unmeasurable characteristic of models. If we assume that agents are rational maximizers, all models yield efficient outcomes - regardless of whether transaction costs are zero or positive. Efficiency is a logical consequence of the assumptions in models assuming maximizing behavior.

Institutions in neoclassical models provide the structure through which individual action is channeled towards collective ends. Without a universal set of markets and privateproperty rights, the Pareto-optimality of competitive private-ownership economies would not be, as the institutional economists view, possible. Importantly, the achievements of private-ownership economies also require that there are no costs of forming markets and private-ownership rights. Once this assumption is dropped (as in a real world), then it becomes important not just to consider the efficiency of alternative resource allocations, but also the efficiency of the institutions themselves (PAPANDREOU 1994:221-2). They can no longer be treated as exogenous elements in models of resource allocation. An optimal set of institutions are needed, therefore, to have an optimal allocation of resources.

Many institutional economists advocate a notion of efficiency that incorporates transaction $\operatorname{costs}^{89}$. The focus of such a notion being whether there exists some feasible reorganization of the economy that would afford Pareto-gains when the institutional costs of reorganization are incorporated in the evaluation of economic outcomes. The status of monopolies is generally not recognized in models that ignore transaction costs. A monopoly would be inefficient only if there existed some alternative institution that could better exploit the untapped resources without at the same time imposing transaction costs that outweigh the 'efficiency' gains. Likewise a missing market, in this case, would represent inefficiency only if the imposition of a market were not too costly (PAPANDREOU 1994: 253). A particularly discouraging feature of the models that criticize the traditional notion of efficiency, argued Papandreou, seems to be that they lead to the unpalatable conclusion that any institution that exists must be optimal otherwise wealth-maximizing agents would have exploited any 'attainable' improvements.

A developed line of argument, of the institutional economists, is represented by STATEN and UMBECK. If efficiency is defined as Pareto efficiency, they argue, then it is logically impossible to derive inefficient solutions from microeconomic models that use the behavioral postulate of constrained maximization. According to the traditional definition of efficiency in neoclassical economies, a resource is used efficiently when it has been

addition, once a departure from rational behavior is allowed, there is no guarantee that 'rational' behavior is the socially optimal behavior. Optimality may no longer be a moot question, however, the prescription that agents be 'rational' is not justified.... It is worth noting that COASE shares POSNER his reservations about the concept of 'bound rationality' espoused by WILLIAMSON and add: ,as I do to any economic concept that includes the word 'rational" (COASE 1993:98).

89 This notion is implicit throughout the Law and economies literature and sometimes refereed to as 'transaction-cost-constrained optimality. 
allocated to the user who has the highest value for it as measured by the user's willingness and ability to pay. Efficient outcomes result from the view that individuals are seen as maximizing utility functions subject to constraints. Pareto efficiency is reached when all transactions that are mutually advantageous have been completed, and when, by definition, agents complete all advantageous transactions, given the model's constraints (EGGERTSSON 1990:22-3). STATEN and UMBECK argue, throughout an provocative example $^{90}$, that in traditional neoclassical models, it is theoretically possible to imagine discrepancy between the marginal social cost and the marginal cost and this would be treated as Pareto-inefficient. They stress, however, that it is logically impossible to derive such a discrepancy from a microeconomic model. An explanation for such unimaginable situation must be that the model is misspecified, that some constraint is missing, such as the costs of collective action ${ }^{91}$ or any other transaction cost preventing this discrepancy. They conclude, as long as the model is fully specified (all transaction costs are incorporated) the equilibrium outcome must, by definition, be Pareto-efficient ((PAPANDREOU 1994:255).

CHEUNG, prior to STATEN and UMBECK, makes the same point but in passing and without developing it further: ,in a world where each and every individual is asserted to behave consistently with the postulate of constrained maximization, economic inefficiency presents a contradiction in terms. even outright mistakes are traceable to constraints of some type. the world is efficient, if the model describing it sufficiently specifies the gains and costs of making it so" (PAPANDREOU 1994 256). PAPANDREOU, in turn, taking the perspective of policy formation, push STATEN and UMBECK's argument further and argue: ,one might not be daunted by their result".

While it might be true that an equilibrium outcome of agents interacting within a fully specified institutional environment (all transaction costs are incorporated in the model) will be Pareto-efficient by definition, policy makers, it would seem, are able to alter institutions (the constraints faced by the agents) and thus bring about new outcomes ${ }^{92}$. And acknowledging the constraints faced by the policy-makers, there seem to be several alternative rules among which an 'optimal' one can be chosen. The conclusion viewed by PAPANDREOU (1994:259) says that any efficiency notion based on comparison of feasible alternatives become, for microeconomic models, meaningless, e.g. Paretoefficiency, social-welfare maximization: „Models with endogenous transaction costs could not provide insights for improving economic outcomes since, given the constraints of the model, no other outcome is possible. Historical analysis of institutions would take the form of uncovering the transaction costs faced by the agents that generated the particular set of institutions. Discussion of the efficiency or inefficiency of the institutions would be meaningless“.

90 If a factory were free to pollute, no effort would be expended curtailing pollution and an excessive amount of pollutants would be indicated by the discrepancy between the marginal social cost of pollution and the marginal cost of abatement.

91 According to BRETON, the new lines of research on the problems of collective choice and action are encompassed in four bodies of theory: the theories of public goods, democracy, decisions rules, and transaction costs (RUTTAN 1978:344).

92 In the case of the factory emitting deleterious substance, for example, policy makers could limit allowable emissions by the factory, or apply a pigouvian tax. Alternatively, they could set up a market for pollution permits with a limit on the number of permits. The factory-owners, potential polluters, and those who suffer from the factory's emissions, could purchase permits (and/or bid up the price) for the right to use the atmosphere. given this new institutional framework air would be allocated to those agents most willing and able to pay (PAPANDREOU 1994:256). 
Another deviation from the Welfare Theorems is needs to be made. In the economic models that endogenize transaction costs, the neat division between distribution and efficiency matters enshrined in the Welfare Theorems, is lost. Any choice of institutions is not only limited by initial distribution of power, but also entail an implicit distributional choice. DAHLMAN sees the function of property rights as (PAPANDREOU 1994:223): ,determining income or wealth distribution, on the one hand, and also serving as signals for behavior, thereby guiding incentives, on the other. If we accept the view that institutions are really nothing but specific collections of attenuated property rights, then it follows that institutions are also tied up with both income distribution and incentive formation. the relative efficiency of various institutions now becomes dependent upon our ability to rank various income distributions ${ }^{\text {‘93 }}$.

\subsubsection{Transaction Costs and the Agricultural Contracts}

EGGERTSSON (1990:213-4) refers to three elements that are important for the coming analysis and illustrate how the NIE approaches the study of economic organization. First, it is assumed as a working rule that low-cost organizations tend to supersede high-cost ones. Second, when high-cost organizations appear to persist and it seems that reorganization would increase net output, the search will be for hidden benefits at unexpected margins. Such offsetting benefits may involve a reduction in supervision costs or an increase in output in a related activity when a nexus of contracts ties several activities, or a host of other factors. Costly behavior is also constrained by contractual stipulations. Finally, if the search for hidden benefits or contractual constraints is in vain, the search will be for political constraints that block the rearrangement of property rights. It is recognized that the polity may not adopt output-maximizing property rights if the new structure might cause distributional losses for those who control the state. And according to Neoinstitutional economics, high (transaction) costs of collective action are the principal reason why the members of a community cannot agree on new rules that would increase the community's aggregate output.

93 Transaction costs theory, based on the economic history, has very interested contribution to the topic Slavery, as production form in the agricultural societies. DOMAR argues that this form is possible only when the cultivable free land and available labor force' ratio is very high. In this case the non-working landowners will try to tie up the labor force (LÖCHEL 1995:76). Taking the market in the background, this criterion, rising labor/land ratio, has been linked by BOSERUP and others to the emergence of individual property rights in land. It is therefore no accident that the British legally codified individual property rights for India, but not for their sparsely African colonies (BINSWANGER and ROSENZWEIG 1986:535). In this respect, NORTH has argued that that changing structure of transaction costs made slavery an inefficient institution. Efficiency gains could be made by owners if they changed from slave labor to wage labor. By shifting to wage labor the farm-owners could drastically reduce enforcement costs. The point as viewed by PAPANDREOU is that institutional change does not require efficiency gains to be initiated, it requires gains to the initiators of change, which may or may not coincide with an overall increase wealth, and would surely leave many potential efficiency gains untapped. Furthermore, whatever efficiency gains are made they are intimately tied to a distribution of wealth. An institution can be said to be efficient if it best attains some welfare goal. For a more detailed discussion of institution of slavery, income distribution, and efficiency see EGGERTSSON 1990:203-13; PAPANDREOU 1994:223-6; and LÖCHEL 1995:75-81. 
Sharecropping or share tenancy is an contractual arrangement involving rights to the use of land and is a traditional form of organization in agriculture. It was traditionally considered that this form, in addition to the open-field system, is inefficient and therefore inferior to other available forms of organization like wage contracts and fixed rental contracts. It is inefficient in achieving optimal resource allocation because it reduces tenants' incentives to apply their own labor and other inputs (Marshallian inefficiency). The sharecropper will have less incentive to increase production as long as he receives only a fraction of the increase in output. Thus he would tend to under supply various inputs and would equate only a fraction of the marginal value product of a variable input to its opportunity cost (see the case of cotton production in New Halfa Scheme, Chapters 5.4.2 and 6.3.3). That is why some economists link economic stagnation in third world countries to the prevalence of share tenancy in their agriculture(EGGERTSSON 1990:223).

The paradoxical status of sharecropping in conventional analysis has bee undermined recently by the new land-tenure economics started by CHEUNG and elaborated by STIGLITZ, NEWBERY and others. In his 1968 article, CHEUNG argues that equilibrium contracts usually have several dimensions, and the puzzle that share tenancy poses for neoclassical economics can be solved by endogenizing the structure of contracts. His model, which derived with the assumption of zero transaction costs, suggests that share contracts need be neither irrational nor inefficient, but the demonstration that various types of contracts can give equivalent outcomes does not explain why one type is preferred to another or provide a theory of contracts. A theory of contracts must take account of transaction costs. Latter (1969) CHEUNG develop his point further and argues: „The choice of contractual arrangement is made so as to maximize the gain from risk dispersion subject to the constraint of transaction costs (EGGERTSSON 1990:226).

According to the new land-tenure economics, if contractual terms can be enforced costlessly, equal efficiency will be established between share tenancy and other forms of land tenure such as fixed-rent tenancy and owner farming. Marshallian inefficiency depends on whether there is a low-cost mechanism in rural communities to enforce the contractual terms of share tenancy. Taking the optimizing behavior of landlords in consideration, land rent under share tenancy is expected to be higher than that of fixed-rent tenancy by a premium for risk and enforcement cost shouldered by landlords. Where the enforcement cost is excessive, fixed-rent tenancy will be preferred to share tenancy if both are available options (MOROOKA and HAYAMI 1989:28). From the other side, it must be remembered, argues EGGERTSSON, that the introduction of enforcement costs influences all forms of contracting. In short, transaction costs are the key variables for explaining the variation in contractual arrangements in agriculture.

\subsubsection{Institution Building (Institutionalization)}

Like Institutional Development (ID) or institutional innovation, Institution Building (IB) is one of the necessary approaches to improve the performance in any agency ${ }^{94}$. It analyses

94 An assessment of the World Bank's twenty years experience with rural development has examined the factors that significally affected the success or failure of a project. It was found that by and large there has been some loss of efficiency associated with the rural development lending strategy and that successful rural development presents major challenges for governments of which local organizing and institution building are the most challenging (DONALDSON 1992:111). 
linkages of various sorts between the institution being considered and its environment, and how to promote a process of 'institutionalization' that gives an organization like an irrigation bureaucracy more than narrowly instrumental capacities to achieve objectives.

UPHOFF (1991:205-6) refers to the view that institutionalization is always a matter of degree, referred to by PARSONS and latter by HUNTINGTON (Chapter 1.2.1), and argues that the capacity of an institution (or agency) to achieve objectives derives from its ability to mobilize and deploy a variety of resources associated with gaining compliance with its directives. Moreover, there are direct relationship, in the same direction, between the degree of legitimacy and status (respect) that people accord to an institution and its decisions from the one side and the forthcoming acquiescence and acceptance of these decisions from those people and, therefore, their ability to achieve the institution's goals in the other side. This fact will explain the behavior of tenants farmers in the two cases of this study (Chapter 6.2 and 6.3)

Resources in IB model, as viewed above, are treated as one of five key factors in creating capacity. The other four are leadership, doctrine, program, and internal structure. The vision of resources here is not restricted on the 'hard' resources (goods and services or coercion) but compasses also the legitimacy and status as 'soft' ones, being based in people's attitudes and values. The IB model, as discussed by UPHOFF, recognizes that what makes an organization into an institution is the valuation it receives from the public, resulting in respect, loyalty, commitment and other supportive behavior based on norms: ,Managers who want to improve the performance capabilities of their agencies will plane and carry out their activities with an eye to how these can enhance the status and legitimacy of their agency, its staff and its program, in the estimation of the various groups on whom it depends for a steady flow of resources and for compliance to achieve its objectives".

Analysts of Institution Building have distinguished several types of linkages that managers need to concerned with UPHOFF (1991:207-9):

(1) Enabling linkages provide the necessary resources (authority and funds in particular) that permit the institution to operate;

(2) Functional linkages represent the working relationships that any agency must maintain with other institutions or groups, such as cooperative arrangements with the Ministry of agriculture or Extension Department to coordinate irrigation activities with agricultural ones, or liaison with water user associations where they exist;

(3) Supportive linkages include interactions with various organized sectors of the public whose backing will strengthen the hand of an institution when dealing with decision-makers and others who control the resources needed to accomplish the institution's tasks;

(4) Diffuse linkages refer to communications and liaison with the public at large, to build up broad approval which will create a favorable climate of opinion, for example, through the press. Forecasting and sustaining the last two linkages are necessary for improving managers' ability to maintain and benefit from the first two.

One main objective of institution building projects is to create an organization that is responsive to the needs of the society around it in some degree. It should help solve the problems of that society. Within this context, an organization becomes institutionalized, i.e., it becomes a valued object (POTTER 1972:152-5). Institutionalization as defined by 
ESMAN and BLAISE is ,the process by which normative relationships and action patterns are established." PARSONS, et al; use the term institutionalization to mean ,the integration of the expectations of the actors in a relevant interacting system of roles, with shared normative patterns of values. The integration is such that each is predisposed to reward the conformity of others with the value pattern, and conversely, to disapprove and punish deviance. Institutionalization is a matter of degree, not of absolute presence or absence“. The focus in both cases is on establishing and integrating patterns of interaction so that they become expected and valued. For institution building to take place, as Potter argued, these patterns of interaction must occur between the organization and its environment.

Institution Building accompanied with a project ${ }^{95}$ needs high coordination and interaction between all organizations that are related to the project. Two concepts are introduced here as important for understanding such interaction; the totality of action - working in concert toward a common objective, and reciprocity - as you do something for someone else, he becomes obligated to you, that means he will help you. This exchange is very important aspect of the establishment of effective working relationships.

Going a step further to apply these concepts to the institutionalization of organization, Potter counts, from the traditional and recent tests of institutionality, four indicators for the degree of institutionalization: the organization's ability to survive, the extent to which it is considered to have intrinsic value by its environment, the degree to which specific relationship and action patterns of the organization have become normative for other organizations of the society, and more recently it has been added whether the institution can maintain its innovative thrust. In addition, he talks about three classes of indicators having to do with institutional development. One is the kinds of inputs the institution receives from the society. Second, there are outputs that the institution provides to the society. The third class are the facilitating mechanisms that the institutions must have to provide these kinds of outputs ${ }^{96}$.

A point here that of particular relevance is that institution building has contributed to our understanding of the institutional transfer process. The possibility of borrowing institutional innovations either through processes of diffusion or through organized programs designed to transfer institutions across social, economic, and political constituencies reduces the cost of institutional change. Modern history has witnessed transfer of different forms of institutions among countries. Inappropriate institutional transfer results in biases in the supply of institutional change that are similar to the biases that inappropriate technology transfer introduces into the supply of technical change (RUTTAN 1978:353).

\footnotetext{
95 The case examined by POTTER is an technical assistance-institution building project.

96 A re-examination of ESMAN and BLAISE's definition of institution building (POTTER 1972:156) shows, argued Potter, that they have not ignored output, as they refer to physical and/or social technologies. They state that ,the introduction of new technologies takes place primarily in and through organizations....institutions as used in this context are organizations which incorporate, foster and protect normative relationships and action patterns, and perform functions and services which are valued in the environment." Nor have they ignored the element of input, although it is less apparent in their definition. They state, ,if there is deliberate planning and guidance of institutional change concomitant with induced technological change, then this will lead to a more effective utilization of the society's resources." They view the institution and its environment as parts of a system.
} 
Literature of institution building has evolved out of an effort primarily in the field of public administration, to provide technical assistance agencies with an effective methodology for intervention to induce more effective institutional performance. This body of knowledge has typically adopted an explicitly normative orientation toward institutional change. Thereby the test of effective institutionalization is the normative impact of the organization on its setting. The institution-building literature, therefore, exhibits a pervasive concern with the problem of transferring particular organizational forms from the developed to the developing counties and with the institutionalization of capacity for technology transfer and innovation.

Institution building approach, at the same time, has been criticized on the grounds that it give no more explicit attention to the development of a typology by which opportunities for appropriate institutional change can be differentiated on the basis of both technological and environmental characteristics. As example, in this connection, RUTTAN (1978:354) refers to SIFFIN's critique who argues that it is easier to institutionalize an organization that focus on developing technology than an organization that is not technology-centered. He points out that the relatively ,closed-system“ quality of many technologies means that the behaviors they require are quite particular to their operations and not common to the socio-cultural system at large. On the other hand, where there is no closed-system technology, as in community development efforts, effective institutionalization may be exceedingly difficult to achieve.

\subsubsection{Organizational Change and Organizational Development (OD)}

Two interrelated trends can be identified as emerging from the review of analytical framework conducted in the last two Chapters. First, the shift away from deterministic forms of explanation and towards explanatory logics which emphasize the crucial importance of human agency in shaping organizational structures and practices. There is a growing recognition that of the fact that human agents both individually and collectively enact social and organizational structures by engaging in forms of reasoning and action which transform the conditions under which they act. A second strand of development can be identified in the refocusing of attention on the problem of control. Within the problematic of control, „organizations“ are redefined as power containers supporting institutionalized structures of dominations and regulation, rather than functional units buttressing the established order, the legitimacy of which can be automatically taken for granted $^{97}$ (REED 1992:184-5).

The particular emphasis on the dynamics of control, as REED (1992:186-7) concludes, has also given encouragement and support to perspective and programs geared to the analysis of change and transformation in organizational forms. In contrast to the previous view organizations are seen as relatively fixed and permanent features of the institutional landscape, change and the inevitable uncertainty and instability that it generates, is now seen as an integral component of complex organization. The shift away from order and permanence towards control and change has also favored a reorientation of theoretical development in which the politics of organization, rather than the technicalities of formal structural design, now play a strategic explanatory role. Indeed, this shift has strengthened the shift towards a more well-developed institutional focus in organizational analysis.

97 For a succinct review of this analysis see REED 1992. 
In the light of this, and the analysis that has been dealt with in this Chapter, we conclude that organizations and institutions are not invariant; they vary with time and location, with political arrangements and structures of property rights, with technologies employed, and with physical qualities of resources, commodities, and services that are exchanged. Institutional change, as discussed above, means also a change in the organizations in order to carry out the social functions more efficiently and in an improved way and to realize more effectively the organizations' goals and those of the members and of external groups (MANIG 1989:32). OD according to this analysis then means improving the discharge of functions and change at the various levels (members, goals, organizational structure) and fields (values, norms, processes). It regards the normative factors not as abstract things but as personalized, motivating forces affecting organization' performance (UPHOFF $1991: 188)^{98}$. OD then must concur with institutional change.

Any strategy of organizational change in developing countries, as stressed by HAGE and FINSTERBUCH (1987:3-4), must confront the political realities and cultural values which influence the organization. They refer to OD (or human relation) as one of three schools of organizational change which focuses on individual morale and motivation. It emphasizes changing employee attitudes, group processes, and job designs by means of training, group discussion, and problem-solving groups. The other two schools are organizational theory (the sociology of organization); and organizational design (Management). Organizational theory emphasizes restructuring the organization in the direction prescribed by contingency theory (a dominant perspective in both this and organizational design), as best suited to achieving either efficiency or innovativeness in its market situation. It usually utilizes the change tactics of decree, data collection, group discussion, and restructuring. Organizational design, in turns, emphasizes improving strategic planning, changing structures for greater efficiency, and improving managerial technologies. It favors the change tactics of decree, group problem solving, and restructuring.

HAGE and FINSTERBUCH (1987:277-8) stress power issues; the role of the influential people and problem-solving groups, in inducing organizational change. If these influential have no interest in productivity, efficiency, innovation, or adaptiveness, then, they argued, our framework has little utility. But such cases, as has been found from the experiences, are rare. Even when elites are unconcerned about the lack of services for the poor, they will become interested when pressure for change builds from below, and data gathering can help build this pressure for change by documenting the gaps. In addition, the role of problemsolving groups, especially at the top of the organization, is to adapt the change to the political and cultural realities of the organization. The authors frankly recognize that the proposed change must leave undisturbed some benefits that powerful elites derive from the existing circumstances. Elites, in fact, should be members of the high-level problemsolving groups or work closely with them. Furthermore, elite opposition is usually partial. Non-elites also, on the other side, have power that can make or break an intervention; resistance to change can occur at many levels and for many reasons.

98 Opposite to Organizational Development, where the normative factors are weighted, a more radical approach has recently emerged known as Organizational Transformation (OT). This approach (discussed in detail in LEVY and MERRY 1986) gives more weight to subjective, value-oriented influences (UPHOFF 1991:196). 
Organizational development discussed by UPHOFF (1991:182) as one of the normative approaches that, together with the structural changes, and incentives and learning, lead to improving the performance of agencies like irrigation organizations. Such approaches deal with what can affect people's norms and values so that individuals within the bureaucracy become more disposed to make persistent, innovative efforts on behalf of organizational objectives. This aspect of reorientation is more uncertain because it deals with social psychology and ideologies, rather than with rules and procedures or with allocation of budgets and responsibilities. The extent to which OD interventions are transferable across cultures is therefor less clear. That means, one is able, perhaps, to take ideas, examples and encouragement from one situation to another but not specific models, roles or incentives. And like the view of HAGE and FINSTERBUCH the leadership in the top levels of the organization is a key element in these transformations.

Organizational change can results either in an improved effectiveness of the services supplied or in an increase in the tendency to innovate, but not in both (MANIG 1989:32-4). Applying in irrigation systems, it aims to fulfill the functions and achieve the goals of the organization and the influential groups. According to this approach, organization forms ought to change by themselves. The real goal that should be the basis of the organization's development in irrigation system is improving the efficiency of land and water utilization for farmers and, furthermore, the increases in labor productivity . Other goals are dependent on achieving this real goal. However, improving the goal achievement after an organizational change requires, stressed MANIG, appropriate behavioral changes even among farmers: Hence social sanction and reward mechanism should be introduced (e.g. increased water taxes, but also attractive prices).

Many modifications are recommended for organizational change and development. A wellknown scholar in this field, BENNIS, refers to six forces at work which are demanding that organizations modify both structure and climate in order to cope successfully with the realities of modern environment. These factors are (SCOTT and MITCHELL 1972:259):

1. An acceleration in change that requires rapid organizational adaptation.

2. Increasing technological sophistication which lends to the acceleration of change.

3. Growing organizational complexity which is partially attributable to technology and partially a result of increasing organizational size.

4. Changing character of the workforce in which more highly educated, professionally oriented people are going into organizations.

5. A growing expectation of the 'new' employee for greater freedom and discretion at work.

6. More disenchantment with traditional authority, with emphasis based on a decline of command (superior-subordinate) authority and the rise of functional authority vested in expertise.

These forces speak for the liberalization of the organization. According to BENNIS, the main avenue for such modification is democracy. As such, democracy is thought to revitalize organizations making them better able to adapt to change and making them more responsive to the needs of their members ${ }^{99}$.

99 The need for democratization is one of the basic recommendations, for achieving the goals of development and elimination of poverty, that dominate the studies of improving the role of United Nations in the future (URQUHART and CHILDERS 1991). 
Recommendations for organizational changes in macro-hydraulic systems tend towards dividing the functions of a complex organization into various small ones. Coordination and self-control mechanisms for the mutual control of activities resulted from the separation of functions is, of course, necessary. Most of such recommendations see in water users' involvement and/or participation, especially in the system of water distribution, the decisive key to an increase in efficiency (MANIG 1989:35-7). It should be noted here, in addition, that change in irrigation organizations must be accompanied by a comprehensive institutional change in land property, land use and expansion of the structure of the supporting institutions in order to improve potential utilization and to achieve basic development goals. It also requires different technique to achieve their aimed objectives.

At the top of such techniques is laboratory training as a very important one accompanied with research, diagnostic, and consulting techniques which are supposed to improve organizational climate. One could sum up that OD can only be perceived within the global context of institutional change at all levels and in all sectors. To emphasize this point a quote by FRENCH is appropriate:“...successful organization development tends to be a total system effort; a process of planned change-not a program with a temporary quality; and aimed at developing the organization's internal resources for effective change in the future. ${ }^{\text {100 }}$

\subsection{Price Policy as a Means for Inducing Optimum Water-Use Efficiency}

\subsubsection{Water and The Market}

Water pricing is one of the most important determinates of improving the performance of irrigation systems in the future. It should be designed to encourage the optimal use of water from the standpoint of the society. Most experts; engineers, hydrologists, ecologists, and economists agree that the inefficacy of water use and poor maintenance of irrigation systems are largely due to the extraordinary extent to which water is not treated as a commodity but as a free good (LINSLEY 1965:89). In much of the Third World, policies that promote an antiquated illusion of abundance have resulted in: ,people rarely pay the true cost of the water they use" (POSTEL 1984:47). While irrigation, there, consumes the majority of water supply, water generally has the lowest estimated marginal value product in agriculture. The lack of farmer awareness of the economic cost of water as a resource results in waste of water and a loss of food-production potential, which is directly translated to a drain on the meager financial resources of these countries (FAIRCHILD/NOBE 1988:356).

The reason of such fact was the absence of the market and its regulating mechanism; the price. We are facing here an exceptional case concerning a certain propensity in human nature, which Adam Smith (EGGERTSSON (1990:3) referred to as ,the propensity to truck, barter, and exchange one thing for another". Such behavior has important consequences of the activities for the use of scarce resources and the creation of wealth ${ }^{101}$.

${ }^{100}$ Quotation from SCOTT and MITCHELL 1972:269.

101 BUCHANAN (1964) in an Article titled: „What Should Economists Do?“ takes up this point from Smith and suggests that economists should place the theory of markets and not the theory of resource allocation at center stage. Economists, he argues, 'should' concentrate their attention on a particular form of human activity, and upon the various institutional arrangements that arise as a result of this form of activity. Man's behavior in the market relationship, reflecting the propensity to truck and to barter, and the manifold variations in structure that this relationship can take; these are the proper subjects for the economist's study. 
BOULDING (1980) has observed, in this context, that in contrast to many other natural resources, water has been viewed as too important to be left to the market place, so that its administration falls largely in the political realm (YOUNG 1986:152-7). ${ }^{102}$ Most societies have therefore chosen nonmarket administrative mechanisms for water allocation.

Several reasons inhibit the adoption of market institutions for water allocation. Of these defined YOUNG three major factors; physical; economic; and conflicting social values ${ }^{103}$ :

- Physical: due to the nature of water and how it is used in production and consumption activities. Because of its nature and the difficulty to identify specific units of it, water presents unique problems in the establishment and enforcement of property rights;

- Economic: which stems from the fact that, until recently, water has been in relatively plentiful supply; and

- Conflicting social values: in that material well-being is not the only yardstick used by society to measure success in water allocation. Rituals and religious teachings may explicity or implicity prescribe against market allocations of water ${ }^{104}$.

In the context of his discussion about the non-profitable nature of most of the irrigation systems in the developing countries (the case of Gezira), RUTHENBERG (1963:706) stressed the social factor as reason for the farmers' rejection of water charging. In the light of the low production, the untrained farmer, who is deeply rooted in the traditional thinking of the society, will see the water charge as very high. Other hindrance in the face of maximizing collections and implementing cost recovery schemes, as we will dwell on latter in the discussion of the results (Chapter 6), is the unsatisfaction with water deliveries: "unless water deliveries are satisfactory, water users will probably avoid paying the government irrigation fees if possible" (UPHOFF 1991:61). Where service is reliable and adequate, several other conditions will affect, he argued, cost recovery. For instance, whether the funds collected from users in a particular system are spent for Operation and Maintenance O\&M in that system rather being siphoned into the central treasury; whether

For a more detailed discussion of the theory of price (microeconomic theory) and its applying to economic and political institution, and therefore the thought of the New Institutional Economics (NIE) see EGGERTSSON (1990).

102 BOULDING refers to the price system as one of three major mechanisms - labeled as the ,three P's“ - that mankind employs to reflect human values in the process of organizing human utilization of the earth's natural resource endowment. Prices represent the market system, operating through free exchange and a relative price structure. The other two „P's“ are Policemen and Preachments. „Policemen“ -- the legitimated threat system or the political order - establish and enforce property rights and administer public regulations, whereas „Preachments“ represent the moral order, the process by which human values are learned, conveyed, modified, and employed in making choices. BOULDING argues that, in the case of water, the political and moral modes have had, up to the present time, the dominant role (YOUNG 1986:152).

103 SMALL and CARRUTHERS (1991:36) add tow others factors: the presence of externalities (for example, if there are uncompensated side effects such as pollution); and if there are economies of scale that set the preconditions for monopoly. These factors, along with the other mentioned above, explain the lack of welldeveloped water markets.

104 There is general thought in such societies, specially the Islamic societies, that water is ,gift of God“", therefore it must be available for all irrespective of the costs. 
fee-paying farmers have some control over the expenditure of O\&M funds so that they are properly and efficiently used ${ }^{105}$.

In addition to the importance of the price structure in resource allocation, there are at least other two functions of it which may not be compatible one with another namely in the field of distribution of income and direct technical change. LINSLEY (1965:90-1) argued that the third function of the price system seldom mentioned in the textbooks, but in the long run it may be perhaps the most important. „Water should be dear and plentiful“. „It should be dear because only it is dear will people bother to economize; and if it is dear will technical change more in the direction of water-saving improvements". He sustained his argument with an example from California ${ }^{106}$ where the value added per cubic kilometer of water was 65 times greater in industry than in agriculture (POSTEL 1984:47). The easiest way to make water dear, according to this analysis, is to tax it. Because, „water is an excellent commodity for tax". It has a fairly inelastic demand, so the yields of taxation should be high. In the same time, it should not be unduly regressive ${ }^{107}$. On the other hand, it is important to not that if the prices of irrigation water exceed some limits, the farmers might reduce the irrigated area as registered in the cases of this study (Chapt. 6.6).

Interest in water markets has recently increased reflecting growing pressure on limited water supplies, (realization) that institutional change will be needed to improve water use efficiency, and the shift toward privatization and market mechanisms to address resource allocation problems ${ }^{108}$. GARDNER (1985) argues that water markets could promote water

105 A suitable example is Gendettu Scheme where the administration always claimed that the farmers do not pay the charges and that is why, view the administration, there is no fund to finance M\&O. In the same time many of the staff who actually work in other irrigation Schemes in the region tack their salaries from Gendettu (See Chapter 6.2.2.1).

106 Because the agricultural water in the Los Angeles area is quite expensive, there have been professions who teach farmers how to use as little water as possible. Since water costs in the Central Valley are little, no such occupation had been exist. The farmers used water as wastefully as they like and was hard to blame them, for there was no incentive to economize and particularly no incentive to develop water-saving improvements.

107 The close relationship between water pricing, water technology, and water control can be illustrated through the Israel's experience. Water authority there is trying to accomplish the twin objectives of water management; equity and efficiency, through water pricing and through the establishment of other incentives for farmers to adopt water-efficient techniques and technology (Chapter 2.3.1.2). Water prices are adjusted to compensate farmers located in disadvantageous areas to reward farmers who use water efficiently, and to penalize the inefficient. Other incentives include, for example, subsidies for the purchase of innovative water-efficient technology (LEES 1986:611). The most interested fact in this case, which we will need in the analyses of our empirical work (Chapter 6.6) is that most of the water consumption in Israel's agriculture (approximately 80\%) is used for cash-crop (profitable) production. In addition, the marketing of these products is well organized.

${ }^{108}$ In the context of a theory of the demand for institutional change, NORTH and THOMAS (1973) explain the economic growth of Western Europe between 900 and 1700 primarily in terms of changes in the institutions whose rules govern property rights. These institutional changes, in their view, were induced by the pressure of population against increasingly scarce resource endowments. More recently, the competition between both agricultural and industrial production and from transportation, has resulted in a dramatic rise in the economic value of common property resources that had previously been regarded as free goods. The result has been the emergence of new institutions designed to clarify the property rights of individuals, firms, and communities in respect to these increasingly valuable common property resources. The same sequence has been observed (JAY 1969) in a number of developing countries, where the use of more intensive farming systems has led to an increase in the economic value of water. And this increased value has induced institutional changes that have led to more precise definitions of property rights in respect to irrigation water and to greater use of market mechanism in the allocation of water (RUTTAN 1978:335-6). 
use flexibility, establish a recognized water value, and thus provide incentives for more efficient water-use (HAMILTON 1989:64). But this efficient use is more connected with the preferences of the water users: "Vielleicht kann man sagen, daß eine effiziente wassernutzung besser definiert ist vom Gesichtspunkt 'was die Menschen mit dem Wasser anfangen werden', als vom Gesichtspunkt 'wie gut das system geplant ist, um theoretischen Normen gerecht zu werden"', (CRIDDLE 1975:142).

Water charges can be one of the viable policy solutions to the management problems of canal irrigation system, on condition that methods of cooperation and trust must be built into the system. Such goal is then achievable only through the farmer involvement and farmer participation. In this case, charging farmers some share of system costs give them, as POSTEL (1984:48) pointed out: ,a stake in the system“ besides generating revenue to improve operations. With other words, water charges must be considered in the context of a package of policies. Otherwise the farmers will see it as fine ${ }^{109}$ not as price for water or the participation in the Scheme as the case in the Sudan. In addition, the existence of water user associations to coordinate management tasks and the collection of fees is necessary.

PAPANDREOU (1994:2-3) take the view a step further and argued, rather than looking at how the signaling devices (prices) of existing institutions fail to do their work, it would be more appropriate to ask how institutions need to be formed so that many important economic activities are explicitly guided by the institutional structure. In a sense, one need to move from the question of optimal prices to the prior question of optimal institutions. Instead of seeking ways of correcting certain prices in the system, we would seek to form a better overall 'voting' system, which would result in improved 'prices'.

Finally, advocates of market solutions to the problems of irrigation efficiency are confronted with several potential shortcomings (SMALL and CARRUTHERS 1991:37-8):

- Market imperfections exist that cause markets to function improperly;

- Markets give wrong signals by ignoring externalities;

- Markets do not work to provide the optimum level of public goods; and

- Markets may yield undesirable results in terms of alternative objectives.

According to the author's observations of government failure and market failure in the developing countries, they advocate the solutions that rely upon:

- Briefing of political leaders on the costs and benefits of policy options;

- Economic analysis of options;

- Decentralization of authority for financing policy;

- Scheme level collection and retention of user fees, normally equivalent to operation and maintenance costs; and

- Encouragement of collective user-group action to increase agency accountability.

109 The sound of this word (call to mind) remind the farmers in Sudan of the colonial time. 


\subsubsection{Water Pricing Systems and Institutional Change}

Because irrigation is expensive, it is agreed upon, then, that farmers should be charged for their participation in irrigation systems. The problem is to what extent and in which form? Should the farmers be required to repay the capital cost or part of it?, or only cover the recurrent $\mathrm{O} \& \mathrm{M}$ costs?, or whether the fees should be based on the benefits received. Even many who view water pricing and water law as the means for creating an environment to induce the system to evolve in a desirable direction are cautious about the answer. Increasing the price of water could not be an effective means for inducing optimum irrigation water use efficiency. On the contrary, high-priced water may actually hinder onfarm development because it captures resources needed for other activities. Consequently, high prices may actually create a disincentive for optimum water use in the long run $\left(\right.$ KELLER 1986:346) ${ }^{110}$.

\subsubsection{Bases for Setting Water Rates}

There are several bases for determining the amount to be paid as water fee. In some countries, it can be based on theoretical calculation, but in many others the water rates paid bear little or no relation to the calculated fees. To a large extent this is due to the fact that rate setting is seldom a purely economic activity, and non-economic factors often impinge upon the decision-making process (SMALL and CARRUTHERS 1991:34). These "noneconomic' factors are more defined by SAGARDOY, BOTTRALL, and UITTENBOGAARD (1986:127):“...water rates are often a political issue rather than a technical one".

SMALL and CARRUTHERS (1991:170-81) examine in this connection three issues that often arise and pose the policy question that must be answered in any given situation. They stressed, however, that there is no a single 'correct' answer exists for all situations:

- Should fees be project specific or uniform across projects? To some extent, the nature of the fee structure depends on the financial and organizational structure that exists for the delivery of irrigation services. In decentralized financially autonomous irrigation associations, as is found in South Korea, it must be possible for fees to be set independently by each association. A single national structure for fees (Sudan) would not be compatible with the autonomy of the individual associations. It is sometimes alleged that uniform fees are better than project-specific fees because they are 'fairer'. From another perspective, in terms of location with respect to the water supply, the force of gravity makes the farms unequal. That is why charging the farmers at the high and lower elevation the same amount would be inequitable. Anyhow, the uniform and project specific fee can practiced in one country.

\footnotetext{
${ }^{110}$ On the ground that; for farmers to increase their water-use efficiency, they must usually increase the labor, capital, and management inputs to their own farm irrigation practices. Thus it costs them considerably more to use water efficiently than to misuse it. However, increasing the price of water actually allows them less leeway for providing the additional on-farm cost of using it well. Conversely, according to other hypothesis, it is assumed that, by means of an excessive increase in duties, the farmers can be forced to increase their productivity since, otherwise, their income will be reduced (MANIG 1984).
} 
- Should rates differ among water users within a single irrigation project? If the cost of serving some users is greater than the most of providing irrigation to others, then this economic logic dictates that higher fees should be charged to those for whom the cost of providing irrigation is greater. But it must be kept in mind that as the number of distinctions increases, the administrative costs also increase. A balance needs to be struck between the differentiation of the fees in accordance with differences in costs, and the administrative ease of assessment and collection under a less differentiated fee structure.

- How can the real value of irrigation fees be maintained in the face of inflation? If, as is frequently the case, the rate of inflation is quite high, the real value of the fees established under the fee structure will soon become seriously eroded, so that the amount of funds collected will no longer be reasonable in relation either to the agency's needs or to the amounts that the users can afford. At the same time, political difficulties can hinder raising the nominal fees ${ }^{111}$. Tying the nominal irrigation fees to some general price index is one possible way to deal with this problem. In the case of a centralized irrigation agency, the advantage of establishing the level of fees in kind is particularly pronounced. On the other hand, in institutions where decentralized autonomous irrigation agencies exist, the problems of raising fees may be less severe because the decisions of individual irrigation agencies to rise rates have only local, rather than national, impact.

\subsubsection{Methods of Setting Water Rates}

Economists often suggest pricing water at its marginal cost- the cost of supplying the next increment from the best available source (POSTEL 1984:47-8). Consumers would thus pay more as supplies become scarcer. With other words, the greater the depletion, the greater the allowance-hardly an incentive to converse. However, conflicting revenue and income redistribution objectives often dictate alternative solutions (YOUNG 1986:158). In practice, farmers are seldom asked to pay fees that cover the total costs of irrigation. Furthermore, water, is rarely priced at marginal cost; charges often bear little relation to the real cost and quantity of water supplied. The governments in the developing countries pay all or most of the capital costs for major large-scale irrigation schemes and seek to recoup only a small fraction of these costs. The focus is then more likely to be on the costs of O\&M. In this view, it would make sense to discuss some of the water rate setting principles or methods.

I. The marginal cost pricing principle. This rate-setting rule is applied where allocative efficiency (maximizing net social product) is the primary objective. When rates are set according to the schedule of marginal cost of supplying water, then the user will demand the commodity as long as marginal willingness to pay exceeds incremental cost, and the optimal level of usage will result. On the other side, the variety of definitions of the appropriate marginal cost concept for pricing policy makes its application difficult. An example concerns the transactions costs

\footnotetext{
111 Philippine is a good example for such case. Irrigation fees, that have been levied since at least 1946, were originally established in monetary terms. But over time, inflation severely eroded the real value of these fees, which, for political reasons, were difficult to raise. Since 1975, the irrigation fees paid by farmers have been denominated in terms of paddy. The farmers may pay either in kind or in an equivalent amount of cash. The cash value of the fee is based on the government's support price of paddy, and therefore increases with any increase in the support price (SMALL/CARRUTHERS 1991.180).
} 
associated with measuring, allocating, and monitoring a water pricing system ${ }^{112}$. In addition, multi-part pricing systems (where marginal price is set equal to marginal cost with no relation to output) often fail to account for the economically correct concept of opportunity costs, focusing rather on historical or embedded costs. Furthermore, opportunity costs should be determined by a market mechanism rather than by administrative procedures (YOUNG 1986:158-9).

II. The ability-to-pay principle. This principle rests heavily on the equity criterion. Commonly, the rate here recoveries fully only operating costs, plus a small fraction of the initial investment ${ }^{113}$. The concept, argued YOUNG, is inherently subjective and political pressures arise to set the formula in ways which redistribute income from taxpayers to water users.

III. Payment per unit of water (volumetric method). Through this method, an economical water use is directly achieved. It encourage efficient water use by maintaining a constant relation between the amount of water used and the payment to be made. Water use reaches its limit wherever the price corresponds to the marginal yield. In spite of the desirability of this method, its introduction often meets resistance and difficulties. Volumetric method, called as potential price, has the disadvantage of requiring high administrative expenditure for measuring and controlling water use and the collection of charges - especially for projects serving numerous small farmers under demand systems. Farmers find ways and means to block the devices, especially in open canal systems. On the other hand, the cost of each device, its installation and subsequent monitoring may not compote advantageously with a less efficient system (payment per unit of land) (MANIG 1984:1105; KELLER 1986:347; SAGARDOY, BOTTRALL, and UITTENBOGAARD 1986:127).

IV. Water charges related to land (flat rate per area unit). This principle is seen as the simplest regulation for levying water charges and easy to administer. It can also be regarded as a kind of land tax. In this connection argues ELLIS (1992:270) that the most practicable and equitable method of fixing the water fee can be then to apply a uniform repayment levy per hectare of cultivated land irrigated by the scheme. ${ }^{114}$ However, investigations carried out in several countries (Pakistan, Mexico) indicate that more than 50 of the farmers deviate by more than 10 percent of the average

${ }^{112}$ For example, in an irrigation system with plentiful water supplies and numerous small field units, the transactions costs of a volumetric pricing system may exceed the value of water saved (YOUNG 1986:159).

113 This because shadow prices, not market prices, are used in the calculation of the economic return. Where the two prices differ sharply, it is possible that the water users could not afford to pay for the total cost of irrigation, even though the investment shows a favorable economic return to the nation. SMALL and CARRUTHERS (1991:163) refer to one significant administrative complication that may make it difficult for a public agency to collect the cost of irrigation services from the water users, even if they can afford to pay for it. This is the difficulty in estimating what benefits each individual farmer receive, and accordingly adjusting the irrigation charges.

114 Some variation in the rate, argued ELLIS (1992:271), may be desirable to reflect visible differences in water access by farmers at differing distances from outlets. The disadvantage here is that some farmers would then feel entitled to receive more water than other farmers, and cooperation between farmers as a group becomes more difficult. 
depth of water applied in the scheme (SAGARDOY, BOTTRALL, and UITTENBOGAARD 1986:129). Such a method of payment is accordingly not equitable for many of the farmers. Furthermore, argue the authors, this principle disassociates the commodity (water) from the rate paid which does not encourage the efficient use of water. It has, in addition, the disadvantage of producing a regressive effect (MANIG 1984).

The last two methods have been evaluated in a study in Egypt (1986). The optimal pricing instrument judged by the efficiency criterion, according to the study, was the instrument that maximizes returns to land and water in the study area and net of social costs incurred in providing and charging for the irrigation water. At that time, aggregate irrigation water supply in Egypt was generally adequate to meet demand in the agricultural sector. It is not surprising, then, that the results of this study have shown pricing systems with a zero marginal charge to be most efficient under nonscare supply. With other words, the study has shown area-based water charges (in particular flat rate) to be more efficient and just as equitable as volumetric charges under the plentiful water supply conditions (YOUNG 1986:174).

Finally, it is worth noting that for already existing schemes, the issue of capital repayment is academic since the capital is a sunk cost. The issue here is then how to encourage the schemes to cover their current costs and to 'pay their own way.' This policy; selfsufficiency of irrigation systems, has been declared in Sudan in December 1992 and through which user contributions should cover O\&M costs.

\subsubsection{Institutional Factors and Strategies Related to Collection of Water Fees}

Even the best designed system of irrigation fees can be destroyed by low rates of collection of the fees assessed. To deal with this issue, argue SMALL and CARRUTHERS (1991:202), we need to be concerned with all conditions, not only the enforcement, which create a willingness to pay on the part of the water users. They occlude the following factors:

- giving the water users a perception that they own the irrigation facilities;

- making the personnel of the irrigation agency accountable to the water users for the performance of the irrigation systems;

- earmarking fees collected in a particular project for use in the operation and maintenance of that project;

- paying water users' organizations a commission to collect the fees from its members;

- providing positive financial incentives, such as discounts for prompt payment;

- providing positive social incentives for payments;

- providing enforceable penalties for non-payment, such as termination of water deliveries or other financial, legal, and social sanctions;

- making direct contact with the water users, rather than waiting for the water users to come to pay their fees;

- giving responsibility for collection to intermediaries who are in more direct contact with the water users; and

- allowing the users to pay their fees in kind rather than in cash. 


\section{Part II: Irrigation Scheme Management Organizations in The Sudan: The Empirical Part}

Sudan is the largest country in Africa covering a total area of about 2.5 million sq. $\mathrm{km}$. with population estimated of about twenty-eight million in $1995^{115}$. The last census indicates that about $69 \%$ of the population is rural while about $20 \%$ live in urban and semi-urban areas. The remaining $11 \%$ constitute a nomadic population. According to the World Bank estimates Sudan is one of the 48 world's poorest countries ${ }^{116}$. The north third of the Sudan is almost a desert with an annual average rainfall of about 20 millimeters. Due to the absence of rain in the northern Sudan, the population depends completely on the Nile River - the sole traditional source of water - for irrigation. The rainfall increases steadily from north to south until it reaches isohytes $400 \mathrm{~mm}$. to $800 \mathrm{~mm}$. Therefore, the water problem in the Sudan range from desert conditions to those of the huge swamps.

According to the Food and Agricultural Organization of the United Nations (FAO) estimate of 1985 there were 33.6 million ha. ${ }^{117}$ (hectares) of irrigable land in Sub-Saharan Africa. Out of 5.6 million ha. under irrigation only 2.7 million ha. consisted of modern farms, and of this, 1.7 million ha. were found in Sudan alone and the other nine countries had 50000 ha. of modern irrigation ${ }^{118}$. Therefore, Sudan has about $63 \%$ of the modern irrigation in SubSaharan Africa (AHMED ed. 1989:5). This indicate that Sudan has one of the greatest potentialities for the world's food production. A fact that has been firmly recognized in Room's International Conference on Food Problems. This recognition has put on the Sudan, among other few countries, the responsibility of increasing their agricultural yields.

In recent years, to sustain food security for increased population, coupled with the desire of improvement in living standards, there is a fundamental need to look for additional possibilities of increasing agricultural production. Theoretically, this is possible because of the existing large area suitable for agriculture. Considering the worldwide tightening of funds and the availability of (fewer) good sites for new irrigation development in Sudan, the goal of sustaining system performance become more serious. As stated by FAO (1986:105), a major step toward improved land-use in the Sudan "would be achieved by putting already available land resource information to work at all levels of decision-making from national to project and farm level".

\footnotetext{
115 The third national population census was conducted in 1983 and estimated population at 21.6 million.

116 According to the cross-country study of DASGUPTA (1993:112), based on the strengths and limitations of the BORDA Index, Sudan is the 21 of the lowest-ranked countries in 1980.

1171.0 ha. (hectare) $=2.381$ feddans. Feddans will be used more often as a mass in this and the next Chapters.

118 For a more detailed discussion of the social conditions in Sub-saharan African, see CARR-HILL (1990).
} 


\section{Agriculture and The National Economy ${ }^{119}$}

Agriculture, as is so often the case in developing countries, is the dominant sector of the Sudan economy, accounting for over the third of the county's GDP throughout the 1980s (38\% in 1993), and about $97 \%$ of its exports. Eighty per cent of the labor force is engaged in agriculturally related activities, and agriculturally based industries represent $80 \%$ of the total manufacturing sector. It has, in addition a significant impact on other sectors of the economy. Component of the sector include crop and livestock production, forestry, fishing, and hunting.

Sudanese government budget and foreign currency availability are based on cotton. The distorting effects of this monocultural production with its roots in empirical economic history, does not need underlining. Cotton production is, however, limited by water resources and crop rotation. Moreover, production of wheat and other staples are important aims of government to improve domestic food supplies and slow down increasing dependency on food imports.

\subsection{Structure of the Agriculture Sector}

Sudan has virtually unlimited agricultural resources with a potential for producing a wide range of crops. Approximately 35 million ha. in Sudan may be potentially arable, and another 100 million ha. are suitable for grazing land. From the total area of Sudan, the more recent salient land-use statistics (Ministry of Agriculture, 1991) show that only 10.2 million ha. (4.1\%) are currently cultivated, about 94 million ha. (37.6\%) are occupied by forestry, 66 million ha. (26.4) are pastures and 80 million ha. (32\%) are uninhabited (Table 4.1). From the total cultivated area, $17.9 \%$ is directly managed by the government, $0.3 \%$ by the cooperatives and $81.8 \%$ is owned by the private sector in different sub-systems of land tenure.

The majority of cultivated land in Sudan is rain-fed. It constitutes $80 \%$ of the Sudanese agriculture comparing to about $86 \%$ in mid 1980s. Rainfed agriculture is the prime source of food grains for domestic use. It contributes more than one-half of the aggregate agricultural production and has, therefore, a higher share of the GDP than the irrigated sector. It also makes a substantial contribution to exports in the form of livestock, gum Arabic, and oilseeds such as sesame, groundnuts and cotton seeds. The traditional and mechanized rainfed farming have been also contributed to a large extent on the attainment of the country's self-sufficiency in the main subsistence food crops such as sorghum and millet.

Traditional agriculture in Sudan is characterized by shifting cultivation, the use of hand tools, and lack of pesticides, fertilizers, and high-yielding crop varieties. The majority of the Sudanese population is engaged in traditional cultivation, including almost the entire population of the southern Sudan. Crop yields are highly variable to large fluctuations in annual rainfall, but are in general low. Soil fertility is declining in many areas owing in part to reduced fallows resulting from population growth and encroaching desertification

119 The purpose of this Chapter is to show, briefly as possible, the background of the agriculture sector, in general and the irrigated sub-sector in particular, in Sudan. The main reason for the brief portrayal is the uncertainty which shape the statistics about Sudan e.g., most of these are either out-of-date or estimated. 
(WHITTINGTON and HAYNES 1985:134). Land is legally owned by the government, but is commonly allocated by community traditions.

Table 4.1 Distribution of the land-use in Sudan

\begin{tabular}{|c|c|c|}
\hline Type of Land-use & Area $\left(10^{3}\right.$ ha. $)$ & $\%$ of the total \\
\hline Traditional Rainfed & 4149 & 1.7 \\
\hline Mechanized Rainfed & 4014 & 1.6 \\
\hline Traditional Irrigated & 0236 & 0.09 \\
\hline $\begin{array}{l}\text { Irrigated Schemes: } \\
\text { Gezira/managil } \\
\text { New Halfa } \\
\text { Rahad } \\
\text { Blue Nile Agricultural Corporation } \\
\text { White Nile Agricultural Corporation } \\
\text { El-Suki } \\
\text { Northern Agricultural Corporation } \\
\text { Other Governmental Irrigated Schemes } \\
\text { Cooperatives } \\
\text { Total Irrigated Schemes }\end{array}$ & $\begin{array}{lll}0 & 840 \\
0 & 170 \\
0 & 149 \\
0 & 127 \\
0 & 084 \\
0 & 034 \\
0 & 028 \\
0 & 384 \\
0 & 028\end{array}$ & $\begin{array}{l}0.34 \\
0.07 \\
0.06 \\
0.05 \\
0.04 \\
0.01 \\
0.01 \\
0.15 \\
0.01 \\
0.74 \\
\end{array}$ \\
\hline Pastoralism & 66011 & 26.4 \\
\hline Forestry & 93746 & 37.4 \\
\hline Unused Lands (Desert and Swamps) & 80000 & 32.0 \\
\hline Total Area of the Sudan & 2500000 & 100.0 \\
\hline
\end{tabular}

Source: Various Sources

Compared to traditional farming, mechanized rainfed agriculture covers about $48 \%$ of the cultivated rain-fed areas but productivity-wise it contributes much more. This percentage was 55 before two decades (SALIH and KHADAM 1976:104). The primary objective of mechanization was to expand sorghum production initially to make the Sudan self-sufficient but later to produce an exportable surplus to cover the costs of wheat imports. However, it is making a substantial contribution to the economy, contributing about $50 \%$ of the country's sorghum production ${ }^{120}$ and $25 \%$ of its sesame.

Mechanization cultivation has witnessed success during the period 1945-1984 (DAVIES 1991a:312). It began in 1945 on an area of 12000 feddans on the clay plains at Ghadambaliya near Gedarf (Fig. 4.1). This site provided suitable land and was accessible to the Port Sudan-Sennar railway, which allowed the assembling of inputs and the marketing of the crop. In 1957 development between the Niles started at Dali and Mazmoum. By 1960 more than one million feddans were demarcated mainly in private enterprise farms of 10001500 feddans, under government supervision. Expansion of the system to new areas in western Sudan, an area suffering constant food supply crises began in 1968 in the Habila area of Southern Kordofan. By 1981 the mechanized area topped 6 million feddans. The 1984/85 famine encouraged further expansion to over 9 million feddans, but due to poor results the figure for 1988 had fallen back to 5.7 million feddans.

${ }^{120}$ In $1987 / 8$, the 'estimated' total sorghum production for the Sudan was 1379000 tonnes, of which $62 \%$ came from mechanized farms (DAVIES 1991a:314). 
Fig. 4.1 Central Sudan: Development of Mechanized Agriculture

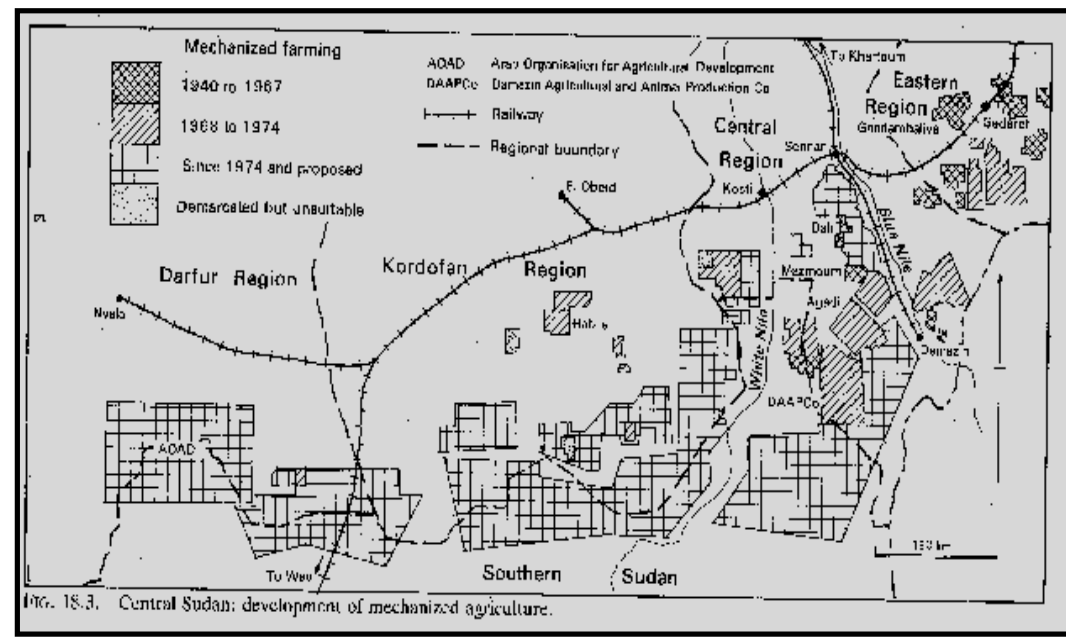

Source: Davis 1991a:313

A serious disadvantage of cultivation in these parts of the country however is the marked uncertainty of production associated with unreliability, timing and localization of rainfall. Since the 1982/83 season, drought conditions built up in the Sudan as elsewhere in the Sahel culminating in 1984/85, causing one of the most serious production shortfalls and famines in Sudanese history where about $20 \%$ of the population were classified as 'drought affected' in that year ${ }^{121}$. The shortage of rainfall was not the sole factor responsible for the deterioration of this important sector. In addition, this sector has been criticized severely (DAVIES 1991a:315) in that it has led to much needles destruction of the vegetation and to a new form of bush fallowing, or land rotation, on a massive and disorganized scale, with land cultivated to exhaustion and then abandoned. After the first flush of new land fertility has been dissipated, yield per feddan have tended to decline gradually. A limited number of absentee lessees have dominated this sector ${ }^{122}$. By 1985 , some $40 \%$ of the cropped rain-fed had fallen into the hands of some 4000 investors.

The Strategy for Development of Rain-fed Agriculture, declared by the government in 1986, emphasizes the potential of the rain-fed sector and describes the objectives of a strategy for its improvement and the basic conditions for success. Unfortunately, this ambitious strategy has not been implemented. For these reasons, the role of irrigation in the future development of the Sudanese agriculture becomes more important.

Irrigated agriculture for the production of cash and food crops is historically essential. The permanent irrigated schemes total areas is about 4 million feddans (1.7 million ha.) (USBR 1986:9). The total irrigated area has risen continually since the turn of the century - 1920: 40 000 feddans; 1935: 300000 feddans, 1955: 1400000 feddans.; 1965: 2800000 feddans; 1975: 4048000 feddans (WHITTINGTON and HAYNES 1985:132). Virtually all of the irrigated land is within the central plain along the Nile River and its tributaries: Gezira/Managil, New Halfa, Rahad, Blue Nile, White Nile, El-Suki, and others (Fig. 4.2).

121 The International Conference on water resources needs and planning in drought prone areas, held in Khartoum 1986, discussed and recommended issues and steps to ovecome the related problems of such phenomenon and water management problems as such (ABDEL-MAGID et al. (eds.) 1986).

122 A similar trend will be registered in New Halfa Scheme (Chapter 6), in particulare between the Nubian tenants. 
Gezira-Managel, with more than two million feddans is today the largest irrigation scheme in the world under one management.

Fig. 4.2 Sudan Irrigation Schemes

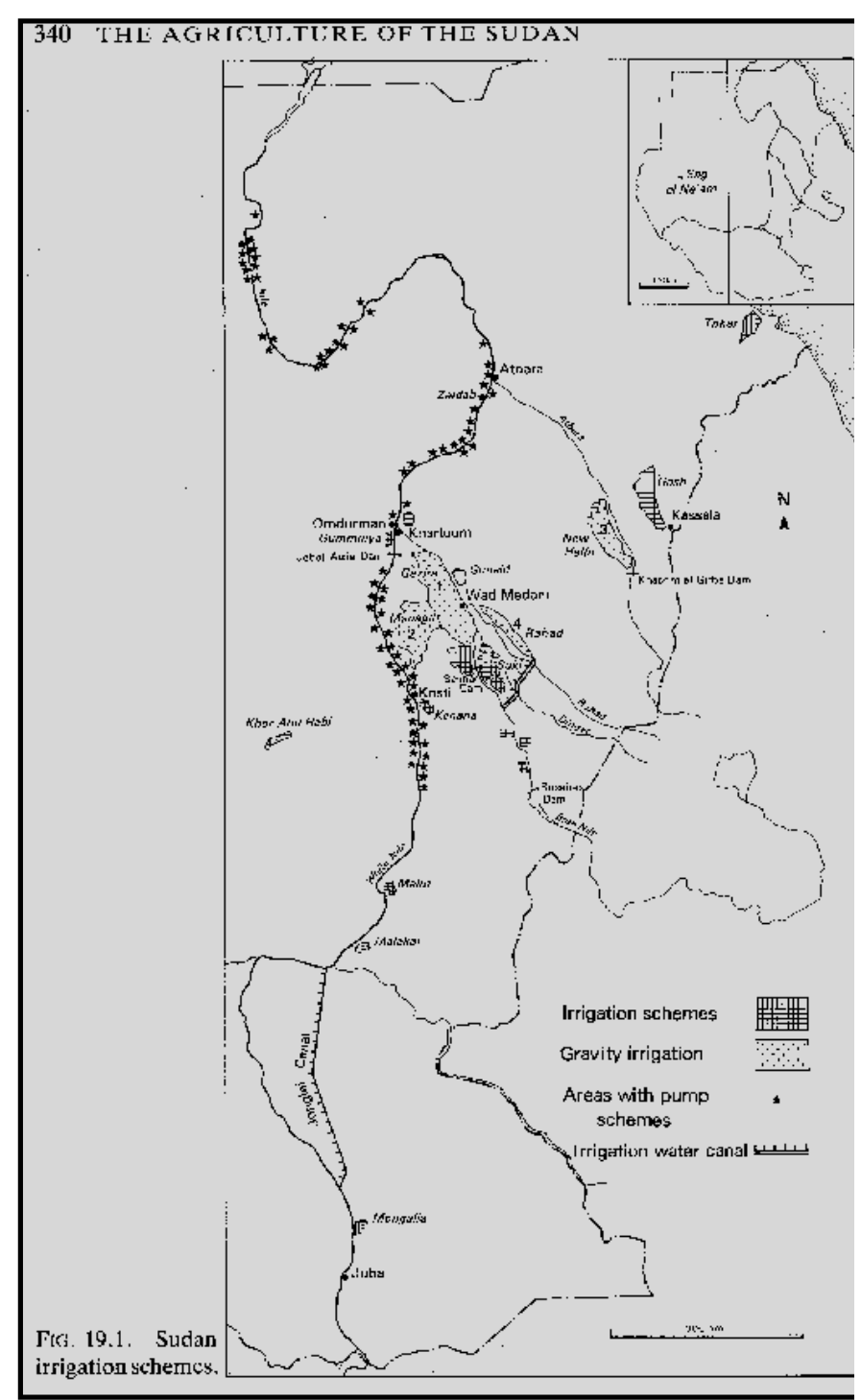

Source: DAVIES 1991b:340

Table 4.2 shows the differences between the total designed cultivable area and the area currently cultivated and irrigated by MOI in most of the schemes. Overall, $78 \%$ of the designed cultivable area is currently cultivated. In the case of New Halfa the difference is explained by lack of water due to the silting of the feeder reservoir. For the majority of the schemes the limitation on cultivated area, concluded the National Irrigation Rehabilitation Program (NIRP), are mainly imposed by lack of water due to the inability of the MOI to fulfil its responsibilities fully. The purpose of the NIRP is to remedy this situation, strengthening the MOI so that it will in future supply water to crops in appropriate quantities and with appropriate timing to raise the cultivated area (MINISTRY of IRRIGATION 1992:Vol. 4, Annex G-5). 
Table 4.2 Irrigated Areas - Current and Potential (1992) feddan

\begin{tabular}{|l|c|c|c|}
\hline Scheme & Cultivable & Curr. cultivated & Percentage \\
Gezira/Managel & 2081692 & 1730000 & 83 \\
New Halfa & 401000 & 285000 & 71 \\
Rahad & 300000 & 280000 & 93 \\
Blue Nile APC & 270000 & 270000 & 100 \\
White Nile APC & 438996 & 228000 & 52 \\
Suki & 86920 & 78000 & 90 \\
Guneid Extension & 45367 & 25000 & 55 \\
Sennar Sugar & 49142 & 22000 & 45 \\
Guneid Sugar & 38270 & 19000 & 50 \\
Assalaya & 35000 & 19000 & 54 \\
Hurga and El Din & 22256 & 11000 & 49 \\
Abu Naama & 30000 & 10000 & 33 \\
Total & 3798643 & 2977000 & 78 \\
\hline Source: Mna
\end{tabular}

Source: Ministry of Irrigation 1992

Although several other crops are grown, cotton still plays a major role, and is important to the country as an earner of foreign exchange. It constitutes $44 \%$ of the exports. The irrigated subsector produces almost all of the Nation's cotton, a substantial amount of oilseeds and food grains (wheat, sorghum, groundnuts), vegetables and sugar. Cotton, sorghum, vegetables and most of groundnuts crops are manually harvested, but wheat is mechanically harvested. The areas devoted to the various crops vary widely from year to year and from scheme to scheme owing to several factors. The most noticeable is the fluctuations in the area of cotton (specially the long-staple) which has constituted $7-8 \%$ of the irrigated area in the first half of seventies (KHALIL 1985:278). The area devoted to cotton at the beginning 1970s was lightly over one million feddans fell to 836000 feddans in the season 1980/81 and then reached a peak of 878068 feddans in the season 1983/84. The provisional figure for 1990 to 1991 was only 427276 feddans. On the other side, the area sown to wheat in 1984/85 fell to 40239 feddans from between 200000 and 300000 feddans previously, and was provisionally reported to have been 887677 feddans in 1990/91. Sorghum has similarly fluctuated between a high of almost one million feddans in 1985/86 with a decline thereafter, and a return to 859452 feddans in 1990/91 (Ministry of Irrigation 1992).

Cotton yields declined dramatically over the last two decades, largely because of the poor management and pricing policies. The yields of medium-staple and long-stable have varied from about $4 \mathrm{kantar} /$ feddans to $5.5 \mathrm{kantar} /$ feddans over the past decade. The yield of the extra long-staple variety, appeared to have improved from about $3.3 \mathrm{kantar} /$ feddans $^{123}$ in the early 1980s but has fallen back again more recently. Additionally, the area sown to this variety has decreased to about half that at the beginning of the decade. According to the Agricultural Research Corporation (ARC), it considered that, with proper water control, medium-, and long-staple varieties should achieve 6 to $7 \mathrm{kantar} /$ feddans (the former can achieve $18 \mathrm{kantar} /$ feddans under optimum conditions) and that the extra long-staple variety, although rather unpredictable, should yield about 5 kantar/feddans (Ministry of Irrigation 1992). This decline in cotton yields wreaked havoc with Sudan's economic development plans.

${ }^{123} \mathrm{Kantar}=141.5 \mathrm{~kg}$. 
As the Ministry of Agriculture responsible for the Agricultural Corporations, the Ministry is required to draw up the overall cropping program for each year. This program is finalized in consultation with the Ministry of Irrigation (MOI) to ensure that the crop water requirements are capable of being fulfilled, taking into account the water expected to be available from the Nile and the constructions of the canals systems, pump stations, etc in actual conditions in which they exist. It is one of the basis of MOI's undertaking to provide the required water that the programs of the various Agricultural Corporations are approved by the Ministry of Agriculture (MINISTRY of IRRIGATION 1992, vol. 1 of 4:A26).

It is important here to review some of the problems encountered by irrigation practices in Sudan during two decades as concluded in the Water Resources Study of 1976 (SALIH and KHADAM 1976:126-8):

I. Problems at storage conveying system

a. Losses due to evaporation (evapotranspiration, seepage, breakage and weeds both in reservoirs and canals.

b. Scouring and erosion problems downstream of dam (example: Kashm El Girba dam).

c. Silting problems at reservoirs and canals (example: Kashm El Girba Dam).

d. Night storage versus continuos flow in minor canals.

e. Accuracy in water measurements.

f. Working out an efficient system of coordination

I. Problems at the field. Work in this side should generally concentrate in improving the application efficiency. In addition to the need of cooperation between different institutions, researches should concentrates on the following:

a. Reduction of losses in farm distributors and subdistributors (i.e. through lining, use of pipe, etc.).

b. Reduction of field application losses (through wider appreciation of the physical characteristics of the soils, etc.).

c. Timing and depth of application (i.e. time of starting and ending the irrigation period, interval between irrigation, etc.).

d. Uniformity of application (lack of uniform distribution of water on the field).

e. Proper drainage and conversation of excess water.

f. Introduction of new methods of irrigation or improvement of present methods

\subsection{Irrigation Schemes in the Context of the Sudanese Agriculture Development}

The irrigation schemes are derived historically from the initiation of the Gezira Scheme in the 1920 s, to produce cotton. The scheme began in 1926 following pilot developments from 1911 at Tayiba and later Barakat on the Blue Nile, these in turn being based on the Zeidab Scheme. Gezira Scheme, at the early stage, was operated on a tripartite basis: (a) the colonial Sudanese Government making land available for the scheme, constructing a dam on the Blue Nile at Sennar, and undertaking the major canalization; (b) the Sudan Plantations Syndicate (SPS), a London-based company, managing the scheme; and (c) individual tenant farmers taking responsibility for the cultivation of crops under the direction of the company. The Sudan Plantation Syndicate's concession expired in 1950 and its functions were taken over by the Sudan Gezira Board (SIMPSON 1991:105). 
The government under the 1921 Gezira Land Ordinance entered into an agreement with the owners to lease the land for 40 years at a rental of 10 piasters per year, representing the annual value of non-irrigated land. Land on lease could only be sold or mortgaged to the government and, as a result, most of the land has come, finally, into government ownership. A part from direct compensation for loss of their land, owners were given the first right to tenancies in the scheme with a maximum of two standard tenancies (each of 30 feddans gross, of which 20 were cropped). The tenancies consisted of several separate 10-feddans plots (howashas) in a 90-feddans field (number) which formed the basic unit for irrigation. Each number was planted to a single crop within a six- or an eight-year rotation, a system which continues to the present.

Tenants agree to grow a fixed area of cotton and other crops as laid down by management. Cotton and wheat are marketed by the scheme management and profits after the sale of crops are divided three ways between the Sudanese Government, scheme management, and tenant. The tenant can dispose of other crops himself. Since 1981, the share arrangement has been changed from what was known as a 'joint account' system to an 'individual account' system, the later relating the tenant's rewards more closely to his input.

The principles of Gezira, that have been introduced to the New Halfa and Rahad Schemes were subject of criticism (DAVIES 1991b:344-5). The first of the main criticism of the Gezira replication policy was the lack of freedom afforded to the tenants who, in practice, were little more than agriculture labors. The second was the tendency for tenants to find offscheme jobs in towns or elsewhere, arranging for someone else to cultivate the tenancy on some sort of crop-sharing - what is refereed to as the development of 'landlordism'. In addition, problems escalated in the Gezira and the other schemes because the system of management did not evolve as the situation changed.

The technical characteristics of the Sudanese irrigation schemes as defined in the National Irrigation Rehabilitation Program of Ministry of Irrigation (1992:F9-11) are as follows:

- they were designed using criteria developed in the 1930s for Gezira, intended for daytime-only irrigation on deep vertisoils;

- they are water-limited (the area irrigated is limited by the availability of water, not land);

- they have unlined canals with few escape structures, and the escapes that do exist are on primary canals only and have capacities intended only to deal with local rainfall;

- the larger canals were designed for continuous flow using the lacey-Matthews regime equations, while the secondaries (Minors) are wide and shallow and inevitably have less than regime slope: these were originally intended for night storage to enable irrigation to be done in daylight only, but the same cross-section is often used without that intention;

- the outlets from the Minors, i.e., the tertiary head regulators called FOPs, were fitted with a type of disc gate which is not robust: it is easily damaged or removed;

- the schemes receive significant quantities of sediment at their headworks, particularly in July and August: the land slops are such that about $70 \%$ of this sediment is deposited in the canals and some passes to the field, where it is not uniformly distributed ${ }^{124}$;

\footnotetext{
${ }^{124}$ Such characteristic is very important for the discussions of land levelling (Chapter 6.2.1.2) and irrigation method (chp. 6.3.4).
} 
- they originally had a disciplined but not very accurate system of estimating crop water requirements, with an indenting procedure to arrange delivery of the requested quantities of water; and

- the earlier schemes once had telephone systems for communication between the operators over large distances, but this is generally lacking now (except Gezira-Managil where a new radio telephone system works well).

These characteristics were in general appropriate for the Gezira conditions of the 1930s. Nowadays, concluded the final report of the Irrigation Rehabilitation Program, conditions have changed in several ways, such as:

- the Blue Nile carries much more sediment (because of increased erosion in Ethiopia), and further increases are likely in the future;

- the cropping is more intensive and the crop calendar has changed;

- weed infestation is worse, and even the restoration of 1935 conditions in other aspects would not be bring the schemes back to the 1935 weed conditions;

- some fields are higher than they were when the scheme was designed.

In addition to the above, the capacity of the MOI and agricultural corporations to maintain or improve the physical infrastructure of most schemes, have deteriorated. The consequences of all these facts is that the available water distributed between fields and from weak to weak, even when total volumes delivered to large blocks over longer time periods are reasonably appropriate. The final consequence is reduced agricultural production.

The expansion of irrigation has failed to bring about the anticipated improvement in the Sudanese economy and can be described, then, as 'development trap', as it hindered the necessary structural change in the economy.

\subsection{Limitations of the Irrigated Agricultural in the Future}

The development of the agricultural sector in the future is dependent on two factors that are (outside) the control namely the availability of foreign currency within Sudan as a whole and the availability of water.

\subsubsection{Performance of the National Economy}

The agricultural sector is suffering from the repercussions of the most sever economic crisis since Independence (1956). This economic crisis which has been affecting the Sudan since 1977/8 is, argued WOLMUTH (1991:436), the result of unfavorable world market trends, over-ambitious development programs in the 1970s and a failure of policy reform at the macro-and sectoral-levels in the 1980s. However, causes and evidences according to this diagnosis are: "the worsening balance of payments situation, the increasing indebtedness, the failure to come to terms with the International Monetary Fund (IMF), the banks and other donors, the decrease of official transfers from Sudanese workers abroad, the decreasing level of foreign aid, the increasing pressure on the Sudanese pound (£s), and the capital flight go parallel with unfavorable cotton marketing conditions and unstable internal political developments". 
The other graph which is showing upward trends beside population (at abut $2.8 \%$ annually overall), is inflation. It is very difficult to find the actually inflation rates in the Sudan. More difficult, however, is to depend on the official rates declared sometimes from the government. That is why, we have to depend instead on the exchange rate as an indicator for the performance of the national economy.

The pressure on the Sudanese pound since 1977/78 has affected, first of all, the agricultural sector. Due to the several devaluations after this date Sudan was not able to secure the necessary inputs for the agricultural sector. For example, the annual increase in the price of fertilizers, due to the devaluation, in the years 1978,1979 , and 1980 was $57 \%, 43 \%$, and $64 \%$ respectively. Insecticides increased also during the same period $14 \%, 72 \%$, and $84 \%$ (KHALIL 1985:422). This trend has continued also, more sharply, during the 1980s and the 1990s. For example, the official exchange rate until the end of October 1988 was £S $4.5=$ US. \$ 1.0, decreased after three months 100\% (in January 1989: £S $9=$ US. \$1.0). In February 1992, the official exchange rate was set at £S $90=$ US. $\$ 1.0$, twenty times the 1988 level (MINISTRY OF IRRIGATION 1992). The negative consequences of these facts on the agricultural production will be discussed in chapter 6 .

Among the discussion of the main problems of Sudan, KASPAR and MOLL (1986:96) argued that the low level of infrastructural and industrial development as well as the lack of national or private capital resources complicate relief efforts and attempts to distribute population and promote economic development. Of note here is the special role of infrastructure in this context. It is known that poor countries usually suffer from the lack of infrastructure. At an extreme is the remarkable fact, even by the appalling standards of the worst of poor countries, that the Sudan, with such population size and area, even now has only about 3000 miles of roads, 2500 miles of which are gravel or unpaved tracks. It is not difficult to imagine, argued DASGUPTA (1993:147), the role this paucity has played in the incidence of famines there.

\subsubsection{Demand-Supply Water Gap}

The total amount of Nile water allocated to the Sudan corresponding to the 1959 Nile Water Agreement between Sudan and Egypt is 18.5 billion $\mathrm{m}^{3}$ (whereas Egypt is using 55.5 billion $\mathrm{m}^{3}$ ) of which over $90 \%$ is utilized in agriculture ${ }^{125}$. This allocation was based on an assumed annual flow at Aswan of 84 billion $\mathrm{m}^{3}$. After Sudan withdraws 18.5 billion $\mathrm{m}^{3}$ as measured at Aswan, the remaining 65.5 billion $\mathrm{m}^{3}$ enters the Aswan High Dam reservoir. Evaporation and seepage losses are assumed to average 10 billion $\mathrm{m}^{3}$ and Egypt is left with its annual allocation of 55.5 billion $\mathrm{m}^{3} .{ }^{126}$

125 The 1959 Nile Water Agreement established a more equitable distribution of water between Egypt and Sudan. The 1929 Agreement allocated only 4 billion $\mathrm{m}^{3}$ to Sudan compared to 48 billion $\mathrm{m}^{3}$ to egypt, and reserved the entire 'timely' flow for Egypt, obliging Sudan to irrigate the Gezira scheme only during the winter months.

${ }^{126}$ WHITTINGTON and HAYNES 1985 commenting on the sharing basis by saying: "Actually, the mean flow at Aswan over the last century is over 90 billion $\mathrm{m}^{3}$, not the 84 assumed in the 1959 agreement. The lower estimate is clearly favourable to Egypt because the difference flows into the Aswan High Dam reservoir for the sole use. On the other hand, annual evaporation and seepage losses are closer to 14 billion $\mathrm{m}^{3}$ rather than the 10 billion $\mathrm{m}^{3}$ originally anticipated (p. 136). In view of the variations in the annual flow of the Nile, the lenght of time required to fill the new high dam reservoir and the knowledge that Sudan would not need the whole of its water allocation immediately, an arrangement was made whereby Egypt could borrow up to 1.5 billion $\mathrm{m}^{3}$ a year until 1977 and then pay back the excess drawings over the following ten years 
This share is not adequate to meet the water demand of the irrigation development stipulated in the prospective short- and medium-term plans for the Sudan. The total amount of Nile water suffices only for the irrigation of some 1.6-1.8 million crop ha. (3.8-4.3 million feddans) per year. Even if additional supplies become available, through further development particularly in the south region, and taking into consideration flood irrigation possibilities in the Gash and Toker deltas, the yearly irrigated area will not exceed 2.4 million ha. (5.7 million feddans), and this target can be achieved only by an efficient wateruse.

The chairing of the Nile waters has long been a problem between Sudan and Egypt, for while Egypt is totally dependent on the Nile, much of the Sudanese major schemes (which are currently being overhauled with the intention of expanded production) are based upon it. As the water of the Nile are finite, it appears unavoidable that at some stage Sudan and Egypt will between them seek to use more water from the Nile than the river contains. Herein lies, as many experts argued a major development dilemma. That is why, the water demand forecasts for both countries treat water as a requirement which must be supplied irrespective to its costs.

In addition to the Sudan-Egyptian problem, an additional complication may arise if, as suggested, Ethiopia endeavors to make greater use of the water of the Blue Nile ${ }^{127}$. According to the above, the inescapable conclusion is that Sudan is rapidly approaching the point where all future agricultural projects will be operated. If at all, at the margin of available water supply. This margin will be determined by the implementation of the upper Nile projects, including perhaps those in Ethiopia in the supply side. In turns, demand will be function on the pace and extent of new irrigation schemes in Sudan, including crop chosen, and the development of the non-agricultural use of water in industry and household.

Sudan is currently using $15-16$ billion $\mathrm{m}^{3}$. Almost (all of this) is for irrigation. Irrigation schemes are planned which would use an additional 10 billion $\mathrm{m}^{3}$ - all of the new supplies which will be available from the upper Nile projects. Both of the upper Nile projects and irrigation schemes require financing ${ }^{128}$. Forecasting water supplies and demands is thus essentially an exercise in forecasting Sudan's macroeconomics and political conditions, and the priority these water development projects will receive in Sudan's extremely limited capital investment program. On the light of these facts, argued WATERBURY (1982) that, given the current economic morass and other pressing investment priorities, in addition to

(DAVIS 1991b:342). Anyway, Egypt feel she has dealt with the issue of nile water allocation honourably since, untile the twentieth century, she was the only state in the basin to rely upon irrigated agriculture.

127 The four major hydroelectric projects planned by Ethiopea, however, are one the Blue Nile between Lake Tana and the Sudanese border. Together these four dams have an initial actine storage capacity of about 51 billion cubic meters and an estimated annual electricity generation of over 25 billion kwh, about three times the actual production of the Aswan High Dam. The annual mean flow of the Blue Nile at the SudaneseEthiopean border is about 50 billion cubic meters, so that the combined active storage is approximately equal to the mean annual flow. The results of this have indicated, however, that the objectives of Ethiopian hydropower production and Sudanese and Egyptian agricultural water use are not conflicting (WHITTINGTON 1985:3,4).

128 According to other Senario (MUSA 1991), it is estimated that $62 \%$ of Sudan's cultivable area is in need of irrigation, considering that rainfed cultivation is a resk due to high variability of rainfall. To use its potintial, Sudan will then need anually 23.4 billion cubic metters in addition to its present share in the Nile water. 
the political conditions, Sudan will not be able to undertake any additional upper Nile projects after 'Jonglei 1'. Even if the Jonglei project is successful in providing the Sudan with a future annual supply of 3 or 4 billion $\mathrm{m}^{3}$ of water, it will only delay the day when further conventional agricultural development will be impossible without new water resources. The way a head will have to be in making better use of existing readily supplies, including reducing evaporation and selecting crop plant species with low water requirements per unit of yield and improving the irrigation systems (WHITTINGTON and HAYNES 1985:137,39).

In addition to the economic situation and the financing bottlenecks, another hindrance for increasing the supply of water in Sudan is the capacity of the reservoirs. For example, siltation is reducing the storage capacity of Reseires much more rapidly than originally anticipated. From the completion of the reservoir in 1964 to $1976,75 \%$ of the reserved dead storage was filled. The accepted solution is to heighten Roseires to $490 \mathrm{~m}$, thus adding approximately 4 billion cubic meters of storage (WHITTINGTON 1985:12). The same problem, as it will coming in the next chapters, prevent Khashm El Girba reservoir from working with its full capacity.

Finally, it is to note that, not only for crop production, water supplies will be a limiting factor for the development of livestock production. Heavy concentration of grazing around a few good watering points might lead to overgrazing and erosion, and the opening up of new areas will depend to a large extent on the availability of water. Considering the socioeconomic objectives, the Sudan is indeed engaged in a battle for more and better water for man, livestock and crops. 


\section{Implementation of The Field Study}

\subsection{Purpose of the Field Study}

The empirical part of this study is implemented in two irrigation schemes in East and North Sudan. The original aim of the field study has been to analyze the two organizations and their management and, in particular, the ways of making such organizations more effective and more efficient in the water use. The focus has been further narrowed by concentrating on the water users levels i. e. whether there is water shortage, wasted water, injustice, co-operation or hassle between water users from one side and between them and the levels at which decisions and actions affecting allocation and acquisition are taken from the other, and what options are available to tackle the existing institutional constraints. To achieve such aims the analyst needs to distinguish the coming three layers of rules that, according to TANG/OSTROM (1993:5-6), cumulatively affect the actions and outcomes achieved in irrigation systems:

Operational rules: (allocating water, clearing canals, and monitoring and sanctioning the actions of irrigators and officials) affect the day-to-day decisions made by users and suppliers concerning when, where, and how to withdraw water ; what information must be exchanged or withheld; and what rewards or sanctions will be assigned to different combinations of actions and outcomes.

Collective-choice rules: are the rules used by irrigators, their officials, or external authorities in making policies- the operational rules- about how an irrigation system should be managed. Here is also the level where the policy-making, management, and adjudication of policy decisions occur. Therefore, they affect operational choices; a change in 'policy' implies a change in operational rules.

Constitutional-choice rules: (formulation, governance, adjudication, and modification of constitutional decisions) results through their effect on : 1) who is eligible to participate in the system and (2) what specific rules will be used to craft the set of collective-choice rules 129

${ }^{129}$ UPHOFF (1991:18-9) has also referred to three main points of reference which constitute the basis of improving the performance of irrigation system : (1) Irrigation system (physical possibilities and the human relationships associated with it), (2) the objectives of irrigation management (whose values dominate and whether there is a conflict), and (3) the context of irrigation Organisation which determines the capacity for irrigation management. In contrast, the GTZ's orientation framework regarding irrigation systems (HUPPERT/WALKER 1988) has developed two packages of factors that exercise a considerable influence on the management of organization and control of irrigation systems. The first package of these factors is concerning with „status of irrigation system“ and include therefore: area, number of users, management levels of the organization, production aims, flexibility and divisibility of technology. Secondly, the package of factors of situation variables, ,management uncertainty“, contains the elements of irrigation tradition, complexity and dynamic of the environment, availability of resources, goal conflicts (MANIG 1989:17). Other package that should be stressed, on its own, is concerning with the farmers (tenant farmers as in the two cases of this study) as water users and beneficiaries of the irrigation. To this package belongs factors such as the role of water users (as individuals and organization) in water distribution and water control, their way of communication with field staff, their attitude towards scheme management and polices. 
For a better understanding of the real causes of the poor or high irrigation agency performance, the analyst needs also to collect a considerable amount of information about some variable or aspects that MORIS/COPESTAKE (1993) calls as 'neglected' or 'invisible' variables. These variables, that are usually omitted from farm-level field surveys, are not only about farmers, villagers and the environment but also about their own and other institutions operating in the communities being served (p.25). They are founded at the two levels; the agency level and the community level (p.25-34):

- the agency level consist of two clusters of concern. One relate to questions about other agencies operating in the same territory; their coverage, reliability, staff morale, past relations with farmers, and specialties organizational variable. The other task variables relate to questions concerning the operations of a particular agency, its internal workings and ongoing performance e.g., are staff sufficiently motivated? do they feel their effort are seen and appreciated? and is the program reaching all segments of the local community?

- The second level - community level - concern with the key community traits which rural planners may need to know about e.g., main sources of cash income, previous development efforts, infrastructure, community leadership traits, degree of inequality and factionalism, degree of corruption and security situation.

These variables and factors, in addition to those of the water users' level, will be in-depth discussed in this part of the study. According to the above, and considering the characteristics of irrigation systems and the different dimensions of their organizations and management that have been discussed in the first two chapters, the field study in the two schemes; New Halfa Scheme, and Gendettu Scheme (elucidated in detail in the next sections) has concentrated upon:

- what is happening at the operational level: characteristics and attributes of the existing management of irrigation systems;

- discussing and analyzing the central and universal issue in irrigation systems: water distribution/allocation between farmers sharing a common watercourse, as defined by CHAMBERS (1980:33) "who get what, when, and where";

- whether the position of the farmers' fields along the particular water course (head-middle-tail) is a critical factor in determining water control;

- behavior of water users in different schemes as to size, the distribution of tasks, and the ownership;

- the relationship between methods of land use and water use;

- the main distinguishing features of the institutional form which carry out the management functions in different forms of schemes; 
- articulation and linkages between the water users and the system authorities; the communication and information canals that are used and respected by the information society;

- the degree of identity between the current practice in water application at field level and the official rules;

- the relationship between the water users, and the project, with the other organizations related to agriculture;

- the human dimension in irrigation system management (the socio-cultural factors, to what extent involvement in day-to-day system operation is practiced, and participation of women);

- the collective-choice entity in both schemes (the different interest groups, whose values dominate; diversity and conflict, and arbitration);

- to what extent influence the political conditions an irrigation system; try to analyze the effect of the despotism/tyranny or absence of democracy upon organization structure;

- the technological situation at the terminal units and the performance of water use; which alternatives are needed: modern irrigation techniques or improvement of existing methods?;

- the economic dimensions:, productivity of each crop, variation in yield with respect to the yield/water delivery relationship, and the relationship between efficiency of water use and productivity;

- could water pricing policies be used to encourage efficient water use? and

- which role play the supporting institutions (research extension, supply of farm inputs, credit, marketing, and health institutions) in achieving the efficiency of water use.

The study is intended, therefore, to be a contribution in understanding, from close up, the managerial and organizational factors that hinder the improvement of irrigation water utilization, and trying, in the same time, to highlight some aspects that may be help in establishing organizational and managerial ethics in the irrigated sector ${ }^{130}$. It is also one of its aims to examine the related three main objectives of irrigation management- e.g. (1) efficiency of water use, (2) productivity of irrigated agriculture, and (3) profitability of irrigated farming- and to find to what extents are they dependent from each other.

${ }^{130}$ DAHAL (1993:66) used the concept of managerial ethics as a target for the leading sector in Nepal (forestry sector) which consider, he argues, very important for the development of the other sectors in the country.

129 The various levels in a system, from field to headworks, are the farm level (the outlet „field channel“ level), the distributary (Minor canal in this case), and the main canal. This permits assessment of differences in management within systems. 
The focus will be on current water management on the tertiary level, i.e., the penultimate stage in the field water distribution system. That means from the field water-course (Abu $\mathrm{XX}$ ) through the lateral water-course (Abu VI) to the crop field- the geographic unit for the study ${ }^{131}$ (see the technical context in this Chapter: 5.4.4). The individual tenant is the most important unit of analysis. Here, we stress the Tenant Farmers' role as water users i.e., water and how they deal with; distribute between them, and factors that influence these aspects.

\subsection{Study Areas}

Two schemes were chosen as case studies during 1992-93 season. The first is large-scale, Agency-Managed system (settlement scheme) in the eastern region called New Halfa (Khashm El Girba) Scheme. The second that can be referred to as Medium-scale ${ }^{132}$, Agency-Managed system, lies in the governorate of Shendi, in north Sudan, called Gendettu (Fig. 5.1).

Fig. 5.1 Study Locations: New Halfa and Shendi

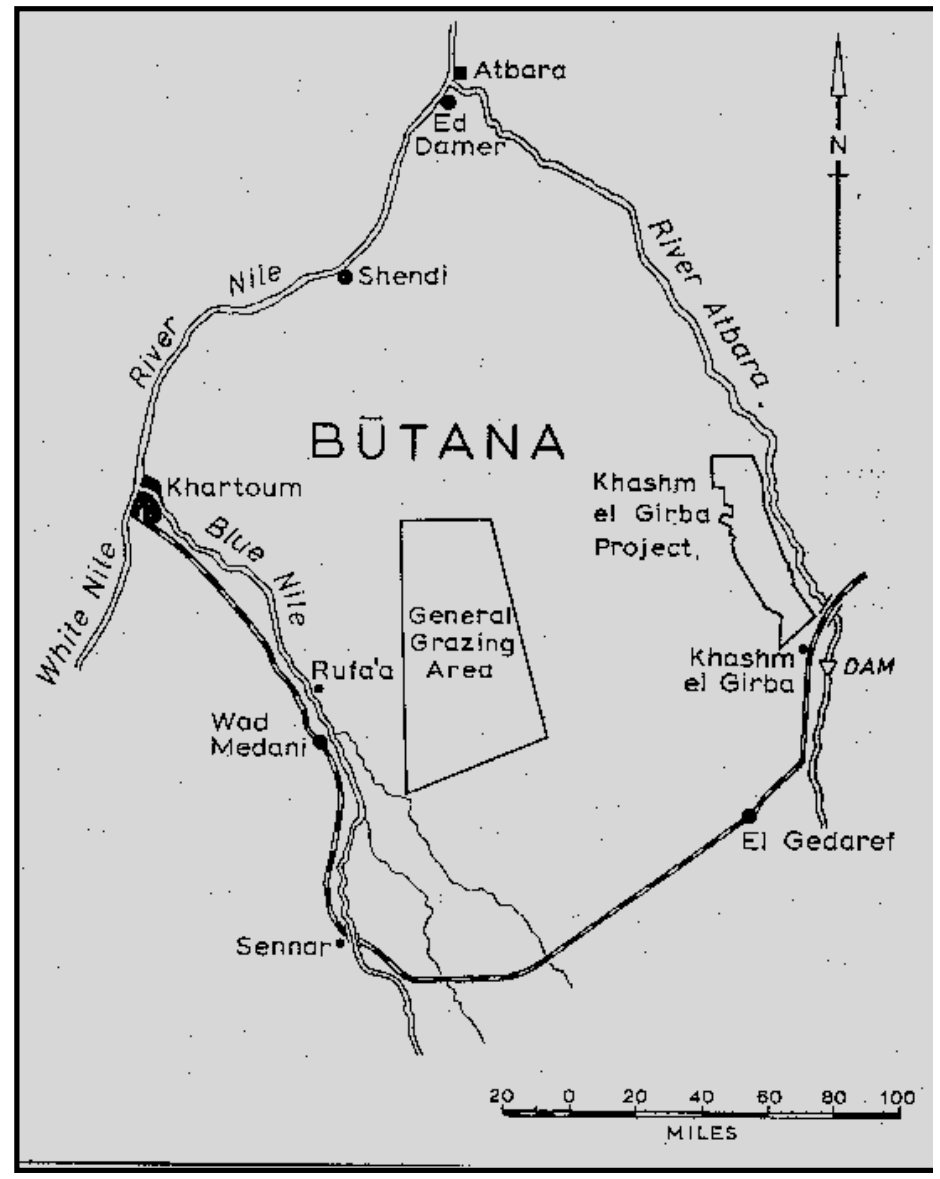

Source:O'KEEFE/WISNER 1977:134

132 Projects greater than 2000 ha and/or more than 500 farm units are usually considered, according to SAGARDOY et al. (1986), as large projects. 


\subsubsection{New Halfa Irrigation Scheme}

The New Halfa Scheme is one of the largest and most important agricultural schemes in Sudan. The Scheme is located on the Atbara tributary in the eastern region ${ }^{133}$ of the Sudan, about $400 \mathrm{~km}$ east of Khartoum and about $80 \mathrm{~km}$ from Kassala, with estimated area about 341340 sq. Km (Fig 5.2). The 1987 population estimated for the region is 3497000 including the Ethiopian (Eritrean) refugees who were accounted for about $24 \%$ of this population $^{134}$. In addition, many of the agricultural labors are not native to the area, but include population from West Sudan, West Africa, and some from Southern Sudan. About $86 \%$ of the population occupation in agriculture (irrigated and rainfed). The total arable land of the region amount to about 21.2 million Feddan of which only 11 million feddan are utilize.

Fig. 5.2 Sudan: Regions.

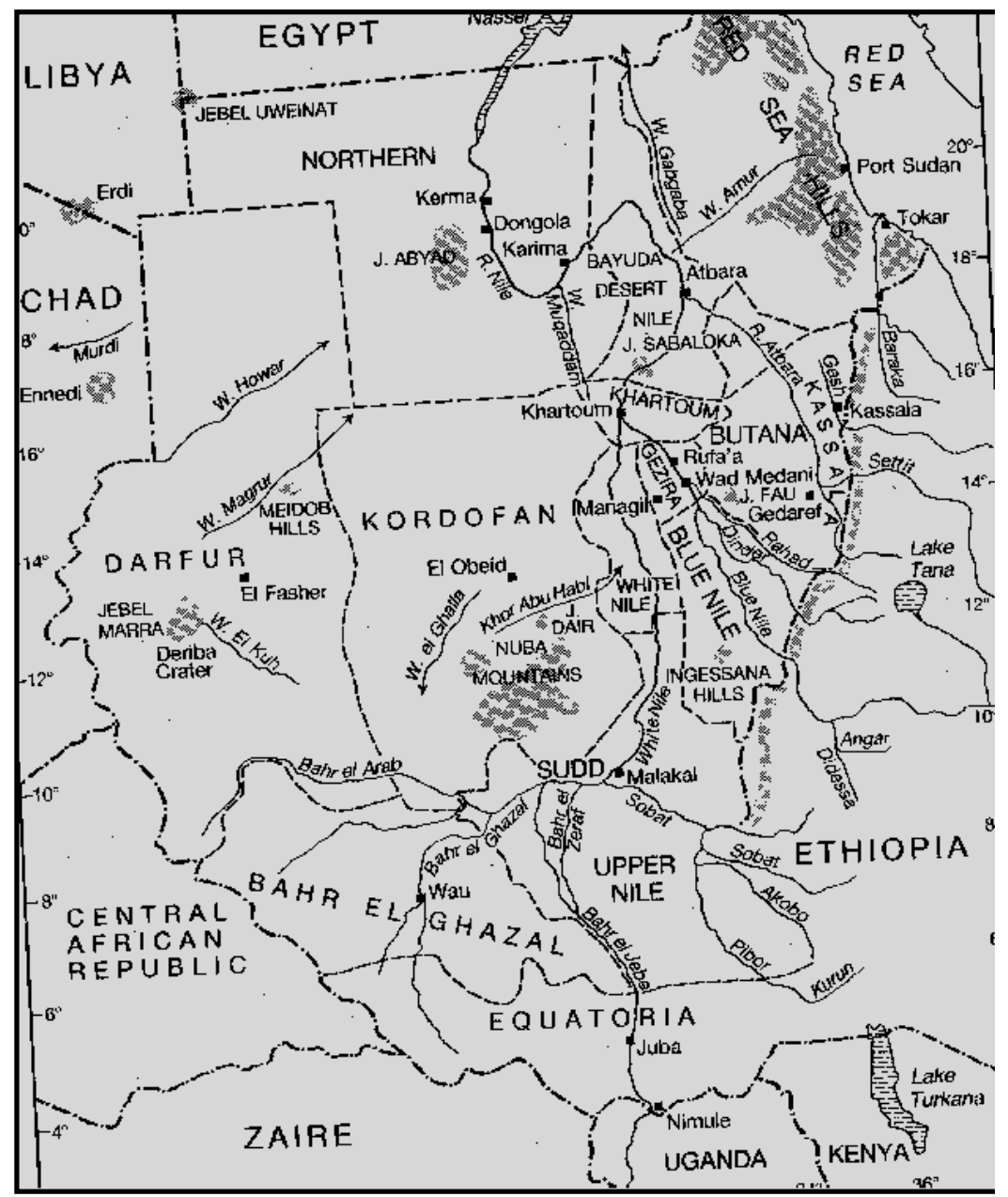

Source: MITCHELL 1991:3

133 The Regionalization Act of 1981 divided North Sudan into five Regions (Northern, Eastern, Central, Kordofan and Darfur) in addition to Khartoum and the South which enjoyed special status and administrative structures. The south was sub-divided in 1983 (WEDDERBURN/ERRINGTON, 1985:21).

134 The population of Atbara River Province according to the food subsidiary Cards is estimated in 1991 at 470 000. The Province consists of three Councils: New Halfa rural Council, Khashm El Girba rural Council, and Atbara River rural Council. 
The scheme has two main types of tenants; the Nubians, originated in Wadi Halfa, will be referred to in the study as Halfawyeen, and the local tenants; the settled pastoral nomads from the Butana, which referred to in the literature as Nomads or nomadic tenants whereas the people in Sudan like to call them Arab El Butana (Arabs of the Butana). The last name will be used frequently in this study. A new urban area, New Halfa, is being developed as a central town with administration schools, a hospital, a large area of freehold shops, cotton ginning factory, cinema and transport connections to the rest of the country (THORNTON/WYNN, 1987:214).

The scheme was initiated in March 1964 and officially inaugurated on July 1967 under the name Khashm El Girba Scheme, which has been changed through the Presidential Establishment Order of January 25th, 1980 to the New Halfa Agricultural Corporation (NHAC). The scheme was initiated for the settlement of the local pastoral nomads (distributed in approximately 51 villages) and re-settlement of the nubians ${ }^{135}$ (55 000 immigrant distributed in 26 villages $)^{136}$ in the Butana area ${ }^{137}$. At the same time, the scheme was aimed at securing the subsistence and the individual income for the tenants. Later on, since the beginning of 1980 s, a national aim was add, namely more contribution to the Sudan's export earnings 138 .

New Halfa Scheme, the only significant existing irrigation on the Atbara River, covered an area of about half a million feddan, roughly $80 \mathrm{~km}$ north-south and $30 \mathrm{~km}$ wide. It was originally intended to serve 400000 feddan under irrigation, including 43000 feddan set aside for the cultivation of sugar by a parastatal corporation and 24000 feddan freehold land owned by Halfawyeen (SAEED, 1978). Because of heavy siltation of Khashm El Girba Reservoir (storage capacity 1.3 milliard cubic meters), on which it relies for its water supply, the scheme has never been developed to its full capacity (USBR 1986:11).

The scheme was developed in five phases, the first two were for Halfawyeen settlement and sugar cultivation and the other three were for settlement of nomads. All tenants in the scheme (16 000 Arabs and 6000 Halfawyeen) were provided with fifteen feddan of leasehold land (6.3 ha.) on which they are to rotate five feddan (one Hawasha) of groundnuts, five feddan of cotton ,Akala" and five of wheat or sorghum (Section 5.3.3.3). Many of the Halfawyeen tenants were given, in addition, some freehold land plots as compensation for their inundated lands in Wadi Halfa district ${ }^{139}$. The rotation crop area is

135 Another interpretation for the reason of initiation the Scheme was presented by the manager of the irrigation Department in the Scheme (M.A. HASAN). He asserts that the idea of constructing project in this area is not, as many thinks (he argues), a consequence of the inundation of the Nubians' area by the filling of lake Nasser, this was only a cause to accelerate its realization. The project was planned since 1948 from the ministry of irrigation to initiated in the beginning of seventieth.

136 According to AGRAR (1978), the New Halfa Agricultural Production Scheme had a population of about 290000 people, of which c. 68000 were Halfawyeen, c. 148000 nomads, c. 50000 migrant Laborers and 35000 inhabitants of New Halfa Town (SORBO, 1985:13).

137 Some 850 kilometer southeast of their original home (Wadi Halfa).

${ }^{138}$ It must be taken in consideration, that since the construction of the project, Sudan has known four different political systems i.e., different orientations (1964-69, 1969-1985, 1985-89, 1989 till now). That means, the policies of government which set for the bureaucracy the objectives of irrigation management were different.

139 For more detailed reviews of the different sides of the New Halfa Project see the empirical studies undertaken by WYNN (1968) THORNTON/WYNN (1987), BLANCKENBURG (1969), SORBO (1977,1982, and 1985), FAHIM (1980), and PEARSON (1980). 
divided into 19 Blocks $^{140}$ grouped into 6 administrative Divisions; Debaira, Sasaraib, Sedaira, Demyat, Reira, and Sheik Omer (Section 5.3.5).

\subsubsection{Gendettu Scheme}

Gendettu Scheme is located in the Nile Province, just to the south of Shendi town, on the eastern bank of the Nile River downstream from Khartoum. The Nile Province form together with the Northern Province the Northern Region of Sudan ${ }^{141}$. Total population of the Northern Region was estimated at 1083000 (1983 Census) representing 5.3\% of Sudan's total population of 20564000 (WEDDERBURN/ERRINGTON, 1985:10). Shendi District is one of the biggest areas in the Nile Province on an area extending of $124310 \mathrm{~km}^{2}$ and, administratively, is sub-divided down to four local Councils with total population in the year1993 of $192000^{142}$. The average annual increase in this District in the period between 1973/1983 censuses was above the UN estimate of annual population increase in the whole of Sudan of $2.9 \%$. For instance, the average annual increase in Shendi Town Council during this period was 4.285 and has exceeded 5\% during the period 1983/1993.

The population group of Shendi district is dominated by the Arabic original groups as known there in the area- Jaalean, Shigea and Ababda tribes- and many other marginal Sudanese sections from other parts of the country. Tow factors have contributed to mixing the ethnical colors on the portrait, first, the location of military area Headquarters in Shendi Town and, second, the drought and famine disasters of the 1980s which have forced their victims to reach the district seeking for opportunity to live and improve their status. Among the Arabic ethnic tribes (Ababda, Hassania, etc.) livestock raising and nomadic spatial mobility become the most style of life emerging here and other to secure the feeding of their herds ${ }^{143}$. the estimated number of these herds according to the agricultural Survey Commission Report (1990) is about 60000 heads (ABD ALLAH, 1992:72). The social organization of these tribes is flexible and reflect a remarkable adaptation to their natural environment.

Gendettu Scheme is one of nine relatively large government irrigation pump schemes in the Nile Province. These schemes, that are irrigated by Nile water tapped by pump stations and supplemented by other sources, from north to south, are: Bagwa (1917) 3650 feddan, Fadlab (1909) 3668 feddan, Zeidab (1907) 30000 feddan (the first scheme in the Sudan to grow cotton), Aliab (1943) 5375 feddan, Kitiab (1927) 5 775, Kelli (1952) 9000 feddan, Kabushiya (1986) 4500 feddan, Saiyal (1976) 6000 feddan, and Gendettu (1917) 3500 feddan. All of these schemes are managed by regional government agency; The Northern Agricultural Production Corporation (NAPC). The main target of these Schemes are achieving food self-sufficiency and improving the farmers' income. NAPC which

\footnotetext{
${ }^{140}$ The Block area is 1750 feddan compared with 2000 feddan in the Gezira-Managel Scheme.

${ }^{141}$ The total area of the Northern Region is about $477074 \mathrm{~km}^{2}$; within the region the Nile Province covers an area of $120807 \mathrm{~km}^{2}$.

142 This figure according to the records of Shendi Town Council. It includes the population of Shendi Rural and Town Councils, Kabushia Town Council and Wad Hamid Rural Council. Whereas El Matama Town and Rural Councils being an independent District.

143 Just like in New Halfa, the rural people in the Nile Province are seen as two main groups; the 'river' Sudanese who engage largely in irrigated agriculture on or close to the Rivers Nile and Atbara, and the nomadic pastoralists of the desert and semi-desert areas to the east and west of the Nile (WEDDERBURN/ERRINGTON, 1985:17).
} 
manage also five schemes in the Northern Province ${ }^{144}$, is one of ten Corporations, responsible to the Central Ministry of Agriculture, that operate the irrigated schemes in the Sudan $^{145}$. Besides these schemes, there are other kinds like private small pump schemes which play important role in the Northern Region, co-operative schemes, and private agricultural firms. In this region, private pump schemes serve about 208,000 feddan of which over 92,000 feddan are government-owned. About 40000 feddan of public and 400 000 feddan of private irrigation and livestock operations are served by gravity-fed basin flooding rather than by pumps (USBR, 1986:10). The private agricultural Schemes in Shendi district estimated by 33000 feddan (the agricultural Survey Commission Report, 1990) mostly irrigated by pumps from the Nile.

The first vital problem of Gendettu is the lack of precise mapping for the Scheme which clearly defines the boundary of the official cultivated area. Since the construction of the scheme in 1917, substantial unauthorized gradual alternations and modifications have taken place around the boundaries of the original scheme, which have, in many instances, resulted in an alteration of the Net Cultivable Area $(\mathrm{NCA})^{146}$. Although this phenomenon is also observed in other schemes owned by NAPC, specially those constructed in the period 1907 to 1943, at Gendettu the measured area is considerably higher than in the official records. The initiated area according to the NAPC records is 3500 feddan whereas the most recently measured area from the series arial photographs (1979) was 4964 feddan $^{147}$ (ODA 1988: 4-2).

The difference between actual and official area (42\%) is more than those founded in the other projects; Kitiab (-19\%), Aliab (-5\%), fadlab (-7\%), Bawga (12\%) and Zeidab (-16\%). This increase is due entirely to, according to the study of NRIRP $(1988: 4-1)^{148}$ : ,unofficial extensions by individual farmers which have been carried out gradually and have not been accompanied by a corresponding increase in pumping capacity". The underlying result is that these areas outside the official scheme receives gravity supplies from the Schemes' canal system whilst some areas within the boundary rely entirely on private groundwater pumps. However, because of the water shortage problems, substantial areas of the scheme are supplemented by pumping from groundwater, specially citrus areas.

144 Nory (1917), El Gurair (1917), El Ghaba (1917), El Kolot (1927) and El Gurgeig (1943).

145 As described in ODA (1988:2-4): „NAPC differs from the other major public sector irrigation corporations in Sudan in two important respects. First, its individual schemes are relatively small, except for Zeidab, and they arescattered over a very large area, with considerable distances between them. Most other corporations have large areas of irrigated land in contiguous blocks or at least within reasonable reach of each other. Second, the other corporations concentrate essentially on only a very few crops (cotton, sugar cane, groundnuts and wheat) whereas the NAPC schemes grow a very wide range of crops. Moreover, the land outside the large schemes is usually either uncultivated or under rainfed cropping, whereas the NAPC schemes from part of the irrigated belt which stretches along much of the main Nile and on which the farming is similar to that followed on the schemes themselves".

146 this phenomenon is specially strong in three areas: dowemat, H. Bannaga and Figaga (see Fig. 5.8)

147 The general manager of the NAPC had reported 4318 feddan, of which 2200 feddan government owned.

148 This study within the framework of agreement between the Government of Sudan and the British Overseas Development Administration (ODA) 1983, to set up the Northern Region Irrigation Rehabilitation Project (NRIRP), a program of assistance to the irrigated farming sector in the Northern Region, focussed initially on the Northern Agricultural Production (NAPC) in the Nile Province. The main aims of NRIRP are to assist NAPC to provide a more secure supply of inputs to its farmers in order to improve agricultural production; to ensure a more cost effective use of resources and to enable NAPC to function independently of government subsidy. 
Holding sizes for tenants vary according to the time in which tenancies were distributed. At the beginning, the standard holding size was $5 \mathrm{fed}$, in other was 6 and $12 \mathrm{fed}$, and more recently it has been dimensioned to 2 feddan. That means, the variation can be between 12 feddan to 2 feddan. Sometimes, because of traditional inheritance systems, smaller plots are to be found, which may reach to only a fraction of a feddan.

\subsubsection{Why New Halfa and Gendettu?}

Although the significance of New Halfa Scheme might seen reduced in comparison with the Managil extension to the Gezira Scheme and further expansion of irrigated agriculture from the Roseires dam on the Blue Nile (Rahad Scheme), in many ways, the scheme which consider the second large scheme in Sudan is unique (THORNTON/WYNN, 1987:201):

1. in the first place the Scheme is the only significant existing irrigation on the Atbara River;

2. part of the Scheme has been devoted to the first major re-settlement carried out in the Sudan;

3. 24-hour watering was to have been used throughout the Scheme which consider an innovation in the Sudan's gravity irrigation works on this scale;

4. the Scheme contains the Sudan's second area of sugar production;

5. the scheme use pumpturbines to simultaneously produce electricity and supply irrigation water when levels in the reservoir are high, and then make the water in the bottom part of the reservoir available for the use by pumping when the water levels have fallen ${ }^{149}$; and

6. in addition, the Scheme is the first large irrigation project established after the independence.

The New Halfa Scheme is a typical example of the communities where tenants are not only dependent on the farm as a sole or even, in many circumstances, a main source of income ${ }^{150}$ as it is in Gendettu. In addition, sources such as livestock holdings among the nomads; trading capital (enterprises); occupations like teachers, governments' officials; and remittances from abroad, constitute important sources ${ }^{151}$. That is why the 'presence' and follow up of the tenant in the farm 'Hawasha' was one important factor in choosing the sample and evaluating the performance ${ }^{152}$.

Hence, the important of choosing this scheme as a sample will be very noticeable, specially in representing the vital rule of the social factor on irrigation systems.

149 FRAMJ, GARG and LUTHRA (1983:1276).

${ }^{150}$ In a recent Survey, carried out by the Federal Agricultural Extension Administration (FAEA) and the NHAPC (1991:5), it has been found that $54 \%$ of the sample (170 tenants) had other occupations.

151 The prior economic condition of the settlers is an critical factor determining successes in Settlement Schemes. This is a well-known situation with most development projects. WIDANAPATHIRANA in his study about Poverty in Irrigation Settlements in Sri Lanka has also identified this fact (ODI, Network Paper 27, 1993).

152 LEES (1986:613) describes similar situation in Israel. Because of the deterioration of income from the small farms in the Israel's cooperatives and increasing the dependency on the employment off the farm, a fairly high proportion of settlers have adjusted their farming practices to accommodate their off-farm employment. „Some neglect their farms entirely, some work them part time only, and some arrange to have others neighbors make use of the holding and its resources by means of informal transfers such as partnerships“. 
The important of the second case study, Gendettu, derives from its: position, history, farm size, kind of farmers, and method of water acquisition (Table 5.1):

Table 5.1 Basic Schemes Attributes

\begin{tabular}{|l|c|c|}
\hline Scheme Attributes & New Halfa & Gendettu \\
\hline Location & $400 \mathrm{~km}$. East of Khartoum. & 250 km. north of Khartoum. \\
\hline Date of Construction & 1964 & 1917 \\
\hline Scheme Area (Feddan)* & 400000 & 3500 \\
\hline Command Area (Feddan) & $90-180$ & $40-50$ \\
\hline Area of Freehold Land & 24000 & $1001^{* * *}$ \\
\hline Plot Size (average) & 15 & 3.2 \\
\hline Type of Product & Export-crops & Regional-crops \\
\hline No. of Tenants & 22367 & $418^{* * * *}$ \\
\hline No. of Tenants Interviewed & 60 & 40 \\
\hline Water Source / acquisition & Dam (Atbara River) & Pump St. (The Nile) \\
\hline $\begin{array}{l}\text { Water Conveyance/ Canals } \\
\text { layout }\end{array}$ & $\begin{array}{c}\text { Canals(Main/Major/Minor/ } \\
\text { Sub-Minor/Field) }\end{array}$ & Canals (Main/Minor) \\
\hline Water application & Angaya system & Angaya system \\
\hline
\end{tabular}

"Actual irrigated area in New Halfa in Season 91/92 was 230260000 feddan In

Gendettu, the Survey in 1988 has registered 4964 feddan. (1 Feddan $=1.038$ acres).

$*$ the actual number is 2200 feddan

*:* include NAPC tenants as well as owners/tenants of freehold land.

Source: Own Survey

- position: the agricultural sector in the Northern Region is characterized by a diversity of production methods covering private, co-operative and company irrigation pump schemes as well as traditional irrigation schemes, some rainfed agriculture and the widespread keeping of livestock in sedentary, semi-nomadic and nomadic systems. Shendi, in particular, where Gendettu scheme located, is a good example for two kinds of irrigation systems in Sudan. Mainly, basin irrigation which applied in the Sudan for most of the irrigated horticulture, irrigated rice, wheat and vegetables. Secondly, pump irrigation which ranking second to gravity irrigation; the largest system of irrigation in the Sudan. In addition, Shendi is primarily a horticultural station;

- history: Gendettu is one of the oldest irrigation schemes in the Sudan and has been established in the colonial era;

- size of the farm, either leasehold or freehold, is small;

- the farmers of the scheme have good experience; and

- the Scheme is well-known in the region as the worst regarding irrigation management.

Furthermore, the difference in size was intentional to prove the view which see: "the larger and more complex the system, the less well-defined the membership boundaries, which

153 Angaya system is a flood system using basins and ridges within the basins for the two row crops (see Chapter 6.3.1). 
makes effective management as a common property resource increasingly difficult“ (ODI, 1995:1).

\subsubsection{Profile of The Common Characteristics}

Notwithstanding the above, there are many common characteristics between the two schemes that could be summed up as follows:

- Corresponding to Weber's model of bureaucracy, as described in MANIG (1989:10-1), both projects belong to Mechanical-Bureaucratic model of organizations which have the following characteristics: simple technology; high demand for standardized goals and services; the organization is large and centralized; fixed process and supervision from top to bottom; routine; no innovation due to their staff's low level of skills and the hierarchical structure of decision-making; and finally the inflexibility towards changes. The two schemes could be used as example to illustrate the general type of structure that is found in the public sector's agricultural schemes in the Sudan.

- the collective choice entity in these cases, therefore, involves not just the water users but also interest groups who shares an interest in irrigation and other related activities;

- in each of the two cases there are two forms of land tenure; the main one is statecontrolled tenancy and farmers are therefore, in legal sense, tenants holding contractual leases. They have therefore no right of succession. On the death of a tenant the Corporation selects a successor who has to compensate the legatees of the deceased for any permanent improvement that may have been made. Normally, the new tenant is selected from the family of the deceased where this is feasible ${ }^{154}$. In addition, have many of those tenants freehold (amlak) land.

- because of the ambiguity over the real nature of the 'tenancy'- defacto, tenancies are inherited - the tenants in New Halfa Scheme seen to feel that they have a moral right to their tenancies as compensation for the land they have lost ${ }^{155}$. Similar feeling having also the tenants in Gendettu who always remind that the scheme has been established to secure a livelihood for their families. Such feelings will explain latter some of the tenants behaviors, specially towards the water pricing.

- in both cases, fast the entire system are governed by the agency ,upper management body." That means, the irrigators' associations (Farmers' unions) have no remarkable role in governing activities at the distributary and water course levels.

- the farmers in both projects, as the most in developing countries, use the oldest and generally the least expensive method to irrigate their fields; that is gravity-flow system. This system distribute water from surface canal or groundwater well through unlined field ditches or siphons. In addition depends many of the nomads in New Halfa, heavily, on rain-fields outside the project.

${ }^{154}$ Because the household and the nuclear family tend to coincide, the terms ,household“ and „family“ are often used interchangeably. This usage, argues POLLAK (1985:589), is misleading even for advanced industrial societies and it is seriously misleading for developing countries. We refer in this case, however, to the family.

155 This is not only the case of nubians' tenants, it is also applicable to the nomadic tenants, specially the Shukrija, the majority of whom received tenancies in compensation for loss of traditional grazing rights on the Butana plains for a period of 400-500 years. 
- the farmers in both Schemes plant different crops according to a three-year croprotation systems.

- finally, both projects considers the best examples in Sudan which obviously reflect the fact that: 'bad management' of the available resources had been, and still, and will continue to be one of the basic factors which causes bottlenecks in the development process.

\subsection{Methodology}

\subsubsection{Factors that have governed Investigation Methods}

Achieving the aims of the study, discussed in Chapte 5.1, requires necessarily, a high degree of judgement and intimate knowledge of the physical resources and agricultural characteristics of the projects' regions. In addition, socio-economic survey is required to furnish the information necessary for the successful diagnosis and then applicable recommendations. Since the study is not only intended to identify and catch on the problems and their causes, but also, with more interest, to guide us to the possible solutions. This approach is called Diagnostic Appraisal which described by CHAMBERS (1983) as 'opportunity rather than problem oriented' (LENTON 1986:52). ${ }^{156}$

The quality of most available data, not just their quantity, is a major constraint on improving irrigation management. Thereby, it is quite known today, for researchers working in the third world's irrigation schemes, that one vital source of difficulty in managing many systems is the lack of valid information on either water distribution or water requirements ${ }^{157}$. That is why, the question which has been strongly raised in this critical phase of the study was, which social research method or combination of methods guarantees gaining such information? The answer has required examining the different approaches that have been used in similar areas and their imperial facts to avoid, within the bounds of possibility, the critique and strengthen, therefore, the effective sides for our two circumstances. The following considerations had, consequently, governed the methodology of the study:

- criticism directed to the Brief Rural Visit by 'the urban-based professionals' (spatial: visits near cities, the centers of villages, and neglect of peripheries; project: where projects were being undertaken, often with special official attention and support; person: meeting men more than women, elites more than the poor, the users more than the non-users of services, and so on; seasonal: going in seasons which are often worse for rural people; and diplomatic) all these could combine to hide the worst situation (CHAMBERS 1992b:7);

\footnotetext{
${ }^{156}$ In the field of irrigation management, the concept which the term „methodology“ embodies is according to LENTON (1986:48): „An irrigation management methodology comprises the generalizable practices, processes, techniques or approaches-not specific to any given irrigation system-employed by irrigation and other agencies and/or farmers to undertake a given irrigation management activity. "

157 In this view, then, it would make sense to separate definitions of information and data. SINGH (1988:358), distinguish the two terminologys in terms of their usability as follows: Data is facts and figures, lying in files, records and reports, which are not organized or processed in a manner that is meaningful to the manager. By contrast, Information consists of data that is properly classified and analysed such that they can be used by the manager for decision making.
} 
- the disillusion with the normal processes of questionnaire surveys and their results. As CHAMBERS (1992b:7,33) argued, the experience had been that questionnaire surveys tended to be: „long-drawn-out, tedious, a headache to administer, a nightmare to process and write up, inaccurate and unreliable in data obtained, leading to reports, if any, which were long, late, boring, misleading, difficult to use, and anyway ignored", „the quality of its data is often so poor, that an improvement is not difficult to achieve“;

- the advantages emergent from 'Indigenous Technical Knowledge' (ITK) (rural people are themselves knowledgeable on many subjects which touched their lives);

- the new methods that have been emphasized in Rapid Rural Appraisal (RRA) such as direct observance and semi structured interviewing ${ }^{158}$. This approach began to emerge in the late 1970s and gained increasing acceptance in the 1980s. It has argued that RRA is cost-effective, specially for gaining timely information and consider in many contexts and for many purposes, the best. In five empirical cases discussed by CHAMBERS (1992), the outcomes of the RRA approach, compared with the more formal questionnaire, were variously more valid, less costly, more timely, and more useful ${ }^{159}$; and

- participation of the those concerned must not be only the base of managing irrigation systems, but also a vital factor of their related researches.

- finally, rural data presently obtainable in developing countries is, as MORIS/COPESTAKE (1993:6) argued, more likely to merit qualitative (informal) than quantitative (formal) treatment.

According to the above, the combination of social investigation methods adopted in this fieldwork, which had commenced on 17th November 1992 and continued until end-April 1993, had included:

- two structural questionnaires; one was directed at water-users, (contained 48 question) and the other ( 25 question) for the officials and the so-called 'experts' or key people (projects' staff, specialists, researchers in Universities - Khartoum and Gezira; and Ministries - Agriculture and Irrigation; staff of other government departments ${ }^{160}$; and numerous non-governmental organizations working in the area ${ }^{161}$ ).

${ }^{158}$ FAO stresses the necessity to collect actual data through Rapid Appraisal field surveys and interviews with farmers (WALKER/CLEVERINAGA, 1989:Vol 2, M.XI.7:5)

159 He refers to BERNADAS' (1991) who reports that in Eastern Visayas in the Philippines, highly structured questionnaire interviews identified declining soil fertility as the most pressing problem of farmers. Bernadas explains that the staff themselves had formulated the questions and determined the areas on the basis of what they felt to be priorities. As a result, „two years of research based on the questionnaire survey findings did not match farmers need and circumstances, and the developed technologies were not adopted by them. " Using an RRA approach led to the discovery that the most pressing problem facing farmers was not soil fertility but the long fallow due to the growth of a weed cotton). Another study on agroforstry in Kenya (ROCHELEAU et al. 1989) had also different results from applying the two methods; a chain of informal in-depth interviews and group interviews, compared with a survey of a formal randomized sample of 63 households (p.34-5).

160 Agricultural planning department in ministry of planning (Khartoum), Gezira scheme, health centers, and the Agricultural Bank New Halfa-Shendi.

161 The Co-operative Union, the Tenants Unions, private input/supply and exports firms, and traders. 
- Furthermore, in the course of this field study, visits were made to the headquarters of Ministry of irrigation in Wad Medany and the head office of the Northern Agriculture Production Corporation NAPC in Ed Damer.

- Structure of the questionnaires, the checklist's topics, and even the expressions used in the questions were latter revised after informal in-depth interviews with representatives of these different groups.

- In addition, other data/information gathering tools were applied, such as observations, and analysis of published and unpublished documents.

The interview schedule includes the following topics, that had been, latter, translated in details into single questions:

- social data (sex, age, education, primary and secondary occupation, and members of the family);

- general farm's information ( location, ownership, and size);

- farmer's cropping patterns and production's data (yield, area cultivated, number of one's own animal, property of agrarian machines, size of labor; family and paid labor, and problems of agriculture);

- farmer's irrigation patterns and behaviors (field distribution, land leveling, irrigation interval, and duration);

- irrigation control $^{162}$;

- water distribution's problems and causes (reliability and predictability);

- communication and linkages with project's Administrations;

- the relationship between tenants as regards water distribution;

- conflicts: 1) between the irrigation administration and water users, and

2) between upstream and downstream water users;

- water user's organizations;

- the role of supporting institutions (credit market, marketing); and

- water pricing system

\subsubsection{Selection of the Samples}

The approach pursued here take in consideration the nature of the two schemes. After studying the sampling frame (the complete lists/maps of the projects), and to get a representative sample to the vast schemes that represent the target population, as accurately as possible, a non-random approach had been used to choose the districts and villages. Thereby, a cross-section of districts and tenants were selected with the help of the projects' officials, experts, and Tenant Farmers' Unions. The following factors had been taken in consideration:

- the different positions of districts in the projects;

- the irrigation situation; the location of the farm along the field water course and the position of the later relative to the distributry (head, middle and tail);

- the presence and follow up of the tenant in his farm (the degree of absenteeism); and

- the ethnical differentiation (in New Halfa Scheme).

162 FREEMAN (1989) defined irrigation control in terms of the appropriate application of water on the field. LAYTON et al. (1994:294) also assuming this and defines it by the farmers' ability to irrigate when they desired and in the amount they believed necessary. 
By using simple random sampling, 60 tenant in New Halfa Scheme and 40 tenant in Gendettu Scheme, were interviewed. In addition, the sample of the key informants (officials) had comprised 44 persons.

In New Halfa, two Sections (five Blocks and thirteen villages) were selected as illustrated in figure 5.3. Concerning the ethnical distribution in the project, the sample was chosen proportionally according to stratified random approach i.e., two thirds of the sample nomads (in 7 villages) and the other third Halfawyeen (in 6 villages).

a) SHEIK OMER is the second biggest section in the scheme regarding area (19 595 feddan) and number of tenants (3920). It includes the two population groups; nomads (the majority) and halfawyeen (Fig. 5.3), and lie on the beginning of the scheme.

1- Abu Nagma: altogether, this Block has more irrigation problems than El Butana Block. Throughout 1980s, because of water shortage, the three villages have cultivated only two rotation. Tenancies here are consider the very extreme example for the unleveled land in the Scheme.

Arab 5: all tenancies lie at the head, ${ }^{163}$ therefore, they have less irrigation problems. The presence of tenants is good.

Arab 6: the biggest village in the scheme; comprise 601 tenants. Tenancies in the middle i.e., has more irrigation problems than Arab 5.

Arab 7: tenancies at the end. It means chronic irrigation problems.

2-El Butana: canals in this Block are more than the average by the others ( 9 compared with average 3-5) and well distributed. The sole problem here is the long of these canals, that extended from $\mathrm{km} .26$ till $\mathrm{km} .33$, and this require, therefore, more control. Two villages were chosen heir; Arab 2, and Arab3.

3-Argin: generally, this Block has no irrigation problem i.e., availability of water. The more serious problem here, specially in villages 5 and 11, is the weak presence or follow up of the tenants. Exception here is village 13, which lie at the end. The tenants there use 'pistols' to guard their water during the night. In addition, because of the acute shortage of water, many tenancies are not cultivated and tenants from neighbor villages drain there. A big part of the command Area in this village is known as ,the dead line.“

163 Head, middle and end refer heir to the location on the minor canal. 
Fig. 5.3 Sample of New Halfa Scheme According to Section, Block and Villages

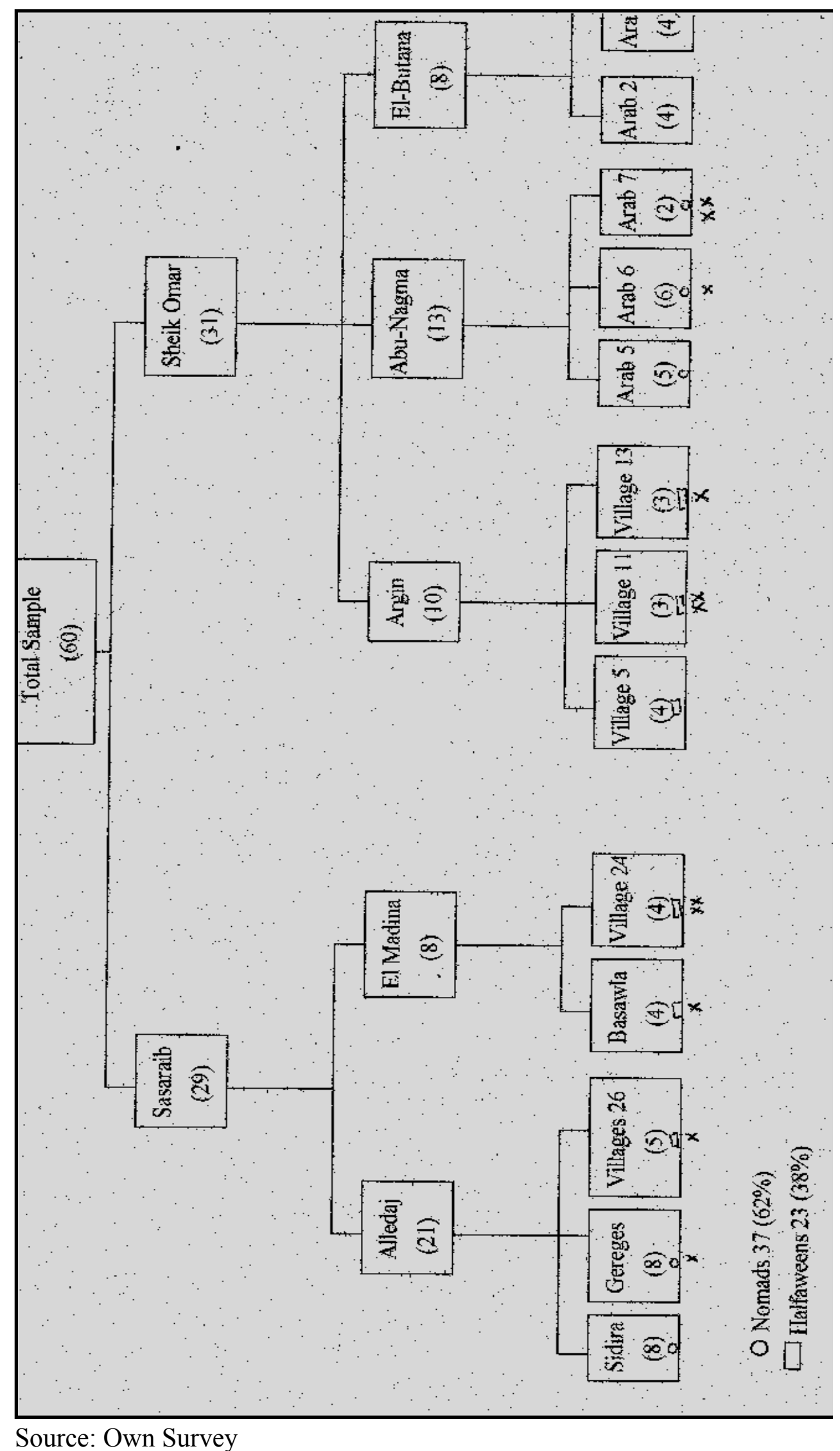


b) The other selected Section, SASARAIB, contains also Arabs and Halfawyeen and lie on the middle and east of the scheme. It comprise 17520 feddan and 3511 tenants. This Section is marked by long canals that have problems at the tail end, and have also easy irrigated places.

4-Alledaj: include the biggest village in the Nubian's area - village 26 - which comprise 334 tenant and 4267 inhabitant. This village is good example for Halfawyeen who are firm connected with the tenancy, and is, in the same time, famous for high women's participation in farm operations. Gereges is the Nomads' equivalent village to village 26 concerning the link with the 'soil'. Performance in sidira, on the other side, is middle and their tenancies lies on the end.

5- El Madina: village 24 represent irrigation problems in this Block because all tenancies lies on the end of long minor. Nevertheless, represent El Basawla the top performance among the project concerning the productivity, specially wheat.

Considering irrigation, Gendettu Scheme is distributed among 8 sections: Kilo 10, Mowes, Minor (Gadual) 8, Minor 6,7, Minor 5, Minor 4, Minor El Bahar, and Gendettu. The structure of the sample here has more emphasized the areas where irrigation problems are strong. That is why, the northern irrigation plant in the scheme (Minors, 4,5,6,7,8, and Minor El Bahar) represent 71 per cent of the sample (Figure 5.4). These areas lie on the end of the scheme, and had been described in the project's internal monthly reports as the main problem of the whole scheme. The field canals there did not receive water among the eight years before season 92/93. That is way all of them have built up wells and relayed on heavily. The main cause of this ,tragedy“ is the long journey of water which has to run 13 $\mathrm{km}$ from the main pump station, through the main canal, to these areas. In addition, as mentioned in the technical background, the tenants in the first five $\mathrm{km}$. have constructed own pipes or canals to draw water directly from the main canal.

It has been also taken in consideration a representation for the 'old' tenants who have long experience with the scheme. In addition, to obtain comparative data, an additional survey was carried out in a very small private project (4 participants, 9 feddan) lies direct on the Nile (Ibriqu project). These kinds of projects are dominant in Shindi and north Sudan, where many farmers sharing pump set (or belong it to one of them) and sharing also the costs. 
Figure (5.4) Distribution of the Sample in Gendettu Scheme
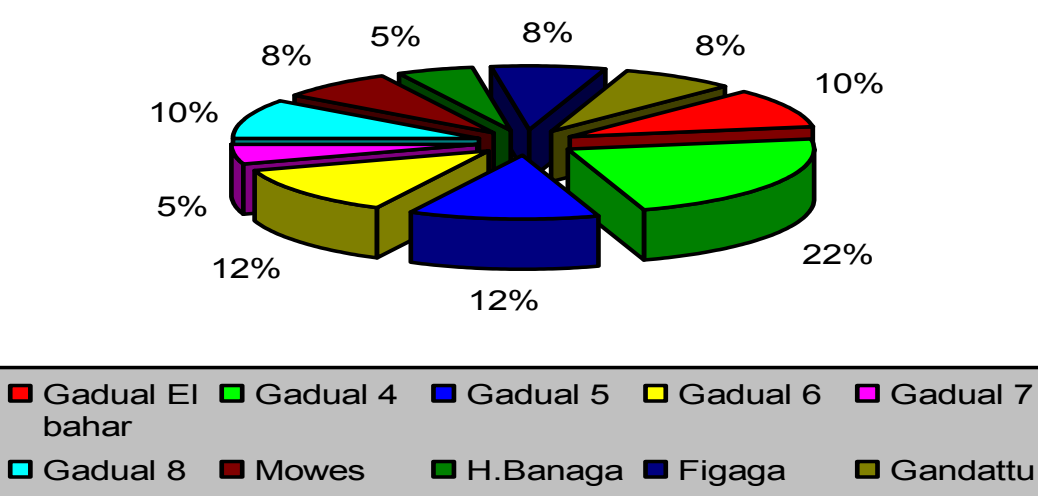

Source: Own Survey

\subsubsection{Some Findings of the Field Investigation's Methods and the Quality of Response}

During the carry out of the field study, it was of interest to find that:

1. It has been noticed in both projects (more obvious in New Halfa) that the tenants were frustrated and not convinced of the positive effects that could be gained from such studies; ,every day come somebody who say that his study is important for us... he put the same questions and meet, more or less, the same people... and the result is ... nothing $n e w ! “$

2. Throughout the interviews with the officials of the schemes, experts, and even the research center's staff, the general perception was that most of them do not prefer what is called ,answer list" or ,closed“ questions. On the contrary, they prefer to say, out of turn, all what they thinks about the discussed topic, one for all, after the first question. This may be a kind of security, or to be out of danger, because 'yes' or 'no' means sometimes for them responsibility! In such political atmosphere, the open discussions give the respondent a better mood to speak with freedom. So, the desire was (with many) to let the respondent speaking rather than intersperse with the researcher's comments and/or offering him specific answers. This means that, in addition to the questionnaire, there was heavy dependence on the individual in-depth interview with check-list topics. On the other side, disadvantages of such method are already known; it takes more time, resources, and effort to control the discussion and many questions, furthermore, can not be answered or even mentioned. These, however, coincide with some components of the researcher's beliefs i.e. 1) details are sometimes very important to explain some phenomenons; 2) 'yes' or 'no' is not necessarily to be in one-word form; and 3) in the field of human behavior, it is difficult to belief in absolute 'fact' or to take it for granted.

3. Again, because of the political constrains, group interviews, that consider key method in the more recent approach; Participatory Rural Appraisal PRA, were not possible ${ }^{164}$.

164 Participatory Rural Appraisal PRA has emerged in the mid 1980s as a result of the massive recognition of the importance of participation. In 1988, were listed by the IIED team as one of four classes of RRA methodologies - the other being exploratory RRAs, topical RRAs, and monitoring RRAs. In the same 
Therefore, it is not valid in such cases what CHAMBERS (1992:41) has argued about ,the sensitive subjects are sometimes more freely discussed in groups, when individuals would not wish to discuss them alone with a stranger" or that „participants fill in gaps left by others and add or correct details". On the contrary, such group activities could be dangerous for the participants. For example, in the time of the field study, the local political administration in New Halfa thumped ${ }^{165}$ three tenants from village 11 because they were participating in an open meeting and criticized the policies of the project's administration $^{166}$. For this reason, the tenants in this village refused the interview because they thought that the researcher work as a secret agent for the government or the project (the same) despite the key person who was accompanied by him.

4. Figuratively speaking, it has been found that, at the field, 'the eye' is more important than 'the ear'. In other words, because of the socio-political conditions in the project's areas which might be attributed to the shades of doubt about the collected data and information, observation in the field was, to a big extent, more valuable than those collected through the project's Management and the questionnaire (listening). Table 5.2, as example, refers to the uncertainty of data that can lead us to wrong ways. Such answers are evidence, for the researcher, that the respondents had no trust in the face of the interviewer - though the family is related to him - or may be, from other side, they were afraid, as many of the staff, that their opinions and information reach, somehow, to the political administration or some governmental agencies like Chamber of Taxation or Zakat Department.

year, this approach was applied in Machakos District in Kenya and in Gujarat in India. From the succinct review of PRA by CHAMBERS (1992), the following advantages could be drawn:

- its lable gives a sense of pride of ownership and originality, so strengthening commitment, enthusiasm and good work among its practitioners;

- information is more shared and owned by local people and shows high validity and reliability;

- outsiders here are conveyors, catalysts, and facilitators to enable people to undertake and share their own investigations and analysis;

- compared with $\mathrm{T}$ and $\mathrm{V}$ (training and visit) the former is more effective and had favorable indicators concerning: agricultural yields, diversity of crops, soil erosion and sedimentation, cost ratios, and wage rates. similar findings have been reported from the work of AKRSP in Gujarat.

- PRA is explained as 'reversal' - from etic to emic; from our knowledge, categories, and values to theirs. Within the frame of that reversal, three clusters of reversal or change intervene and are mutually reinforcing: reversal of modes (from closed to open, from individual to group, from verbal to visual); reversal of relationship/dominance (from extracting to empowering); and reversal of action (from reserve to rapport, from tedium to fun).

165 The local authority practiced this kind of punishment also in village No. 5 Halfaween, but because of other reason.

${ }^{166}$ Within this sample and because of the water shortage, only 13 of the 36 hawashas, have grown wheat. In that time substantial quantity of water ran more than month into the drainage and roads. 
Table 5.2 Some quantitative Answers from the Interview with three Members of one Family in village 13 Halfaween.

\begin{tabular}{|c|c|c|c|}
\hline Topic/Respondent & father & first son & second son \\
\hline Education & Second.School & Second. School & Vocational School \\
\hline Main Occupation & Teacher & Trader & farmer \\
\hline $\begin{array}{l}\text { Area of family's } \\
\text { freehold land }\end{array}$ & 3 feddan & 2.5 feddan & 3 feddan \\
\hline Numbers of Animals & & & \\
\hline $\begin{array}{l}\text { Cows } \\
\text { Sheeps }\end{array}$ & $\begin{array}{l}6 \\
4\end{array}$ & $\begin{array}{l}6 \\
10\end{array}$ & $\begin{array}{l}7 \\
- \\
\end{array}$ \\
\hline $\begin{array}{l}\text { Productivity* (Season } \\
\text { 1991/1992): }\end{array}$ & & & \\
\hline $\begin{array}{l}\text { Wheat } \\
\text { Groundnuts }\end{array}$ & $\begin{array}{l}40 \\
100\end{array}$ & $\begin{array}{l}40 \\
75\end{array}$ & $\begin{array}{l}35 \\
75\end{array}$ \\
\hline $\begin{array}{l}\text { Numbers of Angayas } \\
\text { in Hawasha }\end{array}$ & 12 & 12 & 10 \\
\hline $\begin{array}{l}\text { Numbers of Angayas } \\
\text { irrigated together: }\end{array}$ & & & \\
\hline $\begin{array}{l}\text { Wheat } \\
\text { Groundnuts }\end{array}$ & $\begin{array}{l}1 \\
3\end{array}$ & 2 & $\begin{array}{l}2 \\
2 * *\end{array}$ \\
\hline
\end{tabular}

* By Sack $(100 \mathrm{~kg})$.

** Only the first two waterings and then the whole Hawasha.

Source: Own Survey

So, good observation and well understanding of the environment of the Scheme is the silver lining that needed to the above quantitative picture.

\subsection{Background to Some Contexts of the Schemes under Study}

\subsubsection{Agro-ecological Contexts}

\subsubsection{Rainfall and Other Climatic Factors}

According to the climatic data presented in the Nile Waters Study (USBR, 1986:4-5), average annual air temperature is much the same throughout Sudan, ranging between $27^{\circ} \mathrm{C}$ and $29^{\circ} \mathrm{C}$. Variations during the year, however, are much more noticeable in the north than in the south. In the eastern region, average monthly temperatures are about $29^{\circ} \mathrm{C}$ with a maximum in May of $41^{\circ} \mathrm{C}$ and a minimum winter temperature in January of $15^{\circ} \mathrm{C}$. (PEARSON, 1980:1). In the Nile Province, the middle temperature is also between $28^{\circ} \mathrm{C}$ and $30^{\circ} \mathrm{C}$. The summer season with high temperatures and low humidity extends from April to October. The hottest months, between May and July, with average $34^{\circ} \mathrm{C}$, and maximum around $42^{\circ} \mathrm{C}$ and relative humidity of about $25 \%$, whereas in the cool seasonNovember to February - about $19^{\circ} \mathrm{C}$ (HERWIG, 1991:30). 
The mean annual rainfall increases dramatically from north to south. The area along the Egyptian border receives virtually no rain. By contrast, the areas along the borders of the Central African Republic and Zaire receive an average of about 1500 millimeters of rain. In the desert and semi-desert areas (where the two schemes lies) the rainfall is from 75 to $300 \mathrm{~mm}$. In the Nile Province, rainfall (which normal falls during the months June to September) has not, mostly, exceeded $100 \mathrm{~mm}$. per year since $1973^{167}$. Although the semidesert becomes green during the short-rainy season, during the remaining part of the year most of the vegetation is confined to watercourses, drainage channels, depressions, runnels and catchment areas (BEBAWI/NEUGEBOHRN, 1991:15).

The length of the rainy season also varies significantly from north to south. At Karima, and the eastern region, over 80 percent of the average annual 41 millimeters of rain occurs in July and August, while nearly 80 percent of the annual 988 millimeters of rain at Juba occurs between May and October. The remaining months of the year are hot and dry. Evaporation rates vary significantly across the country. The rates are affected by rainfall and accompanying conditions of humidity, solar radiation, air temperature, wind speed, and elevation. The highest evaporation occurs in the north part of the country and along the Nile and White Nile River, and it decreases progressively toward the east and south-east.

\subsubsection{Soils}

The soil of New Halfa is described by THORNTON and WYNN (1987:207) as follows: ,the topsoil of the area is predominantly clay although a little less so than in the similar Gezira plain. Poorer soils to the north and a stony surface to the north-west limit the further expansion of the scheme in this direction. Salinity and alkalinity are not a problem at present but, as in the Gezira, poor permeability precludes sub-surface drainage and there may be a slow build up of salinity and alkalinity".

A detailed account of the geology and soils of the Northern Region as provided in the Roseires Soil Survey Report No 5 (MacDonalds and Partners, 1964) and summarized by BERY (1987) is outlined by WEDDERBURN/ERRINGTON (1985:6): ,the underlying bedrock consists of Pre-cambrian granites, gneiss and mica schists with quartzite. the granite, where outcrops appear small hills, weathers to give quantities of waterborne sand. Later deposits of Cretaceous Nubian sandstone are widespread, particularly occurring near the Nile, and consists of flat-bedded sandstone, mudstones and conglomerates, giving rise to low-lying rock outcrops and gravel ridges. The surface soil deposits overlying these formations are the qoz sands (deposited by wind under arid conditions), clay plains and laterites. Along the banks of the Rivers Nile and Atbara are the narrow beds of silty alluvia varying from 50 to $1000 \mathrm{~m}$ in width. In general, the area is dominated by shifting sands in sheets and dunes, with occasional alluvial depressions with loams and clays associated with dry watercourses (wadis) ".

167 With the exception of the flood in Agust 4, 1988. All the district experienced a high level of rainfall reaching $210 \mathrm{~mm}$ as reported by the meteorological authorities. ABD ALLAH (1992:71), on the other side, has reported that the total local average annual rainfall of the district is $150 \mathrm{~mm}$. 


\subsubsection{Cropping Patterns}

\section{New Halfa Scheme}

The irrigable area of the scheme is 450000 feddan in total extent but of effective net area 385000 feddan The distribution of the net irritable area, and the current cropping, are reported to be (NIRP report, 1992, Vol. 3 of 4:F5):

New Halfa Corporation

(of which: sorghum

cotton

wheat

groundnut

i.e. intensity $80 \%$ )

Sugar Corporation:

(24 000 irrigated, intensity 57\%)

Freehold land around villages

(fodder and vegetables):

Miscellaneous (forestry, research station, seed farm, etc.):
330000 feddan

80000

80000

54000

50000

42000 feddan

24000 feddan

54000 feddan

It appears that the cropped area is sometimes limited by the water available from the dam, which is affected by the silting of the reservoir and also by the policy followed for hydropower generation. The actual capacity of the Reservoir now is approximately $50-60 \%$, that is why the actual irrigated area is declined to 230-260 000 feddan yearly depending on the amount of the rain (The Technical Department of the Scheme) ${ }^{168}$.

As mentioned before, a three-year crop-rotation system (cotton, wheat/sorghum, and groundnuts) has been prescripted to all tenants (Fig. 5.5). The recognized rotation in Sudan is groundnuts followed by cotton followed by wheat. The primary objective is to ensure that cotton receives the advantage of the nitrogen fixing ability of the groundnuts. These three types of crops had been dictated through the following parameters (NHAC 1986: Annex2 p.5 ):

168 The actually cultivated area in Season 92/93 was as follows: Cotton (44 130 feddan), Sorghum (74 145 feddan), Wheat (60 000feddan), Groundnuts (57 620 feddan) (according to the manager of the New Halfa Agricultural Research Center). 
Fig 5.5 The Rotation System in New Halfa Scheme

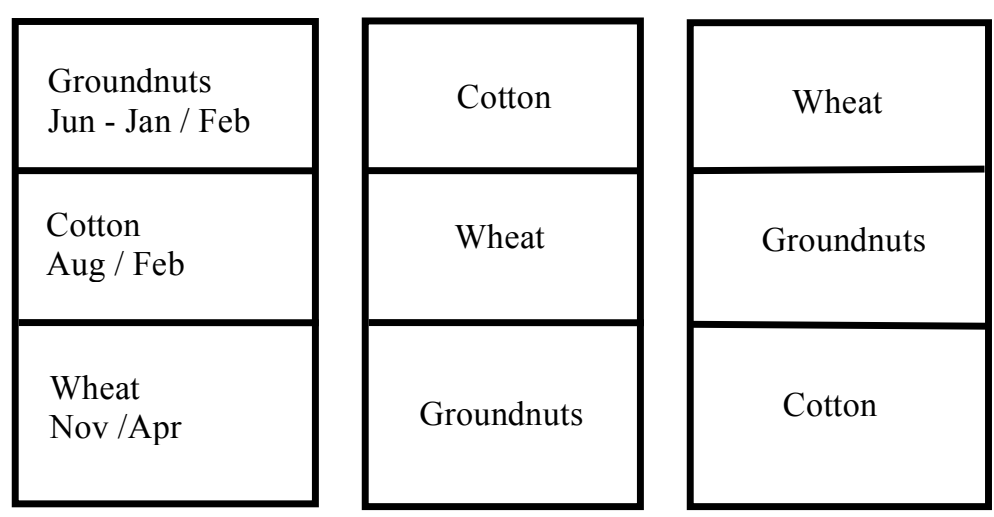

Source: Own Survey

- the total amount of water which the Project as a whole can use (1.62 million $\left./ \mathrm{m}^{3}\right)$

- the storage capacity of the Khashm El Girba reservoir

- the canal and pump capacity

- national interest in foreign earnings

- the climatic factors: rainfall, high temperatures, and low humidity

- soil factors $^{169}$

- markets

- existing infrastructure

- tenant acceptance

Such three-course rotation appears to have several advantages like:

- Cotton, the main national cash crop, is a well tried crop in conditions similar to those of Butana although the Halfawyeen have no previous experience with it and the settlers of phase II and III are not well familiar with;

- The advantage of groundnuts both as a legume and as a cash crop backed by an increasing research effort;

- Wheat (temperate crop) is a grain crop with which the Halfawyeen are already familiar although the other settlers would prefer to grow 'dura' (THORNTON/WYNN, 1987:219).

In the middle of $1980 \mathrm{~s}$, and according to the period of drought, sorghum (dura) were introduced in the irrigated projects as a corn crop as well as a fodder crop. In addition, the rotations here, like the Rahad Scheme, do not include a fallow (Fig. 5.6), opposite of the Gezira and Managel Extension rotations (15\%).

169 Traditional practices such as mixed and sequential cropping help to ensure continuous plant cover of the soil. The introduction of continuous monocropping, in parts of the Sudan, has lead to dust-bowl conditions and loss of top-soil (UPTON, 1987:8). 


\section{Grundnuts \\ Cotton \\ Wheat \\ Sorghum}

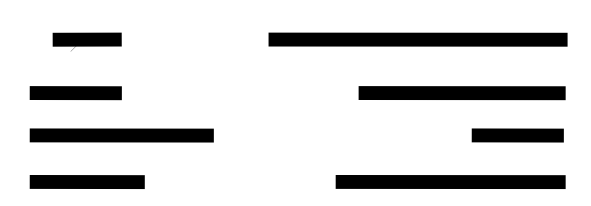

The general features of the agricultural production in the northern Region can be summarized as follows:

- the number of crops that can be produced economically is greater than those produced in any of the other Regions;

- there are some crops whose production is to a great extent monopoly of this region, such as faba beans, haricot beans, lentil and many spices;

- the northern Region is leading other Regions in citrus and mango-growing and is one of the leading Regions in onions production;

- one can say that the region is considered the major producer of fruits.

\section{Gendettu Scheme}

At Gendettu, the farming year is traditionally divided into three seasons influenced by the annual flood of the River Nile (Fig. 5.7):

1- The summer Season (seifi): extends from 1st April to 31st July and is characterized by rising temperatures in April, May and June. Because of the heat, the summer cropped area is low. The main crop is fodder sorghum (sorghum vulgar) and vegetables.

2- The damira Season: from August to October and known also as the flood Season. This season is less hot and more humid. The season is devoted primarily to grain sorghum. In addition, some farmers plant small areas of maize, vegetable and lubia (Dolichos Lablab).

3- The winter Season (Shitwe): extends from November to March and is the main cash crop growing Season. There are a very wide range of crops in winter Season like, faba beans (Vicia faba), wheat (Triticum aestivum), haricot beans (Phaseolus vulgaris), vegetables, spices and onions (Allium cepa).

In addition, Perennial crops comprising orchards and alfalfa (Medicago sativa) occupy significant areas on the Gendettu. Orchards include grape fruit, orange, lime, mango, bananas, guava and dates. Alfalfa is grown as a crop in its own right and as an intercrop in orchards.

This pattern of cropping -judging by the significant areas of irrigated land that are devoted to fodder production both in pure stand and as an orchard intercrop ${ }^{170}$ - shows also that livestock consider an integral part of the farming system. They are kept for the provision of

\footnotetext{
${ }^{170}$ Sorghum has remained the main green fodder supplemented by lubia though this pattern is changing with increasing areas of Alfalfa. Crop residues are also important sources of livestock feed.
} 
draught power, transport, milk, meat and by-products ${ }^{171}$. The need for working oxen is an important consideration in the overall farm power requirements (WEDDERBURN and ERRINGTON, 1985:15).

Fig. 5.7 Cropping Cycle in Gendettu Scheme

Season

1- Summer season

2- Damira season

3- Winter season
J F M A M J J A S O N D

$,,, \%,,, \%$,
Crops

Fodder sorghum, vegetable

grain sorghum, maize, veg.,lubia

$* * *$ faba beans, haricot beans wheat, spices, veg., ,and onions

Gendettu Scheme was originally established to grow cotton according to rotation system; each rotation 1500 feddan. After the establishment of the Gezira Scheme (1924), growing cotton had been canceled, and farmers have been allowed to determines the cropping patterns within a three-course rotation. In 1972, many farmers have got permission to grow fruit and the outcome was that, orchards' areas were expanded from 532 to 1600 feddan. The size of the rotation has also, consequently, expanded from 1500 to 3200-3300 feddan in Season $92 / 93^{172}$. The expansion and changing in the rotation's size and the original design cropping patterns, and the constancy of the original installed pump capacity on the other side, results in a high pumping requirement with pumping between 14 and 18 hours per day for 17 ten-day periods. Such pumping duration is more than the average in the other NAPC projects.

\subsubsection{Production Relations: from Sharecropping Arrangement to a Fixed-rent Contract}

\section{New Halfa Scheme}

It is arguable that many of the specific managerial problems and defective organizational relations in New Halfa have their roots in an overall conception of the role of the corporation, of the nature of the Scheme, and of the nature of tenant-corporation relationships (NHAC 1986: ANNEX 7, p.6). This relationship has been defined, according to the NHAC Establishment order (1980), as a partnership between tenant and corporation (and therefore implicitly, government) in the production, processing and marketing of cotton - other crops and non-agricultural activities normally falling outside the 'Partnership' concept.

\footnotetext{
${ }^{171}$ Camels and donkeys are basic to local transport and marketing whilst sheep, goats and cows provide a valuable source of meat and milk.

${ }^{172}$ According to the manager of the Scheme.
} 
In New Halfa, as well as in the other large irrigation Schemes Gezira and Rahad, the production of cotton remains the conceptual ,raison d'etre" of the Corporation and Scheme (NHAC 1986: ANNEX 7, p.7). Therefore, the relations of production had been divided in the Establishment order of NHIRP (Chapter 5 and 10) ${ }^{173}$ to these of cotton production and those of other crops:

\section{Cotton crop Relations of Production:}

a- Relations of production for cotton shall be based on a partnership between the Corporation and the tenants.

b- Tenants shall be granted rising money incentives if the general yield average in the Corporation exceeds the average established by the Minister from time to time.

c- Return of the cotton crop shall be distributed after discounting the ,joint accounts“ and any duties or other taxes; this shall be calculated according to proportions recommended by the Board and approved by the Minister.

\section{Relations of Production for Other Crops:}

a- Tenants shall pay to the Corporation fees for water and management services provided to the areas cultivated under other crops, except any exempted crops. The fees shall be paid in accordance with rates and procedures recommended by the Board and approved by the Minister.

b- The net total returns from the other crops shall belong to the tenant

The Corporation thereby is (for cotton) responsible for a wide range of operations including:

- distribution of water to the hawasha;

- land preparation;

- ridging;

- clearing of the quartenary canal (for the cotton crop);

- provision of seed and fertilizer;

- crop protection;

- the securing of a supplementary labor force when necessary;

- the securing of the credit (in cash and kind) associated with all those functions; and

- the collection and marketing of the crop

It is thus responsible for the major functions affecting the quality of the cotton crop, and the efficiency of its management is the major determinate of cotton yields.

Tenants' initiative and responsibility, in turns, are exercised only in planting, supervision of watering in the hawasha, cultivating (weeding), picking and delivery to the cotton collection center. Their work that has to be carried out according to timetable, is closed controlled. It is noticeable here, as RUTHENBERG (1963:706-7) pointed out, to find side by side primitive and high mechanized processes. Cotton planting by hand and „Grabstock", field plowing by tractors and pest control by plane. However, this kind of partnership between the scheme, government, and tenants ,production under close supervision", he argues, is successful since it enables the tenants to share the responsibility

${ }^{173}$ NHAC 1981:ANNEX 7, APPENDEX 1, p. 4,5 and 24. 
and- beside the high level of the agricultural technique- achieves a good monetary result for the scheme as well. ${ }^{174}$

In the light of the triple-partnership between the Corporation/government and the tenant, the Corporation had established three accounts; joint accounts, the general, and individual accounts $^{175}$. The first one, Joint Account (JA), had played a long time ago an essential role in all public irrigation schemes:

Joint Accounts (JA): the components of such accounts are demonstrated in Table 5.3.

\section{Distribution of Returns:}

i - The following items should be allocated after deducting from the joint accounts any duties or taxes, at the following rates:

a) $2 \%$ for the local people's government.

b) $5 \%$ for social services.

ii- The Corporation and the tenants share those rates as follows:

- The Corporation shall pay $50 \%$

- Tenants shall pay $50 \%$.

The payments of tenants' share should be played from the sales of cotton, subject to rates and at appointed periods recommended by the Board of Directors.

The General Account of Tenants: this account register the full share of tenants from the net returns on cotton, as well as the total share of profits allotted to them from any other profit sharing crop. The net general account of tenants should be apportioned among tenants in accordance with the weight and the grades of the cotton delivered to the Corporation.

Individual Accounts of Tenants: according to this account, the Corporation issue an account book, against payment to every tenant, in which all loans he might take will be debited against his individual account, and this book will also register details and grades of cotton delivered by the tenant to the Corporation. Furthermore, the following items should be deducted from the individual tenant accounts:

${ }^{174}$ RUTHENBERG (1963:709-13) argues that agricultural ,production under close/strict supervision“" is not general applicable principle. A successful agriculture 'production under close/strict supervision' yet : (1) requires good trained staff; (2) it must be fiscal profitable; (3) diversity can be endangered for its success. Monoculture or concentrating the control on one special crop is advisable; (4) to cover the costs of control, the productivity should be high; (5) it is necessary to recken also with the fact that instructions alone are not enough. It is advisable to put the participators in an ,strained relationship“ between 'pressure' and 'incentive'. The most important incentive in this connection is the high income. On the other side, as example for the pressure element he designate a- the lease must be proved before it renewal, b- the obligatory sale through the scheme Management. It looks like those two elements or techniques of PRICE's empirical analysis (SCOTT/MITCHELL 1972:222)- discussed in chapter 2.4 - i.e., integrate and control, by which an Organisation exercises influence over participation behavior. But in Price's hypothesis play sanctions the central role; (6) we mustn't forget that such system of supervision could be faced with resistance from those concerned. The Organisation required then intuitive understanding and taking this in account; and (7) the scheme manager needs to have political backing support and to feel economically independent.

${ }^{175}$ NHAC (1986), ANNEX 7, APPENDEX 1, p. 25-9. 
Table 5.3 Joint Accounts' Components in New Halfa Scheme

\begin{tabular}{|l|l|}
\hline debit & credit \\
\hline $\begin{array}{l}\text { supplying fertilizers, spraying, sacks, } \\
\text { thread and labels }\end{array}$ & $\begin{array}{l}\text { value of the sale of the cotton crop } \\
\text { produced by tenants }\end{array}$ \\
\hline $\begin{array}{l}\text { ploughing, combating seepage and } \\
\text { fighting erosion }\end{array}$ & $\begin{array}{l}\text { value of any other crops shared between } \\
\text { tenants and the Corporation }\end{array}$ \\
\hline $\begin{array}{l}\text { uprooting cotton stalks, stacking them, } \\
\text { removing and burring them }\end{array}$ & $\begin{array}{l}\text { value of the sale of any machinery, } \\
\text { equipment or material purchased by } \\
\text { discount on joint accounts }\end{array}$ \\
\hline $\begin{array}{l}\text { sowing cotton or any other crop shared by } \\
\text { the Corporation and the tenants }\end{array}$ & $\begin{array}{l}\text { any fine or indemnity secured against } \\
\text { harm or loss inflicted on cotton or any } \\
\text { other crop in the shared returns between } \\
\text { the tenants and the Corporation }\end{array}$ \\
\hline payments for picking & \\
\hline expenses paid for collection centers & \\
\hline transporting from the field to the ginning \\
factories
\end{tabular}

- clearing 'Abu Sita' canals (field canals) and paying for the costs of the water pipe;

- clearing the 'Abu Ishreen' (quaternary canal) which is opposite the holding;

- cutting;

- agricultural loans;

- green ridging;

- fees paid for recruiting pickers;

- other additional loans; and

- any costs paid for operations which tenants failed to carry out and which fall within their obligations, and which they must carry out at an appointed time.

On the other hand, the share of the tenant from the net general tenants' account has registered to his credit in his individual account. 


\section{Critique of The Production Relationship}

The survival and growth of societies depends on generating a set of production relations which allow individuals or households to carry out their current and intertemporal decisions effectively (BINSWANGER/ROSENZWEIG 1989:505). ${ }^{176}$ Production relations therefore should be expected to adapt, however imperfectly, to the current and intertemporal problems faced by people. Thereby, the authors understand the production relations as jointly determined (1) by aspirations for higher incomes, for lowering risks, and for dealing with misfortunes, (2) by the material and technological constraints faced in the specific environment, and (3) by behavioral and technological constraints information acquisition and transmission.

Discussion with farmers, in the scope of NHIRP (NHAC 1986: ANNEX 8, p.7), has found that the practiced Joint Account system is a disincentive to them to grow cotton. They do not expect revenues from cotton sales because ,very often the cotton accounts are burdened with debts accumulated from previous years. Together with the debits of the concerning year the balances of the cotton accounts are often negative, thus the debts are not paid back $^{6 .}{ }^{177}$ The remarkable result from this situation was deterioration in the cultivated and harvested cotton areas and therefore negative influence on the whole schemes concerning the 'relations' and 'production'.

Because of the importance of cotton in the Sudan's economy, the Rehabilitation study has argued that ,the reorganization of the relationship between the corporation and the tenants concerning the costs and revenues of cotton is the most important and most critical point of all measures in the Scheme" NHIRP (NHAC 1986: ANNEX 8, p.12). The study has recommended, therefore, the need of short-term measures, working together with the solution worked out by the IBRD ${ }^{178}$, to establish a modified Joint Account system avoiding some disadvantages of the traditional system, and find an eventual solution for the whole Sudan $^{179}$. In the long run, assumed the study, that the Joint Account system will be replaced by a system fulfilling the following criteria NHIRP (NHAC 1986: ANNEX 8, p.13-4):

- cotton bares only those costs that it itself occasions;

176 This study undertake a step towards a more general theory of production relations in agriculture. The approach it pursue ,attempt to provide an analytical framework capable of assisting the joint analysis of the major features of production relations in rural areas, that is, one which will look at the institution governing production and the exchange (or lack thereof) of outputs and of all primary factors of production." To do this, it incorporate into the analysis risk, risk version, and information problems jointly and simultaneously with the material features of agriculture and the material attributes of the factors of production.

177 Though the JA has been, later, changed, one still hears such complaints as we will see in the next chapter.

${ }^{178}$ The Agricultural Rehabilitation Program Credit has included funds for a Study of cost recovery and tenant charge systems in the public irrigation schemes of Sudan. This has resulted in IBRD's Report (1980).

179 The abolition of ,partnership and the joint account systems“ has been announced in the light of the Presidential Declaration to Parliament (June 1980). 
- the cotton price paid to the farmers is directly derived from the world market price, and does not depend on the quality of cotton produced in the Scheme and the costs of the corporation other than marketing costs ${ }^{180}$;

- the farmers receive most of the payment upon delivery of the cotton to the collection center by deducting all costs of the Corporation directly related to cotton. the remainder would be received 12 months afterwards at the latest.

Furthermore, the solutions that have proposed by the IBRD (1980:15) and adopted by the Rehabilitation study say:

- a credit and service contract would be signed every year by the Corporation and each tenant;

- the cost for machinery services and materials would be charged to that crop which had caused them;

- the overhead costs would be recovered by a farm service charge amount to LS 150 per tenant per annum.

In view of the above mentioned background, the 1981/82 agricultural season witnessed a major change in production relations in all irrigated schemes in the Sudan, where the Joint Account system was replaced by an individual account system known as the land and water charge (LWC). One of the main justifications put forward by the IMF-World Bank for that charge was said to be based on efficiency grounds (SALEEM, 1989:1); the socalled „Marshallian inefficiency.“ The assumption here, which is based on the Marshallian theory of sharecropping ${ }^{181}$, is that the JA as a sharecropping arrangement would result in inefficient allocation of resources relative to the LWC system as a fixed-rent contract. ${ }^{182}$

\section{Gendettu Scheme}

Production relations in Gendettu has been influenced, like the other governments' Schemes, by the above-mentioned development. Farmers are connected with the Scheme through two kinds of fixed-rent contracts. The first is leasehold and water contract for the tenancies, whereas the second; water contract, is devoted to freehold lands. The Scheme itself is no longer, since 1.7.1992, financial dependent on NAPC. All NAPC Schemes have now individual account and have therefore raised the water prices to cover the operation costs.

${ }^{180}$ Within this area of interest, a recent positive change in the cotton pricing system in the neighbor country Egypt, has motivated the producers to keep their performance high, after long conflict with problems like those in Sudan.

181 See Chapter Three, Section 3.1.3.4.

182 By using a model based on the Cobb-Douglas production function, and assuming that there are two variable inputs and one fixed input, SALEEM (1989:22) has investigated the relative efficiency of the JA and the LWC systems by comparing the economic performance of cotton farms in the other two large cotton schemes in Sudan. The empirical results indicate that cotton farms under a JA system (Gezira) and those under a LWC system (Rahad) are equally relative technical efficient, equally relative price efficient, and hence equally relative economic efficient. Similar investigation was also carried out by MOROOKA and HAYAMI (1989) in an upland area in West Java where the share tenancy contract was commonly practiced side-by-side with the fixed-rent contract. Consistent with other experiences tested by OTSUKA and HAYAMI (1988:40), no significant inefficiency in resource allocation was found to be associated with share tenancy as compared with owner cultivation and fixed-rent tenancy. 


\subsubsection{Some Features of Organization Structures}

This part of the study will focus initially on the horizontal and vertical dimension of the two concerned structures. Whereas the other dimensions of the organizational structure i.e., formalization and the water users' side of configuration ${ }^{183}$, will be further discussed in the coming chapter.

\section{New Halfa Scheme}

New Halfa Scheme is managed by the New Halfa Agricultural Corporation (NHAC) whose administration is based on forms and procedures, to a big extent, like the Gezira Scheme which inherit this from the British. As prescribed in the Establishment Order for the Corporation (Chapter 3), the Board of Management was composed of a Chairman and 12 members. The composition of the Board was as follows (NHAC 1980: ANNEX 7,p56):

- representative of Kassala Province

- representative of the Ministry of Agriculture

- representative of the Ministry of Irrigation

- representative of the Agricultural Research Authority

- representative of the Ministry of Finance

- Assistant Commissioner Agriculture, Kassala Province

- four members of Tenant Farmers' Union (TFU)

- two representatives of NHAC personnel (staff and workers)

As it is shown in Fig.5.8, the structure of NHAC (1980) contains three main Departments; Financial and Administration, Engineering, and Agricultural Department. For the purpose of this study, it will be concentrated on the last one, which consider, in the same time, the most important Department. However, the other Departments and their functions will be referred to through the discussion of the modifications and changes recommended by NHIRP.

The main responsibilities of the Department of Agriculture are in the field of supervising (THORNTON/WYNN, 1987:210):

1. clearance and preparation of land;

2. distribution of seed, fertilizer and tools and provision of financing loans and machinery services for crops;

3. supervision of watering and farming practices;

4. plant protection measures; and

5. the transport, ginning and marketing of the cotton crop.

The structure embrace then different set of activities: agricultural services (agricultural extension with research support) and -as in new settlement schemes- commercial services (input supplies, credit, marketing). Cotton marketing is an integral, indeed central, part of the organization.

\footnotetext{
${ }^{183}$ According to COWARD (1980), there is two important Organisational configurations in irrigation system, i.e., the role of water users and the various water-authority roles.
} 
Fig. 5.8 Organization Chart - NHAC (1980)

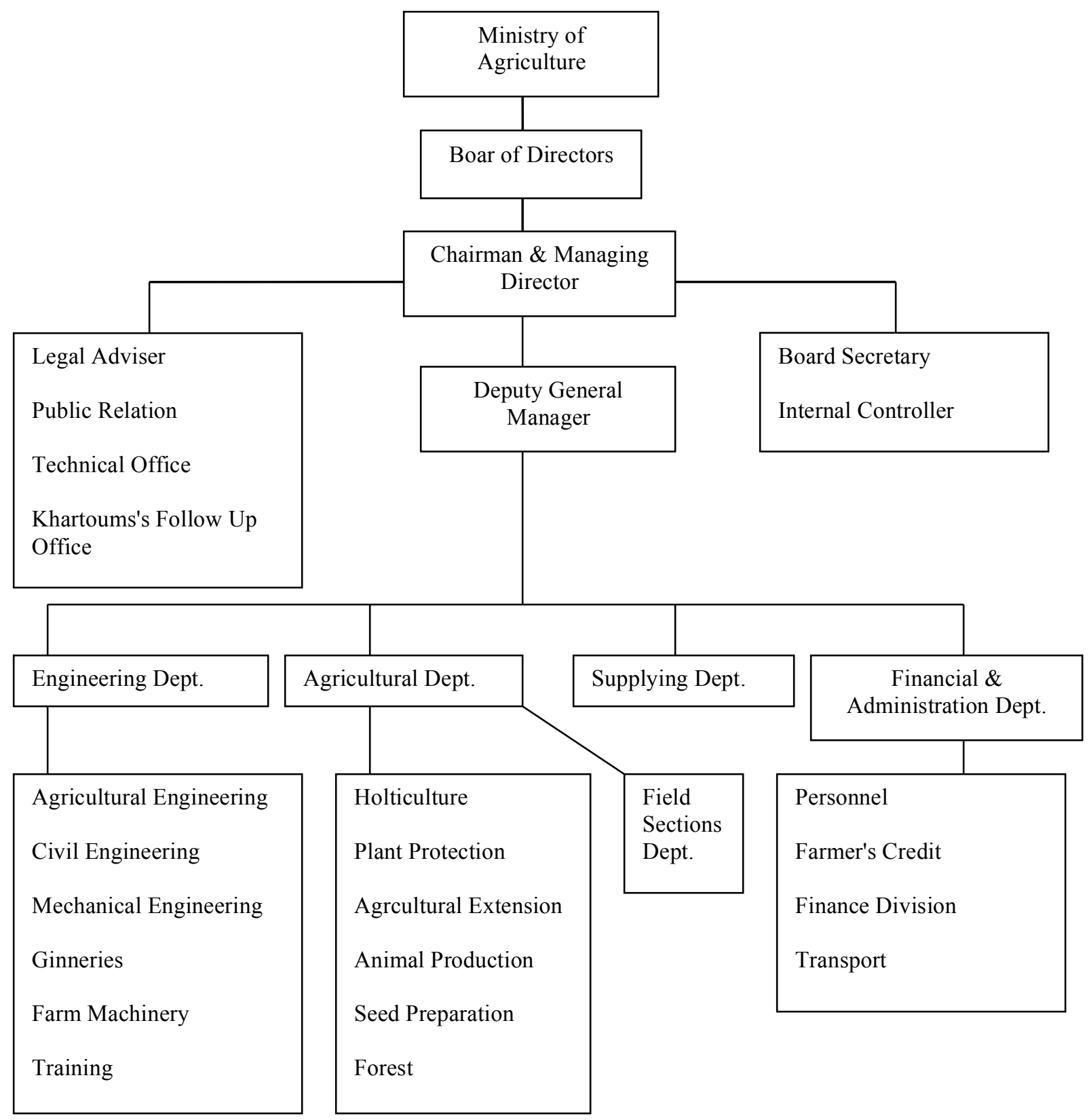


The following organigram Figure 5.9 outline the agricultural administrative structure at section and block level. Figure $\mathbf{5 . 1 0}$ breaks this down further and shows the Organization at section level under the assumption that the section is divided into three Blocks. This is the theoretical or recommended division but, in fact, many of these posts, as it would be shown in the next chapter, are not necessarily filled. For instance, A extensionist, horticultural, plant protection, and maintenance inspectors are usually not filled and they fulfil their duties, if at all, through their departments in the headquarters.

The structure of the staff (Extension Officers) at block and section levels as demonstrated in Table 5.4 provide an extension ratio of 1 EO : 214 tenants. Under conditions of reduced water supply and assuming 70 per cent of tenants present in the Scheme, as assumed by NHIRP ${ }^{184}$, the 103 Extension Service Staff at block and section levels provide an operational ratio of 1 EO : 150. Taking the 23 not occupied posts into consideration, the actual ratio in season 92/93 was 1 EO : 275 tenants or 1 EO: 193 tenants respectively. Operationally, it is the block level EOs who are principally in regular contact with the tenant farmer. That is why the NHIRP has maintained: „the major concentration of retained Extension Service manpower should be at the Block level" (NHAC 1986:Annex 7, p.68). Thereby, It has been proposed the following establishment of extension staff:

${ }^{184}$ Estimates are made in this study (NHAC 1980:ANNEX 8, Chapter 2.6) of variation in the number of tenants in the Scheme under reducing water supply, using alternate assumptions of minimum acceptable income with declining tenant numbers, and tenant populations with declining income. 
Fig. 5.9 Agricultural Administrative Structure in New Halfa Scheme

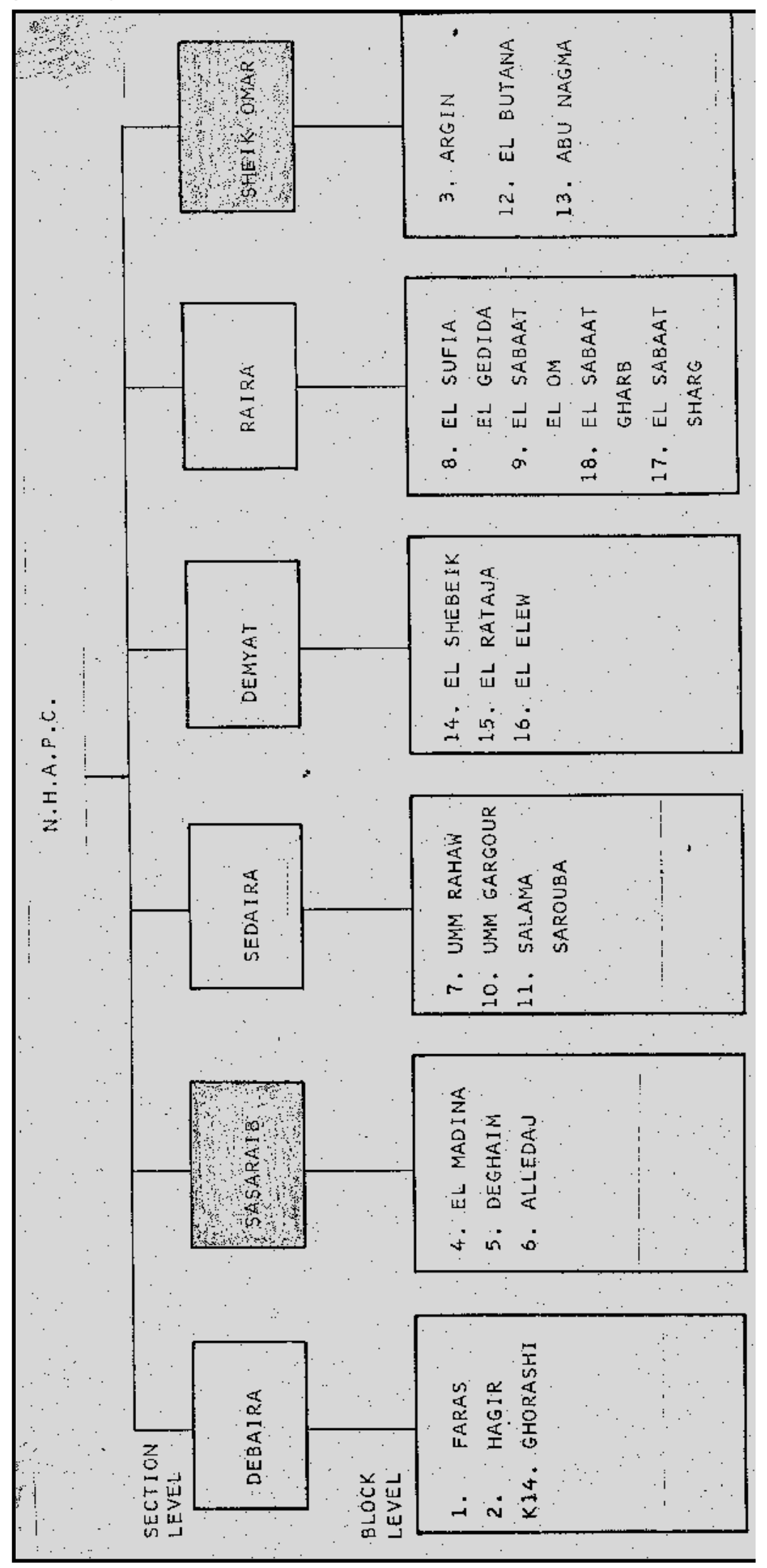

Source: NHAC 1986:ANNEX 2:48 
Fig. 5.10 Personnel at and Below Section Level (New Halfa Scheme)

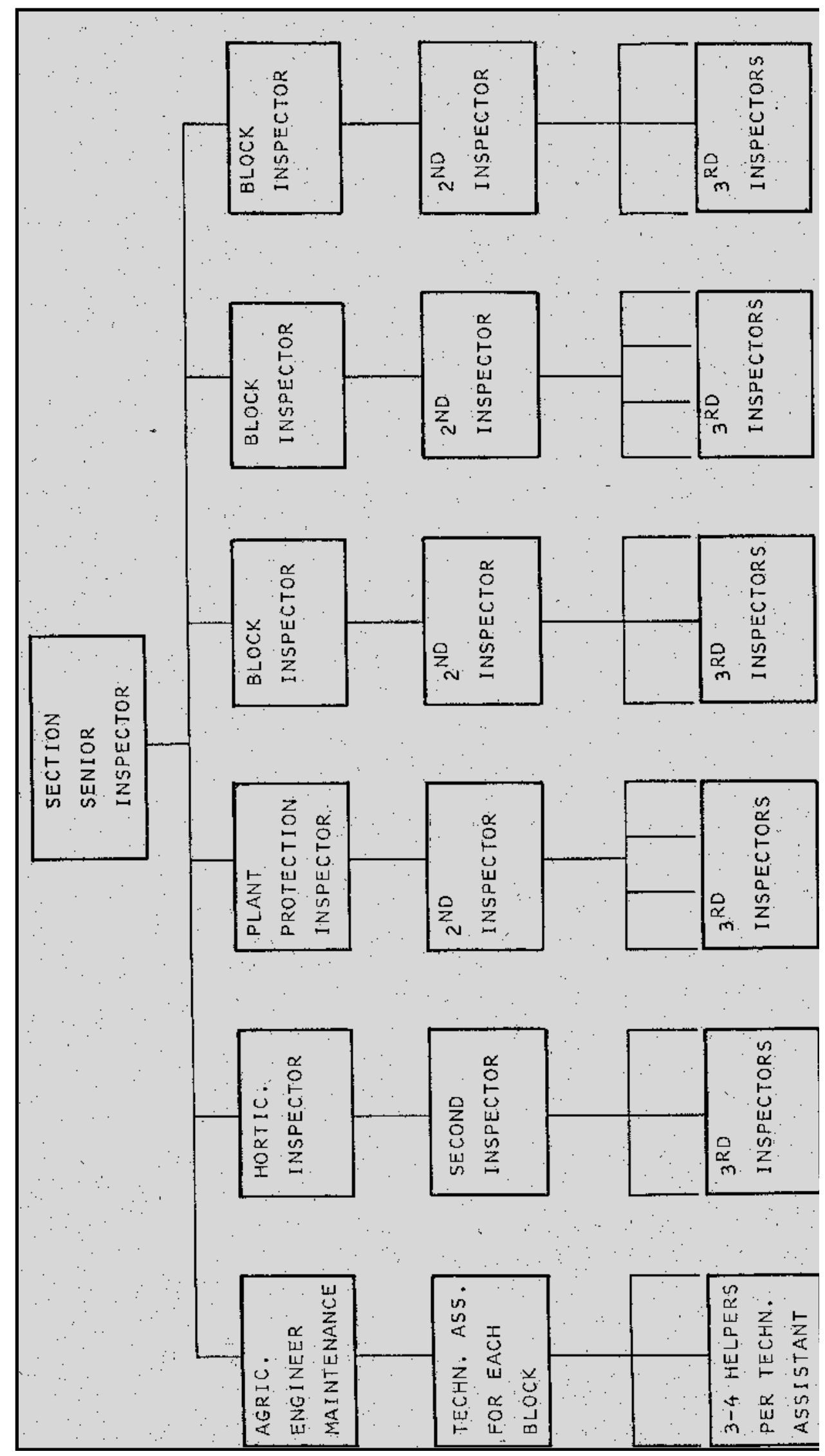

Source: NHAC 1986: ANNEX 2:44 
- Block level: total 114 (6 per Block)

- Section level: total 18 (3 per Section)

Total: 132

At each of these levels, the establishment could be broken down as follows:

- Block level: 1 x Senior EO

1 x Assist. Senior EO

$4 \times \mathrm{EO}$

- Section level: 1 x Senior EO

$2 \times \mathrm{EO}$

This suggestion leads to an improved operational ratio of 1 EO : 193 tenants or 1 EO : 117 tenants respectively.

Table 5.4 Allocation of the Staff (Extension Officers) at Field Level according to Post and Qualification in New Halfa Scheme: Season 92/93

\begin{tabular}{|l|l|l|l|l|l|l|l|l|}
\hline $\begin{array}{l}\text { Degree } \\
\text { of the } \\
\text { Post/ } \\
\text { Qualifi } \\
\text { cations }\end{array}$ & MSc. & BSc. & $\begin{array}{l}\text { High } \\
\text { Inst. }\end{array}$ & $\begin{array}{l}\text { Agr. } \\
\text { Seco. } \\
\text { Scho. }\end{array}$ & $\begin{array}{l}\text { Prim. } \\
\text { Scho. }\end{array}$ & $\begin{array}{l}\text { Post not } \\
\text { occupied }\end{array}$ & Total & Distribution \\
\hline Third & 5 & 1 & 1 & - & - & 1 & 8 & $\begin{array}{l}\text { Section } \\
\text { Directors Field } \\
\text { Director }\end{array}$ \\
\hline Fourth & - & 14 & 2 & - & - & 3 & 19 & $\begin{array}{l}\text { Block } \\
\text { Inspector }\end{array}$ \\
\hline Fifth & - & 6 & 2 & 7 & - & 10 & 25 & Senior Insp. \\
\hline seventh & - & 5 & - & 15 & 2 & - & 22 & Inspector \\
\hline Eighth & - & 3 & - & 15 & - & 7 & 25 & Inspector \\
\hline Ninth & - & 2 & - & - & - & 2 & 4 & Inspector \\
\hline Total & 5 & 31 & 5 & 37 & 2 & 23 & 103 & $\begin{array}{l}\text { average 4-5 } \\
\text { per Block }\end{array}$ \\
\hline
\end{tabular}

Source: various records of the Scheme

The number and qualifications of personnel working at different levels is an essential feature of organization structure. Table 5.3 shows that the structure of field level can be described as 'top-heavy'. This means that a disproportionate number of the staff assigned to higher levels (posts from Third to Fifth). In addition, the fact that most staff with higher education and professional qualifications assigned to the upper levels, with only less formally qualified staff running the system at lower levels, reveals the qualitative dimension of the structure.

The functions and responsibilities of each inspector can be said to fall roughly into the following categories: 
- administration

- crop husbandry
- staff relationships

- extension
- equipment - irrigation

- control of Joint Account.

For many reasons, the functions have become confined to Joint Account control had taking up the vast majority of the personnel's time. This orientation of the staff reflects then the fact that an objective like collecting the earnings of cotton is more important than this of maintaining optimal day-to-day water deliveries for instance. In this connection NHIRP has reported: „Due to the Joint Account commitments and the lack of communications, agricultural staff have inexorably been maneuvered into the present situation of Joint Account controllers rather than Extension officers" (NHAC 1986:ANNEX 2, p.45). Considering this fact, one can say that, here, the degree of administrative intensity as defined by PRICE/MUELLER ${ }^{185}$ is high. Though, in irrigation systems, it is difficult to distinguish the administrative and production staff.

Thereby, it has been suggested that the services of the inspectors should be directed to true extension work with the primary aim of improving the yields and incomes of the tenants in their respective areas, not working their limited manpower resources in the financials field. Note that, as SAGARDOY (1986:12) has revealed, this activity of water management; assistance and extension to farmers on water management at the local level, often failed in the large project organizations (specially settlement schemes) against the other mentioned activities. Furthermore, securing/or guarantee the mechanical inputs means that inspector can spend time with tenants discussing the ,nuts and bots " of crop production, irrigation, tenant inputs, labor requirements, cost/benefit comparisons and all other aspects of extension. Time would be required to train tenants to use irrigation water efficiently. Emphasis should be placed on the income potential of tenants (NHAC 1986:ANNEX 2, p.46). ${ }^{186}$

To enable field inspectors taking over these broad tasks, recommendations put forward for consideration by NHIRP concerning the internal organization of NHAC (NHAC 1986:ANNEX 7, p.61-7):

1. The Tenant Credit Unit (TCU): responsible for the control of all 'direct' and 'indirect' credit provided by NHAC to the tenant, and for the assessment and provision of medium-term credit to the co-operative sector. It is directly responsible to the financial controller provided under the project. It's own field staff (Field credit officers) located at section and Block levels, could be constituted by the suitably retrained accountants, bookkeepers and cashiers previously responsible to the dissolved Field Divisions.

2. Agricultural Extension Service Reorganization: as set out above, the essence of the modification of their role is the removal from the agricultural field inspectors of

185 PRICE and MUELLER (1986:27) define this variable, which is significant for management but is not clearly structural, as: ,the extent to which an organization allocates resources to the management of its output...An organization with a high degree of administrative intensity is sometimes said to have a relatively large 'administrative apparatus' or 'supportive component'." This variable can be perationalized as the ratio within a bureaucracy of administrative staff $(\mathbf{A})$ to production staff $(\mathbf{P})$, i.e., A/P (UPHOFF 1991:49).

${ }^{186}$ In spite of the abolition of JA system, many respondents from scheme Management and tenants have pointed out that the role of inspectors is still limited in the area of cotton administration as will be coming in the next Chapter. 
responsibility for credit operations. In addition to expanding the structure of the Extension Service at field level, the coming related modifications are of interest:

a. Extension Service Tasks: Crop/Livestock Integration: it is also proposed that the reorganized Extension Service be retrained so that it may operate an integrated program of crop-and animal -husbandry counseling. They would thus at one and the same time, be crop and livestock counselors.

b. Livestock Extension Officers: Dual Control and Incentives: it is proposed that the extension officer, when working in the context of the Livestock Development Program, would be subject to the control of the Livestock Advisers attached to the Livestock Production and Marketing Unit (LPMU), a separate body within the overall scheme. As such, the EO will be subject to dual control: while consoling tenants on Livestock, he will be responsible to the Livestock Adviser of the LPMU; in his role as crop-husbandry adviser, he will be responsible to, and continue to be paid from, NHAC.

3. The Development Planning Unit (Technical Planning Office): as part of an existing Technical Planning Office (TPO), a Development Planning Unit (DPU) should be established to assist management in designing appropriate monitoring and evaluation systems and to furnish economic, financial and technical information to management as the basis for sound operations and planning.

Giving more attention to the social context of the scheme management, NHIRP has proposed modifications or innovations in NHAC's relations with a number of external agencies (NHAC 1986:ANNEX 7,p.2). The argument for these organizational changes is to ensure efficient Scheme management and effective co-ordination of scheme operations and planning. It has therefore suggested that the involvement of institutions in scheme Organization should be expanded by immediate additional appointments to the Board. At ministerial level, it was proposed that a Central Monitoring Unit should be established within the Ministry of agriculture to monitor NHAC's performance and anticipate operational constraints. In addition, a liaison Committee should be established at interMinisterial level, to facilitate planning for the agricultural corporations, including NHAC. At scheme level, in the same time, it was proposed that:

- the Ministry of Irrigation, through its irrigation service and the Earth Moving Corporation, should assume greater responsibility for field water management and quaternary canal maintenance respectively;

- the constitution and financing of the Tenant Farmers' Union should be reviewed, with a view to its financial participation in a project scheme-wide impact such as the Livestock Production and Marketing Unit (LPMU);

- All seasonal and medium-term cash credit operations (crop and Livestock) in the scheme area should be handled directly by the Agricultural Bank of Sudan (ABS). ABS would appoint Block-level Agricultural Credit Officer; and it would act as consultant in the establishment of the Tenant Credit Unit.

According to the above, the additional appointments to the Board have been recommended (NHAC 1986:ANNEX 7, p56-9) 
- the Manager, ABS (Agricultural Bank of Sudan) New Halfa Branch

- the chairman or Managing Director of the LPMU

- a representative of the Ministry of Co-operation, Trade and Commerce

- financial controller

- the head of the Technical Planning Office

- two Seats on the Board have to be accorded to the co-operative sector

- the new Halfa Agricultural Secondary School would be brought into a closer relationship with the Co-operation.

As a result of these proposed changes, and to ensure rapidity in decision-making by those most closely concerned in the current operations of the scheme, NHIRP (NHAC 1986:ANNEX 7, p.2, 59,60) has also suggested that ,a two-tier Board system “ should be instituted in NHAC. Namely: ,an enlarged Policy Board to accommodate the increased member of agencies having an interest in Scheme policy and co-ordination with NHAC, and a Working Board to ensure efficient operational management" (Fig.5.11). The Working Board which would exercise all the powers of, and be responsible to, the full Board (or policy Board) composed of 7 members: 1) Director General (NHAC) (Chairman); 2) Manager, ABS New Halfa Branch; 3) Chairman or Managing Director, LPMU; 4) a representative of the Ministry of Irrigation; 5) two representatives of the Tenant Farmers' Union; and 6) the Financial Controller appointed under the Project. Minutes of all its meetings have to be distributed monthly to members of the Policy Board and transmitted to the proposed Central Monitoring Unit. Yet, it would report quarterly in a full meeting of the policy Board.

In the same vein, the purpose of the Policy Board would be ,to give influence in Scheme affairs to as wide a range as possible of institutions directly affected by corporation activity ". It has to meet quarterly to review the management of the Working Board and broad NHAC policy. It's particularly concerned with the work the Technical Planning Office (TPO) and its Development Planning Unit (DPU). Minutes of Policy Board meetings are transmitted quarterly to the Monitoring Unit of the Ministry. In addition to the composition of the old Board (12 members) includes the full policy Board the Following members (NHAC 1986:ANNEX 7, p.61):

- the manager, ABS New Halfa Branch

- Chairman or Managing Director, LPMU

- a representative of the Ministry of Co-operation, Commerce and Supply

- the Director, New Halfa Agricultural Secondary School

- two representatives of the co-operative movement

- the Financial Controller appointed under the Project

- the Head of the Technical Planning Office. 
Fig. 5.11 Proposed Organization Chart (NHAC)

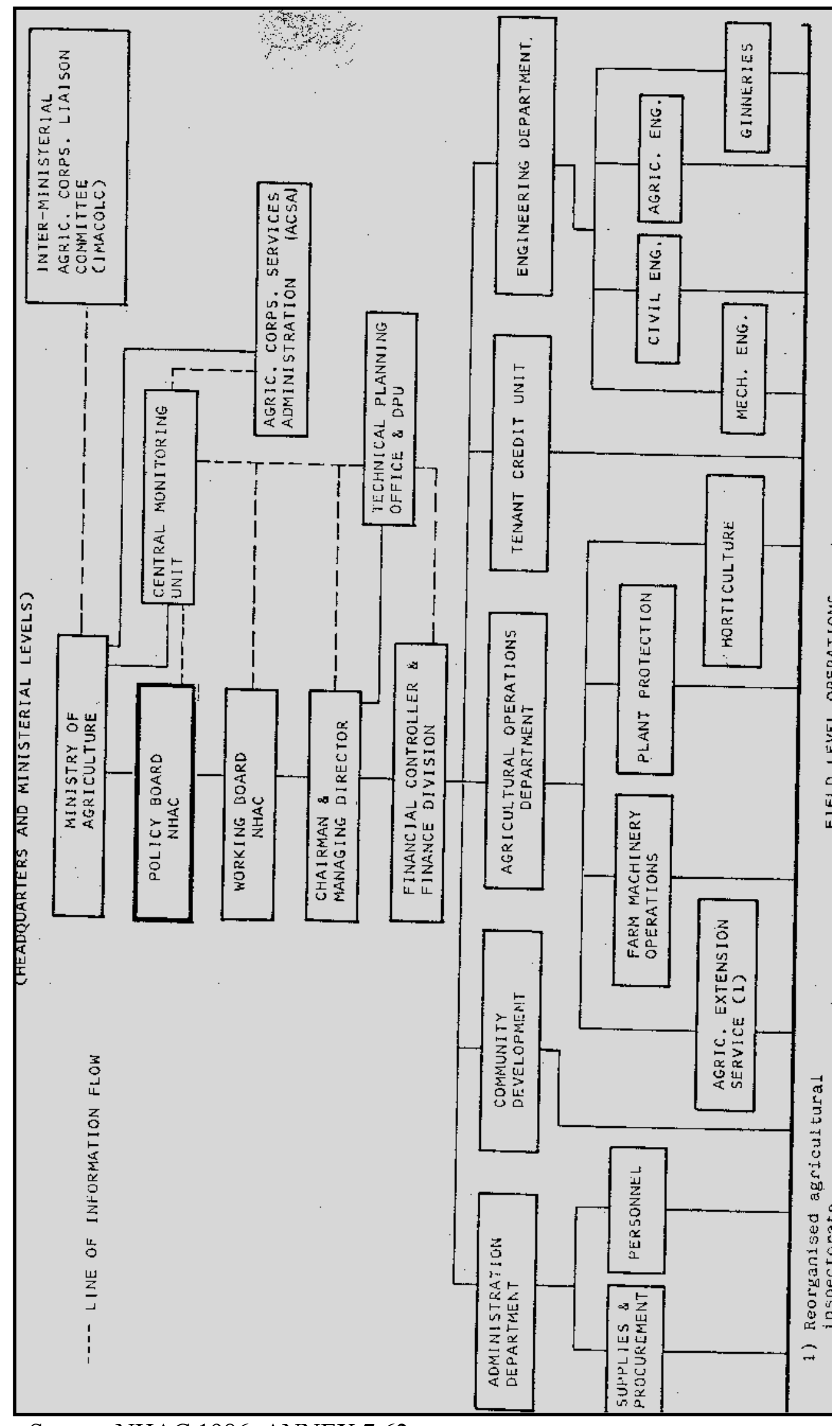

Source: NHAC 1986: ANNEX 7:62 


\section{Gendettu Scheme}

The regional organization; The Northern Agricultural Production Corporation (NAPC), which supervise the management of Gendettu Scheme (Chapter 5.3.2), has been established according to the presidential order No. 512 of September 16th, 1979. Like the other nine agricultural Corporations that manage the irrigation systems in the Sudan, the Board of Directors has been expanded and composed of 22 members including all concerned ministers and institutions as well as 6 representatives of Tenants. To simplify the administration of it's Schemes, NAPC has subdivided Nile Province into three Zones each of which has a Zone Manager, and the overall headquarters is located at Ed Damer:

- Southern Zone, administrated from Shendi; includes Gendettu, Kelli, Kaboushia and Seyal;

- Central Zone, administrated from Atbara; it includes Aliab, Kitiab, Fadlab and Bawga;

- Zeidab, being such a large Scheme with unique cropping pattern, is a Zone in its own right.

Directors of the three main Departments; Agricultural, Civil and Mechanical Engineering had therefore taken their tasks through four Regions Managers (Fig. 5.12). The Regions' system has been canceled since the financial year 92/93. Thereafter, the managers of the different departments in the schemes have become directly responsible to the main departments in Ed Damer and Atbara ${ }^{187}$.

In Gendettu, for instance, there are three main figures who have different orientations and come through different courses:

1- the manager of the Scheme (agriculturist), responsible in the face of the managing director of NAPC;

2- the mechanical engineer, responsible to the main department in Atbara. He supervise, technically, the mechanical staff in Gendettu and the other three Schemes in the southern region; and

3- irrigation engineer (Operations \& Maintenance), responsible to the related department in Ed Damer and works also with his staff in the other three Schemes in the same time (Fig. 5.13).

The staff of both the mechanical and irrigation/civile engineers in Gendettu scheme are responsible, administratively, to the Manager of the Scheme, and technically to the formers. This duplicity was and still a cause of several management problems (e.g., create contradiction between the administrative and technical decisions) and through which the hierarchical control seems to be semi-opaque (see Chapter 6.1.2).

187 Atbara is the headquarters of the Mechanical Engineering Department of the NAPC. 
Fig. 5.12 Organization Chart of NAPC

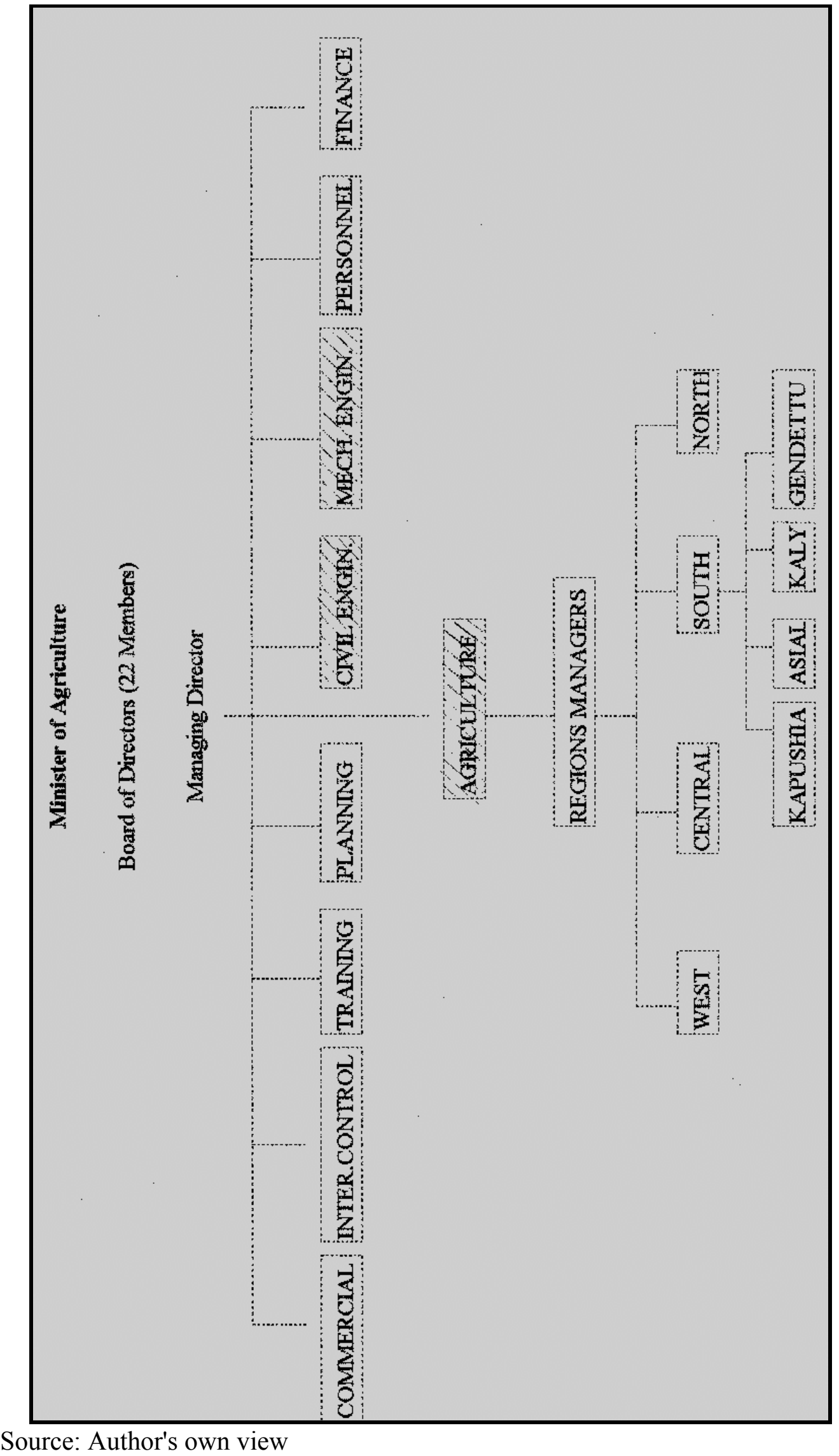


Fig. 5.13 Organization Chart in Gendettu Scheme (1992/93)

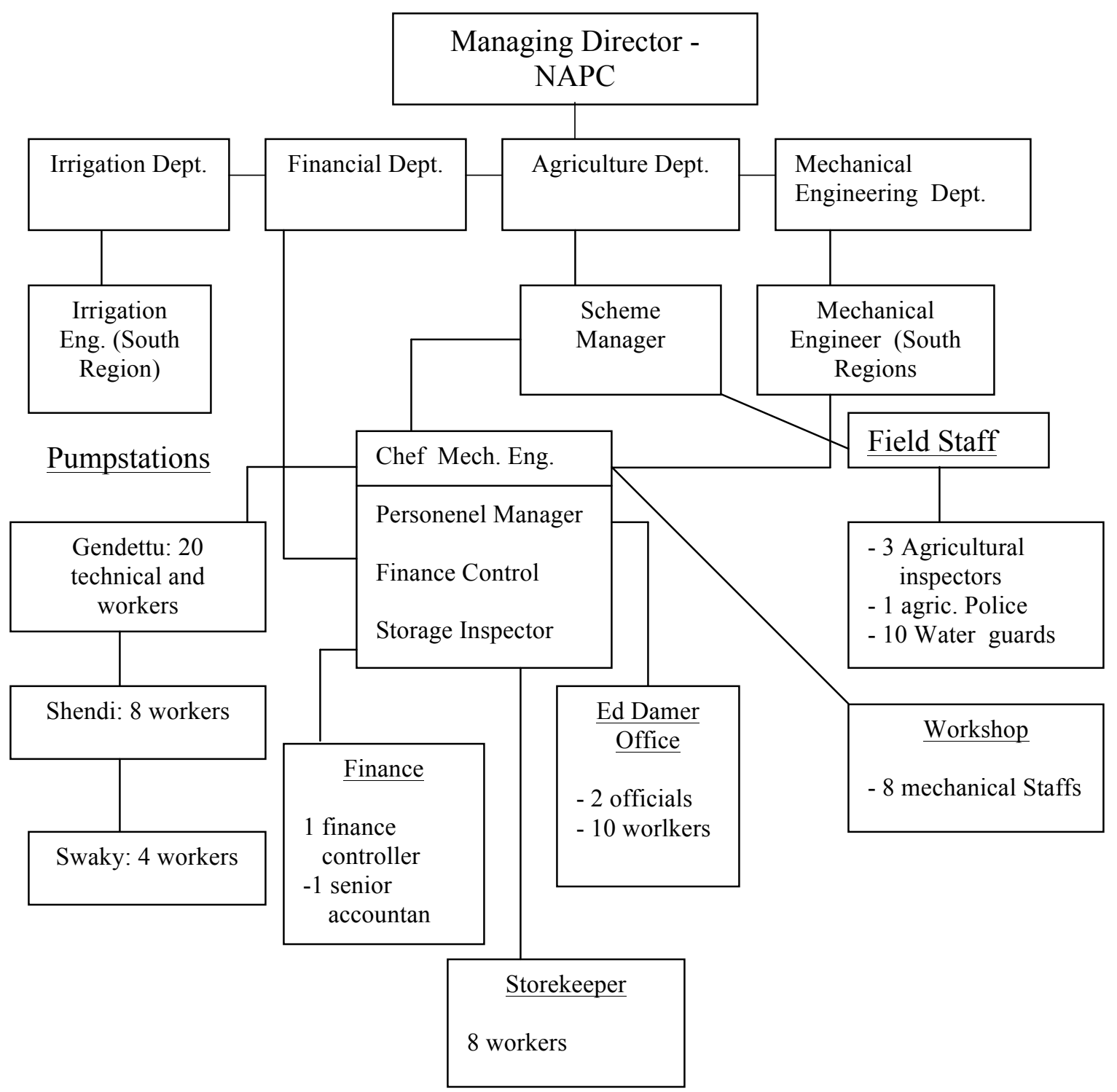

Source: Author's own view

The agricultural staff in Gendettu consists of Senior Agriculturists (Scheme Manager degree in agriculture B.Sc., Fifth degree), Inspector (Agri. Second. School, Seventh degree), 2 Inspector (diploma - high Institute, Eighth degree) and Agriculturist (Agri. Second. School, Eleventh degree). Their responsibilities are mainly concerned with scheme and farmer administration, water distribution and management, rather than the technical aspects of agriculture. In the concrete, their main task is to distribute water and to identify the area under each crop on which water rates must be paid. Thereby, once again, the role of agricultural staff as extension agents, by which they can pass their knowledge to the farmers is, specially after the new production relations, subservient to that of persuasion the tenants to pay the water fees. In addition to the above, one surveyor, 9 Water Guards (Khaffirs) and agricultural Policeman operate the water control structures on the main, minor and branch canals. 
It is an important function of irrigation management at all stages of small-farmer development to ensure the timely supply of other inputs besides water (SAGARDOY, 1986:13). The agricultural services available to Gendettu's tenants are provided by several different organizations in the public sector as well as local merchants and entrepreneurs in the private sector. The main services involved are farm machinery, plant protection, extension, agricultural credit and inputs. However, once these agencies are in a position to tack direct responsibility for such services, the best results may be achieved through good coordination between them and the scheme organization (see Chapter 6.5.3).

\subsubsection{Technical Context}

Where the water for an irrigation system comes from (source factor) and how it is acquired, is the first technical aspect. This affects how irrigation water is managed. In New Halfa, irrigation water is fed by gravity from Khashm El Girba Dam on the Atbara River. The first detailed study of the possibility of using the waters of the Atbara for gravity irrigation was made in 1954 (THORNTON/WYNN, 1987:202). Due to the great fluctuation of discharge in the Blue Nile and the fact that no water flows in the Atbara River after December, pumps have not been used near those rivers (FUKUDA, 1976:265).

\section{New Halfa Scheme}

\subsubsection{Khashm El Girba Dam}

It was the 1954 investigation which drew attention to the advantages of the Khashm El Girba site for a dam. Plans and canalization were started in 1958, and June 1961 saw the first excavation of the dame site. The construction was completed in 1964. This rapid exploitation of opportunities, owes its impetus largely to the 1959 Nile Waters Agreement as mentioned in Chapter 4. Theoretically, in most cases, managers of reservoir systems can concentrate their efforts on allocation and distribution, not supply (UPHOFF, 1991:79). But this is not the case in New Halfa. It appears that the cropped area is sometimes limited by the water available from the dam, which is affected by extensive silting of the reservoir and also by the policy followed for hydropower generation (MINSTRY of IRRIGATION 1992, Vol. 3 of 4:F5). The initial reservoir capacity of 1.3 milliard has been seriously reduced by heavy siltation and estimated recently between 0.65 milliard (SALEH, 1989) and less than 0.80 milliard (1993), according to the Technical Office of the Scheme.

The extremely variable regime of the Atbara dictate the manner of dam management. Ninety per cent of the river's median annual flow is passed in the three months July to September. During this period, the reservoir is filled. From October to June, the river's flow can only be regarded as sufficient to compensate for evaporation and seepage losses and for the flow of water which will in the future be left in the river downstream from the Dam. During this period, therefore, irrigation relies on the stored water of the reservoir.

\subsection{2 The Layout of The New Halfa Irrigation Canal System ${ }^{188}$}

The main difference found in the layout of systems is in the number of levels of operation and organization they have (UPHOFF, 1991:32). This is defined by the hierarchy of points

\footnotetext{
${ }^{188}$ This part draws on the New Halfa Irrigation Rehabilitation Project (NHAC 1986 ANNEX 1).
} 
at which water can be divided and controlled. However, the number of levels in an irrigation system reflects the size of its command area. Irrigation water is fed by gravity from Khashm El Girba Dam through one main canal, lengthen 26 kilometers to the first regulator, and three branches; East, West and Sabir Branch which run parallel (northwards) through the 80 kilometers of the scheme. The regulating devices in the branch canals are vertical lift gates, and the discharge is a function of the gate opening and the difference in elevation between front water and back water. These branches are connected with a series of minor canals through five major canals and carriers.

The minor canals (128) form the irrigation distribution system of the Scheme. Because of the slope of the land (roughly $45 \mathrm{cms}$. per $\mathrm{km}$.), the cost of excavating and regulating minor canals having night storage capacity on the Gezira pattern (where land slope is roughly 15 cms. per $\mathrm{km}$.) is more expensive ${ }^{189}$. To reduce costs at New Halfa, however, it was decided to run a continuous flow of water to the fields, making night watering necessary. In practice, this proved far from satisfactory. The resettled Halfaween were unused to night watering and have been reluctant to water at night for fear of scorpions and snakes (PEARSON, 1980:2 and HORNTON/WYNN, 1987:206). In light of this, night storage capacity has been provided in the minors of phase II and III of the scheme. This means, there are two types of distributaries:

1. Minors designed for continuous irrigation: These minors are found in the first constructed phase of the Scheme; the south part of the Scheme where the nubians have been resettled, as well as in the area of pumped extension. They are situated at spacing of 2,840 meters and take the water directly from a branch canal or are connected to a branch via a carrier. The cheek structures are pipe regulators or well head regulators, the latter to facilitate calibration, although no flow is measured within a minor.

2. Minors designed with night storage facilities are found in the areas which were developed after 1965 (in the nomads' areas). The spacing between these minors is 1,420 meters, and the design is basically the same as for the minors for continuous irrigation, except that the pipe and well head regulators are replaced by circular night storage weirs.

Along each minor canal, at intervals of 296 meters, field outlet pipes (FOPs) pass the water into 300 quarternary canals, known as $\boldsymbol{A b u}$ Ishreens (Abu XXs). These canals, which constitute the boundary of our focus/interest, convey the water to the individual fields (Fig. 5.16). The field offtakes are $35 \mathrm{~cm}$ diameter concrete pipes through which flow can be regulated by a valve having three opening positions. The Abu Ishreens that draw their supply from continuous watering canals have a length of $2.8 \mathrm{~km}$ (known as the long Abu Ishreens) and rotate the water over 36 fields of 5 feddan. This is called a number.

189 In this context, NIRP (1992) has reported: „there is evidence to indicate that farmers and Agricultural Authorities would prefer to use night storage and daytime irrigation, for some but not all crop growth stages, if the water supply in the Minors were suitably reliable: the change of operation mode away from night storage in recent decades may be partly due to the sediment and weeds rather than the other way round" (Vol. 3 of 4:F13). 
Fig. 5.14 Layout of Irrigation Field Distribution System

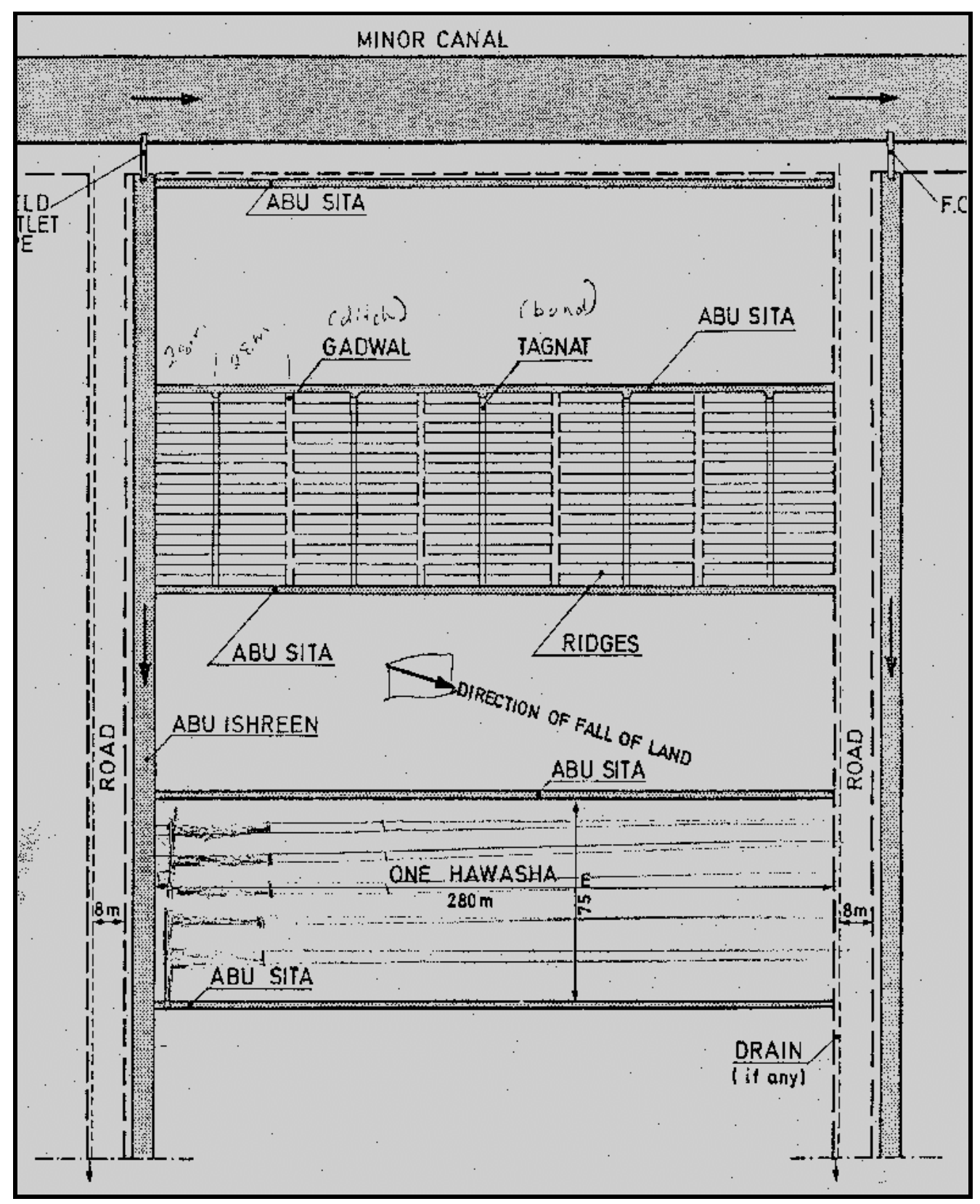

Source: NHAC 1986: ANNEX 1:18

The design capacity of these quarternary canals is $10,000 \mathrm{~m}^{3} /$ day. Due to weed growth, siltation and delayed maintenance, the present capacities are much smaller (NHAC 1986: ANNEX 1:17). This capacity is official estimated in $1992 / 93$ as $5,000 \mathrm{~m}^{3} / \mathrm{day}^{190}$. According to many informants, the irrational estimation of the flows appear to be the main problem in

${ }^{190}$ A survey carried out in November 1979 with a currentmeter showed that a discharge of $3000 \mathrm{~m}^{3} / \mathrm{day}$ was typical (NHAC 1986:ANNEX 1:17). The senior irrigation Engineer of the Scheme argues that the actual discharge become - in the season $92 / 93-2500 \mathrm{~m}^{3} /$ day. 
the distribution system in New Halfa and Gendettu as well ${ }^{191}$. It results in, the period of irrigation takes to long, and the irrigation interval becomes much too large.

The Abu Ishreens that draw their supply from minor canals with storage capacity are 1.4 $\mathrm{km}$ long and irrigate a short 'number' (18 fields of 5 feddan). The capacity of these Abu Ishreens is the same as the 'long' Abu Ishreens but they operate for only 12 hours/day in the irrigation season, whereas the latter (the $2,8 \mathrm{~km}$ long canals) should operate 24 hours/day.

An attempt has been made to solve the problem of the long Abu Ishreens; being too long to rotate the water efficiently over the fields, by introducing two quartenary canals (twin Abu Ishreens, known as El double) running parallel to each other. The first of which rotates the water over the first 18 fields (90 feddan), and the second of which rotates the water in the second 90 feddan. Due to the fact that these twin Abu Ishreens have only one offtake at the minor, and the farmer sometimes perforates the bank between the two Abu Ishreens, the improvement in water distribution is only minor (NHAC 1986: ANNEX 1 p.19).

As is shown in Figure 5.12, a small field canal (lateral water course), named $\boldsymbol{A b u}$ Sita (Abu VI), runs along the side of the field. The design capacity of an Abu Sita is $4000 \mathrm{~m}^{3} / 24$ hours. From these field canals, the water is led into the field by perforating the bank of the canal. A field is divided into basins, and the method of water application in the field depends on the crop grown in the field. Groundnuts and cotton are normally irrigated in small furrows in the basins, running parallel to the Abu Sita, and they are fed via field ditches, called Tagnats. This application method is also practiced for wheat, but wheat is also irrigated directly from the Abu Sita, as well, and the water runs parallel to the abu Ishreen into small basins.

\section{Gendettu Scheme}

\subsubsection{Gendettu's Pump Stations ${ }^{192}$}

At Gendettu, the main source of irrigation water is Nile River. The region has been allocated sufficient water to adequately irrigate 570392 feddan at 100\% cropping intensity. As many other irrigation systems, the Scheme use more than a single source of water. Underground water is recently being exploited. There are, in almost all villages, Wells used for lift irrigation (pump sets). If the main system fails, the pump system can compensate.

The Scheme is supposed to be entirely irrigated by riverine waters tapped by two pump stations and conveyed by main canal (Fig. 5.15). The pump capacity here play a similar role like that of the dam capacity in New Halfa; both of them decide the water supply. The description of pumping plant is as follows:

191 This result come to justify the fact that the lack of valid information on either water distribution or water requirements is a major constraint on managing irrigation system. Two other similar findings have been pointed out in UPHOFF (1991:64). The first has been found by Ford Foundation in four systems in India. The second has been documented by IIMI in a Mahaweli system in Sri Lanka. It was found that the water actually being delivered to farmers be only about half as much as the system managers thought was being made available.

192 These and the irrigation layout's information are based on the studies of ODA 1986 and 1988. 
Fig. 5.15 Gendettu Irrigation Layout

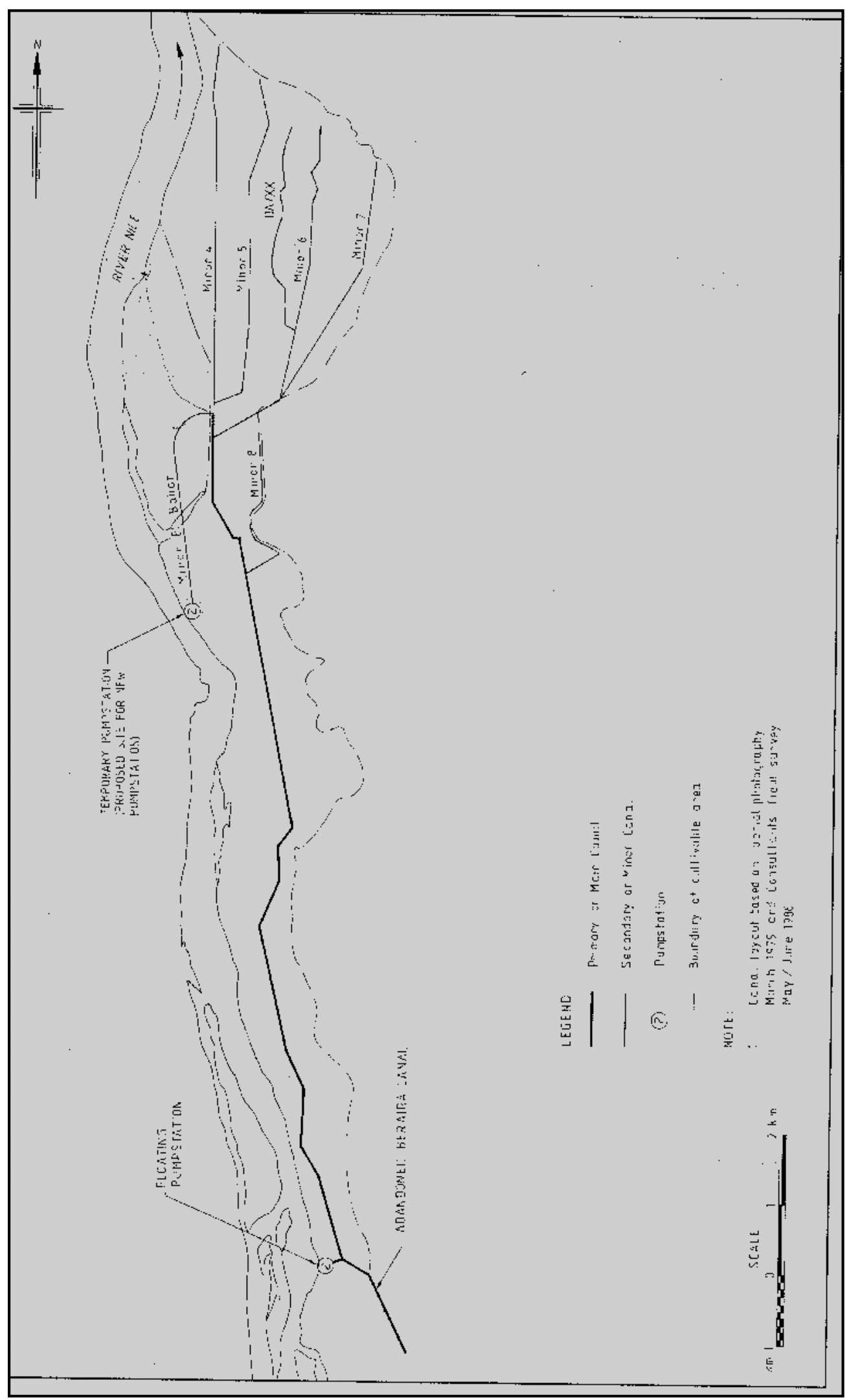

Source: ODA 1988: A2-6 
I. Floating Pumpstation (Gendettu South): This is the main station and contains:

a) 1 large pontoon containing $3 \mathrm{Nr}$ Skoda 6s-160PN engines, and

b) 3 small pontoons each containing $1 \mathrm{Nr}$ Ruston $4 \mathrm{VCBZ}$ engine

II. Temporary Pumpstation (Gendettu North): The station consists of a total of 5 pumpsets; $2 \mathrm{Nr}$ Perkins automative engines, $2 \mathrm{Nr}$ Bedford automotive engines, and $1 \mathrm{Nr}$ Perkins engine.

Operation and maintenance tasks for diesel pump stations are comparatively more complex than those for electric operated. The reliable operation of such systems is, of course, dependent on the existence of an infrastructure capable of repairing pumps as well as maintaining a steady supply of power or fuel. They must also be given a program of irrigation quantities to be pumped. These considerations are more urgent when the canal network is mainly supplied from a single large pump station. This will make the need for good water management practices, and for the supporting facilities such as flow and level measurement and communication, all the more urgently needed. SAGARDOY (1986:84) outlined, in this context, the need for easy communication, specially in case of emergency, between the pump house operator and the officer in charge - either telephone or signal or runner.

Pumping requirements have been determined for the three cropping patterns. The volume of water required in each ten day period has been converted to an equivalent pumping capacity on the assumption that the maximum requirement would be met with 18 hour pumping station operation. This means that the pumping capacities have been determined to meet the maximum demand in any ten day period and don't represent a continuos pumping requirement (ODA 1986:A3/2-2). Generally, the canal sections are undersized due to siltation and the main contribution to conveyance losses is poor water control and distribution. An addition for losses of $40 \%$ has been used for the determination of pumping requirements (ODA 1988:4-4).

The Scheme is currently fed from a floating pumpstation because the offtake is situated on an unstable reach in the east bank of the river. The original pumpstation is now nearly more than $100 \mathrm{~m}$ from the River ${ }^{193}$. Just over 20 years ago a new pumpstation was constructed at Berira, some $20 \mathrm{~km}$ upstream of the present site, and a large canal excavated to feed both the Gendettu and additional extension areas. However, losses in the canal were so large that no water was able to reach the Gendettu area and the pumpstation and canal were finally abandoned

\section{Rehabilitation Options and Recommendations:}

The pumping and directly related plant of Gendettu, Kitiab, Aliab, Zeidab, Fadlab and Bawga irrigation schemes has been inspected, surveyed and its condition and state of repair assessed. The inspections at Gendettu were carried out in April 1986. During these site investigations, the opportunity was taken to assess the cause of plant deterioration, particularly of the relatively new equipment and it was found that, in addition to certain

${ }^{193}$ Recent movement of the course of the river is shown from a study of the aerial photographs and it is therefore considered inadvisable to construct a permanent land based pumpstation for this scheme in the foreseeable future (ODA 1988:4-7). 
design faults, a major cause of early plant failure and deterioration was poorly organized operation and maintenance (ODA 1986:A2/1-1).

The recommendations (rehabilitation priorities) for Gendettu pumpstations were divided into 3 phases:

- Immediate: For works which were essential to keep the plant operating and prevent further deterioration and failure of plant in the immediate further (supply some tools and spares);

- Short Term: Works which should be carried out as funds are available (first or second year of phase 3 of the project); and

- Long Term: Works which should be carried out in year 6 of the project.

Concerning the main pumpstation, it was found that the pontoons of the four floating pumpstations are rehabilitable and with modifications the pontoons' life can be extended well into the next decade. Likewise, the discharges that have been measured there, have indicated that even after rehabilitation the installed pump capacity will be inadequate for the whole scheme area. Thereby, two alternatives have been considered to ensure a full capacity. Both alternatives include the future expansion of pumping capacity through the construction of a new floating pumpstation and the rehabilitation of the existing floating pumpstation. The alternatives were (ODA 1988:4-8):

1. The location of all pumping plant at a single location, the most obvious site being the one presently occupied by the existing floating pumpstation at the southern end of the scheme.

2. The splitting of pumping plant between two installations, one at the existing site and the other at the site presently occupied by the temporary pumps ${ }^{194}$.

The second alternative was recommended on the basis of cost and technical considerations. It has been also recommended, the need of completely rebuilding for the 'onshore' facilities: "This should consist of the construction of office/workshop/storage accommodation at both pumping stations which could be in the standard form of a converted container body. This would be easier to move if the pumpstation has to be relocated" (ODA 1986:A2/4-7).

\subsubsection{Gendettu Irrigation's Layout}

For many years, complains have been registered at Gendettu that there is insufficient water for satisfactory irrigation of the current cropping pattern. The reason according to the rehabilitation study was found to be a combination of inadequate pumping capacity and inefficient water distribution.

The present irrigation layout is shown in Figure 5.17. The canal system comprises the main canal which branches into several minor canals. The first reach of the canal irrigates a thin strip of land parallel to the river which is mostly cultivated as orchards. This reach is notable for the large number of uncontrolled outlet pipes serving individual land holdings.

\footnotetext{
${ }^{194}$ It has been proposed that in year 2 of the program, a new floating pumping station of standard design with 2 duty pumps plus 1 standby pump be provided at Gendettu North to replace the Gendettu Temporary Pumping Station.
} 
The NRIRP has estimated that there are over 300 of these uncontrolled offtakes (ODA 1986:A3/1-5). As a result, water distribution is extremely uneven with field at the head of the system receiving almost constant supplies and little or no water reaching the area at the tail of the canal. The situation is made worse by the poor state of the pumping plant which is unable to deliver the quantity of water required.

Farmers at the tail of the canal have restored to pumping from the canal to maintain their irrigation supplies, in particular for the areas of orchards which require a constant supply of water throughout the year. In addition, the majority of farmers at this end of the scheme have dug wells to supplement their supplies by pumping from groundwater, the groundwater aquifer being recharged by losses from the canal system or directly from the Nile ${ }^{195}$.

An additional problem with the lower reaches of the system, as reported by NRIRP, is the lack of command, with water levels in the canal being below the level of the cultivated land. Although it should theoretically be possible to maintain canal supply levels sufficiently high to be able to provide a gravity supply to all areas, the general shortage of water due to inequitable distribution and inadequate pumping precludes this in practice.

A small pumpstation has been established to provide supplementary supplies to 650 feddan near the tail of the area via the El Bahar minor canal, but it was reported in the middle of 1980 s that only 300 feddan were irrigated from this station due to inadequate pump capacity. The reasons that handicap supplying adequate quantities of water are not only technical. The NRIRP has stressed also to the role of farmers in this connection:

„Apart from the inability of the pumping plant to provide sufficient water the most serious problem on this scheme is the uncontrolled extraction of water from the main canal by the upstream users. Control of these extraction is particularly difficult as most of the land is freehold and NAPC has little control over the farmers' activities. Withholding water is impractical as each holding has its own uncontrolled supply. Strict policing of the canal is also difficult to implement when the farmers are able to take water at night if their normal supplies are interrupted."

The traditional system of irrigation in the Nile Province (as well as in New Halfa), open cannels, has been criticized by the experts (MacDonalds \& Partners). In efficiently terms, they argue, the system, which is deeply engrained into the psyche of the River Sudanese, is somewhat wasteful of water, largely on account of conveyance losses. The experts estimated that about half of the water pumped is lost in seepage and evaporation (WEDDERBURN/ERRINGTON 1985:18-9). Two socio-economic factors, however, sustain this system, that's to say; the excessive use of water:

firstly: water is after all 'freely available' even after several years of poor rains in the Nile catchment areas;

195 UPHOFF (1991:81) argues that farmers who get water from pumps may be unwilling to pay for the upkeep of the canal system even though it raises the water table and makes their pumping easy. On the contrary, in Gendettu, as we will see in the coming chapter, the tenants are willing to pay higher rates for water and they are aware of the economic benefits that can be drawn from it. 
secondly: there are even beneficial socio-economic aspects which should not be lightly disregarded. This system encourages considerable vegetative growth along the canal banks, much of which is cut for fodder or grazed directly by a range of stock. It is likely that this is an extremely valuable 'free' source of fodder for a number of poorer people within the community.

Considering the cost of water pumping, water is not freely available. Using a diesel engine pump requires fuel which is costly and not always readily available at the official retail price. The supply of fuel is dependent on factors outside the control of NAPC or the private agricultural sector, namely the availability of foreign currency within Sudan as a whole (Chapter 4.3.1). ODA (1986:20) has recommended therefore reducing the dependence on diesel fuel. In addition, it has been found that by introducing an modern method like spot irrigation, demand for water is only $14 \%$ of that required by the open channel method, assuming no losses from source to point of use. Spot irrigation, on the one side, involves more physical effort and greater supervision (3-5 mandays per inundation per feddan compare with 1 mandays by open canal), but on the other, it does mean that the amount of water given is accurately known. A further advantage of spot irrigation, according to ODA, is that land preparation and leveling need not be so critical, if necessary at all. 


\section{Implications of the Results: Organizational and Managerial Obstacles to Water-Use Efficiency.}

\subsection{The Division of Responsibility}

\subsubsection{New Halfa Scheme}

Water management in New Halfa scheme is operated, as in the case in similar Sudanese irrigation schemes, on a tripartite basis:

- Ministry of Irrigation (MOI) in charge of dams, scheme headwork and operation and maintenance of canals;

- NHAC in charge of canal operation and management at tertiary level and below (in addition to agricultural services and marketing);

- Tenant farmers responsible for water management in the farm (hawasha).

\subsubsection{Scheme Administration (NHAC) and Ministry of Irrigation (MOI)}

It is necessary to distinguish here between operation (mainly water management) and maintenance (mainly weed and sediment control, plus repair and maintenance of structure). The Engineering Authority (EA), as outlined by NIRP (1992), is responsible both for operating and for maintaining the headwork (and pump stations), and primary canals (main, branch, major and carrier canals), which are designed for continuous flow. The Agricultural Authority (AA) is responsible, along with the farmers, both for operating and for maintaining the territories (Abu-XXs) and smaller canals, which are sometimes operated discontinuously. But, the responsibility for Minors was divided.

The scene of the main questions is the Minor canals (secondaries), which are usually maintained by the MOI (Engineering Authority (EA)), but operated by the Agricultural Authority (AA). The Minors have the special characteristic of being relatively wide and flat, so that they provide a necessary storage buffer between the continuous flow above and the discontinuous flow below. Their head regulators are the smallest flow measuring structures, and their outlets (FOPs) are the smallest formal water control structures (in smaller channels control is by breaking and rebuilding earth banks or checks). Because of this unique position in the canal hierarchy, it is natural and rational, as reported by NIRP, that the interface between the responsibility zones of the EA and the AA should be somewhere on the Minors, but it was by no means obvious whether the interface should be at the Minor head or at the offtakes (MINISTRY of IRRIGATION 1992:Vol.3, F13).

In practice, most of the major irrigation schemes; Gezira-Managil, New Halfa, Rahad and Suki, were operated from the head of the Minor canals onwards by the respective Agricultural Corporation, the Sudan Gezira Board being the original upon which the later ones were modelled. The staff of the AA were responsible for operating the minor canals (but not for maintaining them), for assessing the total crop water requirements for the forthcoming period based on the areas planted with various crops and their state of development and for indenting for that water from the EA (MOI). The indents contain details of the amount of water required to be distributed into each minor canal, and it is the responsibility of EA staff to distribute the total water so as to comply with these individual 
indents ${ }^{196}$. The maintenance of the canal was also the responsibility of EA. Additional weed clearance is performed mainly by laborers under the supervision of EA staff (MINSTRY of IRRIGATION 1992:Vol.1, A24).

This division of responsibility for the Minor canals between EA (maintenance) and AA (operation) brought disadvantages: ,in that priorities may not be seen the same way by the two parties, and either party can (with or without true justification) blame the other for

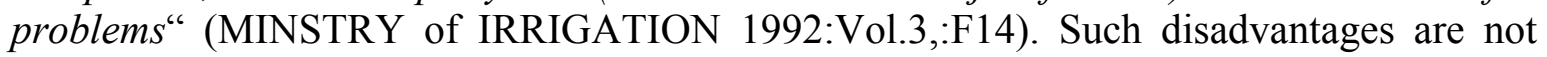
fatal, argued the NIRP study, and they can be alleviated by good communication, appropriate training of staff in both organizations, and appropriate motivation. The study has therefore discussed four alternatives for the future division of responsibility for Minor:

(a) as before, i.e., maintenance by EA and operation by AA;

(b) both by the EA;

(c) both by the AA;

(d) maintenance by the AA and operation by the EA.

The fourth, though it is rumored to have been suggested for some pump schemes, seems to offer no advantages and is not considered further. Either options (b) and (c) would avoid the disadvantages of (a) but in turn they would involve duplication of skills and resources. A key to this matter is the need for accountability, which also requires that performance (primarily the delivery of water) can be measured. Since the EA needs in any case to have skills and equipment for both operation and maintenance of canals, option (c) would mean that two organizations would have to have these skills and equipment. This might be, the study concludes wasteful and inefficient in use of people and machines. Option (b) on the other hand would require the EA to deal directly with farmers in matters of water allocation, which could only be done well if the EA acquired large numbers of staff with a good understanding of agricultural practices and problems; this would also represent a duplication of knowledge between two organizations.

Nevertheless, it is believed that, like the disadvantages of option (a), these problems with (b) and (c) are not fatal and insuperable. A change to either option would, given the scale of Sudanese irrigation, the immense training efforts required, and the rigidity and inertia of bureaucracies everywhere, take many years to accomplish, but it would be possible. As a conclusion, the study has argued: ,it may be worthwhile to try out both (b) and (c) on a pilot scale, but for the bulk of the areas it will be best to take steps to avoid the disadvantages of (a), particularly by improving communication and by organizing joint training for agricultural and engineering staff at all levels “ (MINSTRY of IRRIGATION 1992: Vol.3,F14). Thereby, in quick succession, the Sudanese authorities have decided on the option (b). In November 1992, the EA's responsibility of water management (operation and maintenance) has been extended up to the mouth (offtake) of Abu XX. This means elimination of the water management responsibilities of the AA.

196 This stands in sharp contrast to, for instance, the allocation system in Gondalpur Watercourse in Pakistan where the supply of water to various watercourses is decided by the Executive Engineer whose decisions are based primarily on instructions from headquarters and the available water supply in the main river, and not the conditions and demand in the Command area (TANG, 1993:15). 
This decision changing the boarders of water management, comes to make an end partially - to a long history of conflict between the two organizations concerning sharing of the water management in most large irrigated schemes. This conflict was at the tenant's expense of course. It is worth noting that similar findings have been registered in other schemes in different parts of the world ${ }^{197}$. The decision is also one of the TFU's desires and considers, at the same time, a wide step in the way of achieving the recommendations of the World Bank which has seen that: „MOI has to take control over water issues down to and including the field-outlet pipes" (AHMED/TIFFEN, 1989). Such decision then remains partial because many of respondents within the tenants and most of the Agriculturists believe also that the responsibilities of MOI must be extended until the field canal (Abu VI) ${ }^{198}$.

The decision, what became known as 'Abu Ishreen's decision', is also not enough to fulfil the recommendations of the rehabilitation study. A series of proposals have been made in the different phases of the study to resolve constraints identified in water management and scheme organization which bear on relations between NHAC and agencies responsible to MOI. These proposals, in a highly summary form, are (NHAC 1986: ANNEX 7:26-7):

- the creation of a single water authority for all aspects of water supply management affecting the Scheme, under a Chief water Engineer, to improve supplier-user coordination;

- re-alignment of Irrigation Service Field Units (13 Sections and Sub-divisions) with the 19 Blocks and 6 Sections of the NHAC, to facilitate water indenting and information exchange;

- creation of the post of Head Khaffir responsible for the Khaffirs along an entire minor canal, to improve water control; and

- assignment of responsibility for maintenance of the quaternary system to the Earth Moving Corporation, working on a contract basis to NHAC.

\subsubsection{Tenant Farmers}

As the NIRP has reported, about this vital participant, the provision of the correct quantities of water to the crops at the time they require them is the only major purpose for the existence of the Agricultural Corporations and those MOI departments operating on the scheme. Whatever the importance of the role of the other two participants, the experience has clearly showed that the tenant is the most important factor in deciding when the crops require watering and operating the system to provide the water. The operation of the

${ }^{197}$ Based on works in several countries, FUKUDA (1976:106) has reported: „... as we have seen, two or more ministries (such as agriculture or irrigation and public works) in charge of various aspects of water management at the farmers' level often cause a lot of trouble and bottlenecks in the smooth implementation of an irrigation project". In addition, based on their experience in Philippine, and other countries WALKER/CLEVERINAGA (1989:M.VIII.2/2) pointed out: „Field experience quickly revealed that having one agency responsible for organizing the farmers and a different agency responsible for contrasting the physical system led to confusion and friction and made involving the local people in the preconstruction and construction activities extremely difficult". Similarly, Indian's experience has shown that one of the hardest things to accomplish is cooperation across departmental boundaries. And lack of coordination, unfortunately, cannot be eliminated by bureaucratic fiat (UPFOFF 1991:174).

198 The Chief Engineer has comment on this opinion by saying: ,what else could the agriculturist do ?“. 
FOPs is carried out by the farmers through the water guard (khaffir); in theory the water guard acts under the supervision and instructions of the Agricultural Corporation's Field Inspectors, but in practice farmers act as informal water users' groups and make their own decisions (MINSTRY of IRRIGATION 1992 vol.1.A26) ${ }^{199}$. In addition, it is not obvious now, after the Abu XX's decision, to whom are the Khaffirs along AbuXXs responsible?

All those tenants who benefit from the Abu XX have an obligation to clear it. It is in the interest of the Tail-enders but not the top-enders that the canal should be cleaned and maintained. The maintenance responsibility lay jointly with NHAC which was unable to carry it out. The outcome of such a situation is liable to be that neither NHAC nor the tenants maintains the works. The main reason of this result is, there is no sanction for the tenants who ignore this task. In addition, the tenants are individually responsible for their field canals (Abu VIs).

Whereas the Agriculture Corporation has a consistent and formalized interaction with the tenant farmers and is subject to immediate pressure if crop water requirements are not fulfilled, the MOI was insulated from such pressure, as it does not have such an interaction. Apart from informal interactions, the MOI was in contact with farmers only when its staff attend the meetings of Production Committees with farmers and Agricultural Corporation staff; the frequency with which these Committees meet varies from area to area within the same scheme (see Chapter 6.5.2.3).

\subsubsection{Gendettu Scheme}

In the northern Region, on the other hand, MOI was technically responsible for NAPC' schemes. On 24/12/1982, because of problems similar to those stated above, hassle and non-co-operation between MOI and NAPC, it has been decided to transfer the responsibility of the former to the later. After this date, the NAPC has taken over through mechanical and irrigation Departments the task of water management. The relationship between the two organizations has become advisory.

At Gendettu, a clear distinction must be drawn between the responsibilities of the Scheme Management and the mechanical Section, both being involved in the supply of water. It has been observed that, even the same organization, there appears to be a conflict between the interests of the two parties. On the one hand the Scheme Management has an obligation to provide irrigation to the farmers in the quantity required and at the optimum irrigation interval, whilst on the other hand, the mechanical staff must ensure that plant is correctly operated and maintained. The third party, represented by the irrigation Engineer, is responsible for determining pumping rates and, in addition, he must give adequate notice of these to the Mechanical Engineers, to enable them to program maintenance and to determine which pumps to operate and for how long. The preparation of pumping schedules which meet the requirements of both the crops and the pumps require a great deal of co-operation and understanding between the different disciplines of NAPC and no one discipline can have over-riding control ${ }^{200}$.

\footnotetext{
${ }^{199}$ In other large schemes, like Gezira, this task has been undertaken by one of the Tenant' farmers called samad. He works also, theoretically, under the supervision and instructions of the Field Inspector.

${ }^{200}$ This stands in sharp contrast to the first character of irrigation system discussed in Chapter 1.1.1 and 1.3 $\mathrm{i}$. e. the coordination nature of water management. It is, in addition, an indicator of the absence of vital component of irrigation management; namely conflict management. It is an indicator also of the quality of
} 
In what follows the different performances for all groups in both Schemes are highlighted.

\subsection{The Role of Scheme's Administration in the Problems of Water Management}

\subsubsection{New Halfa Scheme}

Water management facilities at the field level are considered, according to the experience of the Asian Development Bank, an organic part of any large-scale irrigation project and should be constructed with Cooperation between the governmental organization and farmers (FUKUDA 1976:105). Some countries tend to have a paternalistic approach and provide all the facilities as part of the irrigation development while others provide none of them (SAGARDOY 1986:112). Some of the basic handicaps for the proper water management, which come from the New Halfa Scheme authorities' side, are in the field of land preparation, land leveling (joint responsibility with the farmers) and maintenance of minors and field canals (AbuXXs). The first two tasks, land preparation and land leveling are very important issues of field water management in New Halfa Scheme.

\subsubsection{Land preparation}

This vital stage of the agricultural operations is closely connected with planting date and both of them, according to the interview with the officials, constitute $26 \%$ of the problems that faced the performance in New Halfa (Table 6.1). This coincide also with the opinion of the tenants who see the delayed land preparation as the first problem (32\%) which prevent them from increasing the productivity (Table 6.2).

Table 6.1 Officials report on problems of New Halfa Scheme

\begin{tabular}{|l|c|}
\hline Problem & $\%$ \\
land preparation & 15 \\
financing & 15 \\
cost of production & 11 \\
bad management & 11 \\
water storage capacity & 11 \\
planting date & 11 \\
availability of seeds* & 7 \\
co-ordination between ministry of Irrigation and the & 7 \\
production relationships (cotton) & 4 \\
the agricultural labor & 4 \\
relationship between research and practice & 4 \\
\hline
\end{tabular}

* Can be added to financing or cost of production

Source: Own Survey

the differentiation, integration, and responsiveness of the organization structure. See the cases of Peru, Taiwan, and some African countries mentioned in Chapter 2.4. 
Table 6.2 Factors hindering Tenants from increasing the Productivity \% (New Halfa)

\begin{tabular}{|l|c|}
\hline Hinderance Factor & $\%$ \\
delayed land preparation & 31.7 \\
water shortage & 23.4 \\
financing & 9.0 \\
cost of production & 7.6 \\
late weeding & 6.9 \\
Lack of labour & 4.1 \\
supervision staff & 3.5 \\
Marketing & 3.4 \\
land leveling & 2.1 \\
pests and diseases & 2.1 \\
delayed harvest & 2.1 \\
the rains & 2.1 \\
seeds quality & 2.0 \\
Total & 100 \\
\hline
\end{tabular}

Source: Own Survey

To be sure that the tenant have correctly classified the problems that hinder their performance, they were asked again at the end of interview to define the shortcomings that exist in the Scheme. One can say that there is no remarkable anomalies in the results as shown in Table 6.3. ${ }^{201}$ They attribute the shortcomings of the Scheme performance to the late land preparation, water shortage, and financing which is closely connected to the high costs.

Land preparation for cotton, in the form of dry-ridging and channel clearance before the rains followed by a split-ridging before sowing, is done by the agricultural management with the assistance of some contracting to private machinery operators (THORNTON/WYNN 1987:219). But, as we will see, the surface has merely been scratched. All other operations are done by hand. For the other crops, the Corporation has played no role. In practice, Corporation farm machinery was in the past also available for wheat-land preparation (begin in October) and combining, and the Corporation also to provide seed. Increasingly, however, with Scheme decline, this has eased to be the case (NHAC 1986: ANNEX 7:6).

Not only the timing of land preparation is very important but also its quality which is necessary to reduce seepage behind the root zone. The tenant think that the nature of the soil in the Scheme needs better land preparation than in other schemes. In spite of the rehabilitation (136 US million Dollar), the tenant complains that the NHAC is faced with an acute shortage of tractors and spare parts and often have chronic shortages of fuel. Although adequate and appropriate machinery is available to reduce this constrains, the production environment is often unfavorable, with inefficient services. Most of tractors

201 Within the scope of the rehabilitation study, the results of the investigation indicated that the first three reasons constituted $65 \%$ of the issues on which tenants had to contact the TFU's Committees. These were respectively land preparation and lack of machinery (34\%), irrigation-water-shortage (17\%), delay of loans $(14 \%)$. 
which the Scheme have, are overworked and many are permanently or temporarily unoperational waiting for spare parts. That is why the productivity of tractor in the Scheme is 10 feddan comparing with 100 in the private sector ${ }^{202}$. These aspects are closely bound up with the migration of the best technical personnel to the rich Arab countries. This influence has been discussed in more detail elsewhere ${ }^{203}$.

Table 6.3 Percentage of Reasons that hamper the Performance in the Farm and the Scheme

\begin{tabular}{|c|c|c|}
\hline & $\%$ of the total answers Question $1 *$ & Question 23** \\
\hline delayed land & 32 & 22 \\
\hline water shortage & 23 & 19 \\
\hline financing & 09 & 08 \\
\hline cost of production & 08 & 13 \\
\hline weeding & 07 & - \\
\hline lack of labour & 04 & 06 \\
\hline supervision staff & 04 & 06 \\
\hline marketing & 03 & 08 \\
\hline land leveling & 02 & 04 \\
\hline pests (pesticides) & 02 & 05 \\
\hline delayed harvest & 02 & 02 \\
\hline the rains & 02 & - \\
\hline seeds quality & 02 & - \\
\hline uncontrolled cattle 204 & - & 04 \\
\hline lack of co-ordination & - & 03 \\
\hline total & 100 & 100 \\
\hline
\end{tabular}

* Question 1: Is it possible to improve productivity in your Hawasha? If yes, why not?

** Question 23: What kind of shortcomings exist in the Scheme?

Source: Own Survey

The inspectors who are fully aware of these constraints have little time to try to solve it and they argue that many of these problems such as lack of tractors and heavy machines are outside their control. This means that the NHAPC is not able to take over their tasks and hire tenants the land preparation's machinery for cotton or the other three crops at the recommended time ${ }^{205}$. The survey reveals that $12 \%$ of the sample owned tractors but no other agricultural machinery. Consequently, as in Gendettu, the majority of tenants reported that they have to depend on other sources to secure these machines (Table 6.4). „Private“ in New Halfa includes tractors of the Nubian Co-operative Society which were used heavily by the two groups of farmers to cultivate and puddle their fields. The absence

\footnotetext{
202 The Agricultural Extension Department of the Scheme.

203 The number of the Sudanese labors working in the Arab Oil-Exporting countries was estimated in 1981 at 350000 ( $6 \%$ of the labor force). For a fuller discussion of the social and economic effects of the Sudanese labor migration on the different sectors of the economy see KHALIL (1985), chapter 5. pp. 326-447.

204 The Halfawyeen cite the effects of uncontrolled livestock on their economic and personal well-being as an area in which their interest comes into sharp opposition with the Nomads. It seems like the famous problem of common grazing in the open-field systems.

205 For example, only three tractors were available to El Madina Block (1 750 feddan) in the Season 92/93.
} 
of equivalent Co-operatives in the nomad areas reveals that the problem of land preparation in this area is more critical as in the Halfawyeen one ${ }^{206}$.

Table 6.4 Do you hire a tractor or other Machines?

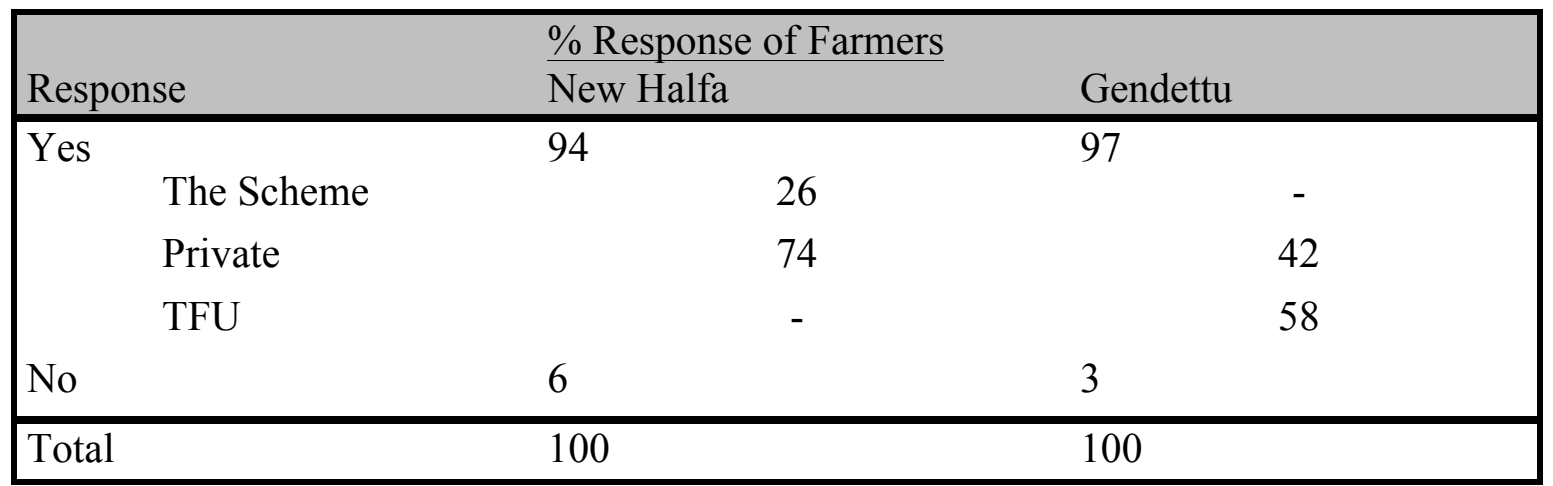

Source: Own Survey

Astonishingly, field interviews during early 1980s indicated clearly tenants' frustration and anger over their inability to control the land preparation performance of Corporation tractor drivers. In this context, the NHIRP has reported: „, where the major operations on farmholdings are performed by an outside organization, and the tenant has limited or no control over the quality of those operations, then his initiative and his own farm management will accordingly deteriorate. If this is true, then within the limits imposed by the disciplines of an irrigated scheme with strict-scheduling of water and crop operations, every effort must be made to transfer progressively responsibility for farm operations to the tenant or to tenant-controlled organizations, or to e.g. private machinery operators who can be directly controlled through payment" (NHAC 1986: ANNEX 7:11). If the case is so, one is tempted to ask whether the Scheme has been really rehabilitated?

Scheme's irrigation engineers argued also that the delay of land preparation makes stress on the water stored in Khashm El Gerba Dam and affects therefore, negatively, the water level in the irrigation network. According to the regime of the Atbara River and the design of the dam, all gates are completely open during the flood season from July to September to flush out sediment, and the water in that time has to be pumped by three pump sets ${ }^{207}$. During this period the tenants have to make use of this water together with the rain-water for watering groundnuts, sorghum and cotton. From October onwards storage is used only for: 1) the watering of the rest these three crops; 2) the entire watering of wheat; 3) the permanent watering for the freehold lands; 4) sugarcane plantation and 5) water supply. Late land preparation muddle this plan and leads consequently to water shortage and conflicts between farmers. As the experience in other irrigation schemes with a large water

${ }^{206}$ In the area of agricultural production, the Halfawyeen tenants think that the TFU should address itself to the following issues as judged from the proportion of responses received from the tenants in relation to each : pricing of crops: 17 per cent; irrigation water: 16 per cent; loans: 12 per cent; livestock control: 12; and land preparation: 9 per cent. In the nomad area the main proposals accorded priority in the field of agricultural production are: land preparation: 20 per cent, loans: 18 per cent; irrigation water: 15 per cent; cotton revenues: 9 per cent; and pricing of crops: 8 per cent (NHAC 1986:ANNEX 5:31).

207 They all working since 1964 and need therefore maintenance and spare parts. 
deficit shows, delayed land preparation means also that production per hectare is low and large areas are sometimes abandoned due to salinity problems ${ }^{208}$.

Correct time of planting is one of the most important inputs to higher yields. The sowing of cotton and groundnuts is a tenant's function, and has to be carried out by hand ${ }^{209}$. The timing is left therefore to them. According to the NHIRP, it has been assumed that by adhering to the suggested June planting of groundnuts and July planting of cotton, the scheme could raise its average yields significantly by this input alone. The watering and harvesting would then follow along predetermined paths easing the management requirement (NHAC 1986:ANNEX 2:26-27). Sorghum planting is scheduled to take place into clay soil in May prior to groundnuts ${ }^{210}$ and cotton. The reasons for this suggestion are:

- planters will not be available June/July.

- sorghum - to keep stemborer invasions low - must be planted early.

- by sowing into dry soil in May, the crop will germinate after the first meaningful rain whenever it occurs ${ }^{211}$.

- most of the physical work can be carried out prior to the start of cotton and groundnuts.

In addition, the recommended dates for land preparation and plantation of crops should be respected and enforced in order to minimize the period of overlap and consequently avoid the water shortage of wheat at the end of the season.

There are more indicators that the Relative Water Supply (RWS) in New Halfa Scheme is low. This means, the amount of pressure that users can put on the staff controlling irrigation water is high. Again this means that raising the level of 'efficiency' here demands more management effort. In view of matching supply and demand of water, several restrictive measures can be utilized by the project management to reduce the gap between them. These measures are related to:

a) the cropping pattern;

b) the water distribution practices; and

c) the water fees.

Unfortunately, no measures have been practiced in the last two spectrums. Even concerning the first one, the management of the Scheme has not tried to change the

${ }^{208}$ One of the reasons for such a state of affairs as pointed by SAGARDOY (1986:61) was: ,although the efficient use of water was essential, the farmers were not assisted in preparing their lands (land leveling, grading) for efficient use when water supplies were limited".

209 The Rehabilitation study has therefore proposed to convert this vital operation to a mechanized system with no input from the tenant other than a cost one. The main reasons for this proposal are (NHAC 1986:ANNEX 2:26):

- correct time of sowing

- sown in straight lines

- correct plant populations

- correct depth of seeding

- the sowing can take place on a planned „number“ basis in conjunction with irrigation

- Scheme labor requirements can be phased to spread the work load.

210 Recommended date is 15-5 until 15-6.

${ }^{211}$ It has been also suggested in Chapter 1.3 of the same study that dryland sorghum should follow groundnuts in the rotation to make use of the high soil moisture reservoir after groundnuts which will sustain the newly germinated sorghum for several weeks should the first rain be followed by a dry spell. 
existing cropping pattern or to reduce the irrigated area, but it has instead stressed the importance of respect (adhering to) the planting time to make use of flood and rain water. Indeed, by suitable regulation of the planting time and other cultivation activities, large reductions can be attained during the peak demand of an irrigation scheme. Careful planning of this also allows controlled staggering of cultivation activities between different sections of the same irrigation system leading to a more rational use of variable machinery and manpower. The Tenants know surely that they must keep to the pre-planned timetable, but because of the delay of land preparation and canals maintenance, as they argued, they are not in a position to adherente $i^{212}$.

Table 6.5 shows clearly that the actually dates for planting executed by the tenants are totally different from the official ones. This is valid for all crops and the two groups of tenants. It is more extreme forthe nomads because they have to plant three crops approximately - in the same time (July). In addition, because many of the nomads are dependent on the rain, Season (begin in July), to secure their main food (sorghum) outside the Scheme, they have to postpone the planting of cotton to the end of August and September ${ }^{213}$. Interestingly, $11 \%$ of them believe that the end of August is normal for cotton planting ${ }^{214}$. The delayed planting for cotton is more extreme by the Nubian where $33 \%$ of cases planted cotton in September ${ }^{215}$. Many of them $(50 \%)$ believe also that the delay of wheat planting is better for the productivity. On the contrary, the other half believe that the winter is very short therefore it is necessary to begin early.

Table 6.5 Distribution of Planting Time in New Halfa According to Crops and Tenants Groups

\begin{tabular}{|l|c|c|c|c|c|c|c|c|c|c|c|c|c|}
\hline Crop & June & July & July & Aug & Aug & Sep. & Sep. & Okt. & Okt. & Nov & Nov & Dec. & Dec. \\
G/Nuts & $3-4^{*}$ & $1-2^{*}$ & $3-4$ & $1-2$ & $3-4$ & $1-2$ & $3-4$ & $1-2$ & $3-4$ & $1-2$ & $3-4$ & $1-2$ & $3-4$ \\
Halfawy. & 35 & 40 & 25 & & & & & & & & & & \\
Arab & 25 & 44 & 25 & 6 & & & & & & & & & \\
Cotton & & & & & & & & & & & & & \\
Halfawy. & - & 11 & - & 22 & 33 & 11 & 22 & & & & & & \\
Arab & & 13 & 12 & 37 & 13 & 24 & & & & & & & \\
Sorgh.(A) & & 30 & 64 & 6 & & & & & & & & & \\
Wheat(H) & & & & & & & & & 9 & 14 & 27 & 23 & 27 \\
\hline
\end{tabular}

* Refers to the weeks Source: Own Survey

212 The survey of FAEA/NHAC (199121-9) revealed that all surveyed CF (Contacted Farmers) attributed non-adoption of the recommended sowing date of cotton to shortage of irrigation water. This reason represented about $70 \%$ of the Non-contacted Farmers (NCF). Other reason claimed by NCF for nonadoption were delayed land preparation and unavailability of pesticides, each constituted $15 \%$. For groundnuts, the reason for non-adoption for all farmers were: lack of water at the proper time $(66 \%)$, the inappropriate time of the land preparation (22\%), seeds were not available (5\%), and resowing $(7 \%)$.

213 Many have reported that the women in the nomads' area don't enable their husbands to plant other crops before securing the planting of the rainfed Sorghum outside the Scheme.

${ }^{214}$ It is worth noting that as the result of different sowing times in the Scheme (from first July until end September), the operation of cotton picking take rather a long time.

215 According to NHIRP results in the oldest Scheme in the Nile Province and Sudan; Zeidab Scheme (1907), cotton should be planted in May, although, in practice, planting is usually delayed until June/July and maybe as late as August, due to delays in land preparation and delivery of inputs and other constraints (NHAC 1986:A1/2-26,7). 


\subsubsection{Land Leveling}

In most cases, on-farm development can be reduced to two essential elements: 1) relocation of irrigation and drainage ditches; and 2) land grading or leveling (SAGARDOY 1986:113). These elements are interdependent and can hardly be separated in practice. Land grading is the movement of the earth necessary to obtain a perfectly uniform inclined plane and land leveling is for a horizontal plane, although both terms are used interchangeably. This operation is indispensable in surface irrigation to obtain a uniform application of the water (RAWITZ 1973:334). Therefore, it is considered, as HÜBENER and WOLF (1991) argued, one of the most important problem in the traditional gravityflow system. The empirical results of this study leads us to agree with this argument.

Even very flat areas may need some land grading in order to provide uniform slope. Of course, continue SAGARDOY (1986:114), the more irregular the topography (as in New Halfa), the more expensive the operation. That is why land grading or leveling is not an operation that is intuitively attractive to farmers. Furthermore, if it is not done with great care, productive top soil can be removed leading to a decrease in productivity in affected areas for a few years. Therefore, in order to make the operation attractive to farmers, it is imperative that some sizeable incentive be offered. A common way is that 50 percent of the costs are aborted by the public administration. Unfortunately, the bearing of this fact was unnoticed in our cases.

The operation of leveling must be done during the fallow period which is usually very short on irrigated schemes. This is one of the reasons for the tendency to use machinery rather than labor for land grading and leveling. It is therefore more difficult in New Halfa where there is no fallow in addition to the fact that the soil is relatively hard. This means, in New Halfa it is also a question of the quality of the machines. In this context it is preferable to use the modern ones like Leaser control machines which are now available for other schemes in Sudan and in Africa ${ }^{216}$, where the fields are well leveled according to pre-determined specifications and water volumes.

In New Halfa, the shortage of „light“ machinery is also combined with acute shortage of heavy machinery which are necessary to break up the compacted soils since the scheme first started. Notwithstanding the points discussed above, it is interesting that the officials of the project did not mention land leveling as one of the problems that need urgent solution (Table 6.1). Nevertheless, through the discussion, 94\% of them assert that land leveling in the Scheme is out of interest. Causes that have been mentioned here are:

- shortage of machinery $(52 \%)^{217}$;

- bad management (20\%);

- tenants are unaware of its importance (16\%); and

- the high cost $(12 \%)$.

${ }^{216}$ For example, Gezira project in Sudan and Kapunga irrigation project in Tanzania (FAO, 1994:70).

217 All the experts outside the Scheme and many of the staff have reported the converse and argued that it is up to the bad management. For instance, the purchasing manager has reported that the existing levelers in the Scheme (76) are not used because they are „unsuitable“! He and the others have also stressed the lack of the technical experience. 
In addition, they maintain that the bad quality of the machines (levelers, ploughs, tractors) causes soil accumulations in front of and besides the quaternary and field canals. The outcome is that the water drain and seep into the field and do not irrigate the whole 5 feddan $^{218}$. Or, to put it another way, the result is: flooding at the end of Hawasha (the ends adjacent to the road), over-irrigation at the middle, and no water at the beginning (adjacent to the Abu Ishreen). The solution of this problem, as the officials pointed out, is the adherence to the rules concerning the field distribution system (Angaya System). The field must be distributed by seven Gaduals (Irrigation Ditches) and seven Tagnats (Field Bunds) i.e., sixteen Basin (see fig. 5.14).

On the contrary, it appears instead that the tenants are more aware of this problem. Only $15 \%$ within the sample have reported that their fields are leveled. Two main reasons hinder the majority from solving this problem namely; the shortage of machinery $(53 \%)$ and the impossibility of financing (47\%). In addition, reasons for the neglect of the recommendations concerning field distribution mentioned by the staff, experts, and tenants were: 1) it means more cost burden, 2) it needs time and effort, 3) more canals (particularly Irrigation Ditches) means more loss in the Hawasha and they aggravate the harvest problems especially for Wheat. This is to be observed in almost every case particularly in Abu Nagma Block in the nomads area (the most extreme case in the Scheme) and in village 5, 24 and 26 in the Nubians area.

\subsubsection{Reasons of Water Shortage}

Implicit in the foregoing discussion is the fact that the officials in this study, especially the staff of the Scheme and the experts, do not see the water shortage as one of the most important problems of the Scheme. Going back to Table 6.1, one finds that they refer to the problem of the dam capacity as if it is the only water problem in the Scheme. To prove this perception, we have mentioned five possible reasons that can be the main hindrance of the irrigation system and they were asked to rank them according to their relative importance. These reasons and their interesting ranking were as follows ${ }^{219}$ :

\section{$\underline{\text { Reason }}$}

2. Water storage capacity is not enough

3. Behavior of tenants in relation to water

4. Administrative problems

5. Canal problems (maintenance, control, etc.)

6. Inefficient water distribution

\begin{tabular}{c} 
\% of responses \\
\hline 26 \\
24 \\
19 \\
18 \\
13
\end{tabular}

In significance here is the fact that the staff of the Scheme see that their responsibility is only limited in the reason 3. The manager of the agricultural department in the Scheme, who was the most influential person in the Scheme in that time, reported only reason 1 and 2 , and said the other three are does not exist.

${ }^{218}$ It is highly believed that the loss due to this accumulation is minimal $1 / 2$ feddan, this means it can be more than $10 \%$

${ }^{219}$ In addition, other reasons have been mentioned e.g. unreality of the available data concerning water flow in field water course, unreliability of water delivery, the long Abu XXs, land leveling, the night irrigation, and the water pricing system. 
On the other side, tenants canvassed in this survey gave responses which could be interpreted according to the fact: a dependable and well regulated supply of water to the tertiary level is a prerequisite for good water management at farm level, while the reverse is not true. There is no causal link between good farm-level practice and better management of schemes as a whole (WALKER/CLEVERINGA 1989:M.XI.3/1). The reasons that are responsible for the water shortage, which considered, according to their opinion as the second vital problem in the Scheme are represented in Table 6.6

Table 6.6 Causes of Water Shortage Ranked by the Tenants of New Halfa Scheme

\begin{tabular}{|c|c|}
\hline Reason & $\%$ \\
\hline $\begin{array}{l}\text { 1. Canal problems } \\
\text { - Unclean } \\
\text { - The design } \\
\text { - Broken } \\
\text { 2. Omission of/from the inspector } \\
\text { 3. Farmers' actions (theft of water, conflicts } \\
\text { on irrigating, etc.) } \\
\text { 4. Supply of water is not enough } \\
\text { 5. Absenteeism of the Khaffir } \\
\text { 6. lack of co-ordination between AA and EA } \\
\text { 7. The position of the field }\end{array}$ & $\begin{array}{l}27 \\
\\
20 \\
18 \\
15 \\
12 \\
4 \\
4\end{array}$ \\
\hline
\end{tabular}

Source: Own Survey

A considerable part of the problem $(63 \%)$ can be traced to poor administration (reasons 1 , 2, 5 and 6). As we will see the exchange of accusation between the two configurations, is the most feature of New Halfa Scheme. Generally speaking, one of the main causes of water shortage in both schemes is the blockage of the minor and field water course by weeds and silt. The tenants reported that they are not satisfied with the canal operations and quality of water-course cleaning carried out by the scheme authority.

\subsubsection{Gendettu Scheme}

Most NAPC schemes suffer at one time or another and to a varying extent from pump failure, fuel shortage, water intake problems, or inefficient water distribution. Gendettu, as was stated before, is the extreme case. The level of water management on the scheme is seen to be at a very basic level. When we try to draw conclusions from the analyses of the NRIRP (ODA 1986 Vol.2:A1/2-17) as outlined in the technical description of the scheme; Chapter 5.4.4.3 and 5.4.4.4, we find that:

- a major cause of the early plant failure and deterioration was poorly organized operation and maintenance;

- the reasons for the chronic complains that have been registered at Gendettu insufficient water for satisfactory irrigation of the current cropping pattern - was found to be a combination of inadequate pumping capacity and inefficient water distribution;

- the need of completely rebuilding for the 'onshore' facilities: the construction of office, workshop, storage accommodation; and 
- there were large number of uncontrolled outlet pipes serving individual land holding (300).

In addition, farmers were asked to identify those problems which are the main constraints limiting their farming activities. In all interviews but one the main problem was said to be inadequate water supplies. A shortage of pesticides was the next most frequently noted problem. Other problems mentioned were shortages of tractors, labor, fertilizer and seeds .

When we compare the above results with the findings of this study shown in Table 6.7 and Table 6.8 five years later, we are forced again to question whether this scheme has also been rehabilitated? Again, in spite of the rehabilitation, the officials assert that the pumping and related plant, and the canal network are the main causes $(67 \%)$ for the underperformance of the Scheme.

Table 6.7 Officials Report on Reasons for the Under-performance of Gendettu Scheme

\begin{tabular}{|l|l|}
\hline The Problem & $\%$ \\
\hline Pump Stations & \begin{tabular}{c} 
\% \\
\hline Canal Network
\end{tabular} \\
\hline $\begin{array}{l}\text { Financing } \\
\text { Ambiguity of the actually } \\
\text { cultivated area }\end{array}$ & 22 \\
\hline Farmers' intervention & 6 \\
\hline Supervision Staff & 6 \\
\hline Transport & 5 \\
\hline Marketing & 5 \\
\hline Others & 4 \\
\hline Source: Own Survey & 4 \\
\hline
\end{tabular}

Source: Own Survey

To assess the opinion of the tenants in Gendettu about the relative importance of water availability in relation to his performance, two questions were put before him to respond to (Table 6.8). The first is a specific one on the factors that hampered increasing the agricultural production; while the second (at the end of interview) is a general one the problems of the Scheme. It is logical then that water shortage come to the front. One can also clearly notice the urgent need for active support service institutions organizing credit, supplies and marketing. The lack of fertilizers, pesticides, and means to finance the expensive operations constitute $43 \%$ of the factors that hinder the production ${ }^{220}$. By way of comparison, these and similar components constitute $24 \%$ in New Halfa (Table 6.3).

\footnotetext{
${ }^{220}$ Many of the 'big' tenants have mentioned the first two ones as the absolute problems that they face.
} 
Table 6.8 Tenants in Gendettu report on the most important problems of the Scheme (\%)

\begin{tabular}{|l|c|c|}
\hline Problem & $\begin{array}{c}\text { as \% of the factors } \\
\text { hindering the }\end{array}$ & $\begin{array}{c}\text { as \% of the } \\
\text { schemes' }\end{array}$ \\
shortage of irrigation water & 45 & 55 \\
unavailability of enough fertilizers & 15 & 15 \\
pests & 15 & 5 \\
cost of production & 13 & 17 \\
tenancy is small & 12 & 5 \\
financing & - & 3 \\
marketing & - & 100 \\
total & 100 & \\
\hline
\end{tabular}

Source: Own Survey

\subsubsection{Pump Stations}

The capacity of the pump stations determine the cultivated area and play the role of the dam in New Halfa. Therefore, scarcities of draught power is considered also as constraining and may at sometimes be more limiting factor than water. The pumping plant in Gendettu is facing many difficulties ${ }^{221}$ :

1) State of repair:

a- instability of the main station. Its position has been changed 7 times.

b- there is no any means of measuring the amount of water being delivered i.e., water discharge records for each pumpsets ${ }^{22}$. This encourages the mechanical workers to steal occasionally some gallons of fuel (diesel or gas oil as referred to in Sudan) and selling in the 'black' market ${ }^{223}$.

c- lack of spare parts; which have to be imported ${ }^{224}$, and workshop in the site.

${ }^{221}$ The 45 percent in Table 6.7 is subdivided as following: the position of the main Station (19\%), pump sets $(11 \%)$, Fuel (10\%), and qualified technicians $(5 \%)$.

${ }^{222}$ One of the recommendations of the ODA's Study (1988) in this context was: „Measurement of water flow from the pumping station would be means of a 'Crump' weir in the discharge channel. This can be directly calibrated in liters per second and is cheaper to install and requires far less maintenance than 'Dall' type flow meters or orifice plate. The 'Crump' weir will enable the staff to monitor and record the output from the pumping station and also to evaluate individual pump performance" (ODA 1988:Vol.1:3-5). It has also been recommended that flow measuring structures should be constructed at the head of each canal to monitor the pump discharge. Previous attempts to install automatic water level records, as at Kitiab and Aliab, have failed due to mechanical breakdown and lack of maintenance and it has been therefore proposed that, although provision may be made for future installation of automatic recorders, initially, flows should be recorded manually (ODA 1986vol.2:A3/4-1).

${ }^{223}$ This fact had been alleged by the scheme Manager, the mechanical Engineer, and even Chief of the pumpset operators.

${ }^{224}$ One of the new pumps in the main station was not working for more than two months in the season 92/93 because of this problem. 
2) Significant quantities of fuel are also being lost through leaks in the fuel pipes and engine connections. In addition, storing fuel and oil outside, on the air, is uneconomical and can damage the quality. That is why, the volume of fuel consumption is often not converted to the expected amount of water. The unavailability of fuel at the critical time for irrigation is therefore a Gendettu's phenomenon within the NAPC schemes. Usually, the other schemes begin the season after securing the whole required amount of fuel. In Gendettu, on the other side, it seems that the policy is „from hand to mouth“. That is why, it was observed during the field work that pumping was many times reduced or suspended because of shortage of fuel. Reduced dependence on diesel fuel would be therefore a great asset WEDDERBURN/ERRINGTON (1985:19).

3) The need of qualified chief and experienced pump-set operators to carry out proper operation and maintenance. This category is very important in pump schemes. They are particularly liable to abuse their positions because they have monopoly control over distribution within the areas commanded by their pumps. To keep this situation in hand, argues SAGARDOY (1986:27), effective management control systems are specially important, linked to incentives, e.g., through promotion, to induce correct operation. So, it is desirable that pump operators be mechanics, or relatively have mechanical training ${ }^{225}$.

4) The chief of the pump-set operators has defended the accusations and pointed out:

a- still, in spite of the recommendation of $\mathrm{ODA}^{226}$, there is a lack of the ,onshore“ facilities; there is no house, office (or even a roof over one's head), store, workshop, transport, or medical care. Very briefly, human being here is neglected and that is why they are depressed. For these reasons, many workers leave the work during the season and we are forced to accept anybody disregard to the experience or qualification.

b- instead of seven persons, work only four per shift. This situation is only in Gendettu. Although 40 persons are registered in the mechanical department, most of them work in other NAPC's schemes. It is interesting here to find that in a scheme like Saial (6 000 feddan) work 15 in the pump station.

c- there is neither 'occupational structure' (job description) ${ }^{227}$ nor training in this department and the scheme at all.

d- the mechanical Engineer is responsible for other three schemes and he is often busy.

225 The chief of the pump-set operators in Gendettu is unqualified, but has long experience in the work. He was normal pump operator and has reached this position without any training courses. Just as the responsible chief of the engineering department in New Halfa at the end of 1980S, who hadn't any technical qualification.

226 ,„... This situation must be remedied as a mater of urgency as rehabilitation of plant should not be undertaken without the establishment of a clearly recognizable operation and maintenance structure, 'onthe-job training', strict operation and maintenance procedures and adequate storage and stock control". The points which require particular attention are (NRIRP, 1988:3-7):

- Operating schedules for pumping plant;

- The rehabilitation of pumpstation structure and facilities;

- Pumpstation records;

- Workshop and storage facilities and the supply of spare parts;

- The introduction of an exchange unit systems;

- Fuel delivery, storage and dispensing.

${ }^{227}$ If individual members of staff are to perform their duties properly, they must have a reasonably accurate and comprehensive knowledge of what those duties are. 
5) All these constraints are responsible for the breakdown of the pumps which causes the delay of planting and confusing the rotation system. According to the monthly reports of the scheme, it was found that the average of this breakdown per month during the pumping time in the main station was 10 days in 1989, and 8 days in 1990 and $1991^{228}$. In addition to average of 8,6 and 7 days respectively in which the pump station had worked with $30-50 \%$ of its capacity.

The answers given from the tenants to the question: „why water is not coming in the right time?" tie well with the above analysis. The overwhelming reasons for delays is due to lack of fuel and pump breakdowns (together $63 \%$ ). More other causes are identified. Given in percentage of respondents supplying each, these causes are presented in Table 6.9.

Table 6.9 Tenants in Gendettu report on causes of water shortage

\begin{tabular}{|l|r|}
\hline Causes & $\%$ \\
1. Lack of fuel & 37 \\
2. Pump breakdowns & 26 \\
3. Farmers' actions & 16 \\
4. Shortage of water & 11 \\
5. The unclean canals & 5 \\
6. The position of the field & 5 \\
Total & 100 \\
\hline
\end{tabular}

Source: Own Survey

\subsubsection{Canal Network}

The following points delineate in broad terms some factors influencing the performance of Gendettu's canal network:

- Expanding of illegal cultivation and horticulture areas (the southern part of the scheme), has changed the cropping pattern ${ }^{229}$, whereas the pumping capacity and canal network is not only stable but also deteriorated;

- The structure of the canal network makes water management difficult (there is no quaternary canals or even, for the most, minor canals). The outcome is that; the farmers take their water directly from the main canal (the northern part of the scheme). In addition, because the canal is narrow, it is difficult to use machines;

- In addition to the age of the canals, lack of routine maintenance i.e., desilting canals $^{230}$ and structures, repairs to gates ${ }^{231}$ and minor, repairs to structures, have resulted in a steady decline in the condition of both canals and structures ${ }^{232}$. The

${ }^{228}$ It is not possible then to improve the performance in Gendettu unless action is taken to improve the environment of the pump station. The benefit of a 'clean' pump station environment is reflected in the fact that in Aliab, Kitiab and Bagwa, old pumpsets are still functioning satisfactorily.

229 This is also a Gendettu's specific problem in the northern Region. As a result, some need's water in a time in which the other does not need.

${ }^{230}$ Clearing the canals must be begin in November (the beginning of the season). Nonetheless, in the season 92/93 it had begun in February.

231 Gates in the main canal, in the area from Gendettu until Mowes, are broken.

${ }^{232}$ Within this area of interest, the situation has been described, before the rehabilitation, as follows: ,..As a result of inadequate routine maintenance, minor problems lead eventually to major failure. For example, gates which have been difficult to close have been hammered shut until eventually they have fallen apart. Similarly, gates which are difficult to open become bypassed as farmers dig new offtake channels around 
canal sections are undersized due to siltation and the main contribution to conveyance losses is poor water control and distribution.

- It has been noticed that the irrigation engineer who is responsible for canal network in Gendettu has no, at times, transport facilities for the field.

\subsubsection{Supporting Institutions}

As discussed in the last Chapter (5.3.5), the agricultural services available to the tenants in Gendettu are provided by several different organizations in the public sector as well as local merchants and entrepreneurs in the private sector. The main services involved are farm machinery, plant protection, extension, agricultural credit and inputs. NAPC is then the only regional government irrigation agency in Sudan which has no its own agricultural service units. That is why the agricultural service in Gendettu is very weak, argued the general Manager of NAPC ${ }^{233}$.

The provision of tractor services is very important supplement to the service provided by the Scheme. Lateness of Land preparation in this scheme, for instance, is partly due to the dependence on the private sector and the inadequate number of TFU's tractors - only five (Table 6.4). Nobody within the sample has owned any agricultural machinery ${ }^{234}$, and they reported that the cost of hiring tractor per unit area/time is high (has the same price in both sources). In addition, on the contrary to New Halfa, there is no co-operative society to help in this field ${ }^{235}$.

Most farmers appear to prefer tractors than oxen as power source for land preparation, but poor tractor availability and the high cost results in many farmers using oxen. Both moldboard and disc ploughs are used, whilst leveling is done with locally-constructed multi-purpose blade terraces ${ }^{236}$. Although the performance here is not enough and needs more effort and modernization, it has been described by the manager of the research center in Shendy as „not bad“. It is anyway better than those in New Halfa. The problem here, said the manager of the scheme, is not concerning the field crops but horticulture and not

them in an attempt to obtain water" (NHAC 1988:3-5). This description is also valid for the situation in New Halfa in the season 92/93.

233 It is important to reckon with the fact that to overcome factors hampering production increases on irrigated small farms in developing countries, support services have to be extended into the agricultural production sphere itself. These services should include farm planning and higher-level technology work operations (WÖRTZ 1993:112).

234 The NRIRP has registered an increase in the number of private tractors available to farmers in Gendettu from 2 in 1984 to 7 in 1988).

${ }^{235}$ NAPC had undertaken this task at the beginning of 1980s. Even though, it is commonly believed that as in New halfa, the services provided by the corporation was inadequate; out of its tractor fleet of 68 tractors, only 17 were in full working order.

236 The NRIRP report (about KSK schemes; Kelli, Saial and Kabushia)) suggested that many farmers either owned oxen or were able to borrow them from friends and relatives and that there were some oxen for hire also. More recent information from NAPC, however, has suggested that most farmers using oxen hire them from others. During the group interviews conducted later by the same study, farmers said that livestock populations have decreased recently and that draught animals are not as freely available as in the past. The costs per feddan of hiring oxen for land preparation appear to be broadly similar to those for tractor cultivation (ODA 1988:A1/2-12). 
regarding land leveling but relating to distributing the land; basins for the trees to control the water. More than $50 \%$ of the tenants, as he pointed out, are not aware of the advantages that can be skimmed from this operation, they are thinking only about the additional costs.

The actual operations involved in land preparation can be variable. Tractor operations are ploughing and leveling: ox-powered operations are ploughing, leveling, ploughing/sowing where the seed is dropped in the furrow, and hod canal bank construction, which is done using the sandtrack leveler. The bunds surrounding hods and forming canals are sometimes made by hand using a 'wasuq'; this is a two man operation with one pulling and the other guiding/lifting (ODA 1988: A1/2-12).In addition, the optimum planting dates are known and used by most farmers. A notable exception is cotton, which should be planted before 15 June but which is seldom planted before July and may be planted (as in New Halfa) as late as August, due to various constraints.

Unavailability of enough fertilizer, pesticides and means of financing have in Gendettu more negative effects on the productivity and the performance ${ }^{237}$. The last one; financing, will be discussed latter (Chapter 6.5.3).

\section{3 Farmers Management: Water-Users' Behavior}

Having pointed out the role of NHAC and NAPAC in water management, it is important to highlight the role of the third actor, which considered to be the focus of this study, namely water users. Depending on the fact that all the structural work to be done within the boundaries of a farm is the farmer's responsibility, the schemes' administrations in the two cases here, as in many other similar cases in the developing countries, blame farmers for spoiling the water distribution system and the bad management in the farm. A majority ( 88 $\%$ ) of the officials in New Halfa reported that they are not satisfied with the behavior of tenants with water. The other $12 \%$ reported ,to some extent". At Gendettu, the reply was divided between the two; $50 \%$,no" and 50\%, ,to some extent". It is interesting that, nobody in both projects reported „yes“. As an explanation, they stated the following arguments (Table 6.10):

Table 6.10 Reasons for the dissatisfaction concerning Tenants' behavior

\begin{tabular}{|l|c|l|c|}
\hline New Halfa & $\mathbf{\%}$ & Gendettu & $\%$ \\
\hline absenteeism & 28 & the excessive use of water & 33 \\
\hline do not adhere to recommendation & 25 & the psychological factor & 33 \\
\hline unawareness & 18 & spoil the canal system & 19 \\
\hline $\begin{array}{l}\text { lack of co-operation between } \\
\text { tenants }\end{array}$ & 12 & $\begin{array}{l}\text { do not adhere to } \\
\text { recommendation }\end{array}$ & 15 \\
\hline selfishness & 9 & & \\
\hline farm size is big & 8 & & \\
\hline
\end{tabular}

Source: Own Survey

${ }^{237}$ These are exactly, to a big extent, some of the constraints in the freehold areas $(A M L A K)$ in New Halfa. 
The argument, which has been often expressed in conversation is the absenteeism of the tenants in the field. This phenomenon is valid in both projects, but more extremely in New Halfa. In many cases, particularly at the beginning of the season, water is available in the field canal but the tenant is not present. This problem is more observed in the Halfawyeen and considered, according to the manager of the Madina Block, the main cause of the bad performance in their areas. He estimated that the concerned tenants within the Halfawyeen as about $50 \%{ }^{238}$. As well as, the Halfawyeen are often described as not convincible. Within the Arab, absenteeism increases in the rainy season. This problem is also observed at Gendettu and considered as one of the causes of the excessive use of water. Generally, concerning irrigation, tenant is surely present at the field for onion and bersem, and may ormay not be present for faba and wheat but absolutely not present for garden irrigation (see also Chapter 6.4.2). In the last case, he opens the canal and goes to home.

One can say that the psychological factor and the excessive use of water at Gendettu are the two sides of the same coin. Low reliability of the needed amount of water makes the tenants unsure. The psychological reaction of this feeling of insecurity is the excessive use of water ${ }^{239}$. Furthermore, because of the bad land leveling, the tenant can not define the accurate amount of water and therefore give the land more water. This results farther in expanding the water intervals and so on. It must be emphasized that water charging system, in Sudan (flat rate per season irrespective of the number or the quantities of watering), as will be seen in Chapter 6.6, has no role in solving this problem.

It is actually true that the gap between the current management practice on the field canal and the officially recognized from NHAPC and NAPC is very deep. But this is, first of all,

${ }^{238}$ It is worth noting that most of the Halfaween respondents reported that they are responsible for more than one Hawasha. This is due to the fact that many families few years after the resettlement had left the Scheme, entrusting their tenancies to those staying behind, to carry production on their behalf.

239 For perspective, REPLOGLE (1986:118-9) related meaningful incident in the United States in the early 1970s, shortly after the steep rise in world oil prices: „A national television talk show comedian host was lamenting the resulting economic disruptions, saying that the whole world seemed to be on ,back-order" with shortages of everything, ,even toilet tissue. " (This was meant to be humorous, since the supplydemand for this item is, in reality, extremely uniform). However, the general public had recently been conditioned to some inconveniences in item shortages, and the national response was an irrational run to the nation's store shelves and the hoarding of toilet tissue to the point that, for a time, it could no longer be found for purchase. “ ", The sudden empty supply chain certainly did not mean that the national demand pattern had changed at all, only that the distribution pattern had changed, and storage of the item was now located in millions of home cupboards rather than on store shelves. This didn't help other families that had depended on an available supply, however. ",The national tissue manufactures knew that it would be foolhardy to build new facilities and increase production because of the temporary shift in storage (not true demand for their product), and eventually, as reliability of supply became apparent, the 'shortage' disappeared". Irrigation projects, argues REPLOGLE, are also subject to some of the hoarding psychology which can be aggravated or ameliorated by the history of the system reliability. If system reliability has been low, then the psychological incentives are to use all opportunities and all mechanical adjustments, authorized and unauthorized, to „hoord“ the water as if it were the last irrigation. Further complicating the social picture is that these shortages are not distributed but are usually completely borne by those farmers farther from the supply source. This means, he continuos, that the reliability usually becomes lower and the hoarding pressures become higher as a function of distance from the supply source. A vicious circle is created wherein hoarding causes low reliability which then increases hoarding. REPLOGLE argues that legal remedies and administrative threats are generally ineffective, so that remedies through physical system changes and system management techniques are more feasible alternatives. 
an indicator for the failure of all concerned organizations. It seems to us that the tenants are trying in one way or another, through their interventions in managing the minor and quaternary canals, to compensate the weakness and absenteeism of these organizations. Unfortunately they do not organize their action or work collectively but they are trying to resolve the problems individually. Because of this intervention as well as the remarkable absence of NHAC and NAPC field inspectors and khaffirs, it is normal to see in the same command area, side by side, under- and over- supply of water. Anyway, the deviation from the instructions of management is not only restricted in the field of water application ${ }^{240}$.

In New Halfa, it was found that the way in which irrigation and farm management are actually undertaken, within the Unit Command Area and at the level of the individual tenancy, differ from the procedures which are recommended by the scheme management. This is particularly of great interest concerning:

\subsubsection{Irrigation Time}

As was stated in the previous sections, the irrigation system in the first phase of the project was designed according to the continuous irrigation system. This means, minor canals must be used as conveyors not as reservoirs in the night. However, because of different reasons, mainly social, the tenants do not perform watering during the night and, therefore, close the intermediate regulator gates by sunset. The consequences of such deviation from the designed system are as follows:

- destroy the canals and regulator gates;

- leads to a remarkable waste of water which affects directly the water management of the quaternary canal (Abu XX);

- due to the rise in the water surface level in the canals during the night, the roadbeds besides the Hawasha becomes very muddily; and

- make with other unofficial intervention the situation downstream worse ${ }^{241}$.

\subsubsection{Water Intervals}

Before discussing the behavior of tenant concerning the water interval, it is important for the analysis to explain first the water requirement for the crops and the instructions of the management concerning the irrigation practices. These parts are described in detail in NHIRP, ANNEX 1 and 2.

In the New Halfa irrigation scheme the irrigation interval recommended by the NHAPC is 14 days and does not vary for the different crops. About $420 \mathrm{~m}^{3} /$ feddan is applied per irrigation. According to this standard, the total applications for the three crops are:

\footnotetext{
240 According to THORNTON/WYNN (1987:222), the resettled Halfaween are inclined to trust their own judgement in their crop husbandry. Their experience as Nile rivrine cultivators has not always proved applicable, however, in contrast, the nomadic peoples have proved more receptive to the instruction of management.

241 To avoid watering at the night, some who have the turn let the water flow and flood the downstream fields
} 
groundnuts 7, Cotton 9, wheat 7 (not including the first watering for all crops). ${ }^{242}$ At a 60 per cent application efficiency, ${ }^{243}$ the average gross requirements from the reservoir are $415 \mathrm{~m}^{3} / \mathrm{fd} / 14$ days for groundnuts, $510 \mathrm{~m}^{3} / \mathrm{fd} / 14$ days for cotton and $445 \mathrm{~m}^{3} / \mathrm{fd} / 14$ days for wheat $^{244}$.

The existing system requires a tenant to dig a channel in the Abu XX bank to lead water into the appropriate Abu VI. The amount of water led off is dependent on the rate of flow in the Abu XX and the dimension of the channel. The rate of flow in the Abu XX is dependent on the head of water in the minor canal, the degree of weed invasion, the siltation factor and the 'Khaffir' operating the field outlet pipe. On this basis it is impossible to regulate the quantity of water applied in any one irrigation.

Assuming that the canal system, up to and including the Abu XX is operating at correct flow rates, the quantity of water led off into the Abu VI, according to the NHIRP, is a function of time. The normal practice is to flood the basins individually and this takes 24 hours. In the Halfawyeen areas where there is no storage arrangement, irrigation application must go on for 24 continuous hours. This is not, as noted above, acceptable to tenants who were unwilling to work at night. The total number required should therefore be supplied over a period of $2 \times 12$ hours and the flow rate in the Abu XX should be able to cope with this requirement.

The design of the Abu $\mathrm{XX}$ is aimed at watering four Hawashas (four Abu VIs) simultaneously. This is known as a roebat. Thus an 18 Hawasha numbers should take a total of 9 or 10 days to complete one watering cycle. It can be seen from this that a four day period of grace exists between the last Hawasha and the start of the next cycle on the first Hawasha of an 18 Hawasha numbers.

In the case of the 36 Hawasha numbers the position is extremely difficult. Because the 'twin Abu XXs' (El double) are serviced by one field outlet pipe from the minors (see chapter 5.3.6.2). These numbers cannot be irrigated in a 14 day cycle and in practice it takes some 20-22 days to complete 36 Hawashas when the twin Abu XX are completely free of weeds and the flow rate is at design level ${ }^{245}$. As a result, the yields on the 36 Hawasha numbers are below average as the crops are basically under-irrigated for the majority of the time and not simply at the one cycle of peak demand. This is due to the 2022 days watering cycle of $2 \times 12$ hours in place of the designed 14 day cycle (NAPC 1986: ANNEX 2:21).

${ }^{242}$ According to the manager of the Agricultural Research Center (New Halfa), Cotton needs 10 watering and sometimes more, Groundnuts needs also 10 waterings, Wheat 7 watering and usually between 5-6, and Sorghum between 5-6 waterings.

${ }^{243}$ By assuming that the three crops mentioned are equally distributed over the area, as is the aim of the NHAPC, and assuming that an application efficiency on the land cropped with sugar cane and freehold land and forest is in the same order of magnitude as on the NHAPC land, an overall field application efficiency of 79 per cent is found.

244 The NHIRP (NAPC 1986:ANNEX 2:20) which has stated the figures see that these figures are theoretical as they assume the ability to adjust the amount of water actually applied to the crops. This is not possible without incurring massive expenditure on metering devices to the actual Hawashas.

245 According to the designed discharge in the Abu VI $(30$ 1/s.), it can be calculated that the time taken to irrigate one feddan is about 4 hours, and one field of 5 feddans (Hawasha) will take about 20 hours, while a roebat will be irrigated at the same time. A total area of 180 feddan (36 Hawasha) will take then, theoretically, $180 / 20 * 20=180$ hours or 7.5 days. 
As conclusion for the situation, the NHIRP (NAPC 1986:ANNEX 1:25) reveals: „During the survey in the New Halfa Irrigation Scheme, it appeared that subsequent watering were not carried out properly. Recommendations as to intervals between irrigation, quantity of water per application and the total number of applications were not kept" Similar findings have been registered and tabulated in this study (Tables 6.11, 6.12, and 6.13).

Table 6.11 The Total Number of Applications for Each Crop as Practiced by the Tenants in New Halfa

\begin{tabular}{|c|c|c|c|c|c|c|}
\hline Crop/ No. of Watering: & $\begin{array}{l}4 \text { or } \\
\text { less }\end{array}$ & 5 & 6 & 7 & 8 & Total \\
\hline \multicolumn{7}{|l|}{ Cotton: } \\
\hline Arab & 8 & 33 & 42 & 8 & 8 & $100 \%$ \\
\hline Halfawyeen & 7 & 13 & 33 & 7 & 40 & $100 \%$ \\
\hline \multicolumn{7}{|l|}{ Groundnuts: } \\
\hline Arab & 12 & 29 & 29 & 12 & 18 & $100 \%$ \\
\hline Halfawyeen & 15 & 26 & 33 & 26 & - & $100 \%$ \\
\hline \multicolumn{7}{|l|}{ Sorghum: } \\
\hline Arab & 86 & 14 & - & - & - & $100 \%$ \\
\hline Halfawyeen & 50 & 30 & 20 & - & - & $100 \%$ \\
\hline \multicolumn{7}{|l|}{ Wheat: } \\
\hline Halfawyeen & 3 & 13 & 66 & 16 & 3 & $100 \%$ \\
\hline
\end{tabular}

Source: Own Survey

The frequency distribution of the number of watering is shown in Table 6.11:

- the application to cotton is under the recommended for all tenants. However, there are some anomalies in the data of the Halfawyeen concerning cotton. Those who mentioned 8 watering have probably better conditions or may be did not understand the question and mentioned instead an ideal number. The latter may be valid by many others.

- concerning Sorghum, most of the Arab (specially in Sedira and greges) said: three and the rest of the water requirement is supplied from rainfall. Similar finding was observed in the Halfawyeen.

- the results of wheat show its importance for the Halfawyeen, just like sorghum is for the Arab.

- the cash crop groundnuts are more insured than cotton and may be at its expense ${ }^{246}$.

In some bureaucratic irrigation systems, like our cases, even though local farmers are unable to develop their own collective-choice arrangements, they have developed „extralegal" rules to suit their own circumstances (TANG/OSTROM 1993:16). ${ }^{247}$ The data of the actual duration of irrigation are represented in Table $\mathbf{6 . 1 0}$ and show that:

246 An interesting comment from the Arab's area: groundnuts do not refuse the water!

247 Examples of the difference between informal, farmer-established rotations and formal rotations established by the Irrigation Department that have been mentioned here (Merrey and Wolf 1986:46) are seen in the Gondalpur Watercourse:

„Unlike the formal rotation, the informal rotation takes into consideration local conditions such as the sandiness of soils and the height of the field relative to the ditch. Thus, a sandy or high field is awarded extra time to ensure it can be irrigated. More time is also allowed for filling long sections of the watercourse". 
- Tenants who reported one day (in particular the Halfawyeen), definitely do not irrigate the field basins individually but flood the whole field in one go (at the same time).

- 45 per cent of the Arab need more than three days to irrigate their fields. This means, the period of grace exists between the last Hawasha and the start of the next cycle on the first Hawasha can not be only four days.

- The reply which has been often repeated is: „one day when there is enough water and 3-4 days in the case of water shortage.

Table 6.12 Percentage of Duration of Irrigation in New Halfa

\begin{tabular}{|l|r|c|}
\hline \multicolumn{1}{|c|}{ Duration } & Arab & Halfawyeen \\
One day & 28 & 26 \\
2 & 17 & 26 \\
$2-3$ & 5 & 13 \\
3 & 5 & 9 \\
$3-4$ & 17 & 17 \\
4 & 6 & - \\
$4-5$ & - & - \\
5 & - & - \\
More than 5 & 22 & 9 \\
Total & 100 & 100 \\
\hline
\end{tabular}

Source: Own Survey

The same can also be said about water intervals. According to the officials:

- The regular irrigation intervals were never practiced with exception of the first two watering for wheat. On the other hand, many tenants believe, it is better when the interval between the first and the second irrigation of wheat more than 14 days ${ }^{248}$. They believe also that water interval for wheat must be three weeks (or more) not two weeks.

- Three factors determine the water interval of Cotton; 1) the availability of water; 2) whether the tenant is busy with other crop, and 3) the existence in the field at all.

- The rainfall confuses sometimes the water intervals (in particular for Sorghum).

On the other hand, the data given in Table 6.13 show that sorghum (dura) is the crop which experiences longer interval than the other, followed by groundnuts and cotton. The data of wheat stand in relative contrast to the opinion of the officials (or the generalization in this opinion). Commenting on this contrast, the water-users pointed out that there are two practiced methods to irrigate wheat. The first is to irrigate the field before the sowing (wet planting). It needs normally more than 21 days water interval. On the contrary, the second method (planting into dry soil in basins) needs two waterings for month. Furthermore, the last method needs few seeds, which is considered as an advantage for the tenants. One may infer that the behavior of water-users is entirely conditional upon the availability of water ${ }^{249}$.

248 As recommended by the Irrigation Department in the Agricultural Research Center (New Halfa).

249 Justification of such observation can be drawn from village 6 in the Arab area (water shortage) and village 5 Halfaween (no water problem), for instance. The average water intervals in the former are: cotton (28), groundnuts (24), and sorghum (30). Whereas in the later the average is as follows: cotton (15), groundnuts (15), and wheat (12). 
Table 6.13 Percentage of Water Intervals Practiced by the Tenants in New Halfa by Crop

\begin{tabular}{|l|c|r|r|r|}
\hline Crop/Tenant* & less than 15 & 15 & $16-20$ & more than 20 \\
Cotton & & & & \\
A & 24 & 43 & 9 & - \\
H** & - & 78 & 22 & 33 \\
Groundnuts & 10 & 52 & 5 & - \\
A & 17 & 61 & 22 & - \\
H & 67 & 33 & - & 11 \\
Wheat & 50 & 21 & 18 & 67 \\
A & 5 & 24 & 4 & 40 \\
H & 20 & 10 & 30 & \\
Sorghum & & & \\
A & & & \\
H & & &
\end{tabular}

* A: Arab, H: Halfawyeen

** Within the Halfawyeen seven of the fifteen cases that grow Cotton, had answered this question.

Source: Own Survey

This is also the case at Gendettu. It is commonly believed that in case of water availability, the adherence to management recommendations concerning water interval is high. The exemption here is the case of faba beans. The water-users believe here also that the interval after the second watering must be longer. It is also possible, in the time of water shortage that the period of irrigation among 6-7 days. Furthermore, the last part of the Scheme; minors 4, 5, 6, and 7 are forced, however, to adhere to these recommendations through the Schemes control of the canal gates. Likewise, the number of irrigation's quoted by NAPC and the Agricultural Research Center in Shendi are:

1- Seifi Season: Sorghum fodder (6), Cotton (8).

2- Damira Season: Sorghum grain (7).

3- Winter Season: Faba Beans (8), Wheat (8), Pulses(8), Onions (14), Bersem (two per month), Horticulture ( 2 or1 per month). ${ }^{250}$

\subsubsection{Crops Preferability: Wheat and Sorghum vis-à-vis Cotton}

The observations in the large agricultural schemes in Sudan highlight the fact that cotton ranks first in the „upper management body's“ priority scale, whilst subsistence and food crops are looked upon more as a necessary addition to cotton production (WÖRTZ 1993:109). On the contrary, it appears instead that the farmers have other scale of priority. As BARNETT (1977) observed in Gezira, the way in which the water is rationed by the tenants between the different crops reflect the primacy of food crops sorghum and wheat in the tenants scale of values. The emphasis is always on „our daily bread" as opposed to „the Government's cotton “. Groundnuts come, however, in the middle between the two extremes. It seems to us that the base of this ranking (classification) is not only food crops

${ }^{250}$ Bayoumi (1976) has stated that the irrigation water requirements of 1 feddan of plantation is $400 \mathrm{~m}^{3}$ per month (WEDDERBURN/ERRINGTON 1985:19). 
vis-à-vis non-food crops, as BARNETT argued, but first of all profitable crops vis-à-vis non-profitable crops ${ }^{251}$. In this respect, it has been observed that many tenants intercrop (between rows) some Pulses and Karkade with wheat and groundnuts to compensate the effect of the high production costs.

Broadly speaking, the tenant priorities in irrigation in New Halfa are as follows:

- crops that are marketed directly by tenants ${ }^{252}$; and

- crops that are already planted as against those that are at the beginning of planting (dura or groundnuts as against cotton or wheat by the Arabs).

In addition, reasons that are always mentioned for such preference are:

- The concentrated rotation which make it necessary to distribute the limited resources; specially labor force, between three crops in three months (June, July, and August);

- lateness of land preparation, and

- the tenant is not convinced of the Research Center's recommendations.

The same phenomenon has been registered at Gendettu, and the reasons are, for the most part, the same. The priority here is for 1) the valuable crop (profitability); this means onion first and then the others; and/or 2) crop which cannot stand water shortage e.g., onion or faba as against alfalfa.

\subsubsection{Irrigation Method}

The introduction of suitable irrigation methods is an important point that is intimately related to the need for appropriate land development work (usually grading). This point bring to light, then, the relationship between the method of land use and the method of water use, in particular in a case of water shortage.

Irrigation system in the New Halfa Scheme is supplied by the Angaya system. This system, as described in the study of NHIRP, is designed as basins in which the water is brought in by perforating the bank of the Abu VI. As already mentioned, the field must be distributed by seven irrigation ditches and seven field bunds. In general one Hawasha of 5 feddan is divided then into 16 basins of 0.3 feddan each (fig. 5.14), and the selection of the number of basins depends on the slope of the field (NAPC 1986: ANNEX 1:40). When the amount of basins is not adapted to the slope, the water distribution in the basins will be uneven, and the basins at the lower end will receive too much water, while the basins at the upper end will be under irrigated.

Therefore, the rule is, the more the number of angayas the better the control of water in the field. This recommendation and its implications are, therefore, less simple than they may first appear. The tenants, as the officials - 92\% in New Halfa, and $67 \%$ in Gendettu blamed do not follow this recommendation. In this context, they stated the following argument:

${ }^{251}$ See Chapters 6.4.5 and 6.6.

${ }^{252}$ It is very important here to emphasize the interests of the emigrant labors who, in the most, undertake the task of irrigation. They prefer to irrigate the crop they are sharing (groundnuts) as against dura for instance. That is why many of the Arabs have to enunciate the groundnuts to secure dura. 
- their costs are high;

- the tenants are absent;

- the relevant machines are not available and then it has to be done manually;

- they take a considerable area from the field; and

- they hinder the harvest machines for wheat.

Although the data given in Table 6.14 confirm this blame, it should be taken with caution. We believe that the actual numbers are less than those mentioned here. The tenants know the importance of this task as indicator for their performance in the field. That is why they were particularly the Halfawyeen who are always accused of absenteeism, overexaggerating their real work to wave away this accusation. This view is reached based on the information of the key informants, the trustable tenants and above all the observation in the field. According to these sources:

- the maximum number is 12 Angaya, and even this is valid only for wheat.

- the number of cotton Angayas are often fewer. The average is eight and in many cases between five and eight. The reason mentioned here is not only the high cost of this practice, but also the high cost of ginning. The base of paying for the labors in cotton fields is the number of angayas.

- the average number in Abu Nagma Block, in particular in Arab 5 and Arab 6, is relatively high whereas in Sedira, for instance, it is between nine and ten.

- the relative high numbers in groundnuts fields for the Halfawyeen show the interests of the emigrant labors.

Table 6.14 Distribution of the Angayas in Hawasha per crop (\%)

\begin{tabular}{|c|r|r|r|r|r|r|r|}
\hline Crop/Tenant & \multicolumn{1}{|c|}{$\begin{array}{c}\text { and } \\
\text { less }\end{array}$} & \multicolumn{1}{|c|}{$8-9$} & $10-11$ & $12-13$ & $14-15$ & $16-17$ & $\begin{array}{r}18 \text { and } \\
\text { more }\end{array}$ \\
Cotton & 5 & 5 & 30 & 40 & 10 & 10 & - \\
A & 5 & 12 & 18 & 53 & - & - & 11 \\
H & & & & & & \\
Groundnuts & & 4 & 26 & 44 & 22 & 4 & - \\
A & - & 4 & 28 & 48 & 4 & - & 16 \\
H & - & 4 & 10 & 50 & 17 & 10 & 9 \\
Wheat & - & & & & & \\
H & 13 & 17 & 33 & 29 & 8 & - & - \\
Sorghum & & & & & & \\
A & & & & & & & \\
\hline
\end{tabular}

A: Arabs

H: Halfawyeen

Source: Own Survey

The information furnished by the survey reveals that the majority of tenants $(53 \%)$ do not irrigate angaya by angaya as is recommended. Factors that determine the number of angayas irrigated together are:

1) kind and age of the crop; cotton and groundnuts: (3-3), wheat: the first watering (1-1) and then (3-3) 
2) volumes and flow of water in the water course; weak flow (1-1), middle flow (2-2), strong flow (3-3).

3) whether the tenant himself irrigate or a hired labor. Wage labors tend to irrigate the whole Hawasha at one time.

The angaya system has several disadvantages:

- Mechanization possibilities are limited.

- Poor water management and water control result in waterlogging of the basins.

- This system tends to over-irrigation due to lack of water measuring and regulating devices at field level.

Therefore, one of the short-term measures for increasing the level of water utilization efficiency, as recommended in the rehabilitation study, was changing the irrigation method (NAPC 1986:ANNEX 1:48). As alternative, irrigation by the double ridging method was proposed. This method is already practiced on some of the freehold land for vegetable production $^{253}$. The system as used in vegetable gardens was inspected during various stages, and the results found were very encouraging. The observed advantages of the double ridge system over the Angaya are (NAPC 1986:ANNEX 2:22):

- the plant line was not inundated;

- germination of fine, small seeds was good;

- ease of watering;

- because the surface was dry and friable, weed control was simpler and more effective;

- the working direction is along the long axis of the „number“ i.e., across the Hawasha to the improvement of machine utilization;

- low and high spots tended to be neutralized ${ }^{254}$; and

- the whole Hawasha could be used ${ }^{255}$.

Notwithstanding the above, almost all the interviewed the officials believe that it would be unwise to change this system. Basin's system, they view, is the best for gravity and the most suitable for the soil in New Halfa. As well, it was very interesting to find that almost nobody had heard about the alternatives recommended by the NHIRP.

The arrangements for irrigation at Gendettu are very similar to those described in New Halfa. Some crops like faba beans, sorghum and lubia (Dolichos Lablab) are irrigated by angaya. For the other crops which consider sensitive to water, like onion, vegetable and alfalfa, irrigation is done by sub-dividing the angayas into small parcels or hods and letting the water flow into each parcel in turn. The smaller the parcel the less the effect of surface variation and the more efficient the irrigation. For instance, onions are grown in small hods with an area equivalent to 300 per feddan ${ }^{256}$. Surface irrigation is also used for fruit trees; the larger trees have individual basins but closer spaced fruits such as bananas have several

253 This method is also practiced in Zeidab Scheme in the Nile Province for cotton irrigation.

${ }^{254}$ Here also, in order to obtain a proper water distribution over the furrows, perfect land leveling is required.

255 In this system furrows will run parallel to the Abu XXs from one Abu VI to another, and thus have a length of $75 \mathrm{~m}$. The total furrows per feddan are 31 furrows i.e., 156 per Hawasha.

256 As the case for cotton in New Halfa, many tend to increase the size of the parcel to reduce the cost of leveling, weeding and transplanting (the parcel is the unit of account for these two operations, or in other words, payments for the hired labors are based on a piece rate system). 
stools in each basin (NAPC 1986:A1/2-17). Anyway, the opinion of the officials about the adherence of the tenants is generally positive. Water management at fields, in comparison with New Halfa, is better. Farmers seemed to have full control on water distribution in the field because of their long experience, with the exception of the case for horticulture. Most of the officials, as well as the Horticultural Department in the Regional Ministry of Agriculture, agree that the management in the gardens is very bad - canals and basins are not well distributed, not clean, and always over irrigated; spaces between trees are not as recommended; and there is no drainage system.

\subsection{Water Distribution}

Schedule systems or allocation rules are the most important activity for management in an irrigation system, especially when the supply of water is inadequate to meet the crop requirements of all cultivators simultaneously. There appears, from the last section, to be a direct relation between the efficiency of water distribution and application efficiency. The objective of water distribution is (WALKER/CLEVERINGA 1989:M.XI.2) a supply of water at each farm or field inlet, responding to the following criteria:

- predictable: foreknowledge of supply;

- reliable: predictably adequate and predictably timed;

- adequate: always sufficient for a particular crop in a particular season;

- timely: at a time desired by farmers and productive for their crops; and

- equitable: supply proportional to land-holding in the area.

Enforcing these rules effectively can reduce uncertainty and conflict among irrigators. The head-enders/ tail-enders' problem is often seen in most public schemes. Those near the top of channels have an immense physical advantage of access which can be very difficult for those farther down to control. In the absence of countervailing custom, social sanction, or physical force, the privileged top-enders satisfy their own needs first before allowing water to flow down a cannel to their less fortunate neighbours below (CHAMBERS 1980:36).

\subsubsection{Allocation system in both Schemes}

We are dealing here with bureaucratic allocation systems (water authority oriented systems). Such systems usually practice rigid ${ }^{257}$ water delivery scheduling systems. These systems include what has been called the rotation distribution system (RD), wherein a fixed flow rate of water is delivered at a fixed duration for a predetermined frequency (REPLOGLE 1989:121-5). This system is commonly used. A higher percentage of cases using such systems as the sole distribution procedure is characterized by problems in rule conformance or maintenance than those using other types or combinations of distribution procedures (TANG/OSTROM 1993:9). ${ }^{258}$

Each irrigation project has a unique schedule. OAD's experience in Southeast Asia, where water shortage is relative, assuming point toward having gate or orifice control at the field channel level to be able to adjust flows, including to be able to reduce offtakes as soon enough water has been received. Considering the social as well as the technical factors,

${ }^{257}$ A rigid system does not respond to information and maintains the same operating schedule under all conditions.

${ }^{258}$ However, it is believed that such a system has many advantages: less losses specially in the case of scarcity, gives more reliable and equitable supplies, and can make better use of rainfall. 
UPHOFF's experience in south Asia, on the other hand, where water shortage is absolute, preferred management system like Warabandi ${ }^{259}$, delivering on a pre-set schedule fixed amount of water, well below what farmers would like to have and could make good use of it. In such case, he argued, fixed structures represent an optimal social adaptation because there is less opportunity for tampering with deliveries (UPHOFF 1991:203). At the same time he confesses what Pakistan case studies have shown, where the installed solid concrete turnouts were modified by farmers. Under these circumstances, farmers at the tail end of the water courses were found to be clearly disadvantaged (SHAH 1991:147).

The rotation system with its allotted time is practiced in our two cases. In New Halfa, the down-the-ditch distribution method is used within a tertiary (up-stream users first). Every four Hawashas along water course (Abu XX) are entitled to receive water simultaneously only one day, including the night and then the next four. Just like in Warabandi, there is no provision in the system to compensate any single individual farmer who may fail to receive his share of the water. This means, the whole 'number' (36 Hawashas) must be irrigated in 9 days. According to the survey, it was found that the period taken to irrigate the 'number' can be one month when the quaternary canal has been poorly maintained. At Gendettu, each field receives water independently from the field channel.

In view of the non-profit nature of New Halfa Scheme, where the main objective is settlement and resettlement, system management activities should be oriented to „equality“ in the spread of water more than the maximization of production. This later orientation is more likely where irrigation schemes have been developed to support the expansion of cash cropping or export (Gezira or Rahad). However, all the respondents (100\%) within the officials, in both schemes, reported that there is no equity in the amount and the time of water distribution $^{260}$. They stated the following arguments (Table 6.15):

- It is known that each canal group (minor or field water course) and each tenant have individual concerns which are very site specific. The extreme form of social disorganization which affected negatively the irrigation management at the field level is the non-co-operation in water distribution between these groups and individuals. The tenants act selfishly.

- Because of the uncertainty, the tail-enders open the gates on the minor canals, and those at the tail end of the water course break the dam built by the first irrigators to obtain the water in the night. They could not therefore control the water in the Hawahsa and this

\footnotetext{
${ }^{259}$ Warabandi system „water by turn“ originating from Northern India and adapted by the British Administration to 'protective irrigation' as part of their policy for the large system (WALKER/CLEVERINGA 1989:M.XI.2/6). It is therefore a permanent method of water distribution management (Pacca Warabandi) shifting from one generation to other in Pakistan (SHAH 1991:147). Warabandi as WALKER/CLEVERINGA described is a system of equitable water distribution by turns according to a predetermined schedule, specifying the day, time and duration of supply to each farmer on the tertiary unit in production to the land holding in the command area of the outlet. The turn is fixed, the flow is fixed, and the farmer may do with the little water as he pleases to satisfy his (crops') needs.

${ }^{260}$ Of note is the fact that to secure a „fair“ distribution of water within irrigation communities may often be difficult. CHAMBERS (1980:40), in the light of this, pointed out: ,in any case there are problems with the connotations and interpretations of fair".
} 
may result in flooding the neighbors' fields. After watering they let the water flow to drainage $^{261}$.

- Mostly, the first ten tenancies get reliable amount of water ${ }^{262}$. It can be that they watering twice or three times before the last ones practice the first watering ${ }^{263}$.

- Sharecropping with the migrant-labors is responsible for the conflicts and bad distribution between the water users. The sharecropper, who is strange, is not interested to make good relation with the neighbors ${ }^{264}$.

- There is no punishment, furthermore it is said that, sometimes, preferential politic is practiced regard by some members of the Scheme authority.

- Normally, the tenant do not irrigate but let this vital task, in particular after the second watering, to others who are often hired labors. Those labours are always responsible simultaneously for watering many fields.

- Those responsible for the execution of water control are not qualified. In principle 'Khaffirs' (water bailiffs), the government official designated to closing and opening the sluice, are not in a position - because of socio-economic reasons- to fulfil their tasks perfectly or at all.

Table 6.15 Reasons of water distribution Problems (Officials)

\begin{tabular}{|l|c||l|c|}
\hline \multicolumn{1}{|c|}{ New Halfa } & $\%$ & \multicolumn{1}{c|}{ Gendettu } & $\%$ \\
\hline tenants' behaviour* & 63 & situation of canals** & 34 \\
\hline supervision staff & 19 & the irrigation system & 33 \\
\hline shortage of water & 6 & tenants' behavior & 17 \\
\hline position of the field & 6 & illegal areas & 16 \\
\hline there is no punishment & 6 & & \\
\hline total & 100 & total & 100 \\
\hline
\end{tabular}

* Conflicts $25 \%$, selfishness $19 \%$, absence of self-organization $19 \%$.

$* *$ cleaning $17 \%$, regular gates system $16 \%$.

Source: Own Survey

The most crucial consideration on Gendettu Scheme (NAPC 1986:A3) is the distribution of irrigation supplies in a more equitable manner to obviate the need for farmers to supplement their supplies from groundwater or by pumping from the canals which no longer command their fields. The solution as the rehabilitation study had argued involves two factors, firstly, the supply of an adequate quantity of water at field level and, secondly, the maintenance of sufficient command to enable gravity distribution of water

261 The responsible engineers reported that sometimes it is difficult to distinguish drainage and irrigation canals because the former are always full of water. In addition, as a result of lack maintenance, waters seep away and destroy the roads. These make a suitable environment for mosquitoes.

${ }^{262}$ It does not mean that there is fair distribution here from the technical point of view. The flow of water through the quaternary canal is divided into four field channels, each of which has a different head. Thus the flow into the four Abu VIs is often not evenly distributed, and one field receives more water than another.

263 In El Basawla area, the first Hawasha on the Abu XX (which is the first on the minor) has practiced four watering whereas the last Hawashas on other Abu XXs did not practiced the first one.

264 Sharecropping is more to be observed in the Halfawyeen area; in particular for groundnuts. The migrant labors from west Sudan are the specialists of such crop because it needs more work at the field (most operations by hands). The migrant labors prefer to share the Halfawyeen than the Arabs. The later reported that sharecropping with the migrant labors influence the production of sorghum; their main food, because the migrant labors take the water to the groundnuts fields. 
from the canals to all fields within the scheme boundary. From tables $6.15,6.8$ and 6.9 , the above recommendations were not been realized, and the failure to manage the irrigation system remain the main reason of water distribution problems (67\%). In addition, distribution of water is controlled very crudely, usually upstream users obtain water on demand at the expense of farmers downstream and the high fields are always disadvantaged.

The ignorance of farmers' optimum and failure to this including in the design and operation of the system can result in a combination of events: aggregate production from the area served will be less than the potential; those farmers with sufficient resources will develop private systems (frequently tube wells where physically possible); those farmers without resources will put increased pressure on the public system. The results of the survey showed that all these events, that have been experienced in Southeast Asian countries e.g., Philippine, Taiwan, and Malaysia (LEVINE 1986:57-8), are realized at Gendettu.In resemblance to New Halfa, an individual sense prevailed among tenants. Every one is trying to solve his problem apart from the effects on the others ${ }^{265}$. As stated in Chapter 5.3.6.4, one of the characteristics of the irrigation system there is that head-enders along the main canal take more than their 'share'. The NRIRP 1986 estimated over 300 uncontrolled outlet pipes serving individual land holdings (most of these are freehold), despite the 9 'Khaffirs' and agricultural policeman who are responsible for controlling these pipes. As a result, farmers at the tail of the land have resorted to pumping directly from the main canal, in particular in orchard's areas.After the decision of removing all these private pumps on the main canal, the competition had increased, specially in minors 4, 5, 6-7, and 8. In our survey, 532 unofficial outlet and breakage now been foundin almost six $\mathrm{km}$ long area at the beginning of the main canal. Each of the 67 Hawashas in minor 6-7 for instance, has its own offtake. As well as $63 \%$ of the respondents reported that they have own offtake; $17 \%$ participate with other farmer, and $20 \%$ with more than one. This is why the Ssheme has bad reputation. One of the NAPC, who had worked more than thirty years in this area, went so far as to use a metaphorical word for his description of the canal network of Gendettu Schemes: ,,it looks like...sieve“. The majority of farmers at the end of the scheme were enforced therefore to dig Wells to supplement their supplies by pumping from groundwater. Many of them were entirely depended on this water; especially in minor 5. Increasing the water availability then by increasing the pumping capacity will not, by itself, solve this problem as additional water will be taken by the upstream users who will continue to extend their holdings and intensity of cropping at the expense of downstream users $^{266}$. When the farmers are unable to get water when they need, this circumstance is

${ }^{265}$ This 'morale value'(individualism), is strongly to be observed in Sudan and the Arab countries after what is known as 'oil revolution' in the 1970s. Elsewhere we have argued that the most negative effect of the labor migration to these countries is that migration has offered individual solutions for problems that should 'only' be solved collectively specially in the long run (KHALIL 1985).

${ }^{266}$ Four possible options of dealing with the numerous uncontrolled offtakes on the main canal have been considered within the scope of Schemes' rehabilitation (NAPC 1986):

The main canal would be divided into reaches and irrigation supplies would be rotated between reaches. Reinstatement of a secondary/Tertiary Canal system. This would entail the closure of all existing offtakes on the main canal with the exception of those serving secondary or minor canals.

(iii) Grouping of offtake. Groups of three or four uncontrolled offtakes would be replaced with a single regulated offtake and individual holdings would be served by small farm channels. This is a compromise which may be acceptable to the farmers and which would not involve excessive expenditure.

(iv) Standard „Mini“ offtake. All uncontrolled offtakes would be replaced by a new standard mini offtake serving an individual farm unit.

It remains to say that non of these options has been adopted or realized. 
defined as the lack of water control. It is of great importance in this respect to question who is really responsible for water control over the penultimate stage (the Abu XX) in the field water distribution system? Control is the capability of the irrigation system to direct the appropriate amount of water to specific farmers' fields when needed (LAYTON ET AL. 1994:291). Actually, the scheme management and the farmers co-manage the control of water as it moves through the irrigation system. At the most local points in the system, the management of water becomes a collective enterprise among farmers who are working within a situation restricted by government regulations implemented by officials and by the actions of neighboring farmers.

\subsubsection{Who controls the water?}

In other words, who is responsible for basic-level water indenting in the schemes? Is the decision taken in November 1992 (transfer of authority) enough to put an end to the problem of "the missing responsibility" between the agriculturists and the irrigation technicians? This leads us to highlight the important role played by the local water staff (water guards) in the operation of the irrigation. The local water staff are the key actors in bridging the gap between the theory and reality of scheme performance ${ }^{267}$. They help to show how improved performance must come from a balance of technical and social interventions. Water operators ${ }^{268}$ are the main communication channel between the scheme management and the farmer; translating information both ways, diffusing local tensions and helping irrigators arrange informal flexible scheduling where formal operational rules are inappropriate and difficult to change (TANG/OSTROM 1993:15). So their success depends on their capabilities and honesty. Furthermore, the water guard must be a man trusted and respected by the farmers as well as it is preferable that he lives among the farmers of the canal in order to facilitate communication. SAGARDOY (1986:70) described the main characteristics of water guards as follows:

a. Job description: these may vary slightly according to the type of scheme. Those relevant to our cases are:

- distribute and control the flows that each intake must deliver

- open and close intake gates or valves

- communication to the block inspector of the request for water

- control of the canals and watercourses to avoid unauthorized use of water

- delivery of water bills

b. Qualifications: basic primary school education is normally sufficient to undertake those functions. Water guards should have neither relatives nor properties in the area they serve. They should also have farming and irrigation experience.

267 These important actors have often been forgotten in debates on the strengthening of water user associations, and in reforming operations. An interesting and vivid examination of the important role played by the water guards in the operation of irrigation schemes (case study in western Mexico) is that of ZAAG (1992).

${ }^{268}$ There are different local names for these key actors: ditch riders, ditch tenders, water guards, guards, water bailiffs, gatekeeper, agricultural policemen, 'zanjeros', 'Khaffir'. 
c. Manpower requirements at the scheme: the number of water guards needed at the scheme level is greatly influenced by the type of water distribution used and by the number of intakes to be controlled. In the case of rotational system, assuming that each farm has one intake, the average standards for each 5000 ha $^{269}$, derived from projects in several parts of the world is: very large farm (6); large farm, 5-10 ha (8); medium farm, 2-5 ha (10) and small farm, 2 ha (12).

The numbers of Khaffirs working in New Halfa in the Season 92/93 was 362. Generally, the average in the southern parts of the Scheme (Debera, Sasaraib, and Shek Omar) is more than those in the northern part (Demiat, Sedira, and Rira), because Khaffirs are also responsible for water control in the freehold lands (Amlak). The average per Block is 17, compared with 14 in the northern Blocks. The distribution of Khaffirs in the survey area was as follows: (1) Sheik Omar (8 232 ha or 19600 feddan)- Argin (19), El Butana (18), Abu Nagma (15) (2) Sasaraib (7358 ha or 17519 feddan)- Doghem (21), El Madina (17), Alledaj (14). In addition, 9 Khaffirs and one policeman are responsible for water control in Gendettu. Each is responsible for one minor. All of them are old men and have no experience in Agriculture. They were either army soldiers or workers in the towns.In principle it was the agriculturist at the Block level who assesses water requirements for the 'numbers' along a minor canal and who instructs the Khaffirs controlling the intermediate regulators on the minors and the FOP to the Abu XX. It is the responsibility of the Khaffir only to open and close the regulator gates along the minors and control water distribution between Hawashas. There is some similarity with the ,semi-demand method“ where the water guards have a crucial role ${ }^{270}$. Usually, Khaffir is responsible for three 'bridges', i.e., three km (approximately $3 \mathrm{Abu} \mathrm{XXs),} \mathrm{and} \mathrm{his} \mathrm{place} \mathrm{of} \mathrm{residence} \mathrm{must} \mathrm{be} \mathrm{in} \mathrm{the} \mathrm{middle.}$

On the other hand, there is often a yawning gap between the principle and the reality. The canals are really suffering from a lack of management and operational discipline. Water distribution from the minor to the Field Water Courses was very bad and was not carried out according to their actual needs. In addition, there were many problems that hinder the discharge of water among minors and eliminate therefore the supply that should be drawn by the FOPs. Control gates operations and maintenance at the scheme need a lot of effort. Because of the poor maintenance and the tenants' intervention, many of them are not operational; some were valveless or did not have bolt or weir blade. In addition, every tenant has a „key“" (spanner) to manipulate the gates according to his own interest ${ }^{271}$. Poor turnout structures ${ }^{272}$ result in in-correct distribution of water in the minor canals, and uneven water distribution in the fields that are under the command area. Minor canals in the survey area are long and need more control and communication. ${ }^{273}$ El Butana Block

${ }^{269}$ Local circumstances, such as transport facilities, ease of access, particular configuration of canal layouts, etc., may reduce or increase the above standards.

${ }^{270}$ Semi-demand is one of the FAO's classification of delivery scheduling methods, amongst others like ondemand method, canal rotation and free demand, rotational system and continuous flow. According to this method, water is made available to the farmer within a few days (generally 2-7) of his request. The amount is often limited to a certain volume per hectare.

${ }^{271}$ One of the respondents in village 13 Halfaween reported that he has to open 27 gates or many of them to get water.

${ }^{272}$ Devices for controlled discharge of water from a pipe or canal onto the land, and consider essential parts of the distribution system in the gravity irrigation systems.

${ }^{273}$ Respondents in this village reported: ,in this village water stealing occur among the minor, which extend $17 \mathrm{~km}$, not among Abu XX. 
for example has 9 minors $^{274}$ extending from $\mathrm{km} 26$ until $\mathrm{km} \mathrm{33}$. But, on the other side, it has one follow up office which has to co-ordinate with the distribution center in the $\mathrm{km} 65$. It is supposed that, in any time, only four FOPs must be opened to keep the discharge in the field water course as designed. Because all FOPs are always opened, the flow is very low and all of them have water shortage ${ }^{275}$.That is why - beside weed growth, siltation and delayed maintenance - the average flow through the FOP in New Halfa is less than the $5000 \mathrm{~m}^{3}$ /day that have been estimated by the MOI. It is approximately $2500 \mathrm{~m}^{3} /$ day. This results in, irrigating instead of 12.5 feddan only 6 feddan per day. This means doublet irrigation period. At Gendettu, the 'high' fields are, for this reason, not able to irrigate ${ }^{276}$. The result of the lack of an entity to control the project control is that tenants try to adjust the system. This action is of course at the expense of the time and effort which should have been given to water control at the field. In the eyes of the department irrigation engineers, these problems are closely bound up with:- lack of formal irrigation training of the agriculturists themselves.- In reality, it is the Khaffir who assesses water requirements rather than the agriculturists. Although a standard calculation is supplied to the Khaffirs by the Irrigation Service (IS), they are poorly trained in its application.- Poor disciplinary measures on the Khaffirs who may open more FOPs than permitted was also a contributing factor. Khaffirs frequently are absent from housing provided adjacent to intermediate regulators. This is mainly because of social and economical constraints. They do not have the resources, support services and incentives, to take over their vital role. The average salary for Khaffir (1480-2430 LS) is approximately half what normal agricultural labor can earn. That is why some of them are ready to accept bribes, and then become dependent on the tenants ${ }^{277}$. Many, on the other hand, have become sharecroppers or have other works in the village, and most of them do not reside beside the canal any more. It is finally to be concluded that the social conditions of the water operators should be brought into the focus in dialogues and discussions concerning water distribution. The tenants were asked whether the Khaffirs are always present (Table 6.16). Although the majority ( $71 \%$ ) of tenants in Gendettu reported the presence of Khaffirs, they added: he can not do anything in the case of water shortage. In addition, the dependency of khaffir on the tenants, to fill his income gap, makes him powerless. On the otherhand, no contacted respondent from the TFU reported „Yes“. The replies in New Halfa reflect the distribution of water problems within the sample. All of the respondents in Sidira, Basawla, and villages 11 and 24 Halfawyeen replied „no“. Most of the tenants who reported „to some extent" like Arab 6 and 7, and village 5 Halfawyeen believed also that he is not in a position to do something and many replied ,he is also like the inspector and the agriculturist....responsible for one or more Hawashas and concentrate of course on his area of interest ".

274 The average in the other Blocks is 3-5 minors.

275 In some villages in the Arab areas' valves of the FOPs were stolen by the tenants or the migrant-labors and used as oven for their bread 'kissra'.

${ }^{276}$ We have observed such a case in minor 6. Although the water was available for 16 days during the survey, one of the respondents could not irrigate whereas the neighbors have irrigated twice. They destroyed his dam and stored the water at the night. In minor 8 we have found 10 dams at the same time among 5 Hawashas. The breaking of such dames aggravates the problem of siltation.

${ }^{277}$ Until the end of 1970 s, the income of Khaffir or the policeman in Gendettu was sometimes more than the income of the small Tenant. He was therefore respected and he was in a position to carry out his job. Khaffirs in Gendettu are not sharecroppers like those in New Halfa but they are dependent on livestock that is why they need the tenant to get fodder at no cost. The only one in Gndettu who does his work perfectly (minor 5) is supported financially from his sons. Consequently, it is hard to blame the Khaffir for keeping his attention to secure daily bread rather than water distribution. 
Table 6.16 Tenants Report on the Presence of the Khaffir

\begin{tabular}{|l|c|c|c|c|}
\hline \multicolumn{1}{|c|}{ Scheme } & Yes & No & To Some Extent & No Reply \\
$\begin{array}{l}\text { New Halfa } \\
\text { Scheme }\end{array}$ & 40 & 33 & 23 & 4 \\
Gendettu & 71 & 19 & 10 & - \\
\hline
\end{tabular}

Source: Own Survey

In addition to the critical water supply situation in the Scheme, the total effect of these alleged practices is, in the opinion of IS authorities, a considerable wastage of water ${ }^{278}$. That is why they have responded positively to the decisions of November 1992 which extended their service until the Abu XX. The decision which is highly accepted from all agriculturists, means also transfer of administrative authority from the Khaffirs to the Irrigation Service. The IS is, according to the decision, responsible for controlling and distributing water requirements -assessed by the agriculturists, among the different Abu XXs. The control of water between and inside the Hawashas remains nevertheless, as many informants argued, without resolution. These additional tasks would have staffing implications for the IS, which would need to be determined. Training and communication means are highly requested. In this connection, it was recommended that a training program for Khaffirs should be conducted by IS in close co-ordination with NHAC. The training should be in line with the job description of the water guard and his place in the organization. In addition, a post of head Khaffir 'Samad' should be created, with the responsibility of controlling Khaffirs along a minor canal (see Chapter 6.1.1). ${ }^{279}$ The question that always raised throughout the survey and remained without logical reply is; why do not the tenants themselves organize the water distribution among the Field Water Course? The argument, which has been often heard expressed in conversation with members of TFU was: "we pay to the NHAC for this purpose and they have to take over this task. This is their duty"! It would be easy to conclude from the above that the schemes are in need of water-users' organization.

\subsubsection{Water Distribution between the Tenants.}

Notwithstanding the above, it is important to move our understanding of water distribution one stage further. Information about water distribution between tenants were reinforced through an additional question. Tenants were asked whether they have problems with their neighbors concerning water distribution. The majority in both schemes (53\% in New Halfa and 59\% in Gendettu) reported „No“. This must not be understood as a criterion for improved management or low 'social costs'. On the contrary, it appears instead that the family connections in New Halfa is the reason for this reply ${ }^{280}$. It comes in the most from Arab villages where the ,esprit de corps“ is still very strong, and from village 26 Halfawyeen where there is no water problems and the supervision of water from the tenants is very high. As we will see, the high dependence of the Halfawyeen on the migrant-labor or others to irrigate the fields (Chapter 6.4.4) has cancelled the role of

\footnotetext{
278 Estimated as in excess of 12 per cent.

279 The system was reported as working well in Gezira, where the samad alone indents to the Block Inspector.

280 "If we were not relatives, then we might have every day an attempt of murder" reported the tenants in Gereges.
} 
relationship and solidarity which they were famous for. At Gendettu the majority were not unduly concerned because they anyway either rely on their pump sets or draw the water directly from the main canal or simply because there is no water at all. Nonetheless, the problems of social costs in this scheme is more remarkable. Those who were unhappy with the relation to neighbors stated the arguments showed in Table 6.17. It is very interesting to compare these reasons with those reported by the staff (Table 6.13). In addition we noticed that:

Table 6.17 Reasons of the Water Distribution Problems (Tenants)

\begin{tabular}{|l|c|c|}
\hline The Reason & $\begin{array}{l}\text { \% of the Reason } \\
\text { New Halfa }\end{array}$ & Gendettu \\
\hline $\begin{array}{l}\text { Shortage and unreliability of } \\
\text { Water }\end{array}$ & 42 & 12 \\
\hline Bad administration & 21 & 22 \\
\hline Conflicts between tenants & 19 & 44 \\
\hline $\begin{array}{l}\text { Lack of co-operation and } \\
\text { co-ordination }\end{array}$ & 17 & 22 \\
\hline
\end{tabular}

Source: Own Survey

1 The high percentage of conflicts among those who have not secured source of water in Gendettu is may be due, to a big extent, to the fact that the neighbors at the field are not the same neighbors in the village.

2 The example of the conflict and lack of co-operation among the Halfawyeen is village 13 and El Basawla area. The downstream area in village 13 is known as ,the dead line“. The reason of this name is: 1) many Hawashas there are not grown because of the water shortage, and 2) it is very rarely to see one of the tenants at field, and those who are interested in growing their Hawashas have, sometimes, to protect their water at the night by guns. In the same time, others in this command area intercrop faba beans, lentil and karkade with other crops. In the other example; El Basawala, although water was available during the last two years, there were many problems between tenants.

3 All decisions about water management are made by the top, with no latitude for tenants. The adjustments they do make are, therefore, not officially authorized. Incasing water efficiency, an objective often discussed, does not harmonize with cultural heritage and hence people's wishes. The tenants complain there is no regularity in the water level of the canals: ,sometimes we need the water but we do not find it. In other times water flow continuously and the canal is over flooding“. In addition, they argued, there is no link between the end of the water courses and minors or drainage canals to receive the excess amounts of water. That is why the Khaffirs and the tenants drain the water in the fallow fields or the roads, which result in damaging the soil, destroying the roads and railways, and increasing the cases of malaria and bilharzia as well as water losses. The Halfawyeen have earlier experience with such system which was practiced in old Halfa ${ }^{281}$. Their suggestion in this connection was

281 This system is also practiced by the farmers in the neighbor country Egypt. The study of OAD (1994:10) in Balaqtar area (Damanhur District) has found that because of the practices of the upstream farmers, the tail escape of the Balaqtar canal is fully open and farmers have breached the canal end to the drain to prevent it from flooding their lands. 
refused by the Scheme Administration. The argument was ,this work must be done by the TFU“. The Engineers who accepted the idea said: ,there is no money“.

The questions of equity are complex and interlinked with the patterns of wealth and power in irrigation communities (CHAMBERS 1980:37) ${ }^{282}$ Water is politics, the allocation and appropriation of which are tools in the structure of power WALKER/CLEVERINGA 1989:M.XI.3/2). Complaints about pressure for irregularities in water allocation or distribution, or about intervention in the operations of the agency have been registered in many irrigation systems. UPHOFF(1991:99) in this context noticed: "something seldom written but keenly perceived by irrigation managers as a variable is the extent of interference by politicians in management activities" ${ }^{\text {" }}{ }^{283}$ Power and influence has been indirectly reported as a reason of water distribution's problems e.g., the areas outside the official scheme that receive gravity supplies (Chapter 5.3.2). In addition, the change of the cropping pattern through the permission of 1972 which allowed many tenants to grow fruits is responsible for the confusion of the rotation system and water management (Chapter 5.3.3.3).

The officials at Gendettu blamed, as well as in New Halfa, the tenants do not respect the regulations, Khaffirs, and the agriculturists, in fact. They are backed up with the absence of either law or specialized court to punish those who infringe the rules, or local social punishment system for the infringements or non-participation in collective work. Sometimes, reported many of the officials, we decide that the breaches have to pay sanction payments (fines), but they avoid it by the help of the members of the TFU or the local politicians ${ }^{284}$.

Tenants, on the other hand, have other ideas as to how problems including dispute over water could be resolved, besides strengthening the punishment system (Table 6.18). However, the concern they always raise is that their interests and suggestions are not appropriately represented even after the rehabilitation. This is a genuine concern and is considered to be the major reason for poor performance of the Schemes. Regarding the previous replies, it is logical that these ideas concentrate on improving the administration side of water management. A part from this fact, it is of great importance in this respect that many, in both schemes, reported that there is a need for samad from the tenants themselves to control the water. The TFU in Gendettu has planned to appoint eight samads from the tenants in the Season 93/94 with salaries and rewards system.

\footnotetext{
282 In general, social power is the ability of an individual or group to alter the conduct of others using the threat of sanctions to attain compliance and submission (LAYTON ET AL. 1994:292).

283 Political interference may be used, he argues, to benefit certain privileged groups or elected representatives may be looking after the legitimate needs of constituents who were ignored or victimized by the bureaucracy. It can be, possibly, responding to unsanctioned payments extracted from water users for irrigation services (commonly referred to as corruption) UPHOFF 1991:100).

284 Investigations have revealed that, in certain settlements in ISRAEL, in defiance of the control and advanced technology, up to $70 \%$ of the water used is unaccounted for (stolen) by tampering with outlets and meters. Sanctions were difficult to enforce in this situation because of the political implications. Those communities most likely to steal and mismanage water were the least prosperous, who were also likely to charge the authorities with discrimination, particularly ethnic discrimination, if threatened with reprisals. The authorities understandably prefer to avoid such confrontations (LEES 1986:613-4).
} 
Table 6.18 Suggestions from the Tenants for the Resolution of Water Problems

\begin{tabular}{|l|c|c|}
\hline \multicolumn{1}{|c|}{ Suggestion } & $\begin{array}{c}\text { \% of the Total } \\
\text { New Halfa }\end{array}$ & Gendettu \\
$\begin{array}{l}\text { Field inspector must take over his } \\
\text { tasks seriously and effectively }\end{array}$ & 32 & 57 \\
$\begin{array}{l}\text { Unitize the authorities that responsible } \\
\text { for water management in the Scheme } \\
\text { Strengthening the co-operation } \\
\text { between the water-users } \\
\text { increasing the supply of water }\end{array}$ & 15 & 17 \\
$\begin{array}{l}\text { The Khaffir must be forced to do his } \\
\text { work } \\
\text { Availability of extension services }\end{array}$ & 12 & 13 \\
Paying fines & 7 & \\
Improving the live conditions of the & 5 & \\
Khaffir & 12 & \\
\hline
\end{tabular}

Source: Own Survey

No doubt that cultural differences and different developmental experiences profoundly influence attitudes toward different forms of arbitration ${ }^{285}$. In our cases we did not find a specific person; a government servant or a local person, who perform this function. However, mention has been made of the role played in this context by the traditional tribal organization in the nomads area in New Halfa. We should also note that, as it is known in Africa, the old men in the families and the religious leaders have a considerable role ${ }^{286}$. The study reveals that 40 per cent of the sample in New Halfa discuss the irrigation and agricultural problems with the other tenants in the village's mosque. Twenty-two per cent reported weddings or death occasions as places where most tenants, particularly the influential, meet with each other. Village's club is also one of these places $(10 \%)$.

285 On the basis of comparison of fifteen irrigation systems in the Philippines, ONGKINGEO (1973) has written, „It is striking to note the satisfaction of farmers when somebody in authority, like a policeman or major, attends to water distribution problems. Under these circumstances, farmer even seen to be satisfied with reduced water supplies" (CHAMBERS 1980:39). In Sri Lanka, the arbitrator is often a government servant. TANG/OSTROM (1993:19) refer to the study of FERNEA (1970) In El Mujarilin in Irak, and reported, „an official representing the Ministry of the Interior is responsible for hearing complaints between irrigators. However, unless the dispute involves a clear infraction of the civil code, the official routinely refers the case back to the leader of the local tribe or other tribesman whom the petitioners might choose. This practice allows the traditional tribal organization to remain a viable instrument for resolving conflicts among irrigators". SHAH (1991), on the other hand, revealed the active role of the elite in Pakistan in this context.

${ }^{286}$ If the community accepts only the authority of religious or tribal leaders, then, as WEITZ (1986:167) pointed out, these leaders should be consulted and asked to endorse the development of their villages. For example, in the development projects in the Zambian copperbelt, the intervention of a tribal leader was solicited by the planners, and it later proved indispensable to the success of their development program. The author stressed also the substantial role of the authority of local leadership in the development in Israel. 


\subsubsection{Who takes over the task of irrigation?}

To put the question another way, who irrigate the field; the tenant himself (or one of the household/family) or wage labor, hired on a daily or a seasonal basis? ${ }^{287}$ This is another question in regard to water distribution between tenants which needs more attention, if one has to have a comprehensive views of the subject matter ${ }^{288}$. Traditional agriculture requires labor to be applied flexibly. There is uncertainty in labor requirements. It is also on occasion a problem for an employer to verify the number of tasks a worker accomplishes. Supervision of labor is crucial, and it involves time and resources (Transaction costs).

A daily paid labor, as BINSWANGER/ROSENZWEIG $(1986: 507,519)$ argued, has no incentive to work hard, unless supervised closely via direct observation of his effort or via inspection of his output. They add, „Whenever a worker is not the sole residual claimant of farm profits there is an incentive problem relating to worker effort. Minimizing or circumventing this problem requires resources". The resources that meant here are the supervision costs. Since household labor is easier to supervise than hired labor, tenancy involves a contract to hire not merely the labor of the tenant, but also the supervised labor of the tenant's family. Therein, as DASGUPTA (1993:229) argues, lies the subtlety of the tenancy; as an important agricultural institution.

In fact, the dependence on hired labors in the Halfawyeen area is more than this shown in Table 6.19. We believe that most Halfawyeen reacting to this question were referring to the pre-watering of wheat and not the three crops. In addition, the reply „I do irrigate myself" refers mostly to the first two watering. The quantitative data supplied by the NHIRP

Table 6.19 Distribution of Irrigation Task among Tenants and hired Labors: Percent of Tenants in the Scheme who:

\begin{tabular}{|l|c|c|c|}
\hline Scheme & $\begin{array}{c}\text { (1) do irrigate } \\
\text { themselves* }\end{array}$ & $\begin{array}{c}\text { (2) irrigate entirely } \\
\text { by hired labors }\end{array}$ & $\begin{array}{c}\text { (3) do irrigate } \\
\text { themselves and by } \\
\text { hired labors }\end{array}$ \\
\hline New Halfa & 59 & 25 & 16 \\
\hline Arab & 64 & 11 & 25 \\
\hline Halfawyeen & 55 & 36 & 9 \\
\hline Gendettu & 39 & 14 & 47 \\
\hline
\end{tabular}

* Including the participation of the family

Source: Own Survey

${ }^{287}$ For more details on systems of labor organization, see KUHNEN 1982:9-12.

288 Though the family farm is the dominant form of agricultural organization, it has been argued that the discussions of agricultural organization in economics have focused almost exclusively on other issues. The principal focus has been on sharecropping, and while incentive and monitoring issues are sometimes mentioned (along with risk aversion and imperfections in capital and other markets) family aspects of agricultural organization are ignored. The transaction cost approach draws attention to the distinction between family and non-family labor and it suggests that their behavior might differ systematically. The transaction cost approach generates interesting empirical research projects in this field because it helps to analyze the degree to which family and non-family labor are imperfect substitutes in various types of agricultural production and it helps to sort out the roles of incentives and asymmetric information. For a discussion of the transaction cost approach to families and households see POLLAK (1985). 
substantiates this view (Table 6.20). The crop for which the tenant employs migrant labor mostly is cotton, followed by groundnuts. Sharecropping is fairly common in the latter. Tenants provide only land and seeds; sharecropper provides labor and supervision from sowing until harvest. Generally speaking, the Halfawyeen involvement in agricultural operations, with regard to the three crops varies from one family to the other. In the majority of cases studied, the contribution of the tenant is limited to supervision. His actual labor input in the tenancy as a worker undertaking operations by his own hands is very negligible. He might work in two minor operations: light weeding and irrigation ${ }^{289}$. And this is the meaning of absenteeism referred to by the staff.

The same applies to the other members of the family ${ }^{290}$. Of the latter, those contributing most are sons at young age, being enrolled in schools or not (Table 6.21). The tenant forwarded one condition with regard to their participation, the farm work should not detain them from schools. Their effective contribution is then expected only when schools are closed, or after school hours. Although the support from the member of the whole family is smaller here, comparing with the Nomads area, it was very interesting to find in village 26 a very co-operative system called EL NAFEER where all the neighbors help in different operations. This system, together with the fact that only in this village - and village 33 - the participation of women is relative high, can be ground for the high performance in this village.

Table 6.20 Contribution of Family labor to total Labor Demand in Irrigation Operations (New Halfa Scheme)

\begin{tabular}{|l|c|c|c|}
\hline Crop/Watering & $\begin{array}{c}\text { Halfawyeen } \\
\%\end{array}$ & $\begin{array}{c}\text { Arabs } \\
\%\end{array}$ & $\begin{array}{c}\text { Average of all } \\
\text { Tenants \% (1) }\end{array}$ \\
Cotton & & & 40 \\
Pre-Watering & 5 & 60 & 38 \\
First Watering & 5 & 55 & 32 \\
Subsequent Watering & 5 & 45 & 45 \\
Groundnuts & 5 & 65 & 38 \\
Pre-Watering & 5 & 55 & 45 \\
First Watering & 5 & 65 & 57 \\
Subsequent Watering & 70 & 50 & 47 \\
Wheat & 60 & 40 & 57 \\
Pre-Watering & 70 & 50 & - \\
First Watering & & 100 & - \\
Subsequent watering & - & 100 & \\
Sorghum(2) & - & & \\
First Watering & & \\
Subsequent Watering & &
\end{tabular}

(1) Halfawyeen $1 / 3$ of the tenants, Arabs $2 / 3$ of the tenants.

(2) Under the assumption, only Nomads are growing Sorghum.

Source: Adapted from Tables 13,14,15, and 16 of NHIRP (NHAC: 1986 ANNEX 8)

${ }^{289}$ NHIRP has found that, of all wheat operations for which the tenant employed migrant labor, the leading one was irrigation ( $25 \%$ ) followed by land preparation $(22 \%)$ and fertilizers $(19 \%)$. Whereas for cotton and groundnuts, weeding was the leading one; $49 \%$ and 26 respectively (NHAC 1986:ANNEX 4, Table $10)$.

${ }^{290}$ Reasons of the partial participation of the families (Halfawyeen and Arab) in agricultural work are discussed in detail in NHIRP (NHAC: 1986, ANNEX 4 :32-64, and ANNEX 8:10-11,19-20). 
Table 6.21 Distribution of Family Members

Contributing their Labor to Farm Operations (\%)

\begin{tabular}{|l|r|r|r|r|r|}
\hline & Sons & Daughters & Brothers & Father & $\begin{array}{r}\text { The big } \\
\text { Family }\end{array}$ \\
New Halfa: & & & & & \\
Halfawyeen & 62 & - & 25 & - & 13 \\
Arab & 31 & $9 *$ & 31 & 15 & 15 \\
Gendettu & 57 & - & 30 & 4 & 9 \\
\hline
\end{tabular}

* This is one case for tenant from Gereges who has only two daughters both of them in primary school. They help mainly in picking.

Source: Own Survey

Despite the figures in Table 6.19, the role of the Nomads in farm operations is seen rather as a participation in production and not full involvement. The involvement of family members is limited to the head of the household; as a tenant supervising production, carrying some of the irrigation operation, and in some areas doing part of the weeding. This means, his reply here is weighted with Sorghum's operations. NHIRP (NHAC 1986:ANNEX4:39) has found that the nomads participation is more narrow than that of the Halfawyeen, since at least for the last two years of the study only two crops are produced in their area. Even for those two crops, labor availability from the family for farm operations is very much determined by three factors:

1- the level of the economic prosperity of the family. Poor families are observed to contribute more, undertaking most of the farm operations by their own hands;

2- the size of the family, since large families have more hands that can be involved in farm operations; and finally

3- the livestock wealth owned by the family, i.e. families with large herds give more priority to their animals as compared to the tenancy, especially if the number of male members in the family is limited.

The nomads employ migrant labor for wheat production, groundnuts and cotton which surpass the former two. Of all operations in which migrant labor is employed, weeding is the leading one, followed by harvesting and picking. Because of the rainfall, weeding practices in New Halfa Scheme is more than those in Gezira. Recent study in Gezira (FAKI, SALIH and KHODARY 1989:276), has registered that most farmers weeded cotton and groundnuts twice while sorghum received two weedings by a little more than half of the farmers. Moreover, groundnuts was weeded for a third time in $45 \%$ of the cases. In New Halfa, the number of weedings by crops are represented in Table 6.22.

Table 6.22 Number of Weeding by Crops in the two Areas of the Scheme

\begin{tabular}{|l|r|r|r|r|r|r|r|r|r|}
\hline Crop/Tenan. & & Halfawyeen & & & Arabs & & & & \\
No. Of. Weed. & 1 & 2 & 3 & 4 & 1 & 2 & 3 & 4 & 5 \\
\hline Cotton & - & 42 & 50 & 8 & - & 25 & 42 & 33 & - \\
G/nuts & & 17 & 58 & 25 & - & & 7 & 67 & 26 \\
Sorghum & & & & & 17 & 67 & 11 & 6 & - \\
Wheat & 69 & 33 & & & & & & & \\
\hline
\end{tabular}

Source: Own Survey 
According to NHIRP, every member contributing in the nomads families is met by three employed persons from outside the family. This ratio within the Halfawyeen was 1:6, i.e. every member contributing in the family has to be met by six from outside the family (NHAC 1986: ANNEX 4:32 and 44). As the ratio of hired to family labor increases, the price of a unit of effective labor thus increases as well.

Sixty-four per cent of the total respondents reported that they receive help from the member of the family. But this is not enough because of the above mentioned reasons and the relatively large tenancy as well. Table $\mathbf{6 . 2 3}$ gives the family labor input for the three crops (wheat is almost mechanized) within the sample.

Table 6.23 Family Labor Contribution in Farm Operations (Percentage)

\begin{tabular}{|c|c|c|c|c|}
\hline Operation & \multicolumn{3}{|c|}{ NHIRP's Results* $\quad(1985 / 86)$} & $\begin{array}{l}\text { Survey's Results } \\
(1992 / 93)\end{array}$ \\
\hline & $\mathrm{H}$ & A & Total & Total \\
\hline All Operations & - & - & - & 26 \\
\hline Land Preparation & 12 & 11 & 11 & - \\
\hline Sowing & 20 & 15 & 16 & 6 \\
\hline Irrigation & 10 & 13 & 13 & 13 \\
\hline Weeding & 40 & 29 & 31 & 22 \\
\hline Fertilizers & 6 & 9 & 8 & 6 \\
\hline Harvesting & 4 & 6 & 6 & 14 \\
\hline Picking & 7 & 16 & 14 & - \\
\hline Transportation & 1 & 1 & 1 & 4 \\
\hline Supervision & - & - & - & 9 \\
\hline
\end{tabular}

* Out of 245 cases interviewed; 184 Arabs (Nomads) and 61 cases Halfawyeen.

Source: 1985/86: NHAC 1986, ANNEX 4, Tables 9 and 12.

1992/93: Own Survey.

At Gendettu, on the other hand, the dependence on the daily paid labor is high (Table 6.19). But, the supervision at the field is also high. The cases who depend totally on the hired labor were in El Figaga ( $8 \%$ of the sample) and Gendettu ( $8 \%$ of the sample), where there is no water shortage. Generally, the tenants are trying to minimize the employing of hired labor because of the high $\operatorname{cost}^{291}$. Therefore, the majority $(85 \%)$ reported the involvement of family labor in farm operation with dominant participation from the sons. As we have already observed in New Halfa, the division of labor within the family is affected by cultural factors, e.g. attitudes towards women. The participation of the latter is hardly seen. They are expected to be industrious, but surely not in the irrigation operation. One can say that the irrigation task in both schemes seems to be a male task. Table 6.24 gives the number of man-days of labor required in all operations for each crop. It is apparent from the table that orchard, alfalfa, and onion constitute most of these requirements.

${ }^{291}$ For example, hand weeding, which absorb high percentage of the labor requirement (Table 6.21), is undertaken on all farms, though often not by the farmer or his family. To reduce the labor input, farmers allow nomads to weed their fields, for which they receive no wages but keep the weed growth, mainly nutgrass, as fodder. While this arrangement has mutual advantages, it can result in weeding being delayed to increase the volume of weed growth, thus adversely affecting crop growth (NRIRP 1986:A1/2-15). 
Table 6.24 Labor Requirement in Man-Days for each Crop (Gendettu)

\begin{tabular}{|l|c|r|r|r|r|r|r|}
\hline Operation & $\begin{array}{c}\text { Faba } \\
\text { beans }\end{array}$ & $\begin{array}{c}\text { Grain } \\
\text { sorghum }\end{array}$ & $\begin{array}{c}\text { Fodder } \\
\text { sorghu } \\
\mathrm{m}\end{array}$ & Wheat & Onion & $\begin{array}{c}\text { Orchard } \\
\text { (Citrus) }\end{array}$ & Alfalfa \\
\hline land preparatoin $^{1}$ & 12 & 10 & 8 & 13 & 20 & $12^{2}$ & 20 \\
\hline Nursery & - & - & - & - & 15 & - & - \\
\hline Planting & 1 & 1 & 1 & 1 & 15 & $-{ }^{2}$ & 1 \\
\hline Weeding & 25 & 20 & 10 & 10 & 45 & 15 & 10 \\
\hline Fertilizer & 1 & 1 & 1 & 1 & 1 & 1 & 1 \\
\hline Pest control & 1 & - & - & - & 2 & 2 & - \\
\hline Irrigation & 5 & 4 & 4 & 5 & 10 & 20 & 20 \\
\hline Harvesting & 16 & 10 & 3 & 22 & $15^{3}$ & -3 & -3 \\
\hline $\begin{array}{l}\text { Thresh, } \\
\text { Winnow, bag, }\end{array}$ & 10 & 15 & - & 13 & 20 & - & - \\
\hline Pruning & - & - & - & - & - & 10 & - \\
\hline Miscellan. & 3 & 2 & 2 & 3 & 4 & 5 & 20 \\
\hline Total Man Day & 74 & 63 & 29 & 68 & 147 & 69 & 112 \\
\hline
\end{tabular}

${ }^{1}$ Includes all inputs; hand labor, ox driving, etc.

${ }^{2}$ Covers both land preparation and planting.

${ }^{3}$ Harvesting for all crops is by hand ${ }^{292}$ and normally done by the purchase of the standing crop

Source: Adapted from Table 2.9, NAPC 1986: A1/2-18.

It is known that irrigated agriculture requires more labor per unit of land than rainfed agriculture. To assess the labor situation in the schemes, tenants were asked weather they have difficulties getting labors. The answers registered here are to a big extent similar to those previously registered by NHIRP, ${ }^{293}$ these are:

$\underline{\text { Yes }} \quad \underline{\text { No }} \quad \underline{\text { To some Extent }}$

$\begin{array}{llrr}\text { Halfawyeen } & 63 & 27 & 10 \\ \text { Arabs } & 75 & 15 & 10 \\ \text { Gendettu } & 36 & 55 & 9\end{array}$

In reply to the question why they find it difficult to get labor, the following answers were given:

- Rise in labor costs (both schemes). The cost of cotton picking, ${ }^{294}$ the common example, has increased four-fold, and those of watering have increased three-fold in this season. The operations cost of onion in Gendettu is also extremely increased.

${ }^{292}$ In New Halfa, only cotton is harvested by hand

${ }^{293}$ The distribution of the reply was: 1- in the Halfawyeens' area: $64 \%$ (Yes) and $36 \%$ (No); 2- in the Nomads' area: $77 \%$ (Yes) and $23 \%$ (No).

${ }^{294}$ It is often said that farmers will neglect their cotton, even to the extent of delaying picking or, in the extreme case, leaving their cotton unpicked, rather than neglect the food crops. This situation is almost certainly exacerbated by a shortage of labor at the critical time and frequently rises in labor wages. 
- overlapping of operations of groundnuts and cotton (by the Nomads) or groundnuts and wheat (by the Halfawyeen). Generally, cotton is the crop which is more influenced by this problem ${ }^{295}$ followed by groundnuts.

- Competition for labor with mechanized agricultural schemes in El Gadaref (New Halfa);

- The return of the Eritrean refugees to their land (New Halfa).

- This problem is more critical in autumn and winter because the migrant labor return to their region (West Sudan) to plant and harvest rain sorghum.

\subsubsection{Availability of Water and Productivity}

The question of equity are linked with questions of productivity. In addition, it is difficult to establish accurately the effect of adequate or inadequate water availability on the yield of a crop as a separate factor of its production. However, some specific measures have been used for assessing equity of water distribution, examining differentials in production or in productivity: (a) between upstream and downstream areas, (b) between head-end and tail fields served by a common canals, (c) among sub-systems within a command area. Though the shadow of doubt concerning the reliability of the production's data collected in this survey (Chapter 5.4.3), and the fact that the other inputs could be in many cases the most determinant factors, we will try to examine the effect of the location of the command area and the farm on the productivity ${ }^{296}$. Anyhow, despite the difficulties of this attempt, the close relationship between the location and the net income of the farm is more to be observed at Gendettu. The manager of the scheme mentioned, the locations of farms along the canal is the determinant factor for the economic return.

The starting point is the fact - emphasized in different places in this chapter - that most of the tenants in both Schemes are affected by water problems. They were additionally asked if they do receive sufficient water in the right time? Their reply substantiates again this picture:

Response \% Response of Farmers

Yes New Halfa 17

No

To some extent

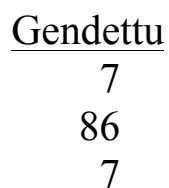

In tracing water availability in time perspective, the answers given by respondents reflect that water has become scarce during the 1980s, as could be depicted from the following figures in reply to the question: „Since when has water become problematic?“"

New Halfa: - since long time $\mathrm{e}^{297}: 58 \%$ of all answers

295 As an example for the moral hazard that face the tenant in agricultural production, one of the tenants in El Basawala, who grow large areas of wheat reported that, because of the labor shortage, he had to hire prisoners in the season $91 / 92$.

296 Recent study (ISHAG/ELOBEID 1989:241) has used Cobb-Douglas function to relate the output of each crop to the set of inputs land, labor and water in different farm locations in Gezira. Concerning the effect on the average net income per farm, the study has found that farmers at the head end of the canal obtained the largest net income followed by the farm at the middle, tail end respectively. Similarly findings have been reported from the study of FAKI (1981:356) in Gezira. He has found that beside climate, the location of farms along tertiary canals influence yields and farm-family incomes.

${ }^{297}$ Although they did not define accurate time, the impression given through the discussions tempts us to say that they mean the beginning of eighty. 
- Since the beginning of drought (1984): $23 \%$

- Since 1989: 19\%

Gendettu: reply has distributed among 1983 (62\%), about ten years back (24\%), and the beginning of eighty $(14 \%)$. After these dates, mostly all the tenants in the survey areas have dug wells to keep their plants.

Most of the tenants in villages 6, and 7 Arabs produce only two crops since ten years because of the water shortage. The area at the end of Gendettu Scheme; minors 4,5,6,7, and 8 , was totally isolated during the period 1985-90. Only after cleaning the main canal and renovating the pumps in the season 91/92 that they have got, with the exception of minor 5 , approximately $50 \%$ of their needs. The average yield should be looked at as a good measure for the success of an irrigation system (Table 25). The sample is distributed according to the location of the field water courses (Abu XXs) that serve the villages on the minors; head, middle, and tail (see the technical section 5.4.2). There was in many cases substantial difference in the yield within the same village according to the location of the field on the water course. Of note are the follows:

Table 25 Average Yield per Feddan among the Sample According to the Location of the Field (New Halfa)

\begin{tabular}{|c|c|c|c|c|c|c|c|c|}
\hline & $\begin{array}{c}\text { Cotto } \\
n\end{array}$ & $\begin{array}{l}\text { Season } \\
\text { Wheat }\end{array}$ & $\begin{array}{l}\text { 90/91 } \\
\text { Ground }\end{array}$ & Sorgh. & Cotton & $\begin{array}{l}\text { Season } \\
\text { Wheat }\end{array}$ & $\begin{array}{l}91 / 92 \\
\text { Ground }\end{array}$ & Sorgh \\
\hline $\begin{array}{l}\text { Halfawy. } \\
\text { Head end }\end{array}$ & & & & & & & & \\
\hline Village 26 & 5.4 & 0.80 & - & - & 7.2 & 1.02 & 1.80 & - \\
\hline $\begin{array}{l}\text { Basawla } \\
\text { Middle }\end{array}$ & 5.2 & 0.75 & 1.90 & - & 7.0 & 0.66 & 2.20 & - \\
\hline Village 5 & - & 0.66 & 1.38 & - & - & 0.62 & 1.38 & 0.30 \\
\hline $\begin{array}{l}\text { Village } 11 \\
\text { Tail end }\end{array}$ & 3.6 & 0.40 & 0.72 & - & - & 0.76 & 1.20 & 0.16 \\
\hline$\overline{\text { Village } 24}$ & - & 0.60 & 1.46 & - & - & 0.76 & 1.60 & \\
\hline $\begin{array}{l}\text { Village } 13 \\
\text { Arab } \\
\text { Head end }\end{array}$ & - & 0.52 & 1.10 & - & - & 0.58 & 1.70 & - \\
\hline $\begin{array}{l}\text { Arab 5 } \\
\text { Middle }\end{array}$ & 5.2 & 0.70 & 1.38 & - & 5.2 & 0.76 & 1.72 & 0.56 \\
\hline $\begin{array}{l}\overline{\text { Gereges }} \\
\text { Tail end }\end{array}$ & 5.8 & - & 0.96 & 0.56 & 7.0 & - & 0.90 & 0.40 \\
\hline Sidira & 4.0 & - & - & 0.32 & 6.2 & - & - & 0.66 \\
\hline Arab 6-7 & 4.0 & - & - & 0.32 & 3.6 & & 1.32 & 0.44 \\
\hline Scheme & 4.0 & 0.41 & 0.54 & 0.45 & 4.67 & 0.70 & 0.80 & 0.60 \\
\hline
\end{tabular}

* Cotton yield is measured in kontar/feddan; wheat, groundnuts and sorghum are measured in tonne/feddan. Feddan (fd.) $=4200 \mathrm{~m}^{2}=0.24$ ha.; Kantar (knt.) $=315 \mathrm{Ibs}=141.75 \mathrm{~kg}$; Tonne (t.) $=1000 \mathrm{~kg}$.

Source: 1- The average yields of the villages: Own investigations

2- The average yields of the Scheme: NHAC 
- Generally, the average yield in the season 91/92 is higher than 90/91.

- It is clear that the Halfawyeen are not interested in cultivating cotton. Only those at the head end are willing to grow it, with the exception of two cases from village 11. Anyway the performance of the village 26 and Basawla is taken as model in the Scheme. The productivity of cotton is still lower than in Gezira and Rahad. It is proposed that, with proper water control, medium- and long-stable cotton should achieve $6 \mathrm{kantar} / \mathrm{feddan}$ to $7 \mathrm{kantar} / \mathrm{feddan}$ (the former can achieve $18 \mathrm{kantar} / \mathrm{feddan}$ under optimum conditions). The total cotton cultivated area in the Scheme has decreased from 108025 fed. in 1971/72 to 57735 fed. in 1981/82 and reached 41055 fed. in 1991/92.

- Wheat, the traditionally stable food for the Halfawyeen, has witnessed similar trend. Causes of the low productivity of this crop are the increasing of the costs of production and the financing bottlenecks. The Agricultural Research Corporation (ARC) indicates that tests have shown that yield could reach $2500 \mathrm{~kg} /$ feddan (about $6 \mathrm{t} / \mathrm{ha}$ ) and field trails have produced yields of $1700 \mathrm{~kg} /$ feddan $(4 \mathrm{t} / \mathrm{ha}$ ) with a full package of inputs, including full irrigation. The current low yields are, they view, attributed almost entirely to water deficiencies (Ministry of Irrigation 1992:G-11). Ministry of Irrigation come consequently to the assumption that yields of $1000 \mathrm{~kg} / \mathrm{feddan}(2.3 \mathrm{t} / \mathrm{ha})$ could be considered normal. Furthermore, the area has decreased from 84000 fed. in 90/91 to 63 553 fed in 91/92 and reached $57000 \mathrm{fed}$. in 92/93 (in addition to $3000 \mathrm{fed}$. cultivated by the co-operative sector). ${ }^{298}$

- The effect of water stress on the wheat growth and its yield depends critically on crop species as well as the magnitude and time of water deficit. However, it should be stated that most farmers were reluctant to give their actual production figures for wheat yield. Such trend has been also registered in Gezira (HAMAD 1989:118). They would like to keep some of it for themselves than to hand it over to the government officials under the salam system (chapter 5.6.3). That is why the difference in productivity can be hardly seen. For example, the Basawla; the most famous farmers in the Sudan concerning wheat production, where productivity of $1.5 \mathrm{t} / \mathrm{fed}$. is normal, gave figures lower than the tenants at the tail end ${ }^{299}$.

- Although the tenants of nomadic origin were also cautious about the figures of their staple food crop i.e. sorghum (most replies are under the average yield of the Scheme), one can speak here about direct relation between the location and yield. The case of sidira was not an exception but, on the contrary, indicates the difference in productivity between upstream and downstream. Sidira is the tail end of the Block Alledaj where all villages are at the beginning of the minors. Whereas, Arab 5 belongs to a Block ( $A b u$ Nagma) where water shortage is generally substantial and suffer at the same time from the problem of unleveled fields. The reason for the low productivity of dura (sorghum) as the tenants argued was the bad quality of the seeds recommended from the Scheme.

298 The manager of the New Halfa Agricultural Research Center reported that in the season 92/93 many tenants were not able to purchase three sacks seeds to grow wheat because of the unavailability of finance. That is why the NHAPC give the rest of wheat area (3000 feddan), for the first time, to the New Halfa cooperative Union's Flour Mill.

299 A more recent study which examines the aggregate behavior of farmers in Sudan in response to government wheat policies, is SALIH (1993). The study shows that the farmers, as a consequence of the compulsory procurement of a fraction of their produce, underreport wheat production. The analysis indicates that wheat production is also responsive to changes in the government policy. A 1 per cent increase in the delivery requirement depresses wheat production by more than a full percentage point. 
For comparison, the average yield in Rahad Scheme, at the beginning of the decade, was $1000 \mathrm{~kg} /$ feddan.

- Despite the remarkable fluctuations in yields, groundnuts stay the most profitable crop in the scheme. This result tie well with the data and analysis stated before (Tables 6.1114). The other reason, beside profitability, might be the activity of the sharecroppers (mainly the migrant labors), specially within the Halfawyeen areas.

- Disparities in productivity within fields sharing water course have been also registered specially in the areas of water shortage. Examples of the difference between head end/tail end fields on the water course come from villages 13 and 24 Halfawyeen and villages Arab 6 and Sidira in the Arabs area. These differences were as follows (Table 6.26):

Table 6.26: Disparities in Yield within Water Course in New Halfa

\begin{tabular}{|l|l|l|l|l|l|l|l|l|}
\hline & \multicolumn{2}{|c|}{$\begin{array}{l}\text { Cotton } \\
\text { Head }\end{array}$} & \multicolumn{2}{l|}{$\begin{array}{l}\text { Wheat } \\
\text { Teail }\end{array}$} & \multicolumn{2}{l|}{$\begin{array}{l}\text { Groundn. } \\
\text { Head }\end{array}$} & \multicolumn{2}{l|}{ Sorg. } \\
Head & Tail \\
\hline & & & & & & & & \\
Vill. 13 & - & - & 0.80 & 0.34 & 2.08 & 0.12 & - & - \\
Vill. 24 & - & - & 1.04 & 0.74 & 2.20 & 1.10 & - & - \\
Arab & 8.6 & 3.0 & - & - & 2.50 & 1.60 & 0.84 & 0.32 \\
Sidira & - & - & - & - & - & - & 0.48 & 0.18 \\
\hline
\end{tabular}

Source: Own Survey

At Gendettu, Table 6.27 shows the difference in yields for the major crops between downstream areas( minors $4,5,6$ ), and upstream area; Gender, as well as reveals the wide disparity between the performance of the Scheme and a small private Scheme on the Nile as an example of the type of irrigation management in the area. Ibriqu is a farmer who uses his own pump set $(4 \text { inches })^{300}$ to irrigate his own land ( 6 feddan) and other three feddan belongs to three farmers; one for each. At the beginning of the season, the four participants store the whole requirements of fuel and oil. Water is distributed through main channel and 5-6 lateral water courses; each is able to serve two participants. An operator is responsible for the management of the pump set as well as water distribution between the farmers. Everybody knows the date of his turn and there is no problem in relation to water distribution.

Table 6.27 Average Yield for the two Major Crops in some Sections of Gendettu Scheme Comparing with Private Scheme in the Area (Tonnes/feddan)

\begin{tabular}{|l|l|l|c|c|}
\hline Section & Faba Beans & & Onion & \\
& $90 / 91$ & $91 / 92$ & $90 / 91$ & $91 / 92$ \\
Minor 4 & 1.00 & 1.00 & 10.00 & - \\
Minor 5 & 0.60 & 0.92 & 8.40 & 8.00 \\
Minor 6 & 1.00 & 0.80 & - & 8.00 \\
Gendettu & 1.00 & 1.10 & - & 12.50 \\
Private Scheme (Ibriqu) & - & 1.40 & - & 18.00 \\
\hline
\end{tabular}

Source: Own Survey

300 The capacity of this pump set is enough to irrigate 19 feddan per rotation. Participation with other farmers will therefore reduce the operation costs; fuel; oil, and operators. 
Productivity in gendettu section ${ }^{301}$, in particular onion, was higher than the downstream sections. The reason for the low productivity of onion in the season 91/92, as the tenants reported, was the breakdown of the pumps. The breakdown was decided by the scheme management as a punishment for the tenants because they did not pay the water fees of the previous season. However, the productivity in the private scheme, which reach to 2 tonne per feddan shows the importance of the stability and reliability of irrigation water.

\subsection{Communication Systems}

To emphasize this point a quote by STIGLITZ (1989:27) is appropriate: ,...models focusing on fully informed rational peasants working within 'rational' and efficient institutions are likely to be not only inadequate, but seriously misleading, just as models that simply hypothesize that peasants are rule (tradition)-bound, irrational, and noneconomic are almost certainly misleading“. „Peasants are rational, but they are not fully informed. And imperfect information (as well as a variety of transaction costs), besides limiting the effective degree of competition, creates institutional rigidities, allowing the persistence of seemingly inefficient institutions".

\subsubsection{The Relationship between Tenants and Project's Management}

For whom work the irrigation bureaucracies in the developing countries? Are there reflections of the interests of the central elites oriented towards the urban areas? (MANIG 1989:23), or dependent organizations work for the interests of the international market? (TETZLAFF 1979:356). For many decades, it has been firmly believed that the underlying conditions of poverty and unemployment can be remedied only through the balanced operation of private initiative and government intervention (WEITZ 1986, SINGH 1986). An „optimal mix“ of these two driving forces is critical to successful economic growth. Efforts have been made in most countries to establish a different relationship between the bureaucracy and the public, e.g. designating the civil services as the 'public Service'. However, recriminations, especially in ex-colonial countries, have been heared that the bureaucrats are not civil servants but civil masters (UPHOFF 1991). To the extent that there is a pervasive tradition of civil service autonomy in a country, government irrigation agencies will be more aloof and powerful vis-à-vis water users.

MAKADHO (1994:38) argues that, what is common in many African countries is that farmers are not given the chance to make management decisions in 'their' irrigation Schemes. He further points out that the management style in use makes it difficult for farmer to have say in the day to day activities of their schemes. Another study of FAO (Ng' Ong' Ola 1993) refers to a similar findings from the work of Kagubila (1992) in Tanzania: „Irrigation schemes are employment 'Offices' for government irrigation technicians and agricultural field officers". THORNTON/WYAN (1987:230) found also that Sudan is not exception to this rule. They pointed out: „perhaps the greatest weakness in the development of this agriculture (New Halfa) has been the failure to recognize the crucial role of the individual farmer. Their individual attitudes, aspirations, training, etc. " The information furnished by the survey and analyzed below reveals the dichotomy of the operational objectives of the Schemes' authorities and the private beneficiaries.

301 This is one section in the scheme and has the same name (see the sample distribution of Gendettu Scheme in Chapter 5. 


\subsubsection{Production Relationship and the 'Government Crop'.}

The failure of NHAPC and/or the government to deliver physical inputs; finance and services, has meant that what was conceived of as a mutually-beneficial partnership in cotton has deteriorated to a state of confrontation between tenants and corporation over the 'government crop'. Partnership has been replaced, as the rehabilitation study pointed out, by alienation and hostility on the part of the tenant, and demoralization on the part of a significant number of corporation personnel (NHAC 1986:ANNEX 7:7). As we have already noted in the last chapters, tenants are accused of absenteeism, laziness and malfeasance; schemes staff of dishonest, diversion of public resources to private ends, and of a destructively authoritarian attitude towards the tenants. The rhetoric of partners has become, concluded the rehabilitation study, the reality of adversaries, and the language of sanctions replaced that of incentives.

What is new in this study is the prove that this reality, that has formed the context in which management institutions had been functioning during the initiative of rehabilitation of the Schemes, is still dominant, despite the rehabilitation and the changing of production relationship. The first action (rehabilitation) is not in a position to induce effective institutional change. And the later, which is a consequence of the rehabilitation, was not enough by itself to solve these problems. This result has been observed in many cases (MOROOKA/HAYAMI 1989, PLACE/HAZELL 1993). ${ }^{302}$ The most important factor is not the type of contract but the attitude of tenant towards the crop; the profitability that can be gained from and, above all, the institutional context in which it grow. Anyway, the essence of the problem is to identify those factors that are:

- the failure of the Scheme administration to undertake their tasks;

- the absence of participation whether inside the bureaucracy or the Scheme;

- the ambiguity of the purpose of the organization; whether it is conceived of as purely a production enterprise or as the leading partner in a resettlement Scheme;

- the ambiguity of the nature of „Hawasha“. The absence of enforceable contract defining adequately and precisely the Corporation's and the tenant's responsibilities. Specific to New Halfa is the fact that 'tenancy rights' in the Scheme were granted as compensation for exporiated land-use/ownership rights ${ }^{303}$.

- No payment is received at the time of delivery of the tenant's cotton production, nor does he receive accrued interest on its value for the (sometimes) several years during which that value remains unpaid.

Evidently, if our informants were correct, the relation between tenant and the Corporation was not in any time a partnership but, as accurately described, a paternalist-dependent, or patron-client.

\footnotetext{
302 In addition to the result registered by SALEEM (1989:40) in Gezira and Rahad (Chapter 5.3.4), the study of MOROOKA and HAYAMI in Upland Java results in: „no significance inefficiency in resource allocation was found to be associated with share tenancy as compared with owner cultivation and fixedrent tenancy“. Similarly, based on household survey data from Ghana, Kenya, and Rwanda, with few exceptions, land rights were not found to be a significant factor in determining whether or not farmers made land-improving investment or used yield-enhancing inputs (PLACE/HAZELL 1993:16-9).

303 The issue of compensation for the two groups is discussed in NHAC 1986:ANNEX 7 and 8.
} 


\subsubsection{Farmers' Views on the Formal Channels of Articulation}

Here emerge again the word 'absenteeism'. In an attempt to trace the question of contact between tenants and field staff, only $4 \%$ of the respondents in New Halfa reported seeing the agriculturist or the Block Inspector regularly. The others reported:

- I did not saw him

- I saw him

- only one visit at the beginning of the season

- I don't remember

- the last season

$$
\begin{aligned}
& 29 \% \\
& 25 \% \\
& 19 \% \\
& 11 \% \\
& 12 \%
\end{aligned}
$$

Tenants who 'saw' the inspector followed their replies by comment: „only when we go to him in his office“. And those who saw him at the field confirmed: „only in the cotton's field". One of the key tenants (Halfawyeen) who manage 13 tenancies, and work at the same time in NHAPC, ${ }^{304}$ reported: ,in the sixties and seventies the inspector was seen always at the field whereas the tenant was absent, it is exactly the reverse now ${ }^{6305}$. Similarly at Gendettu, $56 \%$ of the respondents do not see the agriculturist at the field, 27 $\%$ reported rarely, whereas $27 \%$ see him regularly. As in New Halfa, the last category maintained: ,in his office“.

Tenant was asked: how many times did you talk to the extensionists during this season about farming problems?, and to what extent do you feel that the extension officers have helped to solve your problems within non-cotton crops in the last years? The reply of many was ,smile“. In New Halfa $69 \%$ of the respondents reported that they are not visited at all. The only connection with the Corporation, reported many of them, is a daily 10 minutes TV program. The others who are visited represent $31 \%$. This figure is, in our opinion, overestimated.

New Halfa Scheme has 29 extensionist. Theoretically, they are distributed among Blocks; one for each (Fig. 5.7). Every extensionist is responsible for 1200 tenants grouped in four equal groups ${ }^{306}$. Four days of the week are allotted for regular and scheduled field visits to each area and farmers group. The other two days are devoted to on farm trials. The contacted farmers are approximately $5 \%$ of the tenants as estimated by the manager of the agricultural extension department. In addition to the farm visits, he has to organize a general meeting in every village (in the evenings) to transmit extension messages and discuss the problems, as well as participating in the Block Agricultural Committee. The type of farmers in the Scheme needs an intensive extension work than in any other large scheme in Sudan. Thereby, these tasks must be fully and accurately implemented.

In the reality, the extensionests, just like the horticultural and plant protection inspectors, are not in contact with the farmers in the farm, but works in the central department in New Halfa. The reasons for this situation, according to the manager of the department, are:

\footnotetext{
${ }^{304}$ The manager assistant of the Plant Protection Department.

${ }^{305}$ For a succinct historical review of the work behavior of the field staff in the Sudanese large irrigation schemes, see BARNETT (1977), Chapter 9.

306 The 1200 tenants are approximately distributed among 5-6 villages.
} 
- The Corporation is not in a position to 'finance' agricultural inspector and field inspector (extensionist) in each Block. That is why the agricultural inspector takes over both the managerial and the extension tasks and often the agriculturists prefer the former (inputs and loan distribution, harvesting, etc.).

- The main problem facing extension programs is lack of mobility. All vehicles provided by the World Bank (6) for the T\&V program have been taken and used by the Scheme's Administration (for non-extension purposes) and often by the politicians in the region.

- The importance of this department is not recognized from the Management of the Scheme.

- Field extensionists training is not adequate. Instead of every two weeks, according to the $\mathrm{T} \& \mathrm{~V}$ program, ${ }^{307}$ training is every month. In addition, there is no agricultural extension divisions in the Sudanese Agriculture Faculties, and the national extension division in the central ministry is not qualified to take over training tasks.

- There is no co-ordination with the other departments in the Scheme in addition to weak linkage with the research center.

Within the framework of the planned Agricultural Research Extension and Training Project (ARETP) ${ }^{308}$, IDA has recommended some modification to convert the extension system to $\mathrm{T} \& \mathrm{~V}$ approach. These modification deals with the following positions:

1. Assistant Block Inspector to be assigned full responsibility to deal with all managerial matter concerning inputs and loan distribution with the assistance and help of production committees.

2. Field Inspectors to reform their field visits to be educational rather than inspectorial.

3. Agricultural Manager, Field Manager, Section Manager and Block Inspector to pay regular visits to the field for supervising this educational approach.

4. Extension Department to lead a regular training for field inspectors on technical agricultural matters and extension methods.

5. A strong linkage with research to be created through monthly workshops, on farm trials and a joint technical committee field oriented visits.

${ }^{307}$ It is a management tool which helps to ensure the extension operations effectively and also enable the management to take corrective measure on the shortfalls in the extension approach. The T \& V system of extension has been introduced in the New Halfa Scheme in 1986, with a view to transforming the technology of improved cultivation to farmers and improving their productivity. This system which has included changes in job discretion was not welcomed by NHAC. Resistance for such approach continued for 6 succession seasons until 91/92. It was not confined for the system and its approach but extended to enforcement in using the existing and the new project extension facilities in non extension and even political assignments. This attitude of NHAPC management delayed the effective establishment of the system at field level. This resulted in not being able to add more blocks to T\&V system. The T\&V blocks not exceeded 6 blocks out of 19 blocks for 6 seasons. on the other hand this system is very successful in Rahad Scheme.

${ }^{308}$ One of the main objectives of ARETP was initiation and introduction of T\&V approach at NHAC on the following basis:

1. The one line of command which features the field department fits one of the management principles of T\&V system.

2. Assignment of specific certain area, to the field inspector, although to a great extent for physical inspection is a second factor to this approach.

3. The field oriented visits although not regular nor scheduled can suit T\&V approach. 
In the light of the NHAC resistance for this approach, there was no alternative for IDA missions in proposing an amendment in extension organization. This alteration concentrated on assuagement of one or more full extension worker at each block with no inspectorial responsibilities. These extension workers should be under direct control of Extension Department. The extensionists should be at least provided with the project vehicles already allotted to non extension work. This proposal when put under actual implementation for three seasons (89/90,90/91and 91/92) had increasing negative outputs. This was mainly, as the inspectors reported, due to the deterioration of the project vehicle which lacked spare parts. To overcome this problem in the season 92/93 the Corporation has decided the following:

1. The designated extensionist should be responsible for one canal, an average of 400 farmers, which compress his total close supervision area.

2. Two fields of 36 tenancies should be selected as contact farmers for regular weekly visits to adopt the main production recommendations.

3. Two tenancies should be selected to follow complete packages of recommendation to serve as a result demonstration for conducting result demonstration meetings.

The extensionist should be supervised by Senior Block Inspector. The activity of extension at the three blocks should be monitored by the section managers. A weekly report has to be submitted from each extensionist to senior block inspector and section manager who in turn forward to extension department for discussion at the weekly section managers meetings with the agricultural manager. Also this plane was not implemented in the season 92/93 because of the same constraints.

Because the NAPC has no own support services, the situation in Gendettu is worse ${ }^{309}$. All of the respondents, except two, reported that there had been any type of communication with the extensionist, horticulturist, or the plant protection inspector in the region, nor that this situation had changed. „Thy are no longer field workers, they became officials“ said the tenants. In addition, there was sometimes contradiction in relation to information received from extension ${ }^{310}$.

Regarding the above discussion, a point here that is of particular relevance is that from whom or through which media gets the farmer the messages, information, and the recommendations of the Scheme's Administration? In New Halfa Scheme, the main source of these information, if at all as many stressed, are:

- the representatives of the Agricultural Village Committees in the Block Committees $(68 \%)$;

- there are no messages $(16 \%)$;

- block office (12\%);

- other farmers $(2 \%)$; and

- television $(2 \%)$.

309 The Gendettu farmers are served by the Shendi offices of the Department of Agriculture; Plant Protection Department, and the Horticultural Department.

${ }^{310}$ For example, the extension service recommended 6 sacks urea per feddan, whereas the Corporation, which was responsible for the supply in that time, had given only two. In addition, the garden needs 10 sacks urea and 10 sacks phosphate and most of the tenants, because of the high costs, use only the former. 
At Gendettu, only eleven respondents have answered this question. All of them but one have thought of water fees, that is why they reported the khaffir ${ }^{311}$. This means that the cost of accurate information, that are relevant to irrigation management, are relatively high.

Tenants have few formal channels to articulate their interests and grievances to officials. The answers given in New Halfa to the question: „,who could help you when there is a problem between you and the Corporation?" validate the above analysis. Given in percentage of respondents supplying each, these are:

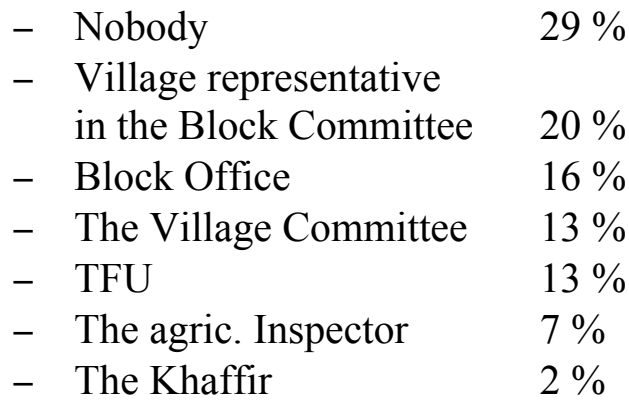

Although in theory, local-level production committees (discussed below) of agricultural inspectors and tenants exist to resolve disputes over corporation or tenant performance, these committees are heavily weighted in favor of the former.

\subsubsection{Tenant Farmers Union (TFU)}

TFU is, theoretically, the middle-level organization which should links between irrigators and central irrigation system.

\subsubsection{Initiation}

Initially, TFU in New Halfa had its start as a purely Halfawyeen institution, known as the „Village Committees" to cater for the rights of the Halfawyeen during the resettlement phases $^{312}$. In 1968 the second stage in its development commenced, with the TFU established, representing both the Halfawyeen and Nomads. The membership of the TFU is mandatory, hence every tenant is a member of the TFU and 'subscription' are annually

311 In recent study in the Guiurat (India), it was found that about 70 percent of the farmers reported that they did not usually receive information about the closure of systems for maintenance and repairs, or even opining dates. In a similar study in Pakistan, it was found that over 83 percent of 389 farmers did not know the published date for canal closures.

312 The main achievement of the Village Committee could be briefly summarized as follows (NHAC 1986:ANNEX 5):

- the approval by the authorities to give the tenant free water for wheat irrigation;

- the establishment of ginning factories within the New Halfa Scheme Area;

- organizing and supervising the marketing of wheat. The idea of the Co-operative Union Flour-mill had its roots during that period;

- contribution to the advancement of the co-operative movement substantially, through encouragement and enlightenment, and

- as a result of their negotiations with the Government, a general secondary school, and a high secondary school were opened at new Halfa Town 
deducted from them. The TFU does not include settled migrant laborers in the Scheme, nor owners of amlak land unattached to tenancies.

TFU in Gendettu, on the other hand, is the oldest farmers Union in the Sudan; established in 1946. The tenants struggled for the establishment of the TFU which replaced the system of sheiks and samads who worked under the supervision, and represented the interests, of the colonial government in that time. After the independence, the role of the TFU stayed a representative body of the tenant looking after their interests and defending their rights before the Scheme.

\subsubsection{Objectives}

The main objectives to be served by the TFU are:

- Ensuring the participation and contribution of the tenant at a wider level in the management of the Scheme through effective representation in the Directing Board, and the section and Block Committees.

- Representation of the tenant in all other spheres outside the field of agricultural production.

- Expressing the tenants' view through forwarding recommendations when necessary to the management in all that advances the tenants' benefits.

- Fostering the relationship between the tenant and the management through resolving the conflicts arising between the two; and also between the tenant and the other bodies which he encounters.

- Maximization of production through cutting down costs and raising productivity by introducing more mechanization, improved technologies, and application of proper scientific methods.

- Promotion and support of the co-operative movement in all spheres of development.

- Adoption of policies that maximize the returns to the tenant from agricultural production.

- Improvement the livestock situation in the Scheme.

- Expansion of the agro-industrial base.

How far the TFU approximates the above objectives as judged by the staff and tenants is considered below.

\subsubsection{The Organizational Set Up of the TFUs}

Structurally, TFU in New Halfa has a well-developed hierarchy of bodies and committees ranging from the grassroots upwards: the Village Committees, the Block Committees, the Section Committees, the General Assembly, the Central Committee, and the Executive Office. All of these bodies are theoretically elected once every four years ${ }^{313}$. The TFU is represented by two members in the directing Board. For the purpose of this study we will concentrate on the first three Committees.

313 After the coup d'etat in 1988, the military rulers has canceled all Unions in the Sudan and appointed new members instead those who are against their polices. In New Halfa, only two elected village representatives have stayed in their position. 


\section{a. The Village Committee}

It is the nucleus of the whole TFU body. Every village is considered as a constituency if it has 100 tenant farmers, who are represented by a committee of five representatives 'elected' by the tenants in the village. Since many villages have more than 100 tenants, every additional 100 to basic one is represented by three. Therefore, the members range between 5 and 11. The Village Committee presently has the main task of linking the village to the Block NHAPC staff, in all issues related to agricultural production i.e. agricultural operations, loans, and livestock control. The Committee is able to ultimately (though rarely) withhold water or evict. Every 100 tenants are represented by one in the general assembly (Fig. 6.1).

Figure 6.1 The Relationship between TFU and NHAC

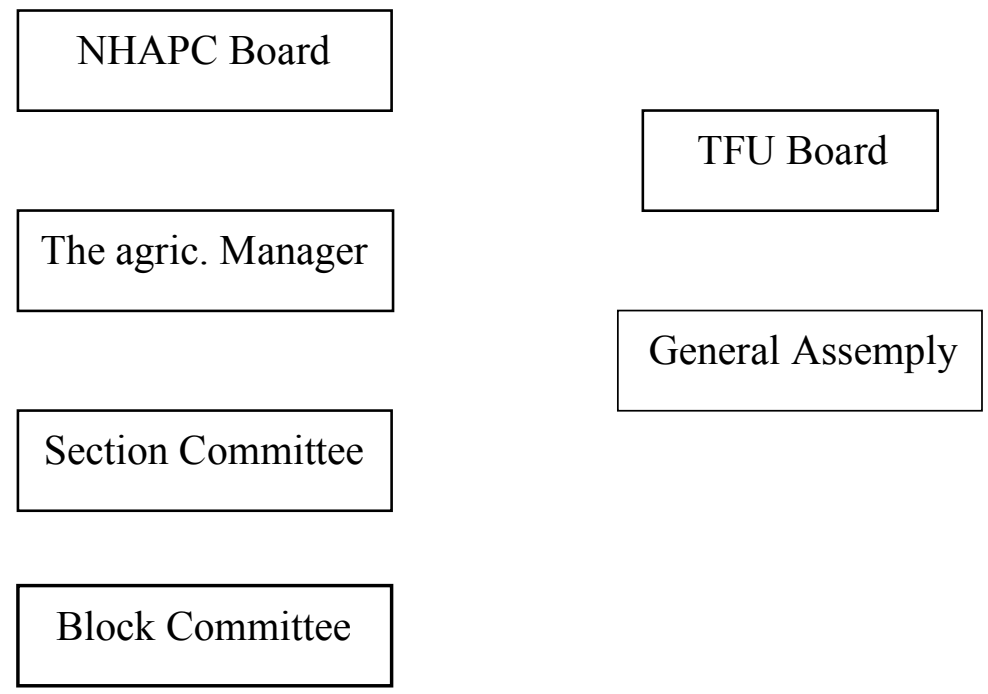

\section{b. The Block Committee}

Each village is represented in the Block Committee by 'elected' member(s) from among the Village Committee. The number varies from one village to the other. The Block Committee performs at the level of the Block, representing the interest of the tenants before the Block staff, co-operating with the latter and disseminating information from the block to the tenant through the village committees, in all issues related to agricultural production. This is done through meetings held weekly between the staff and the Committees. Based on the organizational rules which govern the performance of the Committees, Block Committee members should be present in all meetings, unless formally permitted to absent themselves. A Committee can decide on the dismissal and replacement of a member who does not abide by the above rule.

\section{c. The Section Committee}

Each Block is represented in the Section Committee by one member elected by the Block Committee from among its members. The member should attend all meetings held at the Section level and he should convey to his Block all the decisions passed. Meetings of the Section Committee are held once every month and are chaired by the manager of the Section. Decisions are passed by absolute majority. 
The dissemination of information on the proposed new Extension Service, recommended by the rehabilitation study, should be carried out by TFU Committees (NHAC 1986:ANNEX:7).

The TFU in Gendettu consists also of different bodies to maintain two way communication between the grassroots bodies and the leadership of the Union at the apex of the hierarchy. The TFU is geographically spread over 15 circle covering all the Scheme. The distribution of circles are based upon the position of fields, not the residence areas. Each circle elect one representative in the Executive Committee (15 members). The representative appoints 5 members and constitute with them the branched Committee in this circle (called also as Six-Committee $)^{314}$. Similar to the Village Committee in New Halfa, the branched Committee is then the basic unit from which the organizational structure of the TFU builds up. It links between the tenants and Executive Committee and has to play role in collecting water fees. The 90 members of the branched Committees constitute the General Assembly which formulates the general policy of the TFU and elects the Executive Office; the Chairman and his deputy; the Secretary General and the Treasurer. The TFU also, like the others, is represented in the directing Board. (According to the new order of 92/93; the devolution of responsibility into tenants hands, the TFU should dominate the Board of Directors; represented by 9 members from 15, and the president of the TFU should be the chairman of the Board.)

The representation in the directing Board is not the sole communication means with the Management. In addition, the TFU was represented in the Production Committees; four members from the TFU and the same from the Scheme Management.

\subsubsection{Performance and Role in Scheme Management}

The formal representation at Section and Block to cater for the tenants' interest and coordinate activities with the management in specific tasks e.g. the running of agricultural production Committees, is reported by tenants to be defective ${ }^{315}$. Of the main reasons is the apparent lack of involvement of the TFU Committees members at Section and Block level. This is partly attributed to the non-awareness of the Committee members of their rights and roles in these joint Committees. Survey findings indicate that about 29 per cent of the representatives at Section and Block levels are illiterate; with the figure even higher (44 per cent) in the Nomads area (NHAC 1986:ANNEX 5:19). Furthermore the relationship

\footnotetext{
${ }^{314}$ The idea of the branched Committee is one result of the revolution of April 1985 (Entifada).

315 Such committees are similar to those proposed by UPHOFF in Sri Lanka (1989). He recommended a revised M\&E program applying the principle of specificity to improving management in major irrigation systems in that country. It proposed to operate in a participatory manner, incorporating 'management by objectives' principles, with water user associations making inputs at three levels, helping to set goals, formulate plans of action, and monitor and evaluate performance. On a seasonal basis, distributary channel organizations made up of farmer-representatives from each field channel within the command area, working together with field-level officials from the irrigation and other government departments, are to review past performance of that area in terms of efficiency, productivity, and profitability. The task of these committees is to formulate specific plans_to deal with the priority constraints. Distributary command area plans are forwarded to a joint farmer-official project-level committee, which integrates them into an overall plan for the project (UPHOFF 1991:211-12).
} 
between the tenants' representatives and the inspectors at Block and Section levels which lacks harmony is often weak and strained. The major causes no doubt being mutual hostility and the generalized air of pessimism which imbues the Scheme. The rehabilitation study described such relationship as a "superiority/inferiority gap“ which hinders cooperation between the two groups. Therefore, it comes to the conclusion that the representatives become reluctant to participate effectively in the activities of these Committees.

Except for the agricultural operations that occasionally bring committee members at village, block and Section levels together with the NHAC staff operating at the same levels, the TFU has no activities directly concerned with the tenants. As such, the tenants have expressed their dissatisfaction with the present performance of the TFU. This dissatisfaction is more observed by the Halfawyeen.

The tenant considers that the TFU would be more effective if it undertook other roles in the area of agricultural production and social development, not only representing the tenants before the NHAPC. The rehabilitation Study has therefore suggested that the perception of the role of the TFU has to be improved through training programs for the TFU Committees at village, block, and section levels. As well as, it has recommended that two branchoffices of the TFU be established: one at El Sabaat and the other at Debaira to bring the TFU leadership close to the tenant (NHAC 1986:ANNEX 5:2).

Our field study indicates that all recommendations in this context, like most of the others, are 'dead letters' more or less. Moreover, the situation after 1989 becomes worse. For the first time in this survey, come both tenants and the staff to agreement on a question. The TFU leadership (the Executive Office) has clearly failed to give satisfaction either to the tenants it represents or the officials in the agricultural Sector including NHAC Board of which it is a member. To reach a definite opinion on this issue, both groups were asked to state whether they believe that the TFU play an important role in resolving the problems of the tenants and improving the performance of the Scheme. The answers received are presented in Table 6.28.

Table 6.28 The Attitude Toward TFU in both Schemes

\begin{tabular}{|l|c|c||c|c|}
\hline & Tenants & New Halfa & & Gendettu \\
& & 5 & 26 & 20 \\
Yes & 10 & 76 & 56 & 70 \\
No & 63 & 19 & 18 & 10 \\
To Some Extent & 27 & $100 \%$ & $100 \%$ & $100 \%$ \\
Total & $100 \%$ & &
\end{tabular}

Source: Own Survey

The attitude towards the TFU is generally negative in both schemes and more extreme in New Halfa. No contacted respondent within the Halfawyeen reported „Yes“. The relative high percentage of those who reported „to some extent" comes from the Arabs area, 
specially from Sidira area where the president of the TFU comes from ${ }^{316}$. Both groups were asked to define the reasons of such attitude. For the tenants, the proportion of responses are summarised in Table 6.29.

Table 6.29 Reasons of Tenants' Dissatisfaction with TFU

\begin{tabular}{|l|cc|}
\hline Reasons of the Dissatisfaction & \% of the total answers & \\
& New Halfa & Gendettu \\
\hline 1- dissociate from the farmers & 36 & 10 \\
2- 'weak' & 16 & 30 \\
3- concentrate on their private interests & 10 & 20 \\
4- 'politicized' & 10 & 10 \\
5- the communal composition of the TFU & 8 & - \\
6- they are not farmers & 8 & - \\
7- lack of co-operation and liaison with NHAC & 2 & 5 \\
8- unjustified & 10 & 25 \\
Total & 100 & 100 \\
\hline
\end{tabular}

Source: Own Survey

The basic reason behind the dissatisfaction mentioned by the tenants in New Halfa reflects the social and economic gap that separates them from the leadership of the TFU (reply 1, 3 , and 6). The tenants in Gendettu mentioned age and poor education level (under the term weakness) as the main factor that contribute to the ineffectiveness of the TFU ${ }^{317}$. Whereas this term in New Halfa refers to the composition of the TFU. Many tenants claim that some of the tenants' leadership and representatives have developed personal relations with the staff that create private interest to the exclusion of benefit to all. Specially in New Halfa, it is believed that the TFU tends to operate more at its leadership level than at the tenants' level ${ }^{318}$. To the questions investigating who have benefited from the services of the TFU?, the answers received were: the leadership itself: 47 per cent; relatives and friends of the leadership: 21 per cent; do not know: 20 per cent, all the tenants: 12 per cent.

Not only economically, but also the TFUs are politically pressed to become 'clients subordinate' to the Scheme Management. Most of the TFU Boards are appointed from, and working for, the political system; just like the situation in the colonial era. In addition, the composition of the TFU in New Halfa reflect the social and cultural gap that separates the two communities of tenants (heterogeneous communities). ${ }^{319}$ This lack of homogeneity

${ }^{316}$ From all respondents surveyed in Sidira, 50 per cent report „Yes“ and the other 50 per cent „to some extent", whereas the answer of the Arabs in Gereges, in the same Block were; „No“ (83\%), and „to some extent" (17\%).

317 The symbol of the TFU in Gendettu; the president, is illiterate and was in that time 69 years old. The question is, as many raised, whether the TFU with such leadership is able to tack over the task of management of the Scheme.

318 Related to total expenditure, this part going directly to activities performed at leadership level (transportation, allowances for central committee and executive office to meet travel expenses, and incentives), makes 71 per cent.

319 Since the composition of the TFU is based on proportional representation of Scheme tenants, it is numerically a Nomad-dominated institution. Field interviews indicate that for this reason, the Halfawyeen tenants do not perceive either the TFU or its leadership (in a collective sense) as 'their own'. The major institution for the Halfawyeen, both at village level and that of New Halfa town, has been and remains the cooperative Union and its member societies, providing him with farm-machinery and repair services and 
leads to opposing rights and interests. This is considered, therefore, as one of the main factors that contributed to the ineffectiveness of the TFU, according to the officials.

Also within the officials, the dissatisfaction with the performance of TFU was remarkable in the two cases of study, with especial particular in New Halfa. Of the respondents who answered this question, only one (5\%) maintained the positive role of the TFU in the Scheme. Those replying "No" have presented several reasos as shown in the Table below (Table 6.30).

Table 6.30 Officials Report on Reasons of the Ineffective Role of TFU

\begin{tabular}{|l|c|c|}
\hline & $\begin{array}{c}\% \text { of the total answers } \\
\text { New Halfa }\end{array}$ & Gendettu \\
\hline $\begin{array}{l}\text { 1- the non-awareness of their role } \\
\text { 2- the communal composition of the }\end{array}$ & 35 & - \\
TFU & 20 & - \\
3- lack of harmony with the Scheme's & 20 & 25 \\
Management & 15 & 25 \\
4- concentrate on their private interests \\
5- no role to play in organizing water \\
allocation and control
\end{tabular}

Source: Own Survey

It was difficult to understand what does the term 'their role' means to the staff? Many stress their activity in water fees collection and punishment in relation to water-misuse as main role. Whereas others argue that the TFU is busy with such administrative matters and describe their work as 'official'. Instead of being mediators between the tenants and the administration, the TFU itself become a part of the administration.

The leaderships of the TFUs in the Sudan belong to the few who dominates the social and political activities in the rural areas. They are to be seen everywhere; TFUs; Local Councils; and many are willing to represent different political systems ${ }^{320}$. They are not necessarily the largest farmers in their communities, but they belong surely to those class $^{321}$. They have therefore special influence in the society. That is why they are able to come to these positions even through 'free' election. That is why we have to question whether the free election in rural Sudan was actually 'free' ${ }^{322}$.

flour milling facilities. This is to say in effect, that the TFU has not developed into an integrative institution for the whole Scheme (NHAC 1986:ANNEX 7:40).

${ }^{320}$ Many members of the Executive Office in Gendettu are in their position since more than 15 years, and have represented three contradictory political systems; the military regime of Nemery (1969-85), communal parties in the third democracy's era (1985-89), and lastly the existing 'militarily/fundamentalist' regime!

${ }^{321}$ In comparison with the average field size in Gendettu (3.2 Feddan), the cultivated sizes of three heads of the Executive Office is a s follows: the president: 21 Feddan, president deputy: 38 Feddan; and the Secretary General: 14 Feddan. The president of the TFU in New Halfa bring command areas under control, although he is official in the local authority. He is responsible for the 'religious' affairs in New Halfa Town and called therefore by the nomads as Mawlana (a religious title)!

${ }^{322}$ Legally, the elections in the Sudan in the democracy periods were absolutely free. That means everyone elect voluntary. 
According to the above, all the staff in both Schemes argued that the decision taken in the end of 1992 to transfer the decision-making power in the large irrigated Schemes into the hand of TFUs is unrealistic and ignore all these facts. It would be desirable to promote a gradual transfer of responsibilities and increasing the area of participation. According to the decision that has been planned to be realized in the season 93/94, the Board of Directors will consists of 15 members of which 6 are executives members and 9 are members of the TFU. However, we believe that this decision which comes from the political authority without any preliminary discussion with those concerned, was not serious but rather for propaganda, and aimed in addition to political goals ${ }^{323}$. We argue that this decision was an attempt to avoid, directly, the responsibility of such projects in the light of the economic crisis and, at the same time, a chance to appear as a democratic system in the face of the international organizations.

\subsubsection{The Relationship between the Organizations}

Early theories of organizations focused primarily on internal features of organizations and failed to give serious treatment to the claims that organizations were influenced by, and exerted influence upon, their surrounding environments (see Chapter 2.3). We are interested here to bring to light the important role of the interorganizational relationships; the external linkages with other organizations such as supporting organizations, capable of exercising effects on irrigation efficiency. The previous findings yield insight into interfield relationships calling for a greater degree of integration between the concerned organizations, and first of all those sharing in irrigation management.

As discussed in Chapter 1.3, mobilizing the availability of a total package of necessary agricultural inputs and facilitating their adoption by farmers being supplied with irrigation water is a pre condition for well-managed irrigation systems ${ }^{324}$. Appropriate arrangement must be made for the project participants to secure the supplies of fertilizers, pesticides, high yielding seeds, cattle feed and veterinary medicines they need to adopt the new crop and livestock production technologies.

Implicit in the foregoing discussion is the fact that the interaction of MOI with the agricultural Corporation is an extremely involved day-to-day practical one, with any failure by either party rapidly leading to insufficient water reaching the crops and a consequential influence on production. Unfortunately, the interaction is sufficiently complex to ensure that when water supply deteriorates, each party feels justified in the opinion that the fault lies with the other party and neither seems able to remedy the deteriorating overall situation.

Despite the above statment, the majority of respondents $(79 \%$ in New Halfa, and $84 \%$ in Gendettu) reported that there are cooperation and good relations with the colleagues in MOI and the other organizations. But, this relation and co-operation are dependent on the

323 The staff in Gendettu reported that there were four governmental decisions, one after the other, in the season 92/93 that have resulted in confusion of the management. These decisions related to Region's system; individual account for NAPC's Schemes; the extension of the MOI's responsibility; and the transfer of the Schem's responsibilities.

324 The recent adoption of the command water management project approach by major donor agencies is ased on this comprehensive systems approach. 
persons (informal) and are more routinized than productive. Personal connections and favors play the determinant role inside and between the organizations.

\section{Pests and Disease Control}

Control of insect pests in New Halfa (for cotton) is disappointing. Recommendation in this connections are in the areas of: improved scooting techniques; even plant populations; improved application techniques; and procurement policy (NAPC 1986:ANNEX 2:35). Cotton pesticides are applied by aircraft. Even so, it is recommended that improving the application techniques would raise the efficiency. Aircraft, correctly supervised, will do a satisfactory job but equally it can be extremely inefficient. The application efficiency does not depend on the method chosen so much as the skill of the individual operator. To assume that the use of aircrafts ipso facto efficient, because it is technologically advanced, is a fallacy. Every system is as good as the operator, and supervision of contractors is vital to ensure a high return on costs. For the tenants, the main complaint here is the high costs of this services, that are undertaken by private firm under the supervision of the scheme.

Problems related to pest control are more extreme in Gendettu. The NAPC, Plant Protection Department (PPD), the Department of Agriculture (DoA), Agricultural Research staff and the farmers all said that pests cause problem every year and that, in most years, there is a serious pest outbreak on one crop or another. In theory, these outbreaks can be controlled by the farmers, who should be able to purchase pesticides from the PPD, but the availability of chemicals is severely restricted by the methods of supply. The main reason for this unfortunate situation is that the PPD is administrated by the Central Government, Khartoum, not by the Regional MoA office in Ed Damer.

The PPD office in Shendi, which is responsible for Gendettu Scheme, has one graduate, and seven technicians (two: Agr. Scond. School and five:unquqlified), in addition to five vehicles (only one for spraying) and enough numbers of sprayers. The office provides three kinds of service: first, selling sprayers and chemicals to farmers; second, offering a contract spraying service on request; and third, assists any farmer requesting advice on pest control matters. The PPD tries to persuade farmers to group together so that the area to be sprayed is at least 5 feddan. Likewise, the time and costs involved in spraying smaller areas makes the operation uneconomic.

The manager of the department stressed that it would be better when every scheme has its own PPD. This would enable the Scheme to make regular inspections and bring this service to all farmers with lower cost. Otherwise, the Scheme management must co-operate with the Department in achieving this vital operation. Such co-operation, he argued, is missing. In addition, the unchained canals, gardens, and roads are responsible for increasing malaria cases $^{325}$. Tenants, on the other hand, complain that the services

${ }^{325}$ Malaria and bilharzia are diseases that increased through the misuse of water and lead further to misuse of water because the patients are not able to manage and control the water at the field. It is therefore difficult to define the dependent and the independent factor. Specially in New Halfa the cases of these two were very high. The cases were doubled after the end of the World Bank's program (1983-1990). This can be one reason for the high absenteeism there. In addition, we have found in the documents of Gendettu Schemes many letters written from the inspector of the health Office in Shendi since the beginning of 1980s that seek the Scheme management to clean the main and the minor canals, and the roads. The office views that the Scheme is responsible for the spread of Malaria and bilharzia cases in area. 
available are inadequate, insufficient and too expensive. The costs of this operation have frequently increased. Most of them said that they never received any assistance nor, indeed, had they ever seen any PPD staff. Furthermore, many believe that in the absence of group action, it makes no sense to spray alone because the pests will come from the neighbors.

\section{Credit Services}

Facilities for credit for the farmers to finance the different operations, purchase various production supplies and for the suppliers of inputs should be made to ensure successful implementation of the project. The lack of financing and its influence on the performance of the different operations comes onthe top of problems that are facing the tenants (Tables 6.1, 6.3, and 6.6). In the opinion of some officials this problem is the first one at all ${ }^{326}$.

The Agricultural Bank of the Sudan (ABS) is the main official source of agricultural credit in the rural areas. The New Halfa branch of ABS has been involved with the settlement of the Scheme since its inception, initially in the granting of credit for wheat operations (1965), and since 1966/67 in the provision of seasonal credit for groundnut production. The role played by the bank in the financing of tenants' groundnuts operations until the end of 1970s has been described as instructive and significant (NHAC 1986:ANNEX 7:445). In addition, the ABS has played only a minor role in recent years in non-groundnuts crops - most of it presumably in relation to production on freehold land (Amlak) ${ }^{327}$. The staff of the Bank are of the opinion that if there were better co-ordination between NHAC and ABS, the volume of credit could be considerably higher. Under the new individual account system, cotton is financed through credits from the Corporation.

The bank offer mainly two kinds of loans in Shendi. Short-term crop loans with period of one season (from 15 Oct. to 30 Apr.) at a charge equivalent to 36 per cent of the total loan ( $3 \%$ per month) are mostly given for the winter crops. Medium-term loans, ranging from 2 to 4 years are granted for items such as tractors, equipment and pumps. The 'charges' of these loans are also 3 \% per month under the Morabaha 'islamic' system ${ }^{328}$.

The more recent form of seasons loan is the Salam system (post-harvest credit system) which used mainly to finance wheat in New Halfa and faba beans in Shendi. According to this system, the farmer is obliged to dispose off his crops (particularly pulses) in a time and according to price determined, in advance, by the bank in the harvest period ${ }^{329}$. In the case of crops failure, the bank has, theoretically, to accept the amount of the credit (cash) without charges, but in the reality the bank accept only crops. This means, farmer is obliged in this case to purchase the crop from the market to deliver it further to the bank.

${ }^{326}$ For example, the manager of the New Halfa Agricultural Research Center.

${ }^{327}$ It is estimated that not more than three percent of the farmers in the mid 1980s received institutional credit (HANSOHM 1991:121).

328 Charges have been increased from $15 \%$ in $1986 / 87$ to $19 \%$ and recently $36 \%$ after the 'islamisation' of the economy. Under the Morabaha system, the bank finance the item.

${ }^{329}$ For example, the determinate price of the wheat in the season 92/93 was $1200 £ \mathrm{~S}$ (sack) and the amount of credit was $37000 £ \mathrm{~S}$, this means the farmer had to deliver the bank $37000 / 1200=31$ sacks disregard the production. Under the objection of the farmers the number was reduced to 14 sacks. In the season 91/92 the Salam price was $1000 \mathrm{LS} /$ sack whereas the market price after the harvest was $2100 \mathrm{Ls} / \mathrm{sack}$. 
Many of the officials argued that this system exploit the weakness of the farmer and the absence of the roles played by the concerned organizations. The opinion of the tenants in regard to this system was: unfair (61\%); exploiter (16\%); do not know (9\%); to some extent (9\%); and good system (5\%).

In the 'with project' situation it would be more possible for farmers to make full and rapid use of the water if seasonal crop credit were to be used more extensively. The late of the season-loans in the season 92/93 caused problems for the farmers in Shendi area who are dependent on this source of financing. Although middle of October is the recommended date for the beginning of the Winter Season, from the extension service department, the farmers had not received any credits until the beginning of December. Therefore, they raised the question; to what extent co-ordinate the concerned organizations their policy, if at all?

For such reasons; delay of credits; high charges; and the obligation to repay by crops, formal agricultural credit plays a fairly insignificant part on the schemes. During the study attempts were made to identify the sources of finance for the different tenants and crops:

- The role of the ABS in New Halfa is secondary and limited to groundnuts; $16 \%$ of its finance among the Halfawyeen and $21 \%$ among the Arabs. The rest is selffinance.

- Sorghum in the Arabs area is $100 \%$ self-financed.

- Financing of wheat among the Halfawyeen is heavily (53\%) dependent on governmental credits (under the Salam system) through the Corporation.

- The Halfawyeen are more dependent on the credits of the Corporation to finance cotton ( $82 \%$ of its finance) in compare with the Arabs (53\% credit and 47 selffinance).

- There is no formal credit institution to finance the freehold areas in New Halfa.

- Only $7 \%$ of the tenants in Gendettu have received credit from the ABS in the season 92/93 whereas the rest reported self-finance. In addition to the high rates charged by the bank, tenants reported other reasons for this situation, the most frequent one was: ,in the case of default the bank will send me to prison but the local merchant will endure and protect my reputation." Other most frequent reason was „we don't understand the way of dealing with such system, only the upstreamers could that. ${ }^{\text {‘330 }}$

- The term 'self-finance' in New Halfa refers also to informal credits from the family members, friends or relatives whereas in Gendettu refers, in addition, to food/money

330 The traditional bank system may be sophisticate for the peasant. A simplified approach like this practiced by Grameen Bank in Bangladesh for example, where the bank go to the peasant not reverse, may be more suitable. Other example from Bas Boen, Haiti project, where planners had to do away with even simple bookkeeping since the illiterate population could not cope with such, for them, sophisticated methods. So the planners instituted a system of 'internal money' whereby peasants „paid“ for the supplies and engaged in other financial transactions by remitting or receiving chits (WEITZ 1986:169). 
lending system; the so called Shayl or Sheil system. It is one form of the interlinked (personalized) transactions ${ }^{331}$ in such small face-to-face community which comprise simultaneous deals in the commodity and credit markets between a trader and a farmer where the later gets credit on the precommitment of future crop delivery to the former ${ }^{332}$.

- The members of the TFU in Gendettu stressed that many tenants are dependent on the informal Shayl credit system - apparently it presents better creditor-borrower relation. Only $23 \%$ of the respondents reported directly that they do not practice such system and described it as 'forbidden' from the religious point of view ${ }^{333}$.

\section{Marketing}

Irrigated agricultural production and marketing; crop yields and generated farm income, form the basic indicators against which the 'efficiency' of the system is assessed. In addition, an institution can be said to be optimal if it best attains some welfare goal. Therefore, issues like where the project's output will be sold, whether the market is large enough to absorb the new production without affecting the price and whether suitable facilities are available to handle/process and/or store the new production, are responsible for the failure of many projects. The Scheme Management of our two cases did not make any effort in this context. And it seems to us that market in this sense is absent from 'their' mind $^{334}$. All the staff $(100 \%)$ in both Schemes pointed out that the Corporations have no

${ }^{331}$ Much of the recent theoretical literature spelling out the underlying rationale of interlinked contractual arrangements has served as a welcome corrective to the murky institutionalize of the past and has provided some much needed micro foundations to the study of agrarian institutions (BARDHAN 1989b:238).

332 Shayl (carrying) system is practiced in deferent rural areas in Sudan; mainly north, central and west, to finance low-investment subsistence grain cultivation. According to this system, that is in operation since the Fung Kingdom (around 1500), merchants stored grain to lend in times of shortage and to receive payment in times of abundance. The effect is to bring considerable profits to the merchants and great misery to the peasants (TRILSBACH 1991: 181). In the recent years, similar to the salam system, the merchant give credits (in cash or kind) to the tenant to finance the agricultural operations and the normal daily costs, and the farmer is forced to repay at harvest (from the crop) according to price determined at the beginning of the season.

333 Based on field study in Ad-Damazin, EL TAHIR (1982) represents many shayl students and stressed the disadvantages of such system specially the high rate: „The wide difference between the shail price and the market price shows how exorbitant the rate of interest is that the traditional farmer have to pay. The rate of interest at the above mentioned areas is estimated to be $296 \%$ on the average. This rate of interest is pushed even higher due to the fact that the farmer needs the borrowed money to buy consumer goods from the lender. The price at which he buys, are usually very much higher than the market prices in the urban areas". However, shayl prices differ between individual peasants depending on their creditworthiness, the highly indebted peasants receiving lower prices (OSTERDIEKHOFF 1991:369). On the other hand, AWAD (1967) belongs to the few who oppose the idea of considering the shayl margins as usurious interests. In contrary, he argues: "there are no interest payments in shayl. The margins which the shayl merchants receive are strictly in nature of profits.. they are not fixed in advance, and they are not always positive sums as interest rates are. Because of their habit of confusing shayl with money-lending, the students of shayl usually refer to shayl margins as interest rates. But moneylending is an entirely different system: its transactions are usually carried out in cash only, and so it is an essentially urban institution. Rural borrowers use it only when they can not obtain loans from shayl lenders because its loans have all the risk problem of state and cooperative loans beside being more expensive." (EL LAYTHY 1995:2327).

334 The village shopkeepers, as OESTERDIEKHOFF (1991:368) pointed out, are the central commercial institution of villages. 
role in marketing, and the tenants in this respect are oppressed and exploited again. There must be, they argued, any kind of co-ordination and cooperation between the concerned organizations including TFU.

Cotton is sold to the ginneies (most of which are publicly owned through the scheme management organizations) at a fixed farm gate price. The lint is sold to the Sudan Cotton Company, a publicly owned company, which sells to both the domestic and export markets. Wheat is still predominantly handled by government authorities from the gate to the flour mills. In addition to the unfair system of cotton marketing and the obligation to deliver most of the wheat crops to the state under the salaam system, ${ }^{335}$ the marketing of groundnuts, the sole cash crop for the tenant, is totally controlled by some monopolists. The tenants reported that instead of helping the farmers it seems that the state, through its polices and the big merchants who belong to the party in power, make profits from them. Only 20 per cent of respondents in New Halfa and 17 per cent in Gendettu reported that they have no marketing problems. In New Halfa, most of the farmers grow only cotton and sorghum or only wheat. The obstacles of marketing reported by the tenants are distributed between ${ }^{336}$ :

\begin{tabular}{lcc} 
& \% of the total answers & Gendettu \\
\cline { 2 - 3 } & New Halfa & 42 \\
Low prices & 30 & 16 \\
Monopoly of the market & 17 & 21 \\
High taxes & 16 & 11 \\
Absence of any & 15 & \\
organization to defense the & & - \\
farmers & 7 & - \\
Delay of opening the & & \\
market (groundnuts) & & \\
middlemen & 5 &
\end{tabular}

Groundnuts are marketed in specific market called 'crops market'. As a condition for participation in this market, tenant has to pay eight different local taxes and social services levy per sack. The lack of opening the market enforce the tenant to accept any price because of his need for liquid money. The low prices and monopoly refer to the same problem. Many tenants therefore refused to accept the price available at end of the season $92 / 93$ and stored the crop in the houses.

In the light of: a) the low prices of the crops resulting from the monopoly of the state (cotton and, to a big extent, wheat) and the merchants (groundnuts, faba, onion and fruits); b) the low productivity due to the water shortage; and c) the absence of financial supporting, the problem of increasing the costs of production means low revenues and, therefore, no motive for the tenant to increase the performance at the field.

${ }^{335}$ Only very small quantities of wheat and sorghum enter the free market.

336 The first set of problems affecting agricultural performance and hunger in Africa, according to the World Bank perspective, are the cluster of often inappropriate agricultural price, tax, subsidy and exchange rates policies. In Africa, these policies have generally served in the last 20 years to depress farmers' incomes and incentives to produce. This has discouraged agricultural production for the market, encouraged rural-urban migration, reducing inevitable resources remaining in agriculture hence reducing agricultural investment (SERAGELDIN 1990:243). 
As mentioned before, cost of production is one of the major problems of the two schemes which has direct influence on the water management. The costs of the different agricultural operations and inputs have dramatically increased in the season 92/93 as shown in the Table 6.31 below (in Sudanese Pound $£ S$ ):

Table 6.31 Prices of some Inputs in the last two Seasons

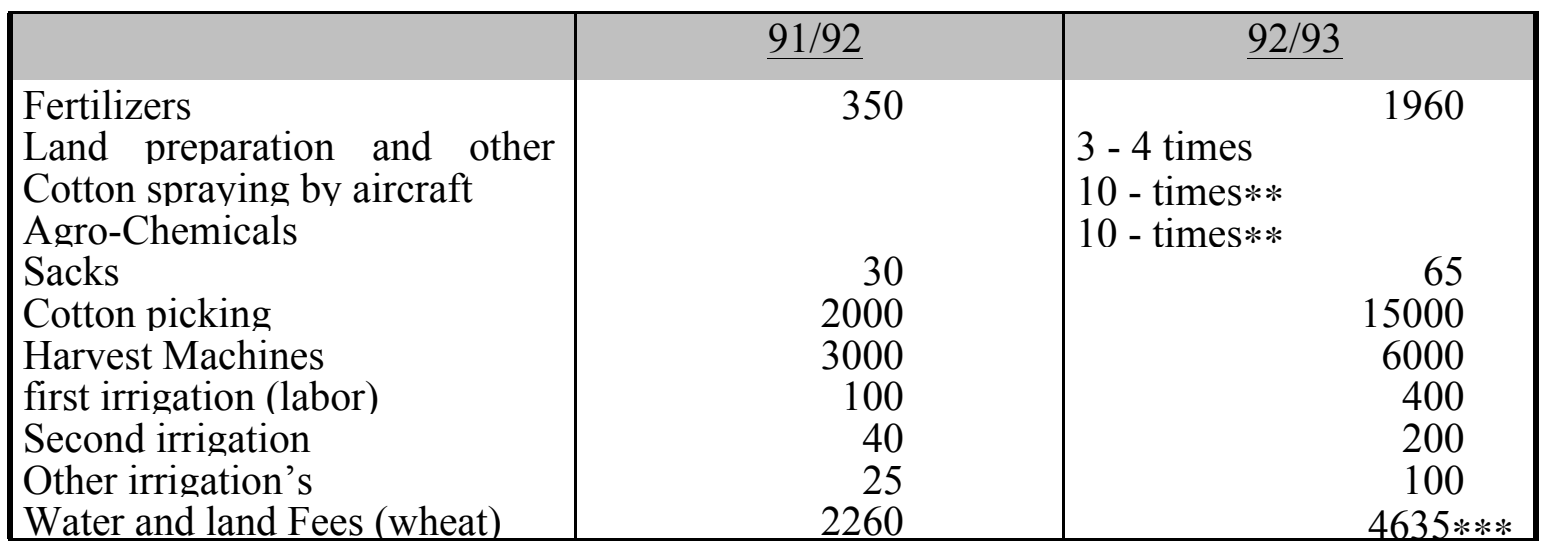

* Because of the increasing of the fuel prices

** Because of the devaluation of the Sudanese Pound

*** Water and land fees for the Whole Hawasha in the Season 90/91 was 875 LS.

Source: Own Survey

On the other hand, crops prices have changed as follows:

$\begin{array}{lcrr} & 1991 / 92 & 1992 / 93 & \text { Increase } \\ \text { Wheat } & 800 & 1500 & 88 \% \\ \text { Groundnuts } & 450 & 500 & 11 \% \\ \text { Sorghum } & 700 & 550 & -21 \% \\ \text { Onion } & 500 & 800 & 60 \% \\ \text { Faba Beans } & & 2000 & \end{array}$

The increase in cost of production in the season 91/92 for the crops in New Halfa were: cotton $113 \%$; wheat $143 \%$; groundnuts $88 \%$; and sorghum $96 \%$. Revenues have, on the other hand, increased as follows: $57 \% ;-0.03 ; 73 \%$; and $118 \%$ respectively. As compared with the productivity (Table 6.25) we find, with exception of groundnuts, net loss. This overshadows the effects of higher yields. The net return to tenants profits (loss) LS/fed. for sorghum during the1980s was negative $(-0.9,-29.6,-64.8,-109.7,-23.4,-139.5,-166.6$, $-160.9,-589.6$, and -80.0 respectively). Similar results in relation to cotton was observed with the exception of the year $89 / 90$.

The estimated increase in production costs of the crops in New Halfa in the season 92/93 was: cotton $335 \%$; wheat $207 \%$ and groundnuts $304 \%$. For sorghum the costs of one sack was $£ S 1200$ whereas the price $£ S 550$. The high estimation for cotton and groundnuts is 
due to the high utilization of the labor input. All these facts indicate the negative returns from the crops and have resulted in changing the arrangement of sharecropping system ${ }^{337}$.

Though the absence of official prices in Gendettu, it seems that the problem related to production costs is very critical. In comparison with the other crops, onion is the most influenced by the cost's problem, but still, because of the high productivity, more profitable for the tenants ${ }^{338}$. There is special reference to inputs like fuel and oil, fertilizers, labor, and insecticides. Fuel, for instance, is only available in the black market. Farmers surveyed said that in 1985/86 they had experienced no difficulty in purchasing fertilizer. It was, however, due largely to NAPC obtaining a special allocation of 2000 tonnes financed by Japanese aid. The prices were: Urea $£ S 38$ and triple superphosphate (for orchards) $£ S$ 24 per $50 \mathrm{~kg}$ sack (ODA 1986:A1/2-14). In this context, FAO Fertilizer Program ${ }^{339}$ had been concentrating on persuading the farmers to use TSP (Triple Superphosphate) in addition to Urea. The availabilty of these inputs have been reflected in more productivity in the middle of $1980 \mathrm{~s}$.

Clearly, we could conclude by emphasizing that 1) the support organizations have substantial role to play in relation to farm management. This role is absent in our two cases as well as the Schemes' Administrations do not co-ordinate with these organizations ${ }^{340}$; 2 ) taking the negative effects of such policies on the income distribution, we are able to characterize the two schemes, according to transaction costs theory, as inefficient; and 3) where irrigated agriculture is profitable for water users, they have more participation in the activity and are willing to cooperage in paying water fees.

\subsection{Water Prices}

The amount of water received by each farmer during the irrigation season is not known, since water is not measured at the individual farm take off point. In New Halfa, the only measuring points in the irrigation water distribution system are at the intakes of the minors. In order to measure discharges into each farm, an intensive network of measuring devices is required. Particularly in the areas where night storage facilities are constructed. This requires, in addition to a high investment per Hawasha, well trained personnel to collect data on actual water use. That is why the rehabilitation study of New Halfa Scheme has suggested water charges based on a fixed rate and related to the land rent. This, however, will only be possible, stressed the study, once operation and maintenance of the irrigation scheme is such that each farmer will be able to apply water at the right time and the correct quantity (NHAC 1986:ANNEX 1:29).

337 Before the season 92/92 the arrangement was that the tenant receive 20 per cent of the 'total' outputs or the return whereas the sharecropper who shoulders all the costs is entitled to receive the rest. Because of the high production costs the new arrangement is that the tenant receives 20 per cent of the net return i. e. after deducting the production costs.

338 The price of onion dropped from $£ S 800$ at the beginning of the season to £S 350 at the end.

339 The FAO Fertilizer Program is initiated in 1977 and intended to promote the sound use of fertilizers, mainly nitrogen and phosphates, through their sale to farmers at favorable price plus extension and training support.

${ }^{340}$ It is worth noting that the need for cooperation and good will between research institutions, irrigation engineers, agriculturists and the farmers was defined in a study, since almost twenty years, as urgentrecomendation for improving the application efficiency in irrigation systems in Sudan (see: SALIH and KHADAM 1976:126). 
In the Sudan, farmers pay water charges based on a fixed rate per area irrigated - but these charges bear no relation to the amount of water used and the numbers of irrigations. Once tenant irrigate one time he has to pay for the whole season (eight watering) even if, for one reason or another, he do not complete the season. The evasion is, in addition, not possible specially in New Halfa. Until season 90/91 charges for water and land had been levied under one rate; called land and water rate. Since season 91/92 water rates and land fees have been separated. Tables 6.32 and 6.33 show water rates structures and explain the variation in the feddan rate for different crops. The flat rate of irrigation water has been tremendously increased specially during the last five years.

Table 6.32 Water and Land Charges in Seasons 81/82-90/91 in New Halfa Scheme (£S/Feddan)

\begin{tabular}{|l|r|r|r|r|}
\hline Season/Crop & \multicolumn{1}{|c|}{ Cotton } & Wheat & Groundnuts & Sorgh \\
$81 / 82$ & 28.5 & 18 & 14 & 7 \\
$82 / 83$ & 36 & 30 & 24 & 12 \\
$83 / 84$ & 48 & 40 & 32 & 32 \\
$84 / 85$ & 62 & 52 & 31 & 41 \\
$85 / 86$ & 80 & 67 & 40 & 41 \\
$86 / 87$ & 98 & 82 & 49 & 49 \\
$87 / 88$ & 124 & 104 & 61 & 61 \\
$88 / 89$ & 155 & 95 & 70 & 70 \\
$89 / 90$ & 177 & 131 & 104 & 104 \\
$90 / 91$ & 196 & 174 & 174 & 174 \\
\hline
\end{tabular}

Source: NHAC, Various Documents.

Table 6.33 Water Charges in Seasons 91/92 and 92/93 in New Halfa Scheme (£S /Feddan)

\begin{tabular}{|l|c|c|c|c|}
\hline Crops & $91 / 92$ & \multicolumn{2}{|c|}{$92 / 93$} & Land \\
\hline & Water & Land & Water & Lat \\
\hline Ground./ Sorgh./ Wheat & 258 & 190 & 737 & 190 \\
Cotton & 346 & 190 & 966 & 190 \\
\hline
\end{tabular}

Source: Own Survey

Water and land charges for the five feddan Hawasha, except cotton, was £S 2260 in season 91/92 increased to $£$ S $4635(190 \%)$ in the next season. Cotton charges have more increased because it needs more watering; from $2680 £ \mathrm{~S} /$ Hawasha in the season 91/92 to £S $5780(180 \%)$ in the season 92/93. The variation in the charges per Hawasha in the last five years was more than twelve times for groundnuts and sorghum, nine times for wheat, and almost seven times for cotton.

Table 6.34 shows dramatically increases in the feddan/rate for some selected crops in Gendettu. During seasons $85 / 86$ and $92 / 93$ these variations have been as follows: berseem (alfafa) $\mathbf{5 5 2 5} \%$, horticulture $\mathbf{4 2 7 5 \%}$, onion $\mathbf{4 0 4 8 \%}$, faba $\mathbf{2 7 1 3 \%}$, vegetable $\mathbf{2 1 0 6} \%$. Of course, one has to question whether these increases are real or nominal. 
Although the deterioration of the Sudanese currency and the inflation ${ }^{341}$ play a substantial role here, the more critical question would be how much is the share of water charges within the production costs? According to the available data from New Halfa, for example, the relative share of water and land rates of these costs constitute average of $14 \%$ of cotton, $23 \%$ of wheat, and $10 \%$ of groundnuts. However, the meaning of such increases would be more clear when we add the increases in the costs of the other inputs and when we, on the other side, compare it with the increases in crops prices.

Table 6.34 Water Charges in Selected Seasons per Crop (Gendettu)

\begin{tabular}{|l|r|r|r|r|r|}
\hline Crop & $81 / 82$ & $84 / 85$ & $85 / 86$ & $91 / 92$ & \multicolumn{1}{|l|}{$92 / 93$} \\
Berseem & 74 & 120 & 240 & 9000 & 13500 \\
Horticulture & 75 & 120 & 240 & 7000 & 10500 \\
Onion & 57 & 66 & 132 & 3650 & 5475 \\
Faba & 18.5 & 36 & 72 & 1350 & 2025 \\
Sorghum & 18.5 & - & & 900 & 2025 \\
Vegetables & 24 & 51 & 102 & 1500 & 2250 \\
\hline
\end{tabular}

Source: Different internal Reports of Gendettu Scheme

Note that responsiveness to water price can be viewed as farm-level land reallocations that would occur with an increase in price and this is known as allocative distortions ${ }^{342}$. Although it makes no sense, however, to test the elasticity of water demand with respect to price in New Halfa, decline in the Wheat area has been registered in the season 92/93. In Gendettu some tenants have begun to substitute away from alfalfa production in the face of higher water prices.

Despite the above, there is another factor which is very important for the decision of setting, and of course increasing, the water rates. This factor is whether the tenants are free in selecting the cropping pattern which maximize their profits. The interview in New Halfa has shown that $53 \%$ of the tenants were not satisfied with the current cropping pattern and 7\% were not sure, whereas $40 \%$ have viewed that they find no reason to change it. Since such questions are very critical for the tenants, because of the political shadows that influence it, we have tried, as in many similar situations throughout the interviews, to repeat the question, later, with other words. Tenants have been asked to suggest a new cropping pattern in the scheme (Table 6.35). The results is shown in the table below as follows:

\footnotetext{
341 As a solution for the inflation's implications on water fees, is to establish the level of fees in terms of the quantity of the crop (specially important crops). It does not mean that they are necessarily collected in kind. The amount of cash necessary to satisfy the fee would depend on the price of the crop. The mechanism for establishing the price to be used each year would have to be specified. This approach has been used in the Philippines since 1975 (SMALL/CARRUTHERS 1991:179). However, the rehabilitation study of New Halfa Scheme has excluded such alternative: "If water charges are related to the harvest and a rate per unit of harvested crop is determined, water wastage will increase. A farmer having good yields will see the water charge as a fine since he has to pay more than his fellow farmer whose yields are poor even though he has used the same quantity of water" (NHAC 1986:ANNEX 1:29).

342 See MOORE, GOLLEHON, and CAREY 1994:867.
} 
Table 6.35 Cropping Pattern as Suggested by the Tenants in New Halfa Scheme

\begin{tabular}{|l|c|}
\hline Crops & $\%$ \\
Wheat & 29 \\
Sorghum & 22 \\
Groundnuts & 21 \\
Cotton & 10 \\
Other Grains & 7 \\
Vegetables & 6 \\
Fodder & 5 \\
\hline
\end{tabular}

Source: Own Survey

- Cotton backed and three new crops are suggested instead. Third of the surveyed has clearly and directly refused cotton ${ }^{343}$.

- Wheat is still the most desired crop in the scheme ${ }^{344}$. Some of the nomads, on the otherhand, asked for the replacement of wheat with groundnuts or sunflower. Sorghum constitute with wheat a considerable share of the subsistence consumption commodities of the poor.

- Most of the Halfaween are not interested to grow sorghum not only because the are wheat consumers, but first of all because it needs a lot of work in the Hawasha. They are tend therefore to share it with the nomads or the hired labor. Distribution of the yield is $50 \%$ for both or $75 \%$ for the sharecropper and $25 \%$ for the Halfawyeen, and even in some cases the later is ready to renounce his share in order to keep the rotation.

Furthermore, the neat answers given to the questions: „what do you want to grow if you would obtain another five Feddan and why?" tie well with the above analysis and draw, clearly, the preferences of the tenants concerning cropping patterns. Seen from the eyes of the tenants, there seem to be several alternative crops that reflect their needs (Table 6.36).

${ }^{343}$ Tenants in village 24 halfaween have decided to drop the cotton in the season 92/93. This decision is practiced in village Gereges by the nomads throughout the last four seasons. The reasons that have been usually mentioned concerning cotton's exclusion are: a) water shortage; b) ..."cotton is not yours, not in your hand,controlled in all phases from the 'others'; and at the end we get the earnings after one years. That is way it has been dicribed as 'Kamel crop' (12 months pregnancy). Some of the halfaween argued: "cotton does not belong to us: the government takes the flower; the remain of the produce used as a fodder for the nomads' animal; and the earnings are to be taken after one year... why should we then grow it?

344 On the contrary, wheat is seen as 'gold', especially by the Nubian (halfaween): "its value is stable and/or with the time its prices go up (store of value);....you can by it any time (cash liquidity); and first of all it is in your hand". This result stands in sharp contrast to what is viewed in the rehabilitation Study: "In view of the acute water supply, it is recommended that the cropping program is confined to cotton, groundnuts, and sorghum with no wheat on NHAPC land" (NHAC 1986:NHIRP, Annex2:1). 
Table 6.36 What Would ou Grow and Why if you Would Become Another Five Feddan?

\begin{tabular}{|c|c|c|}
\hline Crop & $\%$ & Reasons \\
\hline Wheat & 32 & $\begin{array}{l}\text { Self-consumption } 33 \% \text {, simple (mechanized) } \\
30 \% \text {, profitable } 27 \% \text {, low costs } 7 \% \text {, high } \\
\text { Productivity } 3 \% \text {. }\end{array}$ \\
\hline Vegetables & 26 & Income $70 \%$, self-consumption $30 \%$ \\
\hline Sorghum & 13 & $\begin{array}{l}\text { Self-consumption } 67 \% \text {, low costs } 22 \% \text {, } \\
\text { income } 11 \% \text {. }\end{array}$ \\
\hline Groundnuts & 13 & $\begin{array}{l}\text { income } 57 \% \text {, can be intercroped } 15 \% \text {, sustain } \\
\text { the soil } 14 \% \text {, fodder } 14 \% \text {. }\end{array}$ \\
\hline Fodder crops & 11 & - \\
\hline Karkade, Faba Beans, Lentil & 5 & Self-consumption and income \\
\hline
\end{tabular}

Source: Own Survey

These results reveal too an important fact in irrigation system i.e., financing irrigation with user fees requires consideration of both the costs of providing irrigation and, at the same time, the benefits that the users receive from irrigation

But crosscutting these, there are other angles namely the officials. Almost $50 \%$ of the surveyed agree on the current cropping pattern addition to $20 \%$ who view it as "to some extent". Interesting here is that $30 \%$ have described it as: "not suitable" 345 .

There is a general perception about water pricing that the farmers do not accept it. This is not entirely correct ${ }^{346}$. It was very interesting here to find that the tenants were more able to accept the institutional change concerning water prices than the officials. Here is another 'point' where the latter misconstrue the behavior of the tenants. The resistance which has been practiced at the beginning should not be understood, as the projects' staff wrongly did, as refuse or non-conviction of the idea. Indeed, it is the reaction of a series of dissatisfactions. It is, however, the non-conviction that such step will be used to improve the water utilization, as well as their refuse of the way of the 'whole' management whitch result in reducing their incomes. This is, unfortunately, not clear for the Schemes' Management.

In spite of all these dissatisfactions, we find the reaction of the surveyed tenants with respect to change in water rates very interesting. Table 6.37 shows that they are willing to accept the increase in water charges but only in the case if this step, in the same time, would guarantee the improving of water management. From the other angle, staff and

${ }^{345}$ Some of them (Nubians) argued that dura (sorghum) has to be excluded from the irrigated area (it belongs anyway to the rainfed cultivation outside the scheme).

346 Information on communal and private irrigation systems in various countries in Asia, for example, shows that even poor farmers often pay quite large amount for good quality irrigation services because they are still better off than they would be if they had no access to irrigation (SMALL and CARRUTHERS 1991:161). 
officials were asked if they think that increasing water charges could be an effective means for improving water use in the two schemes (Table 6.38)

Table 6.37 Do you Agree to Pay Higher Water Fees with Guarantee its Convenyes to the Field

\begin{tabular}{|c|c|c|c|}
\hline Scheme & \% Replies of Farmers & No & Do not Know \\
\hline New Halfa & 28 & 48 & 24 \\
Gendettu & 57 & 39 & 4 \\
\hline
\end{tabular}

Source: Own Survey

Table 6.38 Do you think that Increasing Water Prices can be an Effective Means for Improving Water-use (Officials)

\begin{tabular}{cccc}
\hline Scheme & \% Response of Officials & & \\
& Yes & No & To some Extent \\
\hline New Halfa & 29 & 59 & 12 \\
Gendettu & 33 & 45 & 22 \\
\hline
\end{tabular}

Source: Own Survey

The answers of these two questions reflects many aspects, for example:

1. Tenant's attitudes towards the project. In New Halfa where the dissatisfaction is high they were not willing to accept the increases. Furthermore, there is no confidence in, or hope of, improvement. They referred to the season $92 / 93$ as example.

2. The kind of water user (e.g., degree of dependency on agriculture as a source of income; the background of the tenant whether he/she is a farmer or a newcomer to this field). Thereby, many tenants in Gendettu have argued: "irrigation is the sprite of agriculture that is why we have to accept the increases in water prices" and "availability of water will motivate us to think about other new crops". It is also to be noted here that many of them are conscious that water costs in the scheme still lower than it is in the private schemes.

3. The different views of both ,configuration“ about one of the most important elements of irrigation schemes. The majority of officials see no relation between increasing water prices and improving water-use. The presumption underlying this argument is that: (a) it is the problem of the current rate setting system which has to be changed, not the amount of price (50\% in New Halfa, $40 \%$ in Gendettu); (b) increasing the price will be reflected on the production costs $(25 \%$ New Halfa, $20 \%$ Gendettu); (c) in addition to the importance of control, farmers have to be explained that the over watering is, the same way like under watering, harmful for crops $(17 \%$ New Halfa, 20\% Gendettu); (d) in addition to the above, the government has to strengthen the law and penalty.

In summary, we argue that the preconditions that guarantee positive results from charging farmers water fees are the same that are needed to alleviate and overcome the problems of water management. As long as the tenant: not involved in the decisionsmaking; face water shortage and unfair water distribution; stay alone in the field without extension services and determinate inputs for the productivity; find no conditions of trust 
between farmers and between farmers as a group of irrigation and officials; has no steady benefits from his farm and then lost the loyalty to the scheme; as long as these obstacles dominate, then waiting that increasing water charges would improve water-use stay as a theoretical hypothesis. 


\section{Conclusion}

The focus of this study has been on improving the performance of irrigation water-use in Sudan. The assessment of this performance is seen as having main points of reference, as concluded below.

It is difficult to imagine a partial solution for a comprehensive problem. Improving the performance of water-use is only possible as part of a comprehensive development approach which takes all resources into consideration. However, in order to get better utilization of the resources in the irrigated sector in developing countries, there is an urgent need for, what could be referred to as Resources Management Ethics. The government of Sudan spent 136 million US dollars at the beginning of the 1980s for the rehabilitation of the New Halfa Scheme (less than two decades after its inauguration). One has to question, after the discussion of the results in Chapter 6, whether there was a rehabilitation at all. The question is also valid for the Gendettu scheme. Technical rehabilitation without changing the institutional deficiencies cannot be the favorable solution, from a cost point of view, to increase production capacity.

The environment of irrigation projects is of particular importance. The case study of the Sudan emphasizes that bureaucratic irrigation systems must take political conditions into account. With regard to the role of the state towards irrigation schemes, one is forced to state that farmers have faced new forms of 'exploitation' with little difference from the precious situation during the colonial era. The current condition is, however, bitter because it has been practiced under a national 'flag'. Sometimes it is hardly possible to find a substantial difference between NHAC, NAPAC, and the national Government on one side, and The Sudan Plantations Syndicate (of the Gezira) and the colonial Government in the colonial era. Now, the elite in power see farmers as a main source of financing activities that serve their own goals (the war in south Sudan as an example).

The recent kind of irrigation management system in the Sudan reminds one of the division of society at the beginning of this century along class lines between a group of rulers, known as hukam and a class of subject commoners, for which the corresponding term was masakin (literally, 'poor people'). This focus has tended to direct attention to the 'colonial inheritance' that has been practiced by the elite since 'independence': farmers have to work for the scheme and not the other way round. These observations highlight the fact that an irrigation system is a political system.

This raises the question: to what extent are the participation approaches applicable in the organizations of such countries? A central conclusion of this study is that an irrigation system could not be seen as a developed 'island' in an underdeveloped 'sea'. If the dominant institutions in the country do not practice the democratic values and prevent others from using it, then talks about participatory approaches in some organizations or institutions or expecting this in such a country remains theoretical.

The absence of tenant participation and the dominance of the scheme management's goals, as representatives of the state, have resulted in a contradiction: efficiency in the opinion of the scheme management vis-à-vis efficiency in the opinion of the tenants. The absence of farmers' participation has resulted, however, in the domination of 'individualism' among water users. 
A point here that is of particular relevance for irrigation systems is that the definition of the term water efficiency has to be join with the productivity per unit of water applied. If this is not the case, the other inputs will be underutilized or wasted. In addition, more productivity motivates tenants for efficient use of water and makes them able to pay water charges. An institution can be said to be optimal if it best attains some welfare goal.

The technology applied has a vital role in order to reach such a goal. One should be clear about the meaning of the term 'appropriate technology' in literature. 'Appropriate' as seen in this study also means the advanced technologies that are needed to save scarce resources. Therefore, modern technology must not be seen as a 'block' that should be taken or ignored completely ('take it or leave it'). Conversely, irrigation projects could use modern technology, in some phases or parts of the schemes, as long as it necessary for water saving. This question arises in a number of areas, the principal one in the immediate future being in relation to land leveling and land preparation, gate control, clearing canals, siltation of canals and reservoirs, harvesting, and communication systems. Although this study suggests improving the technology practiced in irrigation schemes, it is of great importance to stress that this kind of change, as such, is not enough as long as there is no water-user organization to undertake the task of water control.

It is necessary to reckon with the fact that the weak role of complementary or support institutions in Sudan is one of the vital obstacles to water-use efficiency in its broadest meaning. Agricultural extension services, in particular, are the indispensable tool for the representation of new technologies. The importance of the role that can be played by the agricultural extension service must be recognized and really practiced by the scheme management. The performance of this department and the attitude of the scheme administration towards it show what chances Sudan has in this context.

Broadly speaking, previous findings yield insight into interfield relationships calling for a greater degree of integration between these institutions. Because of the integrated nature of the agricultural operations, it should be an area of cooperation between all the concerned organizations and primarily all those organizations that directly share responsibility for irrigation management. For instance, the non-cooperation between NHAPC and MOI has resulted in a lot of trouble and bottlenecks for water management. Support institutions have had no significant role in sustaining the agricultural operations and modernizing the technologies and this resulted in low productivity and wastage of water. Thus, a central conclusion of this study is that the efficiency of water utilization also requires, at the same time, efficient utilization of other resources and inputs supplied by support institutions.

Another issue emerging from these findings is the importance of communication (the 'bridge' or 'gangplank') in coordinating organizational activities. Informationprocessing writers take a somewhat broader view of the organization as an informationprocessing system trying to cope with uncertainty by getting information to the decision point where it is needed. Communication here means information exchange and behavior control. Nevertheless, it is not an easy task, in such bureaucratic schemes, even to define the feature of this communication. After having examined the communication 
and articulation system of the two schemes, a yawning gap was found between the different actors.

The study has attempted to trace the question of contact between the leadership and the base. Deviations from the scheme management recommendation have been found for different operations. Some of the tenants argued that there are no recommendations at all, and therefore, there is no feedback. Many others pointed out that they find nobody to discuss with. On the other hand, it has been mentioned, several times, by officials that the entrepreneurship of tenants (with special reference to the Halfaween) is weak. Such results are familiar in developing countries.

This study draws attention, in particular, to the role of the TFU (Tenants Farmers' Union) as a channel of communication between corporations and tenants. TFU is farmers' organization not an irrigation association. It has no remarkable role in governing activities at distributary and water course levels. There is no doubt that 'building' water-users associations is more conducive to equitable water distribution. It could help to mitigate the problems connected with insufficient water supplies, water distribution and water charges. Clearly, what is at issue here is not the utility of the concept, but the conditions under which it is employed. Water-users' associations needs independence.

It is true that the existence of a farmers' organization is an indicator for the 'dialog' between water users and higher levels like scheme administration or the actual definers of the scheme's goals (i.e. politicians and businessmen). But on the other hand, the socio-economic and political analysis of these organizations and the way through which members of such organizations come to their positions (as in the Sudanese case) allow one to argue that the existence of such organizations can also be seen as merely - as it were - a kind of 'monologue'.

The point to dwell on here, however, is by and large one of the most important factors for improving irrigation systems in the future. As was stated in different places of the treatise, improving water-use cannot exclusively be achieved by arrangements in the field and/or the design, or even through managerial arrangement concerning water distribution. This goal needs, in addition, other aspects of institutional change concerning price policies and market conditions.

Many students of irrigation management have stressed the potential countereffectiveness of increasing the price of irrigation water as a means for inducing optimum water-use efficiency. In order to achieve this goal, some institutional changes concerning the following issues should accompany the administrative capacity of the scheme, the practiced technology, cropping patterns, and production relationships. Therefore, one may infer that, in irrigation systems, the term ceteris paribus has no function. In addition, intervention in pricing and payment systems should be aimed towards creating improved systems based on reduced distortion and well-stated, clear objectives that take account of the specific circumstances of the country concerned and the potential impact on all parties involved.

It has been found that the generalization of the common idea that tenants/farmers are against water pricing is of no effect. Moreover, they are willing to accept considerable increases in the price as long as an additional source of financing is used to improve 
water delivery and distribution within their schemes. It is necessary to reckon also with the fact that many of them are firmly aware of the benefits they could gain from this change. Therefore, it is not possible to imagine benefits from levying water charges in such projects as long as the tenants have no full hand on the decisions of water distribution, land use, cropping pattern, and as long as the markets are not free.

The first concern tenants raise is that: "the revenue from increasing water charges will be used for 'their' interests not for solving 'our' problems ..... the price has been increased several times and water problems have remained unchanged". On the other hand, increasing costs of production in the same time as decreasing the productivity as a result of water and financing bottlenecks, as well as the ambiguity of property rights, create no atmosphere of trust or a feeling of loyalty. These are genuine concerns and are considered to be major reasons for the poor performance of the schemes.

In Chapter 6 an attempt was made to prove one of the factors that are closely bound up with water pricing i.e. tenants' attitudes towards cropping patterns. As illustrated in many studies in the last two decades, cotton areas and yield declined dramatically because of the poor management and pricing policy despite the change in production relationships. Because of the unprofitability, this crop reflects the conflict between the goals of the national policy-makers and those of the tenants. One is facing here an example of clashing objectives similar to the one practiced in the Dominican Republic, where the government stressed the total volume of rice produced whereas farmers, understandably, were more concerned with its profitability. Similar to the behavior of the tenants in New Halfa and other schemes in Sudan towards cotton, when the price paid for rice in the Dominican Republic fell too low, farmers left crops unharvested in the fields, to the consternation of officials. The investigation in Sudan has shown, however, that if the choice were possible, which it is not, the tenants would prefer cash crops and those that needs low water and fertilizers (because of their costs).

Ultimately, it is concluded that the water pricing system in Sudan has failed to achieve its stated objectives of: (a) introducing funds for operation and maintenance, (b) influencing the manner of water-use, (c) promoting innovations and investment, and (d) sustaining loyalty to the scheme. 


\section{Bibliography}

AASS, S. (1980), The Relevance of Chayanov's Macro Theory to the Case of Java, in: E. J. Hobsbawn et al. (eds.), Peasants in History: Essays in Honour of Daniel Thorner, Oxford University Press for Sameeksha Trust.

ABD ALLAH, A. O. (1992), Disaster Management in Sudan, Diplom Dissertation, School of Management, University of Khartoum.

ABDEL-MAGID, I. et al. (eds.) (1986), Proceedings of the International Conference on Water Resources Needs and Planning in Drought Prone Areas, Sudan Engineering Society (SES), International Association for Hydraulic Research (IAHR), UNESCO and UNDP, Khatoum.

AHMED, A. A. (ed.) (1989), Proceedings of the Conference on Irrigation Management in the Gezira Scheme, Khartoum University Press.

BACHARACH, S. B. \& E. J. LAWLER (1980), Power and Politics in Organizations, Jossey-Bass Publishers.

BARDHAN, P. (1989a), Alternative Approaches to the Theory of Institutions in Economic Development, in Bardhan, P. (ed.), The Economic Theory of Agrarian Institutions, Clarendon Press, Oxford, pp. 1-29.

BARDHAN, P. (1989b), A Note on Interlinked Rural Economic Arrangements, in Bardhan, P. (ed.), The Economic Theory of Agrarian Institutions, Clarendon Press, Oxford, pp. 237-242.

BARNETT, T. (1977), The Gezira Scheme: An Illusion of Development, London.

BEBAWI, F. \& L. NEUGEBOHRN (1991), A Review of Plants of Northern Sudan: With Special Reference to Their Uses, Deutsche Geselschaft Für Technische Zusammenarbeit, Eschborn.

BERGMANN, H. (1967), Zur Sozial-ökonomischen Beurteilung größerer Bewässerungsproekte, in: P. Blanckenburg, O. Schiller und H. Wilbrandt, DLG Zeitschrift für ausländischer Landwirtschaft, Jahrgang 6.

BINSWANGER, H. \& M. ROSENZWEIG (1986), Behavioural and Material Determinats of Production Relations in Agriculture, The Journal of Development Studies, Vol. 22 (3), pp. 501-538.

BLUNT, P. \& M. JONES (1992), managing Organizations in Africa, De Gruyter Studies in Organizations; 40, New York.

BLUNT, P., JONES, M. \& D. RICHARDS (eds.) (1993), Managing Organizations in Africa: Readings, Cases, and Exercises, De Gruyter.

BOSCH, D. J. \& V. R. EIDMAN (1987), Valuing Information when Risk Preferences Are Nonneutral: An Application to Irrigation Scheduling, American Journal of Agricultural Economics, Vol. 69 (3), pp. 658-668.

BROWN, D. (1993), Bureaucracy as an Issue in Third World Management: An African Case Study, in Blunt, P., Jones, M. \& D. Richards (eds.), Managing Organizations in Africa: Readings, Cases, and Exercises, De Gruyter.

CARR-HILL, R. A. (1990), Social Conditions in Sub-Saharan Africa, Macmillan, London.

CARRUTHERS I, \& C. CLARK (1981), The Economic of Irrigation, Liverpool University Press.

CHAMBERS, R. (1980), Basic Concepts in the Organization of Irrigation, in: Coward, W. (ed.), pp. 28-50.

CHAMBERS, R. (1992a), Participatory rural appraisals; past, present and future, in: Forst Trees and People Newsletter, No. 15/16 (Febraury), pp.4-9.

CHAMBERS, R. (1992b), Rural Appraisal: Rapid, Relaxed and Participatory, Discussion Paper 311, Institute of Development Studies, University of Sussex, England. 
CHAMBERS, R., \& I. GUIJT (1995), PRA - Five Years later. Where are we now?, in: Forst Trees and People Newsletter, No. 26/27, pp.4-14.

CLARK, C. (1970), The Economic of Irrigation, Oxford.

COASE, R. H. (1993), Coase on Posner on Coase: Comment, Jurnal of Institutional and Theoretical Economics (JITE), Vol. 149 (1), pp. 96-98.

COWARD, W. (1980a), Irrigation Development: Institutional and Organizational Issues, in: Coward, W. (ed.), Irrigation and Agricultural Development in Asia: Perspectives From the Social Science, Cornell University Press, ITHACA, pp. 15-27.

COWARD, W. (1980b), Management Themes in Community Irrigation Systems, in: Coward, W. (ed.), pp. 203-218.

CRIDDLE, W. D. (1975), Steurung Des Bewässerungseinsatzes Bei Bewschränktem Wasserangebot, Zeitschrift für Bewässerungswirtschaft, Heft 1, Juni, pp. 133-144.

DAHAL, M. \& D. DAHAL (1993), Environment and Sustainable Development: Issues in nepalese prespective, Nepal Foundation For Advanced Studies (NEFAS) and Friedrich Ebert Stiftung (FES).

DAHLMAN, C..J. (1979), „The Problem of Externality.“ Journal of Legal Studies 22 (1): pp. 141-162

DASGUPTA, P. (1993), An Inquiry into Well-Being and Destitution, Clarendon press, Oxford.

DAVIES, H. R. J. (1991a), Development programmes in Non-Irrigated Rainland Areas, in: G. M. CRAIG (ed.), The Agriculture of The Sudan, Oxford University Press, pp.308-338.

DAVIES, H. R. J. (1991b), Irrigation Development Programmes, in: G. M. CRAIG (ed.), The Agriculture of The Sudan, Oxford University Press, pp.339-364.

DE JANVRY, A., SADOULET, E. \& M. FAFCHAMPS (1989), Agrarian Structure, Technological Innovations, and the State, in Bardhan, P. (ed.), pp. 356-382.

DONALDSON, G. (1992), Government-Sponsored Rural Development: Experience of the World Bank, Quarterly Journal of International Agriculture, Vol. 31 (1), pp. 97-113.

DONALDSON, L. (1995), American Anti-Management Theories of Organization: A Critique of Paradigm Proliferation, Cambridge University Press.

EGGERTSSON, T. (1990), Economic Behavior and Institutions, Cambridge University Press.

EL LAYTHY, I. M. A. (1995), Ländliche Kreditmärkte im Sudan: Vergleich der informellen und bankmäßigen Kredite in der Landwirtschaft der Provinz 'Umm-Ruwaba', Ph.D.-Thesis, University of Erlangen-Nürenberg

ELLIS, F. (1992), Agricultural Policies in Developing Countries, Cambridge University Press.

EL TOM, O. et al. (1989), Water Management of Abu XX in the Gezira Scheme, Sudan. in: Ahmed, A. A., (ed.), pp. 93-151.

EUSKE, N. \& K. ROBERTS (1989), Evolving Perspectives in Organization Theory: Communication Implications, in: Jablin, F. M. et al. (eds.), Handbook of Organizational Communication: An Interdisciplinary Prespective, SAGE Puplications, California, pp.41-65.

FAEA \& NHAPC (1991), Report on Monitoring Survey on Contact and Non-Contact Farmers in New Halfa APC, 1990-91 Season. 
FAIRCHILD, W. \& K. C. NOBE (1986), Improving Management of Irrigation Projects in Developing Countries: Translating Theory into Practice, in: Nobe, K. C. \& R. K. Sampath (eds.), pp. 353-412.

FAKI, H. (1981), Effect of Irrigation-Water Management on Farmers' Incomes in the Gezira, Sudan. Quarterly J. of International Agriculture, Vol. 20, pp.345359.

FAKI, H. SALIH, A. \& O. KHODARY (1989), Estimation of Crop-Water Production Functions and Optimization of Water Allocation under the Gezira Farm Conditions, in Ahmed, A. A., (ed.), pp. 271-315.

FAO (1986), African Agriculture: The Next 25 Years, Food and Agricultur Organization of the United Nations, Rome.

FAO (1994), Farmers' Participation in Irrigation Management in Tanzania: A Case Study, Food and Agricultur Organization of the United Nations, Rome.

FORD, R., ARMANDI, B. \& C. HEATON (1988), Organizational Theory: An Integrative Approach, Harper \& Row, Publishers, New York.

FRAMJI, K., GARG, B. \& S. LUTHRA (1983), Irrigatation and Drinage in the World: A Global Review, Vol. III, International Commission on Irrigation \& Drinage, India.

FREEMAN, D. et al. (1989), Local Organizations for Social Development: Concepts and Cases of Irrigation Organization, Boulder: Westview Special Studies Press.

FUKUDA, H. (1976), Irrigation in the World: Comperhensive Development, University of Tokyo Press.

HAGE, J. \& K. FINSTERBUSCH (1987), Organizational Change as a Development Strategy: Models \& Tactics for Improving Third World organizations, Lynne Rienner Publishers, Inc. Boulder \& London.

HAMILTON, J. R., WHITTLESEY, N. K. \& P. HALVERSON (1989), Interruptible Water Markets in the Pacific Northwest, American Journal of Agricultural Economics, Vol. 71 (1), pp. 63-75.

HARRISS, J. (eds.) (1982), Rural Development: Theories of Peasant Economy and Agrarian Change, Hutchinson University Library for Africa.

HASSARD, J. (1993), Sociology and Organization Theory: Positivism, Paradigms and Postmodernity, Cambridge University Press.

HÜBENER, R. \& P. WOLF (1991), Bewässerungslandbau und Entwicklungszusammenarbeit: Wo bleibt der Mensch?, in: Entwicklung und Ländliche Raum, (5).

HUPPERT, W. \& H. WALKER (1988), Management von Bewässerungssytemen: Ein Orientierungsrahmen, Handbuchreihe Ländliche Entwicklung, Deutsche Gesellschaft für Technische Zusammenarbeit (GTZ), Eschborn.

HUPPERT, W. (1989), Situationskonformes und Dienstleistungsorientertes Management von Bewässerungssytemen: Konzeptionelle Grundlagen, Deutsche Gesellschaft für Technische Zusammenarbeit (GTZ), Eschborn.

IBRD (1980), Staf Appraisal Report, New Halfa Irrigation Rehabilitation Project, Report No. 2608a-SU, April 24.

IDS (1994), Participatory Methods and Approaches: Sharing our Concerns and Looking to the Future, a Workshop on Developments in the Theory and Practice of Participatory Rural Appraisal, May 9-13.

IDS, (1996), The Power of Participation, IDS Policy Briefing Issue 7 (August).

ISHAG, K. \& H. ELOBEID (1989), The Farm Location and Farmer's Performance: Gezira Scheme, in: Ahmed, A. A., (ed.), pp.235-249. 
JREISAT, J. E. (1988), Administrative Reform in Developing Countries: A Comparative perspective, Public Administration and Development, (8) pp. 85-97.

KARPIK, L. (ed.) (1978), Organization and Environment: Theory, Issues and Reality, International Sociological Association/ISA, London.

KASPAR, PH. \& W. MOLL (1986), The case of Sudan, in K. KLENNERT (eds.), Rural Development and areful Utilization of Resources: The Cases of Pakistan, Peru and Sudan, Report of International Seminar of the Food and Agriculture Development Centre of the DSE in Feldafing, 19-24 November, pp. 92-132.

KELLER, J. (1986), Irrigation System Management, in: Nobe, K. C. \& R. K. Sampath (eds.), pp. 329-352.

KHALIL Y. M. (1985), The Socio-Economic Effects of the Sudanese Labor Migration to the Arab Countries (in Arabic), Unpublished M.Sc Thesis, Faculty of Economic and Political Science, Cairo University, Cairo.

KÖTTER, H. (1988), Institutions and Organizations in Rural Development, Quarterly J. of International Agriculture, Vol. 27 (1), pp.7-19.

KUHNEN, F. (1982), Man and Land: An Introduction into the Problems of Agrarian Structure and Agrarian Reform, Deutsche Welthungerhilfe, Bonn.

LAYTON, J. et al. (1994), Social Power, Water Control and Irrigation Systems: The Egyptian Farmers' Ability to obtain Irrigation Water, in: Irrigation and Drainage Systems, Netherlands, (7), pp. 291-304.

LEES, S. H. (1986), Coping with Bureaucracy: Survival Strategies in Irrigated Agriculture. American Anthropologist 88 (3), pp. 610-621.

LENTON, R. (1986), On the Development and Use of Improved Methodologies for Irrigation Management, in: Nobe, K. C. \& R. K. Sampath (eds.), pp. 32-66.

LEONORD, D. K. (1988), The Political Relations of African management, World Development 15, p. 899-910.

LEVINE, G. (1980), The Relationship of Design, Operation, and Management, in: Coward, W. (ed.), pp. 51-62.

LÖCHEL, H. (1995), Instituionen, Transaktionskosten und wirtschaftliche Entwicklung: Ein Beitrag zur Neun Instituionenökonomik und zur Theorie von Douglass C. North, Berlin, Duncker \& Humbolt.

LOWDERMILK, M. K. (1986), Improved Irrigation Management: Why Involve Farmers?, in: Nobe, K. C. \& R. K. Sampath (eds.), pp. 427-456.

MAKADAHO, J. (1994), Farmer Participation in Irrigation Management: Experiences from Zimbabwe, Food and Agriculture Organization of the United Nations (FAO).

MANIG, W. (1978), Aspekte der lokalen Administration in der ruralen Entwicklung, in: Groeneveld, S. \& H. Meliczek (Hrsg.), Rurale Entwicklung zur Uberwindung von Massenarmut, Verlag der SSIP-Schriften Breitenbach, Saarbrücken, pp...

MANIG, W. (1984), Water Charges and Underutilized Productivity Potential in Irrigation Systems, in:Transactions, Vol. 1(A) of the Twelfth International Congress on Irrigation and Drainage, New Delhi, pp. 1093-1110.

MANIG, W. (1989), Appropriate Organizations in Irrigation Systems for a SituationSpecific Management, in: DVWK (ed.), Situation-Specific Management in Irrigation, Irrigation Symposium Kongreß Wasser Berlin, Bulletin No. 16, pp. 363-405.

MANIG, W. (ed.) (1991), Stability and Changes in Rural Institutions in North Pakistan, Socioeconomic Studies on Rural Development, Vol. 85, Aachen. 
MANIG, W. (ed.) (1992), Rural Institutional Development and ist Impact in NorthwestPakistan, Socioeconomic Studies on Rural Development, Vol. 88, Aachen.

MANIG, W. (1993), Sind Moderne Bewässerungstechnologien in Kleinbäuerlichen Landwirtschaften Empfehlenswert? Entwicklung und Ländlicher Raum, 27 Jahrgang (4).

MANIG, W. (1994), Situation-specific Management in Appropriate Irrigation Organizations: Areas of Conflict in Water Distribution, Quarterly Journal of International Agriculture, Vol. 33 (3), pp. 243-259.

MASCARENHAS, J. (1992), Participatory rural appraisal and participatory learning methods: recent experiences from MYRADA and South India, in: Forst Trees and People Newsletter, No. 15/16 (Febraury), pp.10-17.

MINISTRY OF AGRICULTURE (1991), Annual Wealth and Natural Resources: Agricultural Situation and Outlook, Khartoum.

MINISTRY OF IRRIGATION (1992), National Irrigation Rehabilitation Programme (NIRP), Khartoum.

MITCHELL, C. W. (1991), Physiography, Geology, and Soils, in: G. M. CRAIG (ed.), The Agriculture of The Sudan, Oxford University Press, pp.1-18.

MOORE, M. R., COLLEHON, N. R., \& M. B. CAREY (1994), Multicrop Production Decisions in Western Irrigated Agriculture: The Role of Water Price, American Journal of Agricultural Economics, Vol. 76 (4), pp. 859-874.

MOROOKA, Y.\& HAYAMI, Y. (1989), Contract Choice and Enforcement in an Agrarian Community: Agricultural Tenancy in Upland Java, The Journal of Development Studies, Vol. 26 No. 1, pp.28-42.

MÜLLER, J.O. (1978), Soziale Partizipation-Konzept, Probleme und Bedingungen eines entwicklungspolitischen Ideals, in: Groeneveld, S. \& H. Meliczek (Hrsg.), Verlag der SSIP-Schriften, Saarbrüken.

MÜLLER, J.O. (1979), Zur Soziologie der Bewässerung in Großprojekten: Analyse und Kritik einer sozialökologischen Problemlage im gefolge wirtschaftlicher Entwicklung, in: Die Dritte Welt, Jahrgang 7 (1), Sonderdruck.

MUSA, S. B. (1991), The Nile Basin, The Need for Cooperation, A Paper presented in the International Congress of Africa Studies, Khartoum.

NHAC (1980), New Halfa Irrigation Rehabilitation Project (NHIRP), Ministry of Agriculture, Khartoum.

NG' ONG' OLA, D. (1993), Farmer Participation in Irrigation Management in Malawi, Food and Agriculture Organization of the United nations (FAO).

NOBE, K. C. \& R. K. SAMPATH (eds.) (1986), Irrigation Management in Developing Countries: Current Issues and Approaches, Proceedings of an Invited Seminar Series Sponsored by the International School for Agricultural and Resource Development, Westview Press.

OAD, R. (1994), Performance Improvement of Balaqtar Canal Irrigation System, The World Bank, Washington, D.C.

OAKLEY, P. et al. (1991), Projects with People: The Practice of Participation in Rural Development, International Labour Office (ILO), Geneva.

ODA (1986), Northern Region Irrigation Rehabilitation Project, Phase 2 Non-KSK Studies, Draft Final, Volume 2-Annexes, Overseas Development Administration, london.

ODA (1988), Northern Region Irrigation Rehabilitation Project, Phase 2 Non-KSK Studies, Final Report, Volume 1- Main Report, Overseas Development Administration, london. 
OESTERDIEKHOFF, P. (1991), Agricultural Markiting and Pricing: A Synopsis of Current Problems, in: G. M. CRAIG (ed.), The Agriculture of The Sudan, Oxford University Press, pp.364-394.

O'KEEFE E. \& B. WISNER (1977), Land use and Development, International African Institute in association with the Environment Training Programme.

PAPANDREOU, A. (1994), Externality and Institutions, Clarendon Press, Oxford.

PENNINGS, M. \& R. C. TRIPATH (1978), The Organization - Environment Relationship: Dimensional Versus Typological Viewpoints, in L. Karpik (eds.), pp.

PLACE, F. \& P. HAZELL (1993), Productivity Effects of Indigenou Land Tenure Systems In Sub-Saharan Africa, American Journal of Agricultural Economics, Vol. 75 (1), pp. 10-19.

POLLAK, R. A. (1985), A Transaction Cost Approach to Families and Housholds, Journal of Economic Literature, Vol. XXIII (June), pp. 581-608.

POSTEL, S. (1984), Water: Rethinking Management in an Age of Scarcity, Paper 62, Worldwatch Institute, Washington.

POTTER, R. H. (1972), Criteria of Institutional Change As Guidelines for Assessing Project Maturation, in: Thomas, D. W. et al. (eds.), Institution Building: A Model For Applied Social Change, Cambridge, pp. 149-161.

RAWITZ, E. (1973), Gravity Irrigation in: YARON, B., DANFORS, E., \& Y. VAADIA, (eds.), Arid Zone Irrigation, New York.

REDDY, J. M. (1986), Management of Gravity Flow Irrigation System, in: Nobe, K. C. \& R. K. Sampath (eds.), pp. .

REED, M. I. (1992), The Sociology of Organizations: Themes, Perspectives and Prospects, Harvest Wheatsheaf, England.

REPLOGLE, J. A. (1986), Some Tools and Concepts for Better Irrigation Water Use, in: Nobe, K. C. \& R. K. Sampath (eds.), pp. 117-148.

REVANS, R.W. (1967), Development of a Department of Business Administration in the University of Khartoum, Journal of Managemaent Studies (4) pp. 169-175.

ROSEGRANT, M. W. (1995), Dealing With Water Scarcity in The Next Century, A 2020 Vision for Food, Agriculture, and Environment, International Food Policy Research Institute (IFPRI), Brief 21.

RUTHENBERG, H. (1963), Produktion unter genauer Aufsicht. Ein Ansatz zur Landwirtschaftlichen Entwicklung dargestellt an Beispielen in Ostafrika und in dem Sudan. In: Schmollers Jahrbuch für Wirtschafts- und Sozialwissenschaften, Bd. 83, Nr.6, Berlin, pp. 697-713.

RUTTAN, V. W. (1978), Induced Institutional Change, in Binswanger, H. P. \& V. W. Ruttan (eds.), Induced Innovation: Technology, Institutions and Development, Baltimore/London: John Hopkins University Press, pp.328357.

RUTTAN, V. W. \& HAYAMI, Y. (1984), Toward a Theory of Induced Institutional Innovation, The Journal of Development Studies, Vol. 20 (4), pp. 203-223.

SAGARDOY, J. A., BOTTRALL, A. \& G. O. UITTENBOGAARD (1986), Organization, Operation and Maintenance of Irrigation Schemes, FAO Irrigation and Drainage Paper No. 40, Rome.

SALEEM, S. T. (1989), Resource Allocation under the Joint Account and the Land-waterCharge Systems: Is there a Case for Abondoning the Joint Account?, Monograph Series No. 33, Khartoum University Press. 
SALIH, A. M. \& M. A. KHADAM (eds.) (1976), Irrigation Water Requirements, in: Water Resources, Sudan, A Study prepared by the National Council for Research, The Council for Scientific and Technological Reseach, Khartoum.

SALIH, S. A. (1993), An analysis of Unreported Sales of Wheat in Sudan, Australian Economic Papers 32 (60) pp. 161-174.

SCHMEHL, W. R. (1986), From Diagnostic Analysis to Designing and Conducting OnFarm Research, in: Nobe, K. C. \& R. K. Sampath (eds.), pp. 67-93.

SCOTT, W. G. \& T. R. MITCHELL (1972), Organization Theory: Astructural and Behavioral Analysis, Irwin-Dorsey Series in Behavioral Science, Illinois.

SERAGELDIN, I. (1990), The Human Dimension of Structual Adjustment Programmes: The World Bank's Perspectiv, in: Adedeji, A., Rasheed, S. \& M. Morrison (eds.), The Human Dimensions of Africa's Persistent Economic Crisis, United Nations Economic Commission for Africa.

SHAH. M. K. (1991), Irrigation Organization and Management, in MANIG, W. (ed.), Stability and Changes in Rural Institutions in North Pakistan, Socioeconomic Studies on Rural Development, Vol. 85, Aachen.

SHMUELI, E. (1973), Efficient Utilization of Water in Irrigation in: YARON, B., DANFORS, E., \& VAADIA, Y., (eds.), Arid Zone Irrigation, New York.

SIMPSON, I. G. (1991), Land Tenure, in: G. M. CRAIG (ed.), The Agriculture of The Sudan, Oxford University Press, pp.101-116.

SINGH, K. (1986), Rural Development: Principles, Policies and Management, SAGE Publications, New Delhi.

SMALL, L. E. \& I. CARRUTHERS (1991), Farmer-Financed Irrigation: The Economic of reform, Wye Studies in Agricultural and Rural Development, Cambridge University Press.

SMITH, S. C. \& E. N. CASTLE (eds.) (1965), Economics and Public Policy in Water Resource Development, Iowa State University Press.

SÖRBO, G. M. (1985), Tenants and Nomads in Eastern Sudan: A Study of Economic Adaptations in the New Halfa Scheme, Scandinavian Institute of African Studies, Uppsala.

STIGLITZ, J.E. (1989), Rational Peasants, Efficient Institutions, and a Theory of Rural Organization: Methodological Remarks for Development Economics, in Bardhan, P. (ed.), pp. 18-29.

TANG, S. Y. \& E. OSTROM (1993), The Governance and Management of Irrigation Systems: An Institutional Perspective, Network Paper 23, Overseas Development Institute (ODI), London.

TETZLAFF, R. (1979), Die 'Durchkapitalisierung' der Landwirtschaft im Sudan und ihere Auswirkung auf den 'traditionellen' Sektor: Eine Strategie zur Überwindung Ländlicher Armut?, in: Elsenhans, H. (ed.), Agrarreform in der Dritten Welt, Campus Verlag, Frankfurt. pp. 339-363.

THORNTON, D. S. \& R. F. WYNN (1987), An Economic Assessment of the Sudan's KHASM EL GIRBA SCHEME, in Shaaeldin, E. (ed.), The Evolution of Agrarian Relations in the Sudan, The Hague.

TRILSABACH, A. (1991), Historical Development of Agriculture, in: Craig, G. M. (ed.), The Agriculture of the Sudan, Oxford University Press, pp. 117-189.

UPHOFF, N. (1986), Improving International Irrigation Management with Farmer Participation: Getting the Process Right, Boulder, co: Westview Press.

UPHOFF, N. et al. (1991), Managing Irrigation: Analyzing and Improving the Performance of Bureaucracies, Sage Publication, India.

UPTON, M. (1987), African Farm Management, Cambridge University Press. 
URQUHART, B. \& E. CHILDERS (1991), Towards A More Effective United Nations, development dialouge (1-2), Dag Hammarskjöld Foundation, Sweden.

USBR (1986), Report on the Nile Waters Study Evaluation, for the democratic Republic of Sudan, Ministry of Finance and Economic Planning, Project Preparation Unit.

WALKER, H. \& R. CLEVERINGA (eds.) (1989), Management of Irrigation Systems: Working Aids for Operational Irrigation System Management, Draft Version 5/89, Vol. 1,2, Deutsche Gesellschaft für Technische Zusammenarbeit (GTZ), Eschborn.

WATERSTON, A. (1965), Development Planning: Lessons of Experience; The Johns Hopkins Press.

WEDDERBURN, R. \& M. ERRINGTON (1985), Forest development in Relation to the Northern region Irrigation rehabilitation Project in the Nile Province of Sudan, Overseas Development Administration (ODA), London.

WEITZ, R. (1986), New Roads to Development, A Twentieth Century Fund Essay, Greenwood Press, New Yourk.

WHITLEY, R. D. (1988), The Management Sciences and Management Skills, Organisation Studies, Vol. 9 (1), pp. 47-68.

WHITTINGTON, D. \& K. E. HAYNES (1985), Nile Water for Whom? Emerging Conflicts in Water Allocation for Agricultural Expansion in Egypt and Sudan, in: Beaumount, P. and K. Mclachlan (eds.), Agricultural Development in the Middle East, pp. 125-149.

WHITTINGTON, D. (1985), Implications of Ethiopian Water Development for Egypt and Sudan, Development Studies and Research Centre, University of Khartoum.

WILLIAMSON, O. E. (1993), Transaction Cost Economics Meets Posnerian Law and Economics, Journal of Institutional and Economics, Vol. 149 (1), pp. 99-118.

WOHLMUTH, K. (1991), National Policies for Agriculture, in: G. M. CRAIG (ed.), The Agriculture of The Sudan, Oxford University Press, pp.436-454.

WÖRZ, J. (1993), Organizational Forms of Support Service Structures for Small Farms in Egypt and Sudan, Quarterly J. of International Agriculture, Vol. 32, pp.106-113.

YOUNG, R. A. (1986), On the Allocation, Pricing, and Valuation of Irrigation Water, in: Nobe, K. C. \& R. K. Sampath (eds.), pp. 151-178. 